\title{
Glaciotectonic processes associated with the central Alpine Fault: \\ a gravity study of the central West Coast, South Island, New Zealand
}

Richard Davy

A thesis

submitted to the Victoria University of Wellington in fulfilment of the requirements for the degree of Master of Science in Geophysics.

Victoria University of Wellington 2012 



\begin{abstract}
The rugged topographic relief of the central West Coast reflects ongoing interplay between active tectonic and climatic processes. Major geomorphological features have formed in response to convergence between the Pacific and Australian continental plates, and the principal locus of this collision is the transpressive Alpine Fault. This thesis describes a gravity study of glaciotectonic structures in the footwall of the central Alpine Fault and the processes responsible for their formation.

During this study 361 new gravity observations were collected in the Wanganui, Whataroa, Waiho, and Fox river flood plains on the western (footwall) side of the Alpine Fault. When combined with existing gravity observations, the available database comprises 932 measurements over the four catchments. These gravity data are used to produce detailed gravity maps and 2-3/4D gravity models of the subsurface structure below the flood plains. Models reveal extensive glacial erosion focused within the flood plains, with individual glacial channels reaching depths of $\sim 800 \mathrm{~m}$. Based on fault-perpendicular models, it is proposed that the South Westland Fault is a transition between a thrust-driven monocline structure in South Westland and the steeply dipping Hohonu reverse fault in North Westland.

Using gravity data, dextral offsets on the Alpine Fault since the Last Glacial Maximum have been determined by examining the structure and geomorphology of deeply incised glacial erosional channels. By studying how the lower reaches of the Wanganui, Whataroa, and Fox rivers have been translated with respect to their channels on the eastern (hanging wall) side of the Alpine Fault, horizontal fault displacements have been determined in three of the four catchments. Fault offsets of $383 \pm 388 \mathrm{~m}, 372 \pm 88 \mathrm{~m}$, and $450 \pm 99 \mathrm{~m}$ are estimated for the Wanganui, Whataroa, and Fox River valleys respectively. A range of possible channel formation ages are used to estimate dextral strike-slip movement rates, with the preferred formation age of $19 \pm$ $1 \mathrm{ka}$ yielding rates of $20.2 \pm 24.0 \mathrm{~mm} / \mathrm{yr}, 19.6 \pm 6.0 \mathrm{~mm} / \mathrm{yr}$ and $23.7 \pm 8.5$ $\mathrm{mm} / \mathrm{yr}$ for the Wanganui, Whataroa, and Fox river valleys respectively.
\end{abstract}




\section{Acknowledgments}

First and foremost I would like to express my gratitude to my supervisors Tim Stern and John Townend, for helping me define the project, providing guidance throughout and sharing their enthusiasm for geophysical research. A huge thanks to Euan Smith, for cheerfully providing help and advice on challenging problems. I also greatly appreciate the input from other staff in Victoria University of Wellington's Geophysics department, Susi Woelz, Simon Lamb and Martha Savage. A big thanks to Mark Henderson for all the assistance and company provided in the field, and also for ensuring that I was never the only clown in the room.

I would like to thank the kind-hearted people of the South Island's West Coast for always being friendly and generously allowing me to access their land. I greatly appreciate the input and discussions with my father, Bryan Davy. A special thanks goes to my friend Nicolas Brikke, who was the first to alert me of this project, and whose previous gravity study provided the foundation of this study. Thanks to all my awesome officemates, Brook Tozer, Banana Maas, Denise Fernandez, Karen McKinnon, Khati Unglert, Laura Kehrl, Lloyd Pledger and Nick Cozens, I couldn't have asked for a better bunch of people to work beside everyday. I would like to show my appreciation to all my classmates over the years, who have made my university experience a memorable and enjoyable one. 
I would like to sincerely thank and acknowledge GNS Science for access to thier gravity and geospatial data. Thank you to the New Zealand Marsden Fund for providing the funding which made this project possible.

Thanks to Matt Edwards, Sam Nees, Oliver Clark, Chris Davy, Danny Rood, Sam Nowland, Brook Tozer, Brook Keats, Georgia Grant, Paascalino and Kolja Schaller, Matt Ryan, Ramona White, Sanne Maas, Gemma Wihare, Tim Bartholomew, Leroy Crawford-Flett and Gregor Bennett, without you all, I could probably have done this thesis in half the time, but with infinitely less fun.

Last, but by no means least, I pay my biggest thanks to my family. To Mum, Dad and Chris, I thank your for your neverending support, encouragement and love. I truly appreciate it. 


\section{Contents}

1 Introduction $\quad 1$

1.1 Motivation and objectives .............. 1

1.1.1 Motivation . . . . . . . . . . . . . . . 1

1.1.2 Research objectives .............. . . 5

1.2 Study area . . . . . . . . . . . . . . . 6

1.2.1 Wanganui, Whataroa and Waiho flood plains . . . . . 6

1.2 .2 Tectonic setting . . . . . . . . . . . . . 8

1.2.3 Geological setting . . . . . . . . . . . . . . 11

1.2.4 Glacial and erosional processes . . . . . . . . 18

1.3 Previous studies . . . . . . . . . . . . . . . . . . . . . 20

1.3.1 South Island Geophysical Transect . . . . . . . . . . 20

1.3 .2 Seismicity . . . . . . . . . . . . . . . . 23

1.3.3 Gravity .................... . . 24

1.3 .4 Geodesy ..................... 26

1.4 Gravity model constraints . . . . . . . . . . . . . . . 27

1.4.1 Borehole data . . . . . . . . . . . . . . . 27

1.4.2 Whataroa seismic model . . . . . . . . . . . . 29

1.4.3 Rock density . . . . . . . . . . . . . . . . . . . 29

1.4.4 Bulk densities and sedimentary layer thickness . . . . . 32

1.5 Thesis structure . . . . . . . . . . . . . . . 33

2 Gravity and gravimetric study 35

2.1 Gravity ........................ 35 
2.2 Gravity of the Earth . . . . . . . . . . . . . 36

2.2.1 Absolute gravity . . . . . . . . . . . . . 37

2.2.2 Gravity variation due to Earth tides . . . . . . . . 39

2.2.3 Gravity variation with latitude . . . . . . . . . . 40

2.2.4 Gravity variations with elevation . . . . . . . . . 42

2.2.5 Gravity variation due to topography . . . . . . . . . 44

2.2.6 The Bouguer gravity anomaly . . . . . . . . . . . . . 46

2.3 New gravity observations . . . . . . . . . . . . . . . 47

2.3.1 Instrumentation and field procedure . . . . . . . . 47

2.3.2 Data reduction . . . . . . . . . . . . . . 49

2.3.3 Uncertainty in the Bouguer gravity anomaly . . . . . . 49

2.4 Regional-residual separation . . . . . . . . . . . . . . 52

2.4.1 Numerical regional removal . . . . . . . . . . . . 53

2.4.2 Modelling . . . . . . . . . . . . . . 54

2.5 Gravity modelling . . . . . . . . . . . . . . . . 55

2.5.1 Two dimensional modelling . . . . . . . . . . . 55

2.5.2 Two and a half dimensional modelling . . . . . . . 56

2.5.3 Two and three quarter dimensional modelling . . . . . 57

3 Gravity of the central West Coast $\quad 59$

3.1 Introduction . . . . . . . . . . . . . . . . . . . . 59

3.2 Existing data . . . . . . . . . . . . . . . . . 60

3.2.1 New Zealand Gravity Network . . . . . . . . . . . 60

3.2 .2 Whataroa gravity data . . . . . . . . . . . 60

3.2 .3 Existing coverage . . . . . . . . . . . . . 60

3.3 New gravity data . . . . . . . . . . . . . . . . . 65

3.3 .1 Survey design . . . . . . . . . . . . . . 66

3.4 Gravity maps . . . . . . . . . . . . . . . . . . . . 68

3.4.1 Bouguer gravity . . . . . . . . . . . . . 68

3.5 Regional correction methods . . . . . . . . . . . . 79

3.5.1 Numerical method . . . . . . . . . . . . . . . . 79

3.5.2 Regional modelling . . . . . . . . . . . . . . 88 
3.5.3 Detailed regional model . . . . . . . . . . . . 96

4 Gravity modelling and interpretation 103

4.1 Gravity/geology map . . . . . . . . . . . . . . . . . . . . 103

4.2 Gravity gradient . . . . . . . . . . . . . . . 106

4.3 Modelling . . . . . . . . . . . . . . . . . . . . . . . 108

4.3.1 Fault-perpendicular models . . . . . . . . . . . . 108

4.3.2 Fault-parallel/oblique models . . . . . . . . . . . 117

5 Offset and slip rates $\quad 129$

5.1 Offset on the Alpine Fault and slip rates . . . . . . . . . . . . 129

5.2 Offset estimates from gravity and topography . . . . . . . . . 131

5.2 .1 Glacial channel location . . . . . . . . . . . . . . 133

5.2.2 Projected glacial trajectory and channel offsets . . . . 136

5.2 .3 Glacial channel offsets . . . . . . . . . . . . . . . . . 141

5.2.4 Proximal data projections . . . . . . . . . . . 143

5.3 Slip rates . . . . . . . . . . . . . . . . . . . . . 146

5.3 .1 Channel age . . . . . . . . . . . . . . 146

5.3 .2 Strike-slip rates . . . . . . . . . . . . . . . . 147

5.3.3 Alternative slip rate method . . . . . . . . . . . . . . 148

5.3.4 Rate comparison . . . . . . . . . . . . . . . 151

6 Discussion and conclusions 153

6.1 Discussion . . . . . . . . . . . . . . . . . 153

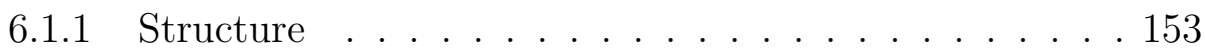

6.1 .2 Offset and slip rates . . . . . . . . . . . . 162

6.2 Conclusions . . . . . . . . . . . . . . . . . . 168

$\begin{array}{lr}\text { A Appendix A } & 169\end{array}$

B Appendix B 185

$\begin{array}{ll}\text { C Appendix C } & 191\end{array}$ 


\section{List of Figures}

1.1 Map of New Zealand showing continental tectonics of the region 2

1.2 Diagram of the orographic system across the Southern Alps . . 4

1.3 Topographic maps of the Wanganui, Whataroa and Waiho flood plains . . . . . . . . . . . . . . . 7

1.4 Photo of Lake Ianthe showing its generalised shape . . . . . . 8

1.5 Strike-slip movement rates along the onshore Alpine Fault . . 10

1.6 Surface geology of the central West Coast . . . . . . . . . . . 14

1.7 South Westland Basin overview . . . . . . . . . . . . . 16

1.8 Fault-perpendicular geological cross-sections . . . . . . . . . . 17

1.9 Ice extent of the Otira glaciation on the West Coast of the South Island . . . . . . . . . . . . . . . . . . . . . . 19

1.10 Diagram showing the South Island Geophysical Transects . . . 21

1.11 Seismic shot gather from the Karangarua River valley . . . . . 22

1.12 Existing gravity model in the Whataroa flood plain . . . . . . 25

1.13 Borehole stratigraphy of Harihari-1 and Waiho-1 . . . . . . . . 28

1.14 Overview of the Alpine Fault-perpendicular seismic model in the Whataroa flood plain . . . . . . . . . . . . . 30

2.1 Looping procedure for drift corrections . . . . . . . . . . . . . 40

2.2 Geodetic reference surfaces . . . . . . . . . . . . . . . . . . 41

2.3 Correcting gravity for the effects of elevation . . . . . . . . . . 42

2.4 Correcting gravity for the effects of topography . . . . . . . . 45

2.5 Hammer zones for topography correction . . . . . . . . . . . . 46 
2.6 Two dimensional gravity modelling . . . . . . . . . . . 55

$2.723 / 4$ dimensional gravity modelling . . . . . . . . . . . . 56

3.1 Existing gravity observations over the central West Coast . . . 61

3.2 Existing data coverage over the Wanganui flood plain . . . . . 62

3.3 Existing data coverage over the Whataroa flood plain . . . . . 63

3.4 Existing data coverage over the Waiho flood plain . . . . . . . 64

3.5 Combined gravity data coverage over the Wanganui flood plain 65

3.6 Combined gravity data coverage over the Whataroa flood plain 66

3.7 Combined gravity data coverage over the Waiho flood plain . . 67

3.8 Existing data Bouguer gravity map of the central West Coast 70

3.9 Combined data Bouguer gravity map of the central West Coast 71

3.10 Bouguer gravity anomaly maps of the Wanganui flood plain . 74

3.11 Bouguer gravity anomaly maps of the Whataroa flood plain . 76

3.12 Bouguer gravity anomaly maps of the Waiho flood plain . . . 78

3.13 Polynomial surface and residual gravity field of the central West Coast . . . . . . . . . . . . . . . . 80

3.14 Polynomial surface and residual gravity field of the Wanganui flood plain . . . . . . . . . . . . . . . . . . 82

3.15 Polynomial surface and residual gravity field of the Whataroa flood plain . . . . . . . . . . . . . . . . 85

3.16 Polynomial surface and residual gravity field of the Waiho flood plain . . . . . . . . . . . . . . . . 87

3.17 Overview of the Southern Alps simple crustal model . . . . . . 90

3.18 Models of the Southern Alps crustal root . . . . . . . . . . . . 92

3.19 Schematic of the simple crustal root model . . . . . . . . . . . 94

3.20 Residual gravity map for the simple crustal root model . . . . 95

3.21 Overview of the Southern Alps detailed crustal model . . . . . 97

3.22 Schematic of the detailed crustal root model . . . . . . . . . . 100

3.23 Residual gravity map using the detailed crustal model . . . . . 101

4.1 Central West Coast geology/gravity residual map . . . . . . . 105 
4.2 Maximum directional derivative of the West Coast Bouguer gravity field . . . . . . . . . . . . . . . 107

4.3 Whataroa flood plain fault-perpendicular transects . . . . . . 110

4.4 Whataroa flood plain fault-perpendicular models (i) . . . . . . 111

4.5 Whataroa flood plain fault-perpendicular models (ii) . . . . . 112

4.6 Wanganui flood plain fault-perpendicular transect . . . . . . . 114

4.7 Wanganui flood plain fault-perpendicular model . . . . . . . . 114

4.8 Waiho flood plain fault-perpendicular transect . . . . . . . . . 116

4.9 Waiho flood plain fault-perpendicular model . . . . . . . . . . 116

4.10 Whataroa flood plain fault-parallel lines . . . . . . . . . . . . 119

4.11 Whataroa flood plain fault-parallel models (i) . . . . . . . . . 120

4.12 Whataroa flood plain fault-parallel models (ii) . . . . . . . . . 121

4.13 Wanganui flood plain fault-parallel lines . . . . . . . . . . . . 123

4.14 Wanganui flood plain fault-parallel models . . . . . . . . . . . 124

4.15 Waiho flood plain fault-oblique line . . . . . . . . . . . . . 126

4.16 Waiho flood plain fault-parallel models . . . . . . . . . . . . . 127

5.1 Dextral offset of the Dun Mountain Ophiolite Belt . . . . . . . 130

5.2 Determining channel offsets with gravity . . . . . . . . . . . 132

5.3 Gravity anomalies along fault-parallel and proximal profiles . . 135

5.4 Topographic profiles for determining glacial trajectory . . . . . 138

5.5 Picking glacial topography with Fledermaus . . . . . . . . . . 139

5.6 Closely spaced fault-parallel gravity profiles and associated residual anomalies . . . . . . . . . . . . . . . . . . . 140

5.7 Projection error of glacial trajectory . . . . . . . . . . . . . . . 142

5.8 Refined glacial valley topography centres . . . . . . . . . . . . 145

5.9 Whataroa footwall channel gravity model . . . . . . . . . . . . 149

5.10 Updated strike-slip movement rates along the onshore Alpine

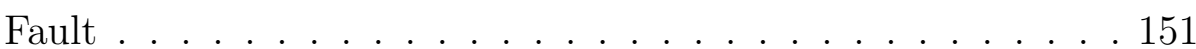

6.1 Schematic of glacial advances in the Wanganui flood plain . . 156 
6.2 Idealised schematic of glacial flow into existing erosional structures . . . . . . . . . . . . . . . . . . . 158

6.3 Gravity anomalies of fault structure . . . . . . . . . . . . 160

6.4 Schematic of the South Westland Fault and Basin development 161

6.5 Compiled strike-slip movement rates on the Alpine Fault south, of the Hope Fault . . . . . . . . . . . . . . . . . . . . . . . . . 164

6.6 Improved survey methods for determining fault offset . . . . . 167

B.1 Gravity models of the mantle and crustal structure below profiles 1 and 2 for the dynamic regional gravity model. . . . . . . 186

B.2 Gravity models of the mantle and crustal structure below profiles 3 and 4 for the dynamic regional gravity model. . . . . . . 187

B.3 Gravity models of the mantle and crustal structure below profiles 5 and 6 for the dynamic regional gravity model. . . . . . . 188

B.4 Gravity models of the mantle and crustal structure below profiles 7 and 8 for the dynamic regional gravity model. . . . . . . 189

B.5 Gravity models of the mantle and crustal structure below profiles 9 and 10 for the dynamic regional gravity model. . . . . . 190

C.1 Wanganui fault-parallel topography picks. . . . . . . . . . . 193

C.2 Whataroa fault-parallel topography picks. . . . . . . . . . . 194

C.3 Fox fault-parallel topography picks. . . . . . . . . . . . . . . . 195

C.4 Wanganui channel models . . . . . . . . . . . . . . . . 196

C.5 Whataroa channel models . . . . . . . . . . . . . . 197

C.6 Fox channel models . . . . . . . . . . . . . . . . . . . . . . . . 198 


\section{List of Tables}

1.1 Seismic velocities and inferred densities of the South Westland subsurface . . . . . . . . . . . . . . . . . . . 31

1.2 Rock densities from catalogues . . . . . . . . . . . . . . . 32

1.3 Thickness and density of local geological units . . . . . . . . 32

2.1 Whataroa absolute gravity station details . . . . . . . . . 38

3.1 Gradients along profiles of the simple crustal model . . . . . . 91

3.2 Gradients along profiles of the detailed crustal model . . . . . 98

3.3 Conditional programming for detailed modelling (i) . . . . . . 99

3.4 Conditional programming for detailed modelling (ii) . . . . . . 99

5.1 Properties of the closely spaced gravity transects . . . . . . . . 134

5.2 Closely spaced gravity transect anomaly minima . . . . . . . . 136

5.3 Projections of topography determined glacial trajectory . . . . 141

5.4 Alpine Fault channel offsets determined by gravity . . . . . . . 142

5.5 Refined projections of topography determined glacial trajectory 144

5.6 Refined Alpine Fault channel offsets determined by gravity . . 144

5.7 Alpine Fault strike-slip movement rates . . . . . . . . . . . . . 147

5.8 Alternative Alpine Fault strike-slip movement rates . . . . . . 150

5.9 Updated Alpine Fault strike-slip movement rates . . . . . . . . 152

A.1 Details of new gravity data . . . . . . . . . . . . 184

C.1 Glacial topography centres . . . . . . . . . . . . . . . . . . 192 
C.2 Proximal glacial topography centres . . . . . . . . . . . . . 192 


\section{Chapter 1}

\section{Introduction}

\subsection{Motivation and objectives}

\subsubsection{Motivation}

New Zealand lies across the active continental plate boundary between the converging Australian plate to the west and the Pacific plate to the east. The convergent motion between these two continental plates has given rise to two oppositely oriented subduction systems (Sutherland et al., 2000; Okaya et al., 2007). The Pacific plate subducts below the Australian plate along the eastern margin of the North Island, at the Hikurangi Trench, while the Australian plate subducts below the Pacific plate off the southwest tip of the South Island, forming the Puysegur Trench (see Figure 1.1) (Sutherland et al., 2000; Wallace et al., 2007). These two subduction systems are connected by a continental transcurrent fault, the Alpine Fault, which runs obliquely through New Zealand's South Island (Sutherland et al., 2000; Okaya et al., 2007).

The Alpine Fault is transpressive in nature accommodating components of both dextral and reverse slip (Sutherland et al., 2000; Okaya et al., 2007). During ongoing convergence since $\sim 6.4$ Ma the continental lithosphere has thickened and crust of the Pacific plate has been ramped up over the Australian plate along the Alpine Fault (Walcott, 1998; Sutherland et al., 2000). 


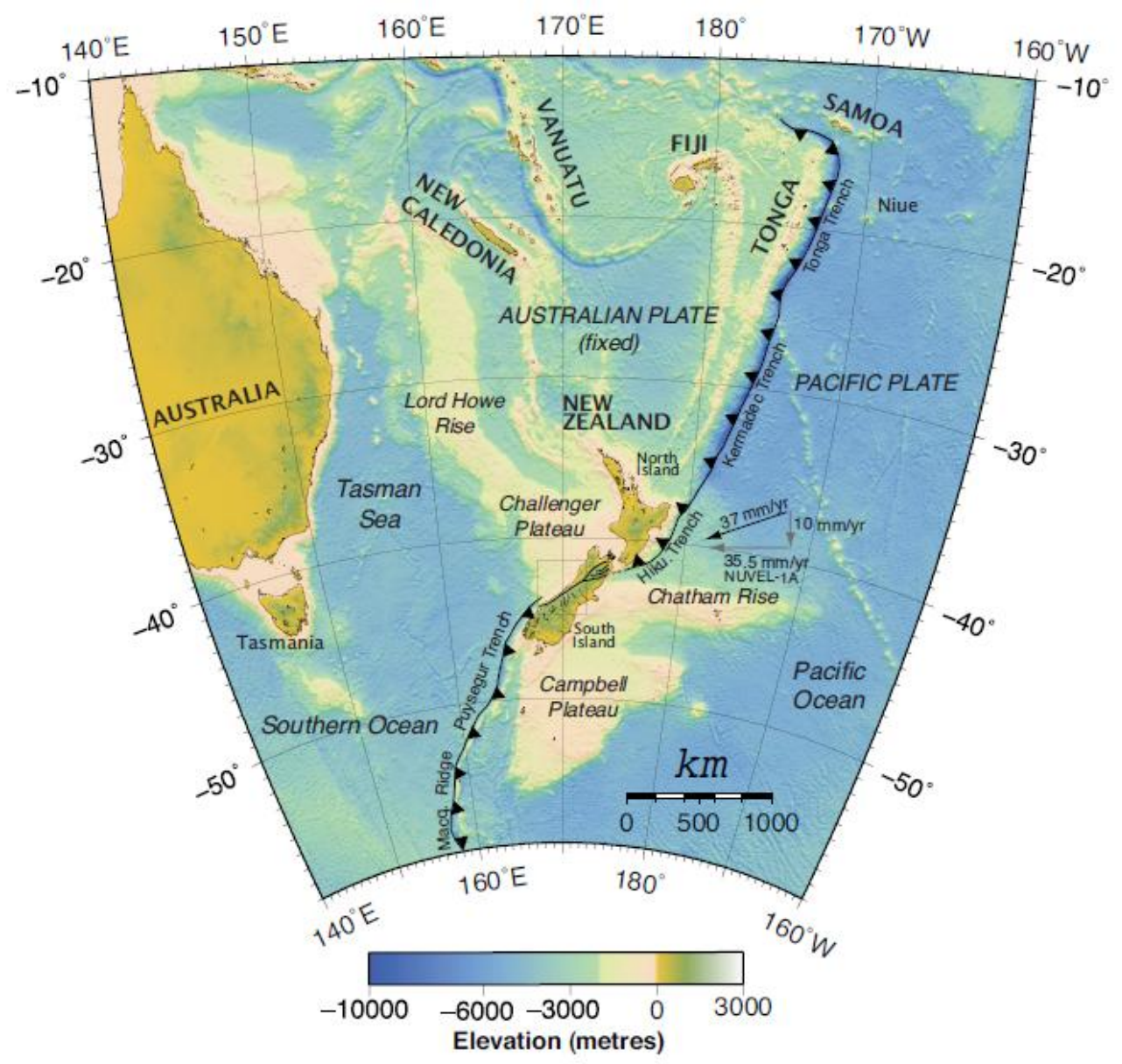

Figure 1.1: Map of New Zealand and surrounding areas. To the east of New Zealand lies the Australian continental plate, to the west is the Pacific continental plate. East of the North Island the Pacific plate subducts below the Australian plate. Off the southwest of the South Island the Australian plate subducts below the Pacific plate. The NUVEL-1A model relative plate motion vector (black arrow) is of $37 \mathrm{~mm} / \mathrm{yr}$, and its north and east components (grey arrows) are of 10 and $35.5 \mathrm{~mm} / \mathrm{yr}$, respectively (De Mets et al., 1990). Figure from Brikke (2010).

Mid-crustal rock is exhumed at a vertical rate of $\sim 10 \mathrm{~mm} / \mathrm{yr}$, producing the Southern Alps orogen (Norris and Cooper, 2007; Van Avendonk et al., 2004; 
Cox and Sutherland, 2007; Davey et al., 2007).

The Southern Alps are exposed to a predominantly westerly air circulation, producing an asymmetric orographic pattern over the range (Koons, 1990; Shulmeister et al., 2004), in which the western side is exposed to heavy precipitation of the order of $\sim 15 \mathrm{~m} / \mathrm{yr}$, while the eastern side receives $<1$ m/yr (Henderson and Thompson, 1999). The Southern Alps height and location produce widespread glaciation which periodically advance as far as the coastal plains and retreat back up alpine valleys with glacial cycles (Suggate and Almond, 2005; Herman et al., 2007). Glacial erosion exacerbates the orographic asymmetry, with extreme erosion occurring west of the main divide and modest erosion to the east (see Figure 1.2) (Cox and Sutherland, 2007).

The high rate of uplift combined with high rates of erosion keep the Southern Alps in a dynamic equilibrium, while also restricting the width of transpressional deformation to a zone 70 - $90 \mathrm{~km}$ wide (Walcott, 1998; Norris and Cooper, 2003). This makes the Southern Alps an ideal case study for investigating the processes associated with continental transpression, the early stages of mountain building and the evolution of topography juxtaposed against such a margin (Okaya et al., 2007).

The central section of the Alpine Fault is of particular research interest. It is here that both uplift and erosional processes are maximal (Herman et al., 2010; Okaya et al., 2007; Kamp et al., 1992). While the kinematics of the Alpine Fault are well understood in the northern and southern sections of the onshore portion of the fault, the kinematics of the central Alpine Fault remain relatively unclear (Norris and Cooper, 2007). The high erosion rates in this area have erased surface offset markers, making it difficult to quantify fault kinematics (Norris and Cooper, 2007).

One outstanding question regards what fraction of the lateral plate motion is accommodated as deformation on the Alpine Fault and how much is accommodated as distributed deformation in structures surrounding the fault. Walcott (1978) was the first to address this question, finding that 


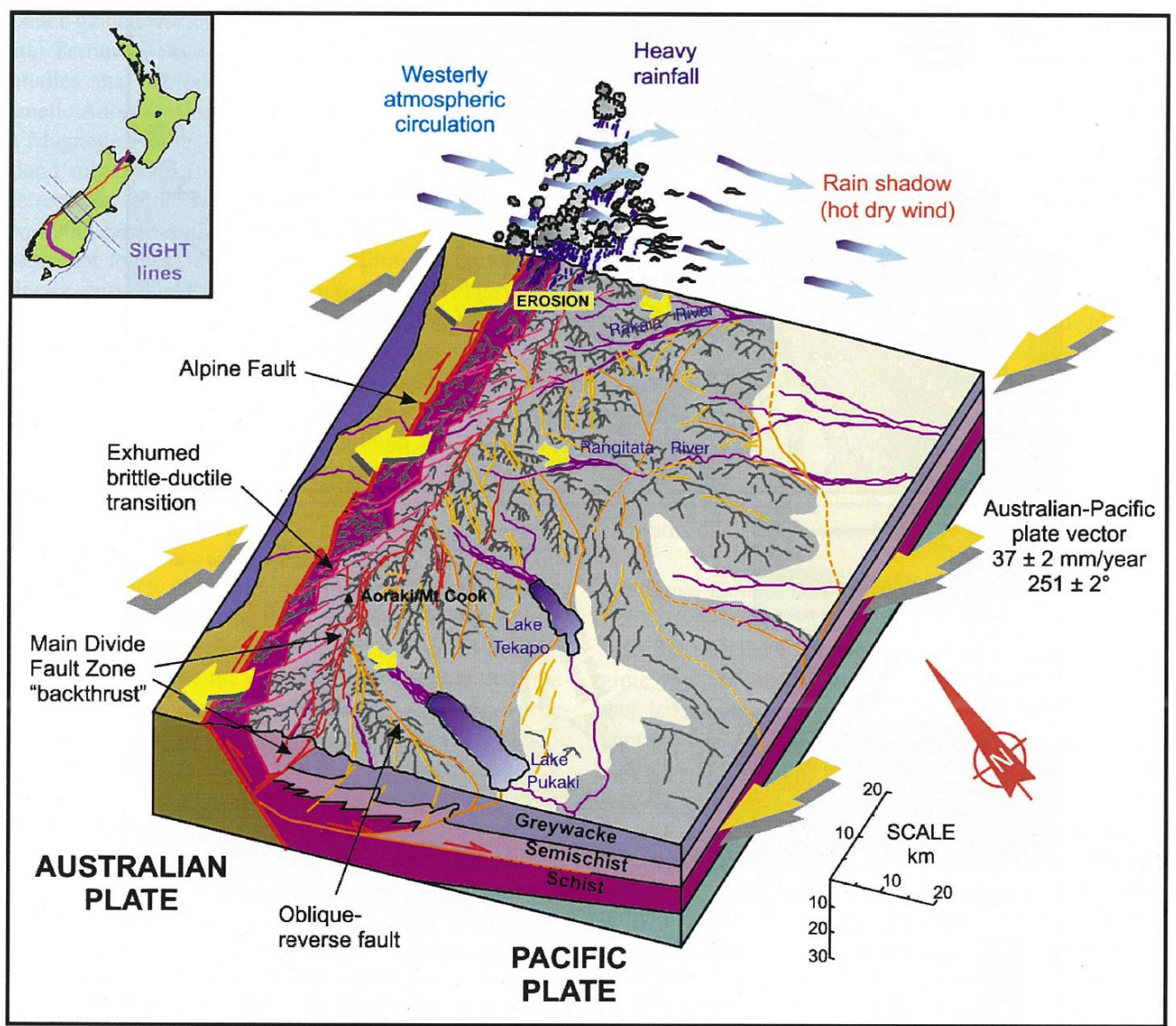

Figure 1.2: The orographic climate system over the Southern Alps. Extreme erosion on the western limits have produced an asymmetric orogen. Figure from Cox and Sutherland (2007).

while there was clear evidence that the southern section of the Alpine Fault accommodates around $75 \%$ of the plate motion, there was little evidence for the same proportion of horizontal displacement in the central fault section. Walcott's geodetic data indicated that horizontal movement rates on the central Alpine Fault were comparable to its uplift rate of $10 \mathrm{~mm} / \mathrm{yr}$, leading to the suggestion that the central Alpine Fault accommodates $25 \%$ of horizontal plate motion on the fault and $75 \%$ in surrounding structures. While subsequent studies since have generally disputed this suggestion in favour of 
a constant deformation distribution along the fault, there remains a need for observations with which to better constrain the deformation in the central Alpine Fault (Norris and Cooper, 2007).

\subsubsection{Research objectives}

This study investigates how three central West Coast flood plains adjacent to the Alpine Fault have evolved through the interaction between tectonic and climatic processes. The work aims to reinforce and expand on previous studies conducted in the central section of the Alpine Fault. The primary method of observation is a comprehensive gravity survey over the Wanganui, Whataroa and Waiho flood plains and surrounding areas. Gravity surveying provides an alternative method for determining the kinematics of the central Alpine Fault, through the identification and analysis of offset sub-surface features of known ages.

The primary objectives of this research are to:

1. Construct Bouguer and residual gravity maps of the central West Coast flood plains to highlight processes of glacial erosion and the effects of accumulative fault offset.

2. Produce two-dimensional (2D) gravity models of basin and erosional structure west of the Alpine Fault, constrained where possible by seismic model and geologic observations.

3. Estimate strike-slip fault rates along the central section of the Alpine Fault to ascertain whether strike-slip rates are constant or variable along the Alpine Fault. 


\section{$1.2 \quad$ Study area}

This subsection provides a brief overview of the study area and regional tectonic features of interest.

\subsubsection{Wanganui, Whataroa and Waiho flood plains}

The focus of this study encompasses three central West Coast flood plains juxtaposed against the central Alpine Fault. From north to south these flood plains are the Wanganui, Whataroa and Waiho. All three flood plains exhibit similar topographical features, which are briefly summarised below.

\section{Description of the flood plains}

The Wanganui and Whataroa flood plains each exhibit three geometric splays of low topographic relief in the marginal low hills. These splays in the topography extend to the north-north-east, the north-west (to the coast) and the west (Figure 1.3). The western splay of the Wanganui flood plain connects the Wanganui and Poerua river valleys, both of which host glaciers during glacial periods (Almond et al., 2007). The Waiho flood plain contains two of these splays, one extending north-north-east, while the other splay extends north-west to the coast (Figure 1.3). All three flood plains contain sub-rectangular glacial lakes in their north-north-eastern splays, marking the terminus of the last glacial maximum (Almond et al., 2001). Figure 1.4 illustrates the geometric nature of Lake Ianthe, located in the north of the Wanganui flood plain. The Whataroa flood plain possesses an additional sub-rectangular glacial lake (Lake Wahapo) in its western splay.

These geometric splays and glacial lakes are inferred to have formed during glacial advance. According to this interpretation during glacial maxima, glaciers occupy the flood plains and extend as far as the coast, retreating during interglacial periods (Almond et al., 2007; Suggate, 1990; Suggate and Almond, 2005). Following the retreat of the glaciers since the last glacial maximum, the deep troughs formed through glacial (and fluvial) erosion 


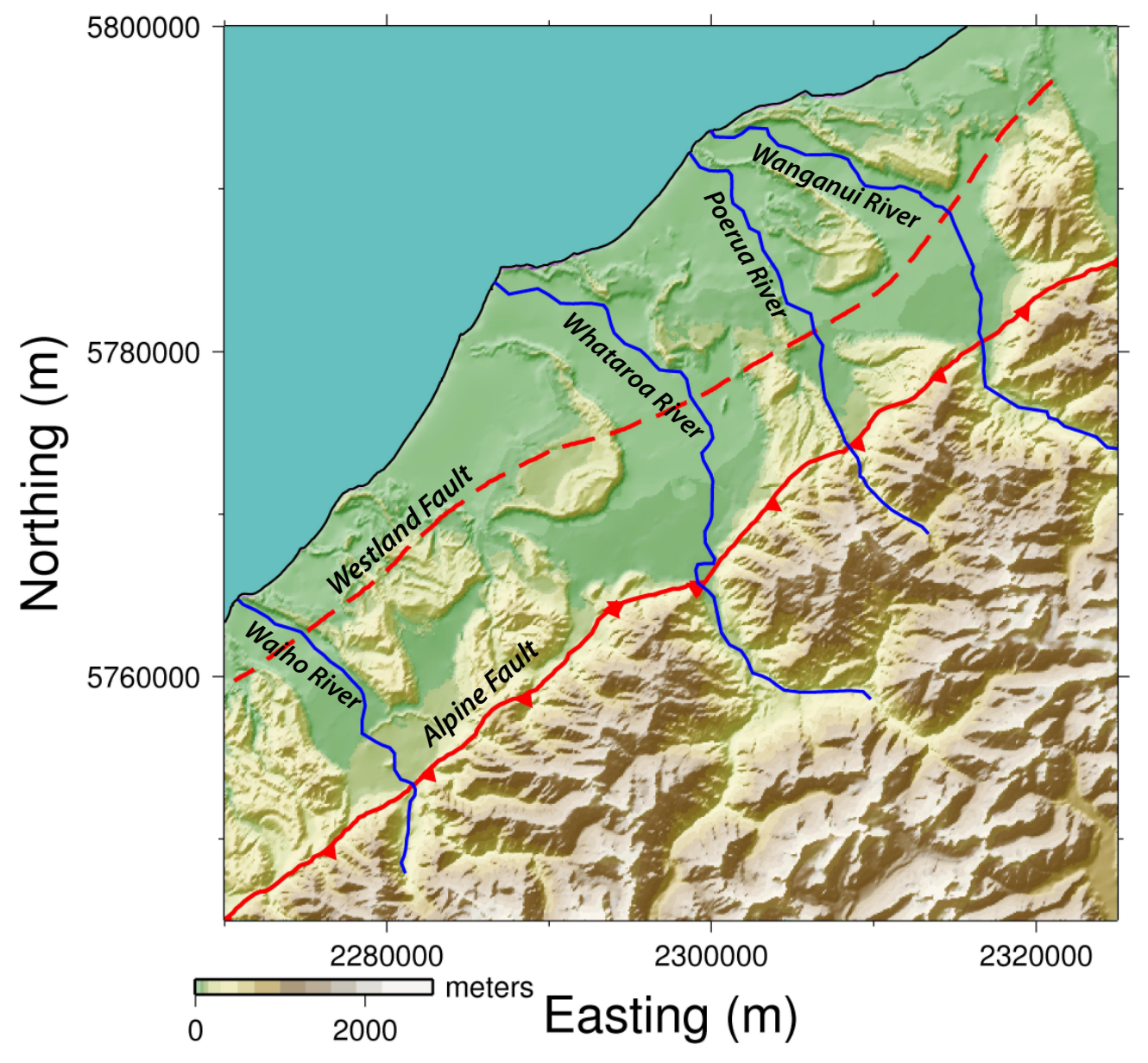

Figure 1.3: Topographic map of the study area, showing the Wanganui, Whataroa and Waiho flood plains. Note the "lazy Z" shape of the river flood plains with respect to the Alpine Fault. This represents the integrated effect of dextral offset.

have been infilled with late-glacial and post-glacial alluvium (Davey, 2010). Continuing dextral movement along the Alpine Fault has truncated these glacial troughs, with subsequent glacial advances eroding new channels in the footwall. This process gives each of the plains what can be described as a "lazy Z" shape. The flood plains continue to extend north-east with further glacial and tectonic cycles. 


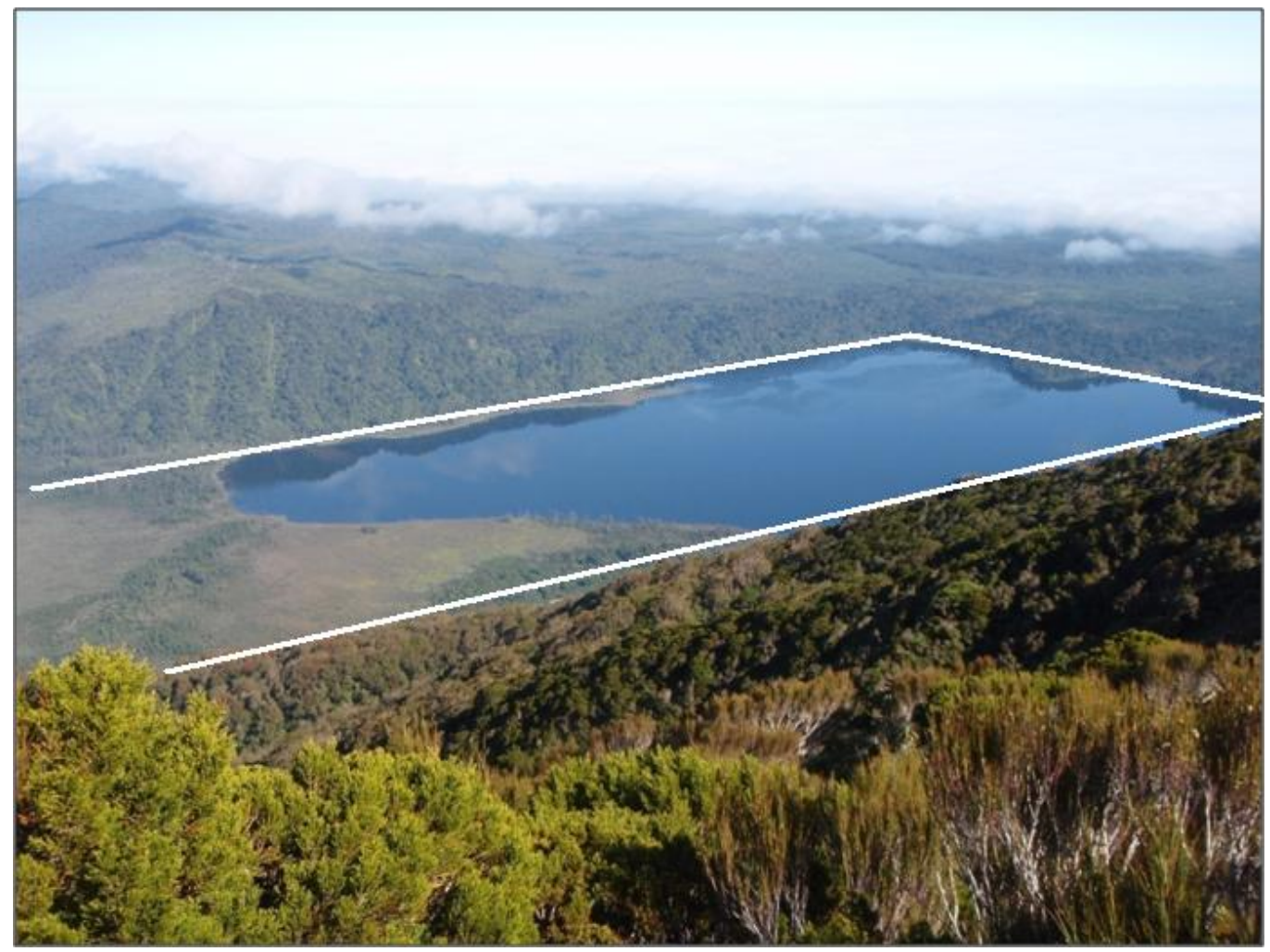

Figure 1.4: Photo of Lake Ianthe in the Wanganui flood plain. The white lines highlight the distinct geometry of a glacial lake.

These features and their consistency between adjacent flood plains is the direct result of the inferred interplay between climatic and tectonic processes focused on the central West Coast. In the present day, these flood plains are utilised for dairy farming, making the area amenable to geophysical study via the network of roads and farm tracks covering each flood plain.

\subsubsection{Tectonic setting}

Around 25 Ma the Alpine Fault was established as a dextral transform boundary between the Australian and Pacific plates (Sutherland, 1995a; Little et al., 2002). Today the fault runs obliquely through New Zealand's South Island over a distance of $\sim 480 \mathrm{~km}$ (Okaya et al., 2007). 


\section{Accommodation of convergence}

Transpression between the Australian and Pacific plates is thought to have initiated on the Alpine Fault 6.0 - 6.4 Ma (Walcott, 1998; Sutherland et al., 2000; Cande and Stock, 2004). Fault normal plate convergence has been accommodated since by the ramping of the Pacific crust onto the Australian plate, developing the Southern Alps orogen. Uplift of the Pacific crust is accompanied by delamination of the Pacific plate along a sub-horizontal interface at a depth of $20-30 \mathrm{~km}$ (Koons, 187). This results in rock above the decollement being uplifted and exposed along the fault boundary, while rock below the decollement is thrust under and thickened (Molnar et al., 1999; Little et al., 2002). The development of a thick crustal root, extending $17 \mathrm{~km}$ deeper than the incoming Pacific crust, occurs via delamination of the lower crust and thickening of the overlying middle-crust (Stern et al., 2000; Scherwath et al., 2003). During the $\sim 7$ My of transpression there has been a total of $\sim 90 \mathrm{~km}$ of crustal shortening of the Pacific plate in the central Southern Alps, seen as the zone of deformation east of the fault trace, as well as $\sim 230 \mathrm{~km}$ of dextral strike-slip movement (Walcott, 1998; Little et al., 2002).

\section{Relative plate motion and deformation distribution}

Based on the NUVEL-1A model of De Mets et al. $(1990,1994)$ the current relative velocity between the Pacific and Australian continental plates in the central Alpine Fault has been determined as $37 \pm 2 \mathrm{~mm} / \mathrm{yr}$, with a shortening component of $10 \mathrm{~mm} / \mathrm{yr}$ and strike-slip component of $35.5 \mathrm{~mm} / \mathrm{yr}$. How this motion is accommodated within and adjacent to the plate boundary zone can be estimated through studies of the Quaternary offset along the Alpine Fault. Quaternary slip movement rates have been collated by Norris and Cooper (2007): Figure 1.5 shows the collated strike-slip rates along the Alpine Fault. The most constrained strike-slip rate along the fault is $23 \pm 2 \mathrm{~mm} / \mathrm{yr}$ in the southern fault section south of Haast (Sutherland et al., 


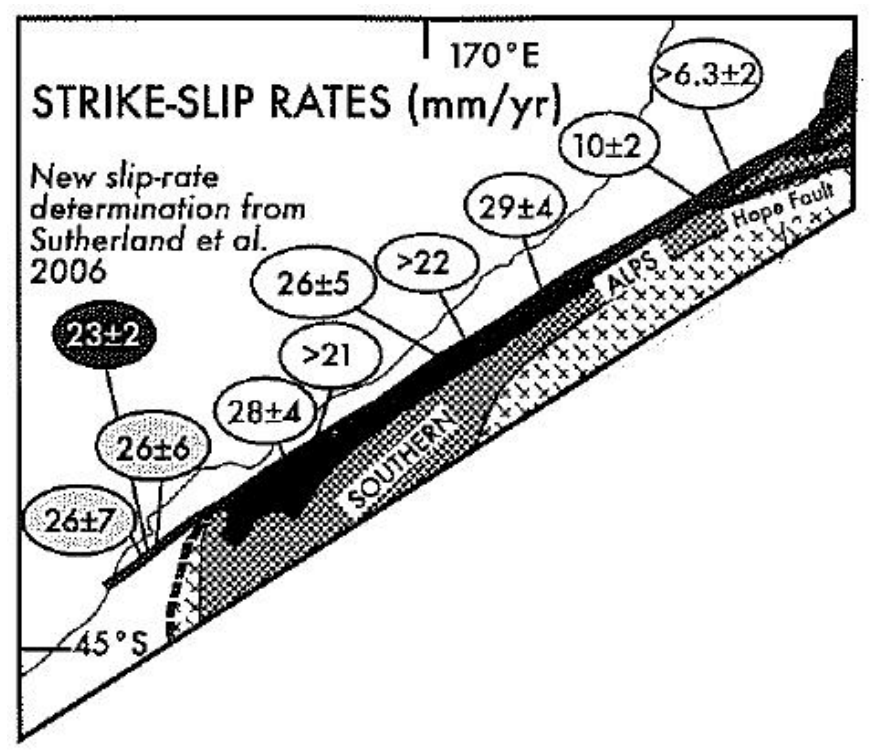

Figure 1.5: Quaternary strike-slip rates along the length of the onshore Alpine Fault (mm/yr) (Norris and Cooper, 2007).

2006). These Quaternary strike-slip rates indicate that between $50-80 \%$ of plate-parallel motion is accommodated on the Alpine fault (Sutherland et al., 2006; Cox and Sutherland, 2007). Geodetic results are consistent with these Quaternary rates, showing that $50-70 \%$ of this inter-plate motion is accommodated on the Alpine Fault (Beavan et al., 1999). The remaining $30-50 \%$ of movement is accomodated on other structure; principally reverse faulting both west and east of the fault and block rotation south-east of the fault trace in the 90 km-wide deformation zone (Beavan et al., 1999; Sutherland et al., 2006; Wallace et al., 2007). It has been noted by many authors that the central Alpine Fault lacks well-constrained Quaternary strike-slip rates, which would provide useful information on the deformation distribution in this area (Norris and Cooper, 2007).

Studies of seismicity along the Alpine Fault generally reveal low amounts of seismicity down to a maximum seismogenic depth of $10-12 \mathrm{~km}$. It is interpreted that elastic strain is stored on the fault to these depths, with 
periodic earthquakes releasing the strain in the form of brittle deformation and fault movement (Leitner et al., 2001). Seismicity is diffuse south-east of the Alpine Fault trace, and is not strictly localised on the primary fault plane. This indicates that inter-plate motion not accommodated on the Alpine Fault is being accommodated on auxiliary fault structures (Boese et al., 2011; Eberhart-Phillips, 1995).

\section{Geometry of the fault trace}

The geometry of the fault trace exhibits three distinct styles in different locations. In the northern section between Hokitika and Whataroa, the fault forms a near-linear trace undergoing oblique dextral-reverse slip and overthrusting on reverse faults in the west (Norris and Cooper, 2007). In the central section between the Whataroa and Haast rivers, the fault is serially partitioned into a zigzagging series of north-striking oblique thrust sections connected by east-striking zones of dextral strike-slip (Norris and Cooper, 2001, 2007). South of the Haast river, the trace geometry is once again linear but contains short en-echelon traces and step-overs typical of strike-slip faulting (Norris and Cooper, 2007).

\subsubsection{Geological setting}

\section{Basement rock}

The basement rock either side of the Alpine Fault is defined as Eastern and Western province basement rock respectively (Mortimer, 2004). Figure 1.10 below shows the distribution of basement rock in the South Island.

The oldest rocks of the Western province can be divided into the Buller (formed $\sim 500 \mathrm{Ma}$ ) and Takaka terranes (formed $\sim 540 \mathrm{Ma}$ ) (Cooper and Tulloch, 1992). The Buller terrane forms the basement rock of the West Coast, whereas Takaka terrane lies north of the Hope Fault, in north-west Nelson (Cooper and Tulloch, 1992; Davey et al., 2007). The Buller terrane is composed predominantly of quartz-rich clastics, siltstone and black shale 
with age varying from early Ordovician to Late Ordovician (Cooper and Tulloch, 1992; Davey et al., 2007). The Takaka terrane comprises siliciclastic, carbonate and volcanic rocks of Cambrian to Early Devonian ages (Mortimer, 2004).

The Eastern province basement east of the Alpine Fault consists of Haast Schist and Torlesse groups, which have ages of up to 300 Myr (Adams, 1981; Norris and Cooper, 2003). The Torlesse rock, found toward the east coast of the South Island, consists of low-grade metamorphic greywackes of Permian to Jurassic ages; Haast Schist which is found in contact with the Alpine Fault formed via schist metamorphosis of Torlesse greywacke at depths of $20-30$ km during continental collision in the Jurassic (Adams, 1981; Norris and Cooper, 2003). The Haast Schist has since been exhumed from depth along the Alpine Fault, and has an increasing metamorphic grade with proximity to the fault.

\section{Fault rock}

Mid-crustal rock has been exhumed along the Alpine Fault from depths of $20-30 \mathrm{~km}$, resulting in a $\sim 1 \mathrm{~km}$ wide zone of mylonitised Haast Schist south-east of the Alpine Fault trace (Norris and Cooper, 2003). Cataclasites and pseudotachylytes are found in direct contact with the Alpine Fault, with ultramylonite found directly above these units (Norris and Cooper, 2007). The degree of mylonitisation decreases eastward with ultramylonite grading through mylonite to protomylonite, and ultimately to Haast Schist $\sim 1 \mathrm{~km}$ east of the Alpine Fault (Norris and Cooper, 2003, 2007).

\section{Sediments}

Extensive glaciation has produced widespread glacial and fluvio-glacial moraines and associated outwash aggradational surfaces (Suggate, 1990; Cox and Barrell, 2007a). The generation and transportation of these glacial sediments is a byproduct of cyclic glacial advance and retreat. Glacial and fluvioglacial till and outwash have infilled eroded structures and formed the topography 
surrounding catchment areas and the terminal locations of past glacial advance (Suggate, 1990; Almond et al., 2001; Cox and Barrell, 2007a). Glacial till in the Wanganui, Whataroa and Waiho flood plains is generally grey in colour and consists of bouldery gravels, sands, silt and clay, while the glacial outwash is a poorly sorted silty gravel (Cox and Barrell, 2007a).

Rainfall of $\sim 15 \mathrm{~m} / \mathrm{yr}$ and associated high rates of erosion generate voluminous clastic and alluvial sediments in river valleys (Henderson and Thompson, 1999). These sediments are generated in the mountains of the Southern Alps and are transported fluvially to the coast, with decreasing grain size going away from the mountain range (Ackers and White, 1973). Clastic and alluvial deposits in the Wanganui, Whataroa and Waiho flood plains are typically grey or brown angular gravels, silts and sands (Cox and Barrell, 2007a).

\section{Surface geology map}

Figure 1.6 shows a simplified surface geology map of the central West Coast study area. There are few basement outcrops west of the Alpine Fault, with extensive fluvial and glacial processes distributing Quaternary sediment over a large portion of the coastal flood plains. There are, however, several Buller terrane outcrops surrounding the Waiho flood plain which are not observed further north. Granitic intrusions seen in the Whataroa and Waiho flood plains are regional unconformities and are formed by pegmatite, mafic dikes and gabbro plugs (Cox and Barrell, 2007a). 


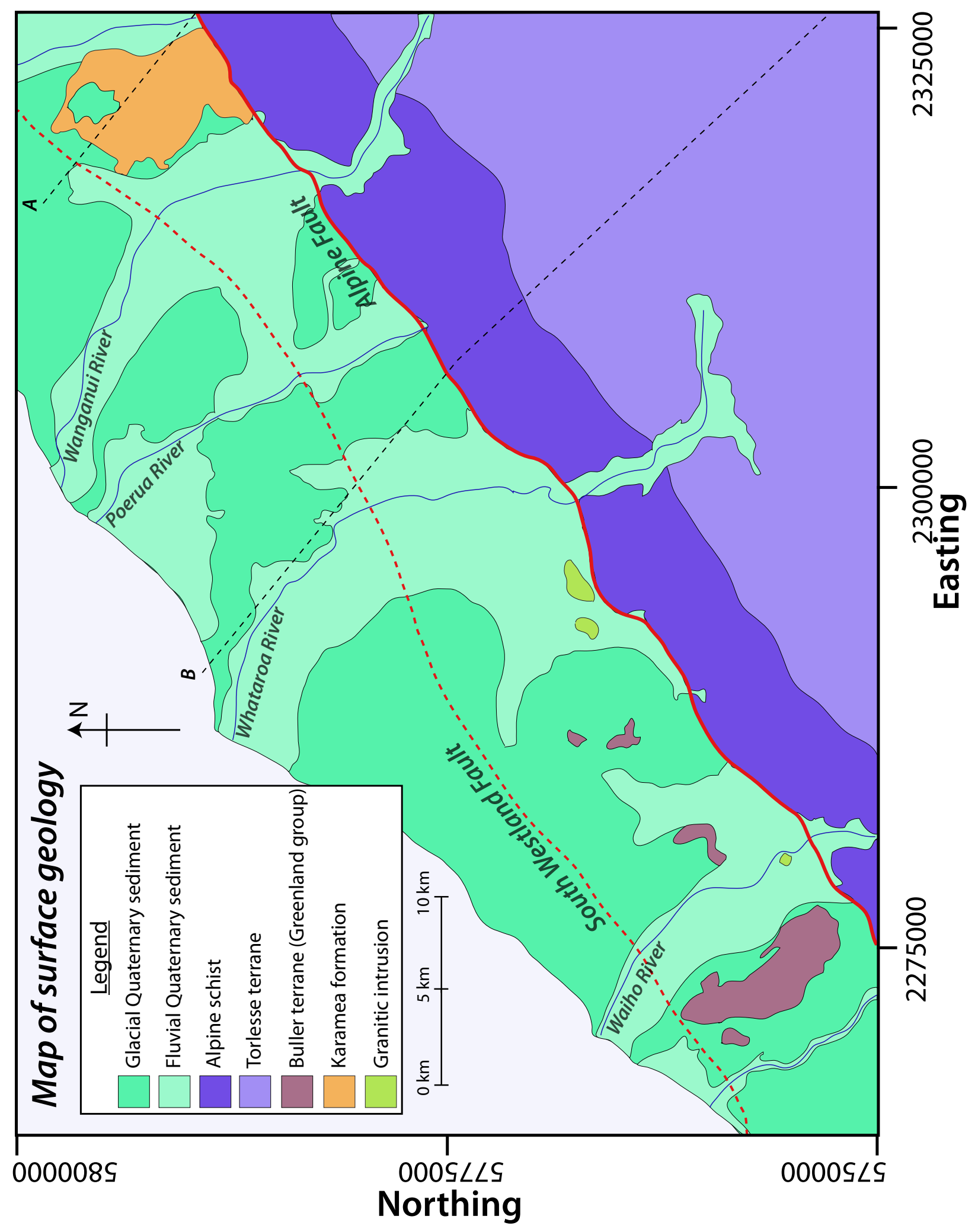

Figure 1.6: Simplified surface geology map of the central West Coast study area modified from the Aoraki QMAP produce by Cox and Barrell (2007a). Black dashed lines labelled A and B are geological cross-sections which can be seen in Figure 1.8. 


\section{South Westland Basin and Fault Zone}

The South Westland Basin is predominantly an offshore sedimentary basin overlapping onto the coastal plain west of the Alpine Fault between Hokitika and Milford Sound (Nathan et al., 1986; Sircombe and Kamp, 1998). Information on the basin's stratigraphy and structure has come from offshore petroleum seismic lines and onshore boreholes, particularly the Waiho-1 and Harihari-1 boreholes (Nathan et al., 1986; Sutherland, 1996; Sircombe and Kamp, 1998). The geometry of the South Westland Basin can be seen in Figure 1.7. The basin is bound by the Puysegur Trench to the southwest, the South Westland Fault Zone to the southeast and to the northwest by the shallowing Paleozic continental crust of the Challenger Plateau (Nathan et al., 1986; Sircombe and Kamp, 1998; Davey, 2010).

The South Westland Fault Zone developed approximately along the present coastline some $20 \mathrm{~km}$ west of the Alpine Fault, with steeply dipping reverse faults becoming active in the mid-Miocene (Sutherland, 1996; Walcott, 1998). Dip-slip displacement of $\sim 3.5 \mathrm{~km}$ resulted in a coastal monocline that outcrops in the Southern Westland region and the formation of the South Westland Basin (Sutherland, 1996; Walcott, 1998; Sircombe and Kamp, 1998). The rate of subsidence and deposition in the basin increased at $5-6 \mathrm{Ma}$, coinciding with the development of the Southern Alps orogen (Sutherland, 1996; Walcott, 1998; Sircombe and Kamp, 1998). Within the $3.5 \mathrm{~km}$-deep basin Paleozoic basement rock is overlain by a thin but continuous Oligoceneearly Miocene limestone (Smart, 1971, 1972; Nathan et al., 1986; Sircombe and Kamp, 1998); above this unit is a middle-late Miocene conglomerate, sandstone and siltstone which thins abruptly offshore (Smart, 1971, 1972; Nathan et al., 1986; Sircombe and Kamp, 1998); and the youngest layer is a Pliocene-Quaternary sequence of conglomerate, sandstone and siltstone (Smart, 1971, 1972; Sutherland, 1996). The extent and location of this basin produces a significant gravity signature near the Alpine Fault, which is considered in the data interpretation below.

The South Westland Fault Zone is believed to be a thrust fault system 


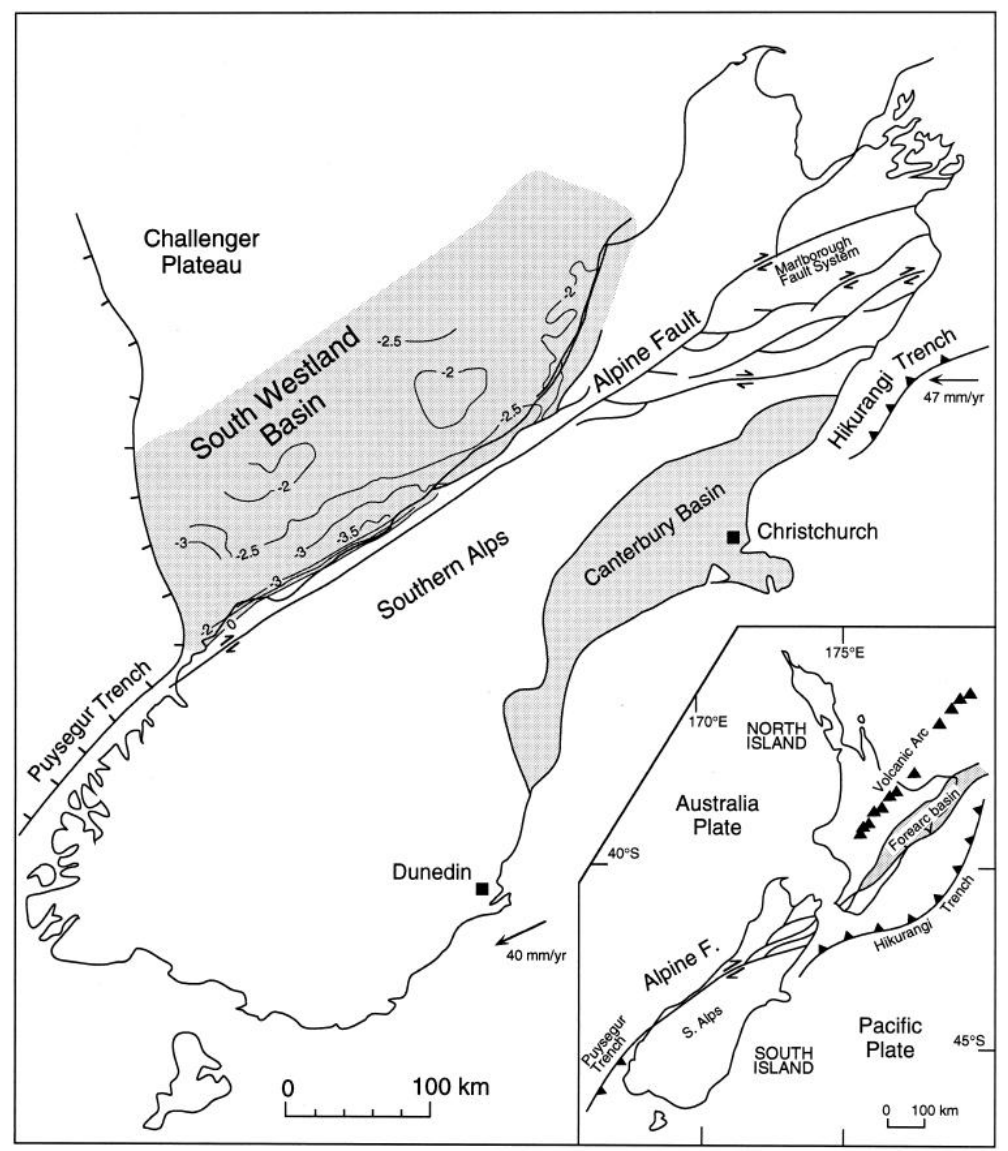

Figure 1.7: An overview of the South Westland Basin, from Sircombe and Kamp (1998)

striking sub-parallel and lying between $10-20 \mathrm{~km}$ west of the Alpine Fault, marking the northwestern limit of plate boundary deformation (Kamp et al., 1992; Sutherland, 1996; Sircombe and Kamp, 1998). Kamp et al. (1992) identifies the 10-20 km strip of coastal land between the Alpine Fault and South Westland Fault as remnants of the South Westland Basin overlying basement rock. The results of fission track analysis reveal that the basin once extended over the entire Westland region, increasing to a thickness of $\sim 4$ $\mathrm{km}$ toward the Alpine fault. Convergence between the Australian and Pacific plates has been partially accommodated as crustal thickening and surface 


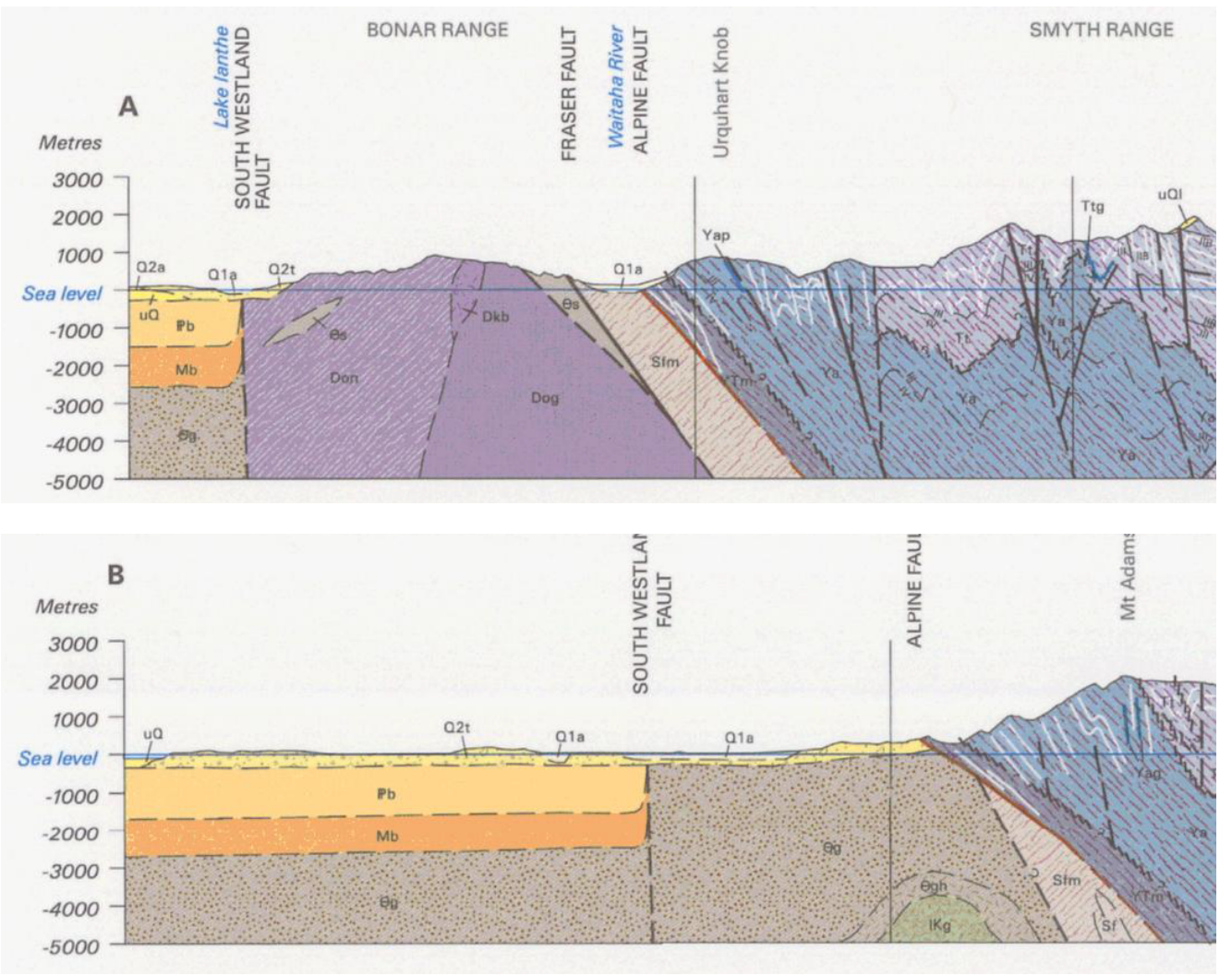

Figure 1.8: Geological cross-sections from the Aoraki QMAP (Cox and Barrell, 2007a). Plan views of these cross-sections are illustrated in Figures 1.6 and 4.1. Cross-section A is from the Wanganui flood plain and B is from the Whataroa flood plain. Both cross-sections illustrate the South Westland Fault as a vertical line. For symbol descriptions see Aoraki QMAP by (Cox and Barrell, 2007a).

uplift along reverse faults west of the Alpine Fault. This accommodation has resulted in the $10-20 \mathrm{~km}$ of foreland basin directly east of the Alpine Fault being uplifted and subsequently eroded (Kamp et al., 1992). Kamp et al. (1992) found that in south Westland the crustal shortening west of the Alpine fault totaled $2 \mathrm{~km}$ over 5 my on one fault bound block, with a rock uplift rate between 0.8-2.0 mm/yr. In north Westland the crustal shortening totals $12 \mathrm{~km}$ over 10 my on two fault bound blocks, with a rock uplift rate 
between 0.4-1.2 mm/yr (Kamp et al., 1992).

With no surface exposures, the location of the South Westland Fault Zone over the Wanganui, Whataroa and Waiho flood plains has been inferred from onshore-offshore seismics, reverse faulting in North Westland and coastal monocline structure in South Westland (Cox and Barrell, 2007a; Nathan, 2011). Because of this inference, the location of the South Westland Fault Zone and its nature is not well controlled, with Davey (2010) showing the primary fault strand runs closer to the Alpine Fault than indicated. Geological cross-sections crossing the South Westland Fault illustrate the fault as a vertical line, as its true dip is unknown (Figure 1.8).

\subsubsection{Glacial and erosional processes}

\section{Glacial cycles}

The cyclic glacial and inter-glacial periods are the result of the of Earth's eccentricity, axial tilt and precession cycles, known as the Milankovitch cycles (Muller and MacDonald, 1997). In the last 1 Myr these Milankovitch cycles have produced glacial cycles with three distinct periods of $23 \mathrm{kyr}, 41 \mathrm{kyr}$ and 100 kyr (Imbrie et al., 1993). Glacial maxima follow the 100 ka cycle (Muller and MacDonald, 1997). There have been four significant glaciations in the last $0.35 \mathrm{Myr}$, with the Last Glacial Maximum culminating at $18-19$ ka (Suggate, 1990; Suggate and Almond, 2005). The last glaciation, known as the Otira glaciation, involved three significant ice advances culminating at ca $28.0 \mathrm{ka}, 21.5 \mathrm{ka}$ and $19.0 \mathrm{ka}$ (Suggate and Almond, 2005). During these ice advances, the glaciers occupied the flood plains and extended to the coast, with evidence of terminal moraines now found below sea-level offshore (Korup et al., 2005). Terminal moraines can be mapped to show the extent of glacial advance during the Last Glacial Maximum, as illustrated in Figure 1.9 from Suggate and Almond (2005) or in Quaternary maps such as those of Cox and Barrell (2007a). 


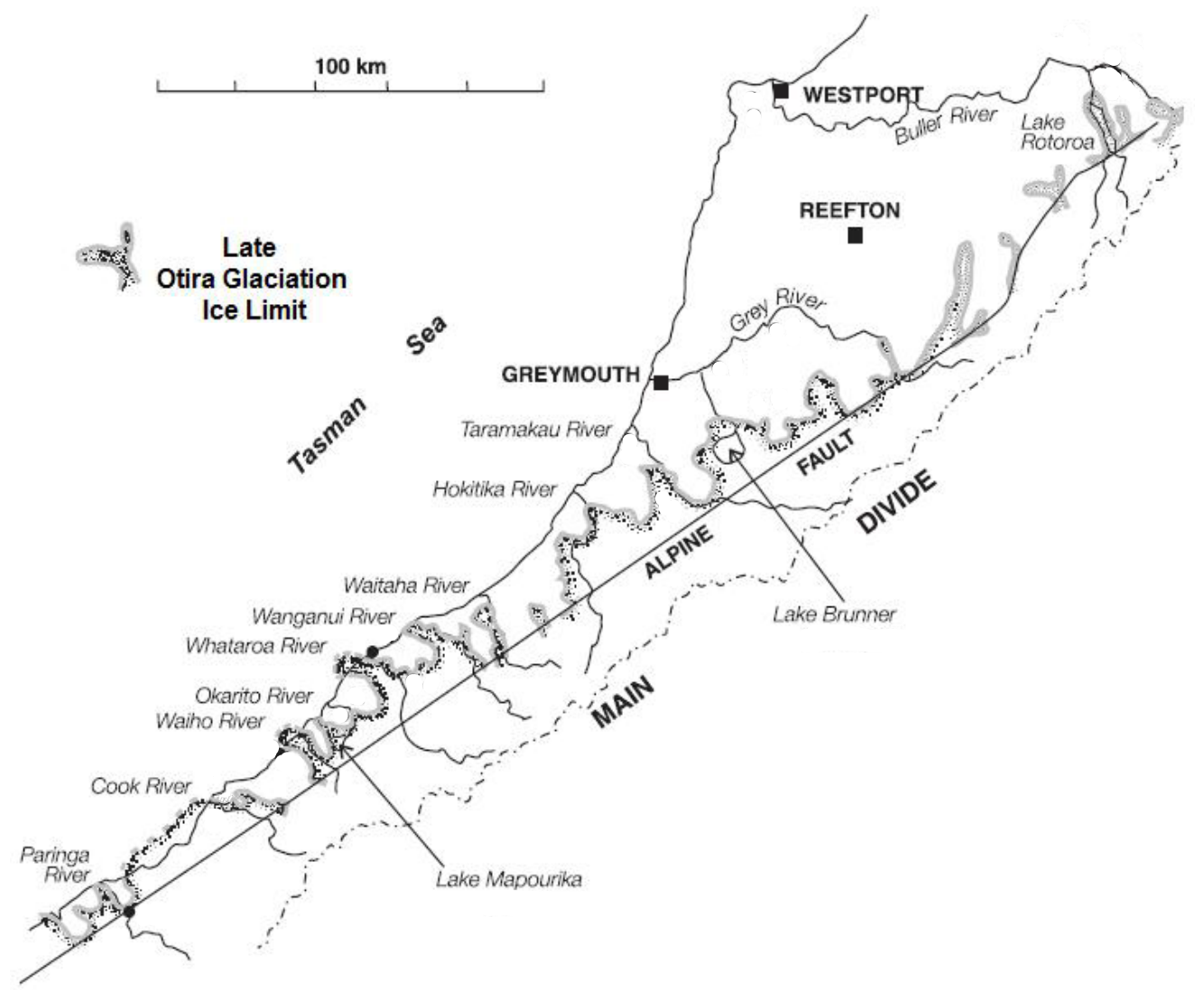

Figure 1.9: Ice limits of the Late Otira glaciation over the West Coast of the South Island, from Suggate and Almond (2005)

\section{Erosional processes}

In regions of rapid tectonic rock uplift, both fluvial and glacial erosion rates can reach $>10 \mathrm{~mm} / \mathrm{yr}$ (Koppes and Montgomery, 2009). This indicates that the rate of erosion in the central western Southern Alps is controlled by the rate of uplift, regardless of whether the valleys are glaciated or not (Hicks et al., 1990; Herman et al., 2007; Koppes and Montgomery, 2009). The geomorphic expressions of glacial and fluvial erosion have differing characteristics. Glacial erosion acts to widen and deepen valleys while removing little material from the valley walls, forming U-shaped valleys. Fluvial erosion 
carves sharply down, removing material from the valley walls and incising V-shaped valleys (Adams, 1980; Herman et al., 2007). The overall topography of the western Southern Alps is best described as transitional between glacial and post-glacial conditions, as the Earth emerges from the most recent glacial period (Herman et al., 2007). Estimates of total present-day erosion rates and sediment discharge rates at West Coast localities were derived by Korup et al. (2005). The Wanganui, Whataroa and Waiho have erosion rates of $6.1 \mathrm{~mm} / \mathrm{yr}, 11.4 \mathrm{~mm} / \mathrm{yr}$ and $12.2 \mathrm{~mm} / \mathrm{yr}$ respectively, while the sediment discharge of each river system is $2.1 \times 10^{6} \mathrm{~m}^{3} / \mathrm{yr}, 1.1 \times 10^{6} \mathrm{~m}^{3} / \mathrm{yr}$ and $2.0 \times 10^{6}$ $\mathrm{m}^{3} /$ yr respectively (Korup et al., 2005).

\subsection{Previous studies}

\subsubsection{South Island Geophysical Transect}

The South Island Geophysical Transect (SIGHT) was a joint research project between New Zealand and American research institutes, carried out in 1996 and 1998 (Davey et al., 1998; Van Avendonk et al., 2004; Okaya et al., 2007).

The primary objectives of SIGHT were to investigate:

1. The expression of the plate boundary zone in both the crust and mantle;

2. Structures and processes of the lithosphere in response to the oblique convergence of continental collision;

3. How processes in the crust are related to those in the mantle;

4. How strain is partitioned along the boundary of an oblique-convergent continent-continent collision.

The SIGHT project's primary means of investigation was an active source seismic survey, complimented locally by passive seismic, magnetotelluric and gravity data. Data were acquired along two parallel transects spanning the central South Island, perpendicular to the plate boundary, (Figure 1.10). 


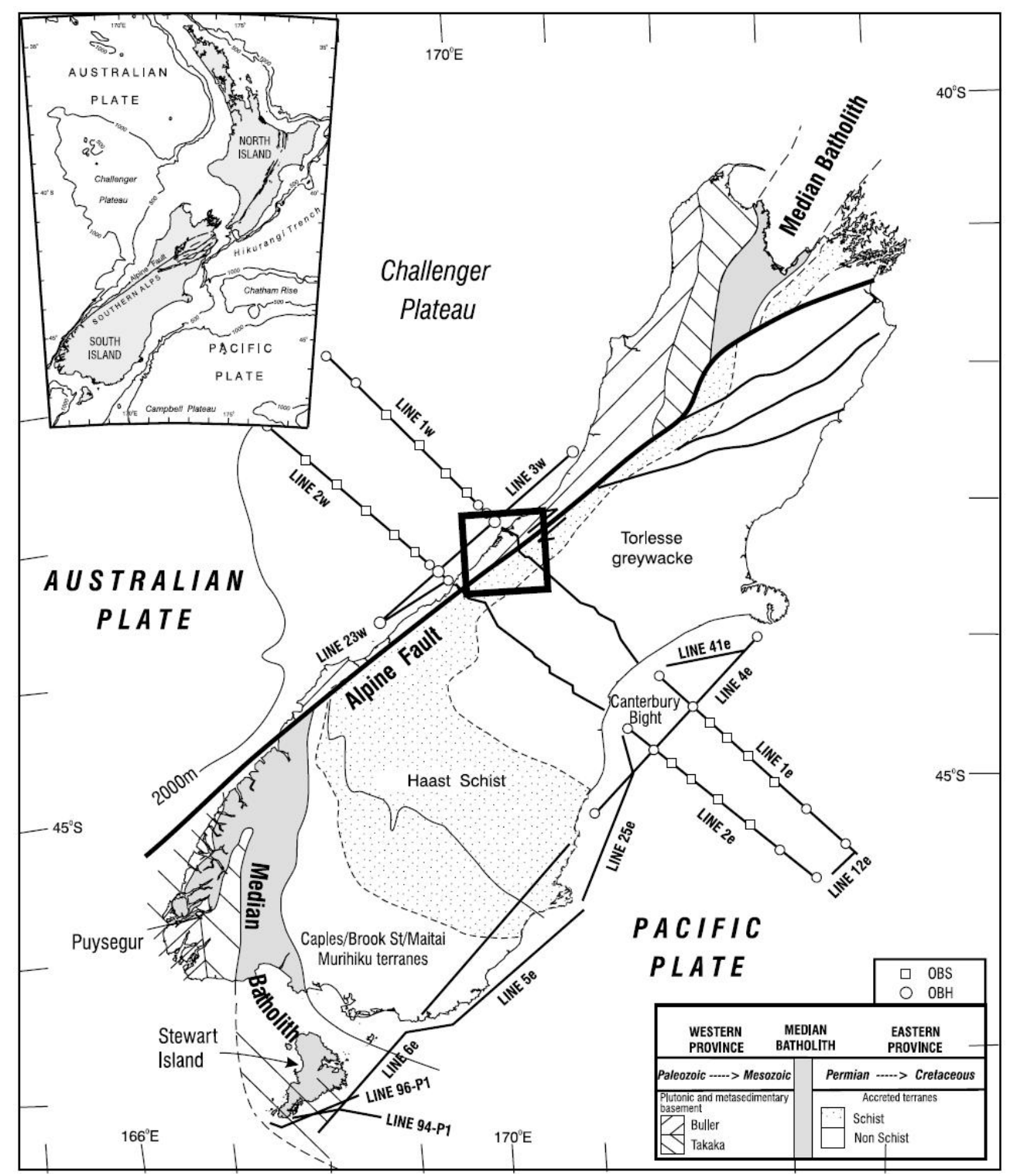

Figure 1.10: Parallel SIGHT transects traversing the central South Island. Figure from Davey (2010).

SIGHT transect 1 extended from the West Coast at the Whataroa river valley, over the Main Divide and to the east coast along the Rangitata River. SIGHT transect 2 extended from the Karangarua river, and over the Main 


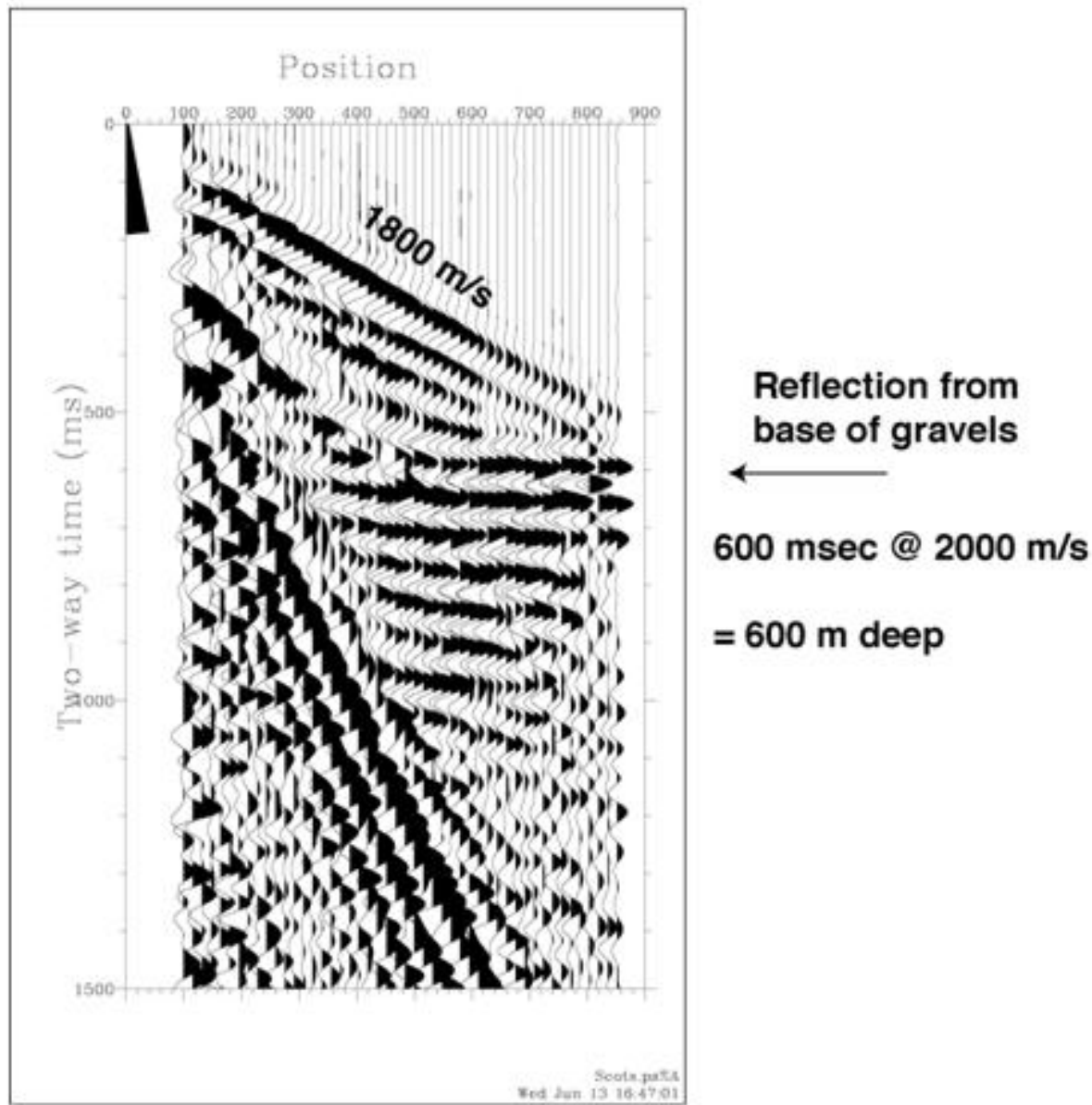

Figure 1.11: An unpublished shot gather from SIGHT transect 2 showing a strong reflection at $600 \mathrm{~m}$ depth in the Karangarua River valley (Stern, 2011).

Divide before passing through Tekapo and the Cannington Basin to the east coast, south of Timaru (Scherwath et al., 2001).

An unpublished shot-gather from the Karangarua river valley shows a strong reflection at a depth of $600 \mathrm{~m}$, inferred to be the base of gravels in the hanging wall river valley, see Figure 1.11. This gives an indication of the extent of glacial erosion in the hanging wall of the Alpine Fault.

Seismic and gravity data acquired along the SIGHT transects have been 
used to image the crust and mantle structure below the central Southern Alps. The crustal root of the Southern Alps reaches a maximum depth of 45 $\mathrm{km}$ directly below a regional $(-90 \mathrm{mGal})$ Bouguer gravity low along SIGHT transect 2 (Henrys et al., 2004). In order to satisfy the regional Bouguer gravity low and the pattern of teleseismic $\mathrm{P}$ waves, a high velocity mantle blob, with a width of $80-100 \mathrm{~km}$ and depth extent of $100 \mathrm{~km}$, is also inferred to be centered $120 \mathrm{~km}$ below the central Southern Alps (Stern et al., 2000; Henrys et al., 2004).

\subsubsection{Seismicity}

Ongoing investigation into the seismicity of the Alpine Fault also reveals vital information on the fault processes and distribution of deformation at the continental plate boundary.

The Southern Alps Passive Seismic Experiment (SAPSE) was conducted in 1995/1996 and involved the deployment of 40 temporary seismometers augmented by 17 permanent seismic stations (Davey et al., 1998; Leitner et al., 2001; Kohler and Eberhart-Phillips, 2002). These stations formed a network across the Southern Alps with an average spacing of $30-50 \mathrm{~km}$ (Davey et al., 1998; Leitner et al., 2001). The experiment ran for six months and recorded 5491 earthquakes (Leitner et al., 2001). Some of the key findings from SAPSE were (Leitner et al., 2001; Kohler and Eberhart-Phillips, 2002):

- The central Alpine Fault has low seismicity, comparable to sections of the San Andreas Fault and has the potential for large earthquakes;

- The maximum depth of seismicity is relatively uniform over large parts of the central South Island, but becomes $3-4 \mathrm{~km}$ shallower beneath the high Southern Alps as a result of higher temperatures east of the Alpine Fault;

- The maximum seismogenic depth along the Alpine Fault is $10-12$ km. 
Research by O'Keefe (2008) investigated microseismicity along the Alpine Fault and found significantly lower seismicity in the region between Harihari and Karangarua. The study suggested a laterally varying brittle-ductile transition at $15 \mathrm{~km}$ depth along most of the fault, reducing to $10 \mathrm{~km}$ below regions with the highest orogenic uplift rates (O'Keefe, 2008).

More recently, the Southern Alps Microearthquake Borehole Array (SAMBA) project has been undertaken to expand on the SAPSE data set by detecting and recording microearthquakes $(\mathrm{m} \sim 0)$. In early 2009, 11 short-period seismometers were installed in $1-100 \mathrm{~m}$ deep boreholes along a $50 \mathrm{~km}$ stretch of the central Alpine Fault between the Whataroa and Karangarua rivers, and in 2010 the array was augmented with 12 Deep Fault Drilling Project instruments (Boese et al., 2010, 2011). The SAMBA deployment is due to be completed in 2012, but early results are consistent with the lack of seismicity north-east of the Whataroa river valley, and has revealed microearthquake cluster triggering after the 2009 Dusky Sound MW 7.8 in Fiordland (Boese et al., 2010, 2011).

\subsubsection{Gravity}

Brikke (2007) performed a gravimetric and active source seismic study across the Whataroa flood plain using seismic data from the SIGHT transect 1, gravity observations from GNS Science's gravity network, and new gravity data across the Whataroa flood plain, parallel to the Alpine Fault. Brikke's $2 \mathrm{D}$ transect is illustrated in Figure 1.12. The primary findings of the study were:

1. The detection of buried glacial channels below the flood plain, with modelled depths extending to $550 \mathrm{~m}$;

2. The deepest channel is dextrally offset from the current Whataroa river by $\sim 1 \mathrm{~km}$ (Figure 1.12);

3. The presence of an elongate gravity anomaly extending north-west to- 


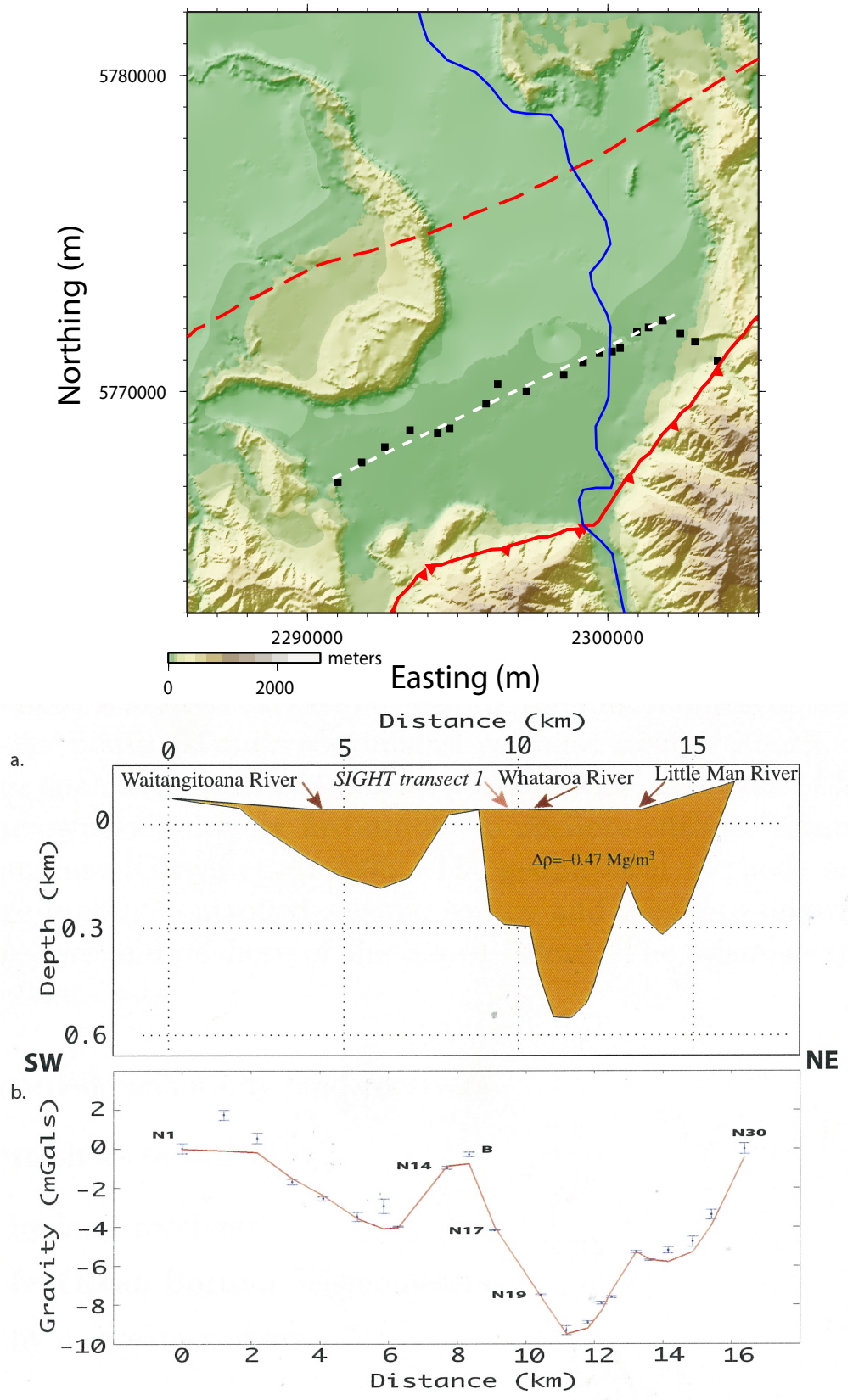

Figure 1.12: Above: map of the gravity transect measured by Brikke (2007). Below: Gravity model from Brikke (2007), a shows the observed and modelled gravity anomaly, $\mathbf{b}$ shows the gravity model. 
ward the coast, dextrally offset by $3-4 \mathrm{~km}$ north-east from the hanging wall river valley. Associating this gravity anomaly to the Waimea glaciation which culminated at 140 ka BP infers a mean strike-slip rate of $25 \mathrm{~mm} / \mathrm{yr}$ on the Alpine Fault at Whataroa;

4. Two kettle holes below the Whataroa flood plain, proposed to have been carved by the Waimea and subsequent Otira glaciations;

5. The horizons of Quaternary and Tertiary sediments, as well as the basement rock of the Australian plate appear to be unperturbed by the plate boundary.

Scherwath et al. (2006) investigated the crust and mantle structure below the Southern Alps using gravity and seismic data across the South Island. The results of this study revealed differences in isostatic compensation between the northern, central and southern sections of the Southern Alps. These differences are explained by an increased thickening and widening of the crustal root from north to south, and by the long wavelength gravity response of an anomalous mantle body which increases in size to the south (Scherwath et al., 2006). 2-D and 3-D models of the lithospheric thickening are presented, which can be used to help constrain regional gravity models.

\subsubsection{Geodesy}

Studies of plate velocities derived from permanent GPS stations have aided in understanding how strain is accumulated, distributed along and subsequently released along the Alpine Fault (Wallace et al., 2007). Most recently, GPS studies have been carried out by Beavan et al. (1999), Wallace et al. (2007), Beavan et al. (2007) and Beavan et al. (2010). Results from these studies have led to the following interpretations:

- The fault is locked down to depths of $5-8 \mathrm{~km}$ and below this $50-70 \%$ of interplate motion is accommodated as steady-slip; 
- The highest relative vertical velocity across the Southern Alps is $\sim 5$ $\mathrm{mm} / \mathrm{yr}, 20-30 \mathrm{~km}$ southeast of the Alpine Fault; the velocity distribution over the Southern Alps suggests interseismic coupling falls to zero at $13-18 \mathrm{~km}$ depth;

- Up to $5 \mathrm{~mm} / \mathrm{yr}$ of inter plate movement is accommodated on fault structures within the Southern Alps, in a $100 \mathrm{~km}$ zone east of the Alpine Fault.

\subsection{Gravity model constraints}

\subsubsection{Borehole data}

Boreholes were drilled in both the Wanganui and Waiho flood plains for the purpose of hydrocarbon exploration. Harihari-1 and Waiho-1 were drilled respectively in 1971 and 1972 by NZ Petroleum Exploration Co. Ltd and provide information on the stratigraphy of the onshore section of the South Westland Basin (Smart, 1971, 1972).

The locations of Harihari-1 and Waiho-1 are seen in Figure 1.14.

The stratigraphy of each borehole can be divided into three primary units distinguished by age and overlying one another. The top unit is a Pleistocene layer consisting of glacial outwash and fluvial deposits; the middle unit is of Pliocene age and is an interbedding of soft silty Wanganui series mudstones and shales; the bottom layer is Upper-Mid Miocene in age and formed of compacted Taranaki series mudstones and Taranaki series sandstones and conglomerates. (Smart, 1971, 1972). Table 1.3 gives the layer thicknesses from each borehole. The boundaries of these sedimentary layers produce strong seismic reflectors which have been identified in the analysis of onshoreoffshore seismic surveying (Nathan et al., 1986; Sircombe and Kamp, 1998; Davey, 2010). 


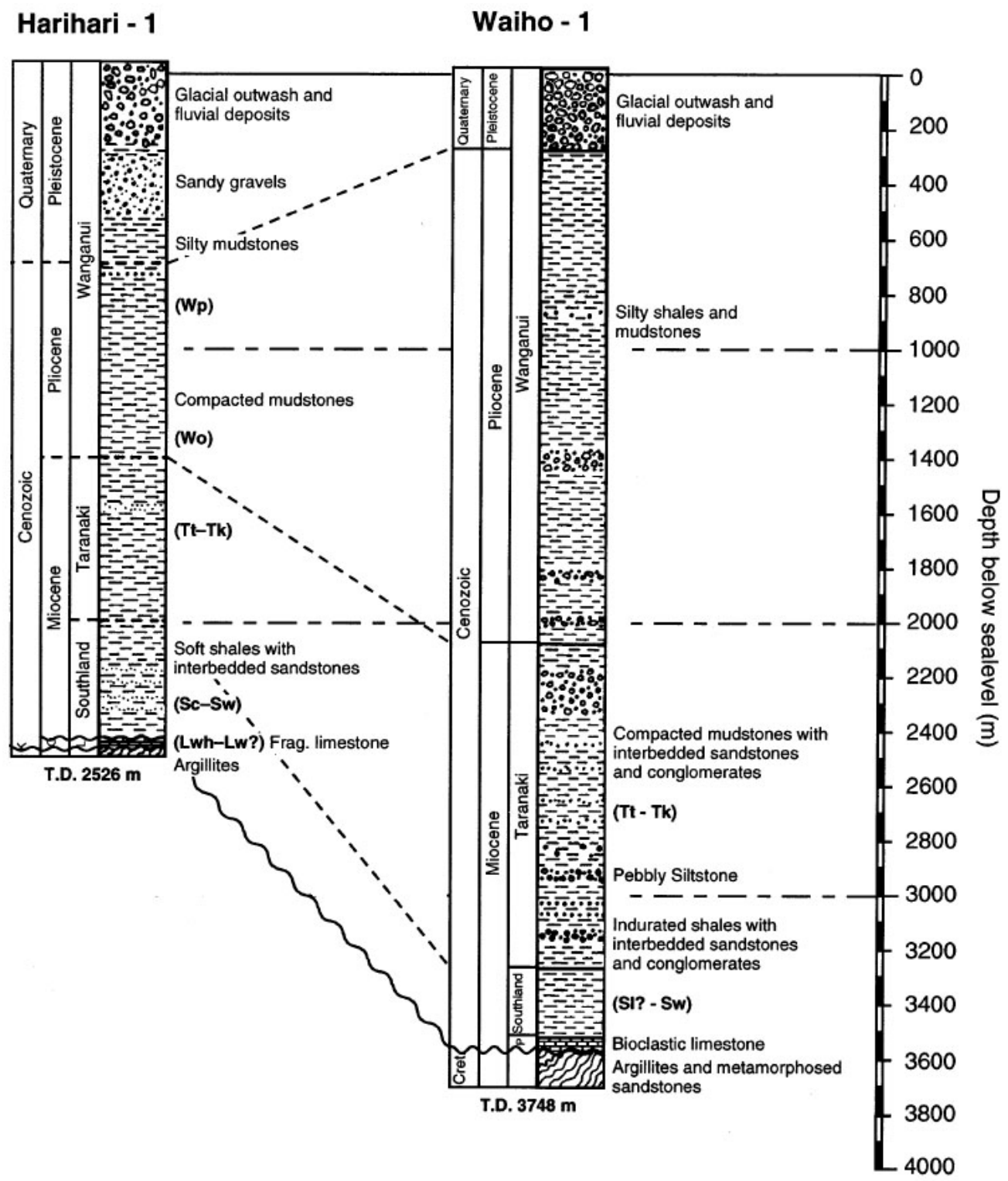

Figure 1.13: The stratigraphy of boreholes Waiho-1 and Harihari-1, figure from Sircombe and Kamp (1998). 


\subsubsection{Whataroa seismic model}

Davey (2010) produced a seismic model striking perpendicular to the Alpine Fault from data collected along SIGHT line 1 (Scherwath et al., 2001). SIGHT line 1 and the seismic model of Davey (2010) are shown in Figure 1.14. The model shows the geometry and seismic velocity of three layers identified in the South Westland Basin, the uplifted and eroded basin structure, the modelled location of the South Westland Fault $(\sim 4 \mathrm{~km}$ southeast of the mapped trace) and the mapped location of the Alpine Fault.

Existing and new gravity observations (Chapter 3) along the SIGHT seismic line enable a joint interpretation of gravity and seismic data.

Seismic velocities from this model are used to help determine the bulk density of rock units. Table 1.1 summarises the seismic velocities from the model of Davey (2010). It is important to note that a distinction has been made between the Pleistocene sedimentary layer of the the South Westland Basin and Quaternary glacial sediment which infills erosional channels in the flood plains and river valleys.

\subsubsection{Rock density}

The assumed densities of different rock units is the most critical parameter in the process of gravity modelling (Dobrin and Savit, 1988). The bulk densities of rock units within the study area are estimated using the methods outlined below.

\section{Seismic velocity relations}

Both the bulk density and compressional seismic velocity of sedimentary rocks are influenced by the process of lithification, both increasing as sediment lithifies into rock. Several empirical relationships between seismic velocity and bulk density have been established. Gardner et al. (1974) established an approximate relationship between p-wave velocity $\left(V_{p}\right.$ in $\left.\mathrm{km} / \mathrm{s}\right)$ and bulk 


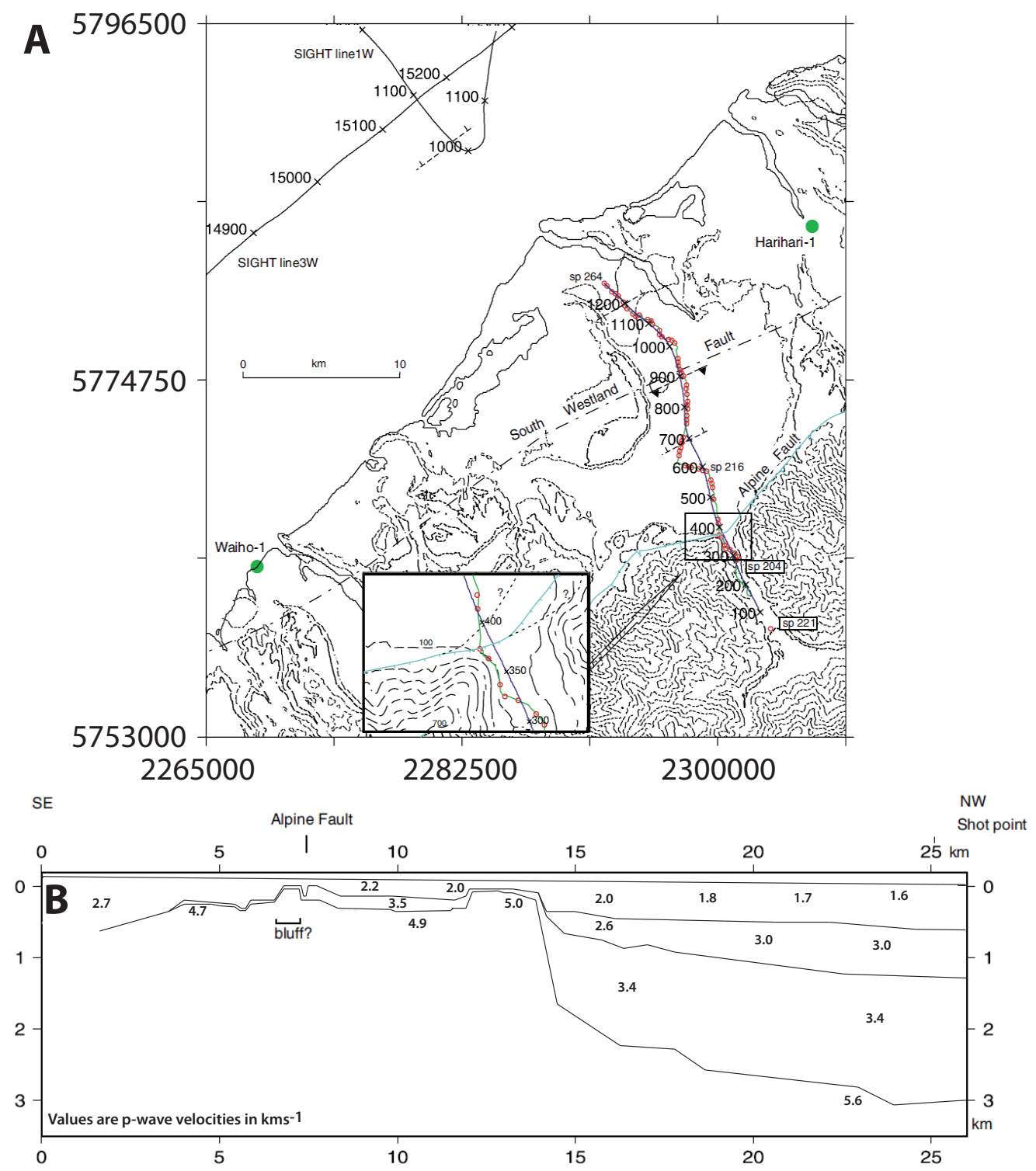

Figure 1.14: A) Map of the SIGHT receiver transect in the Whataroa flood plain. B) Dimensions and seismic velocities of the seismic forward model made by Davey (2010). Figures from Davey (2010). 


\begin{tabular}{cccc}
\hline & $V_{p}$ & \multicolumn{2}{c}{$\rho\left(\mathrm{kg} / \mathrm{m}^{3}\right)$} \\
Geological unit & $\left(\mathrm{km} \mathrm{s}^{-1}\right)$ & $($ Gardner $)$ & $($ Nafe-Drake $)$ \\
\hline Quaternary glacial sediment & $2.0-2.7$ & $2070-2230$ & $1910-2150$ \\
Pleistocene sediment & $1.6-2.0$ & $1960-2070$ & $1700-1910$ \\
Pliocene sediment & $2.6-3.0$ & $2210-2290$ & $2120-2220$ \\
Miocene sediment & $3.4-3.5$ & $2360-2380$ & $2300-2320$ \\
\hline
\end{tabular}

Table 1.1: Seismic velocities of the Quaternary sediment cover and the geological units of the South Westland Basin, from the seismic model of Davey (2010). Bulk density of geological units using the Gardner and Nafe-Drake empirical relations (Ludwig et al., 1970; Brocher, 2005).

density $\left(\rho\right.$ in $\left.\mathrm{gm} / \mathrm{cm}^{3}\right)$ given by Equation 1.1.

$$
\rho=1.74\left(V_{p}\right)^{1 / 4}
$$

The Nafe-Drake curve (Ludwig et al., 1970) is another approximation of the relationship between $V_{p}$ and $\rho$, expressed numerically in Equation 1.2 (Brocher, 2005):

$$
\rho=1.6612\left(V_{p}\right)-0.4721\left(V_{p}\right)^{2}+0.0671\left(V_{p}\right)^{3}-0.0043\left(V_{p}\right)^{4}+0.000106\left(V_{p}\right)^{5}
$$

Table 1.1 shows the range of calculated densities for the four geological units using the seismic velocities of Davey (2010) in Equations 1.1 and 1.2.

\section{Rock catalogues}

Whiteford and Lumb (1975) produced rock catalogues for the Department of Scientific and Industrial Research which detail the physical properties of New Zealand rocks by their geographic location and rock type. The only rock sample in the database from within the study area is of Tuhua group granite. Rock units not sampled within the study area have been sampled throughout the South Island and can be used to infer appropriate bulk densities to be used in gravity modelling. Table 1.2 gives the average dry and wet densities for rocks encountered within the study area. 


\begin{tabular}{cccccccc}
\hline \multirow{2}{*}{ Period } & \multicolumn{6}{c}{ Density $\left(\mathrm{kg} / \mathrm{m}^{3}\right)$} \\
\\
\hline \hline Pleistocene & Rock & Meries & Dry & $\sigma$ & Wet & $\sigma$ & Samples \\
\hline Pliocene & Mudstone & Wanganui & 1890 & 340 & 2140 & 220 & 14 \\
& Siltstone & Wanganui & 1890 & 340 & 2140 & 220 & 14 \\
\hline \multirow{2}{*}{ Miocene } & Mudstone & Taranaki & 1590 & 40 & 1970 & 40 & 3 \\
& & Southland & 2100 & 160 & 2240 & 110 & 3 \\
& \multirow{2}{*}{ Siltstone } & Taranaki & 2500 & - & 2290 & 60 & 2 \\
& & Southland & - & - & - & - & - \\
& \multirow{2}{*}{ Sandstone } & Taranaki & 2460 & - & 2550 & - & 1 \\
& & Southland & 2330 & 130 & 2420 & 90 & 5 \\
\hline Cambrian & Granite & Tuhua & 2660 & 70 & 2690 & 70 & 83 \\
\hline
\end{tabular}

Table 1.2: Dry and wet rock densities from rock catalogues produced by Whiteford and Lumb (1975).

\begin{tabular}{cccc}
\hline & \multicolumn{2}{c}{ Layer thickness $(\mathrm{m})$} & Density \\
Rock unit & Harihari-1 & Waiho-1 & $\left(\mathrm{kg} / \mathrm{m}^{3}\right)$ \\
\hline Quaternary sediment & - & - & 2100 \\
Pleistocene sediment & $700 \pm 10$ & $240 \pm 10$ & 2150 \\
Pliocene sediment & $760 \pm 10$ & $1860 \pm 10$ & 2250 \\
Miocene sediment & $1040 \pm 10$ & $1520 \pm 10$ & 2450 \\
Granite & - & - & 2690 \\
Basement & - & - & 2670 \\
\hline
\end{tabular}

Table 1.3: The thickness of sedimentary layers from the Harihari-1 and Waiho-1 boreholes, and the bulk densities used for the geological units modelled within the study area.

\subsubsection{Bulk densities and sedimentary layer thickness}

Table 1.3 details the bulk densities used for modelling and the thickness of sedimentary layers from local boreholes. 


\subsection{Thesis structure}

This thesis is structured as follows:

- Chapter 1 (this chapter) gives the motivation and objectives of the research and provides an overview of the geology and geophysics of the study area.

- Chapter 2 covers the theory of gravity analysis and its use as a means of exploring the Earth's subsurface.

- Chapter 3 illustrates the new gravity data over the central West Coast of the South Island and how a regional gravity trend was accounted for. The data are presented as Bouguer and regionally corrected residual gravity maps of the Wanganui, Whataroa and Waiho flood plains.

- Chapter 4 presents gravity models of data from the Wanganui, Whataroa and Waiho flood plains and investigates the structure of the subsurface, with discussion of the processes responsible for its formation.

- Chapter 5 details the methods used and the results obtained for the estimation of the Alpine Fault's strike-slip movement rate in the Wanganui, Whataroa and Fox flood plains.

- Chapter 6 discusses the results found in Chapters 3, 4 and 5 and their implications for the central Alpine Fault's kinematics and the study area's geomorphologic evolution. 


\section{Chapter 2}

\section{Gravity and gravimetric study}

The purpose of this chapter is to summarise the theory behind gravimetric studies in order to familiarise the reader with the ideas and techniques discussed in later chapters.

\subsection{Gravity}

Newton's universal law of gravitation states that the force $F$ between two particles of masses $m_{1}$ and $m_{2}$ is given by equation 2.1 , where $\mathrm{G}$ is the universal gravitation constant and $r$ is the separation between particles (Burger et al., 2006; Gerkens, 1989):

$$
\begin{gathered}
F=G \frac{m_{1} m_{2}}{r^{2}} \\
G=6.6732 \times 10^{-11} \mathrm{Nm}^{2} / \mathrm{kg}^{2}
\end{gathered}
$$

In the simplest scenario, the Earth can be approximated as a uniform sphere with a radius $R$ and a mass $M$. Given this approximation, the force $F$ acting on a mass $m$ at the Earth's surface is given by the equation:

$$
F=G \frac{m M}{R^{2}}
$$


Newton's second law of motion relates the acceleration $a$ of a particle of mass $m$, to the force $F$ applied:

$$
F=m a
$$

Substituting equation 2.3 into equation 2.4 gives the equation for acceleration due to gravity, $g$ :

$$
\begin{gathered}
F=m a=m g=G \frac{m M}{R^{2}} \\
g=\frac{G M}{R^{2}}
\end{gathered}
$$

This approximate formula for the Earth's gravity has a simple reliance on the mass and radius of the Earth. If the Earth truly were a perfect sphere with uniform mass distribution, then the acceleration due to gravity would have a constant value at all locations on the Earth's surface.

While gravity is the force of attraction between bodies of mass, it is commonly expressed as acceleration due to gravitational force. Acceleration $a$ has units of $\mathrm{m} / \mathrm{s}^{2}$, however, in geophysics the gravitational acceleration $g$ is measured in Gal, after Galileo, which has units of $\mathrm{cm} / \mathrm{s}^{2}$. Generally, variations in the Earth's gravity are of the order of milliGal, where $1 \mathrm{mGal}$ $=0.001 \mathrm{Gal}$ (Burger et al., 2006).

\subsection{Gravity of the Earth}

The Earth is not a uniform sphere with a homogeneous density distribution; it has an oblate shape and a complex geoid with a heterogeneous density distribution. The heterogeneous structure of the Earth results in a varying potential gravity field over the Earth's surface.

The measured absolute value of gravity at any location on the Earth's surface is influenced by five factors: latitude, elevation, surrounding topography, tide and instrument drift, and density variation within the Earth's 
subsurface (Telford et al., 1990). The majority of geophysical gravity studies exploit the last factor in order to understand the structure of local and regional subsurface. Small changes in rock density and hence small changes in rock mass produce small variations in the Earth's gravitational field, which can be observed at the Earth's surface using a portable gravimeter (Milsom, 2003). To isolate the gravitational effect of subsurface structures, the gravitational effects of latitude, elevation, surrounding topography and Earth tides must be corrected for.

The following subsections describe the physical effects of these factors and how they are corrected for in this study.

\subsubsection{Absolute gravity}

Absolute gravity is the total force of gravity at a location on the Earth's surface at a particular point in time (Burger et al., 2006). In this study gravity observations are made using instruments which measure relative changes in gravity between observation points and not the absolute force of gravity. In order to establish absolute gravity values for survey observations, a site of established absolute gravity must be observed during the course of surveying. The survey observations can then be related to the absolute gravity reference to determine the absolute gravity of these observations (Telford et al., 1990; Burger et al., 2006):

$$
g_{a b s}=g m_{\text {relative }}-g m_{\text {reference }}+g_{\text {abs reference }}
$$

where $g m_{\text {reference }}$ is the gravity meter reading at the absolute gravity reference, $g_{a b s \text { reference }}$ is the absolute value of gravity at this reference point, $g m_{\text {relative }}$ is the relative gravity reading at a new observation point and $g_{a b s}$ is the absolute value of gravity for the new observation point.

\section{New Zealand primary gravity network}

Systematic gravity surveying began in New Zealand with the establishment of New Zealand's primary gravity network by the Department of Scientific and 


\begin{aligned} & \hline \multicolumn{2}{c}{$\begin{array}{c}\text { Whataroa absolute } \\ \text { gravity station }\end{array}$} \\ & \hline Elevation: $81 \mathrm{~m} \\ &$ Latitude: $43^{\circ} 08^{\prime} 57^{\prime \prime} \mathrm{S} \\ &$ Longitude: $170^{\circ} 24^{\prime} 01^{\prime} \mathrm{E} \\ &$ Northing: $5764945 \mathrm{~N} \\ &$ Easting: $2300004 \mathrm{E} \\ & g_{a b s}: 980408.72 \mathrm{mGals} \\ &$\hline\end{aligned}

Table 2.1: The location, elevation and absolute gravity values for the Whataroa gravity reference site from the New Zealand Primary Gravity Network (Reilly, 1972). $g_{a b s}$ is the absolute value of gravity, latitude and longitude are in the WGS84 datum, northing and easting are in the New Zealand Map Grid reference system.

Industrial Research between 1949 and 1956. The primary gravity network consists of 418 gravity meter and 19 pendulum stations measured across New Zealand which provide absolute gravity control points for further gravity observations (Robertson and Reilly, 1960; Reilly, 1972). During the 1970's detailed gravity surveys were added to the New Zealand gravity network in order to produce a series of basic gravity maps across the country with an optimum station density of 1 per $10 \mathrm{~km}^{2}$ (Reilly, 1972; Reilly and Whiteford, 1979).

The Institute of Geological and Nuclear Sciences, trading as GNS Science (formerly a part of the Department of Scientific and Industrial Research), now maintain the New Zealand gravity network. Observations in the network were established between 1949 and 1996. Gravity observations in the database exist as absolute gravity values, free-air gravity anomalies, isostatic gravity anomalies and Bouguer gravity anomalies. 


\section{Whataroa gravity tie}

In order to obtain absolute gravity values for the relative gravity observations collected in this study, the relative gravity readings were tied to an absolute gravity reference station located in the Whataroa river valley (Reilly, 1972). Details of this absolute gravity station are provided in Table 2.1.

\subsubsection{Gravity variation due to Earth tides}

Field gravimeters are sensitive enough to detect changes in gravity due to the relative movement of both the Moon and Sun. The range of gravity variation due to this phenomenon is around $0.3 \mathrm{mGal}$ and may have a rate of change as high as $0.05 \mathrm{mGal} /$ hour (Telford et al., 1990; Burger et al., 2006). In this study, both tidal and instrument drift are corrected for using a simple looping procedure.

Figure 2.1 shows a simple looping procedure in which gravity at a base station is measured at the beginning and end of a survey, and the difference in readings is divided by the time between base measurements to establish a drift rate. The amount of drift, $g_{d r i f t}$, for each gravity observation is calculated using:

$$
g_{\text {drift }}=\frac{\left(g_{\text {base }}\right)_{n+1}-\left(g_{\text {base }}\right)_{n}}{\left(t_{\text {base }}\right)_{n+1}-\left(t_{\text {base }}\right)_{n}} \times t_{o b s}
$$

where $\left(g_{\text {base }}\right)_{n}$ and $\left(g_{\text {base }}\right)_{n+1}$ are subsequent gravity values at a designated base station, $\left(t_{b a s e}\right)_{n}$ and $\left(t_{b a s e}\right)_{n+1}$ are the subsequent times of base station readings in minutes since the start of the survey and $t_{o b s}$ is the time of the gravity observation which is being drift corrected, in minutes since the survey was initiated. Base observations need to be made at a frequency greater than that of the tidal variations in order to determine accurate drift rates. Subtracting this drift amount from the gravity observation will correct for both the varying tidal effects of the Sun and Moon as well as any drift of the gravity meter due to its slowly varying physical properties (Burger et al., 2006). 


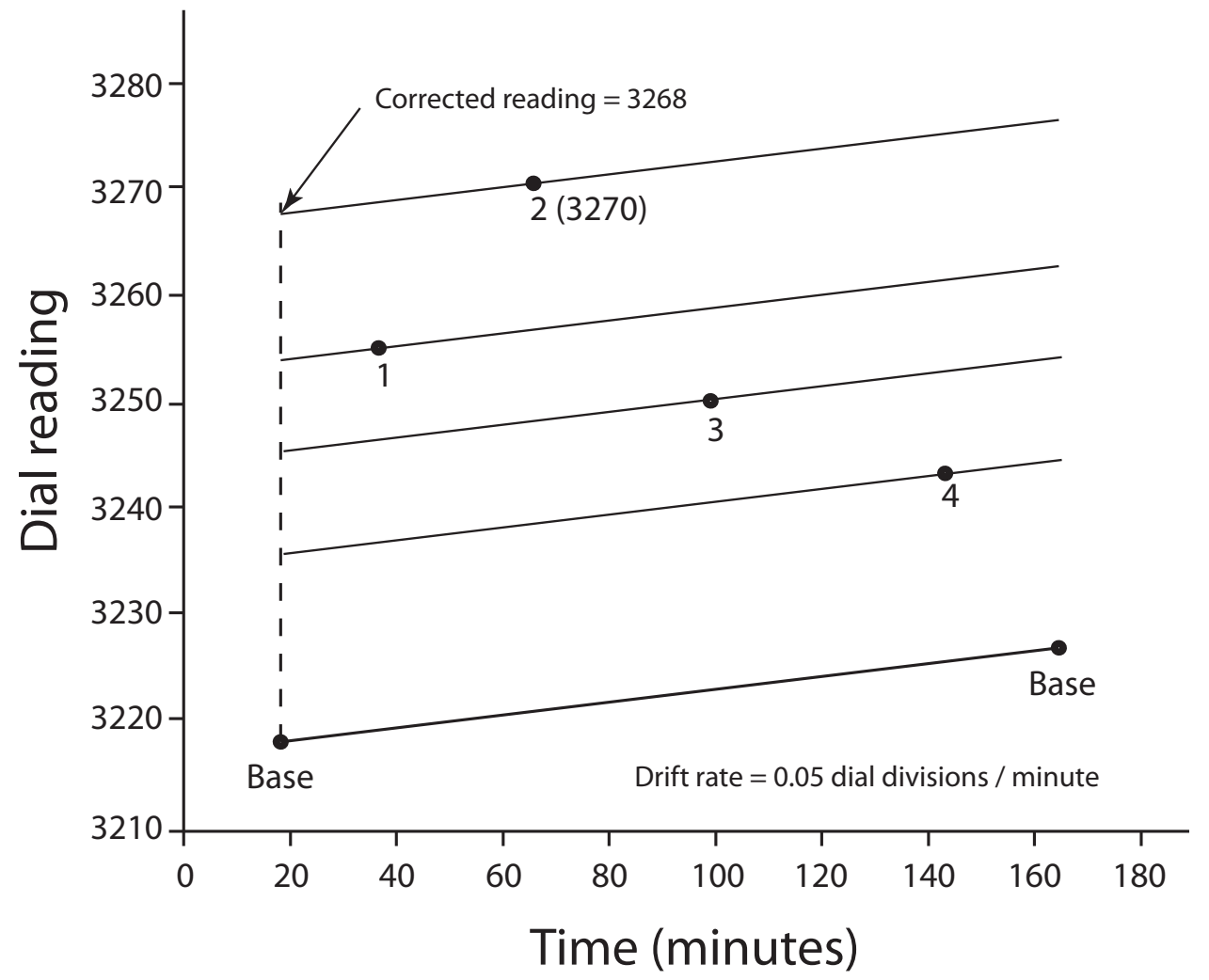

Figure 2.1: A simple looping procedure allows a drift rate to be determined for correction of both tidal and instrument drift effects.

The absolute gravity observed at a station, less instrument and tidal drift, is known as "observed gravity":

$$
g_{o b s}=g_{a b s}-g_{d r i f t}
$$

\subsubsection{Gravity variation with latitude}

The Earth's rotation produces an outward-directed centrifugal force, opposite to the force of gravity. This centrifugal force acts to diminish the force of gravity and is at a maximum at the equator, reducing to zero at the poles (Burger et al., 2006; Telford et al., 1990). At the equator, the centrifugal 


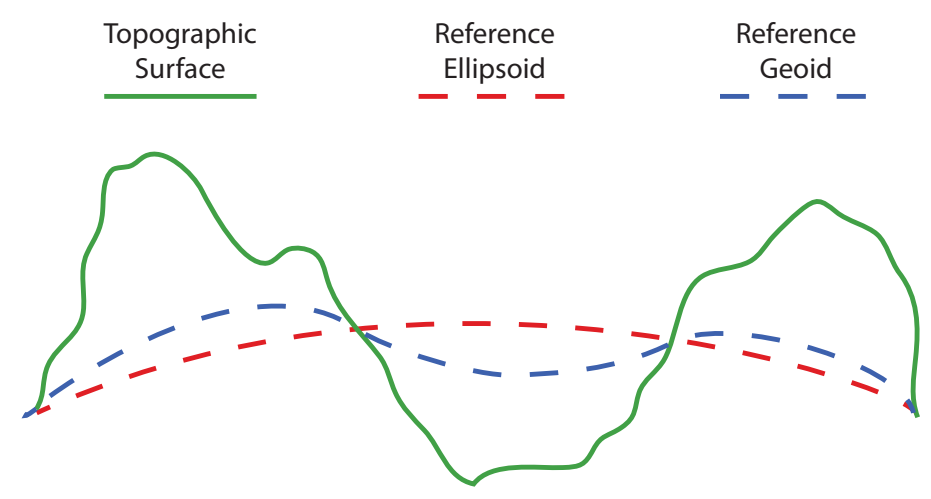

Figure 2.2: The shape of the Earth. Topographic, reference ellipsoid and reference geoid surfaces.

force is $0.3 \%$ of the attracting force (Gerkens, 1989). The Earth responds to this centrifugal force on long time scales by behaving as a fluid, resulting in a bulge at the equator and flattening at the poles. The resulting shape deviates from a sphere and is referred to as an oblate ellipsoid (Burger et al., 2006).

Given equation 2.3, this difference in radial distance causes the acceleration due to gravity to increase from the equator to the poles. However, there is now additional mass between the equator and centre of the Earth and less mass between the poles and the centre of the Earth. This decrease in mass going from equator to the poles acts to decrease acceleration due to gravity. The combined effects of the Earth's rotation (centrifugal force, distance factor and mass factor) mean that the acceleration due to gravity at the poles is $5.2 \mathrm{Gal}(5200 \mathrm{mGal})$ greater than at the equator (Burger et al., 2006).

The geoid can be thought of as the gravitational equipotential surface created due to the shape and internal structure of the Earth plus its centrifugal effects; it is a complex surface affected by all geological features large and small. The oblate ellipsoid shape of the Earth approximates the geoid and is referred to as the reference ellipsoid (Telford et al., 1990; Burger et al., 2006). A cartoon comparison of the surfaces can be seen in Figure 2.2 (Telford et al., 


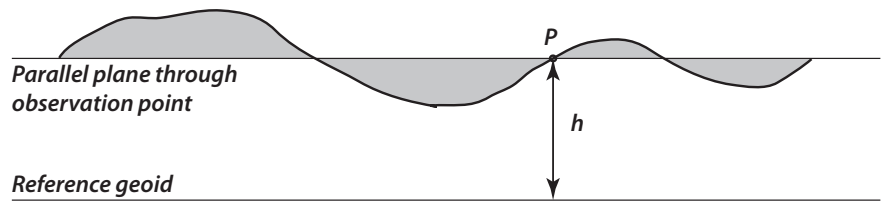

Figure 2.3: The gravity at the observation point $P$ is affected by the additional radial distance $h$, as well as the additional mass between $P$ and the geoid.

1990; Burger et al., 2006; Beck, 1981).

Although the reference ellipsoid deviates from the geoid, it can be utilised for a first-order approximation of gravity at latitude $(\theta)$ (Telford et al., 1990). In 1930 the International Gravity Formula (IGF30) was developed, giving an approximate value of gravity $\left(g_{\theta}\right)$ expected at a given latitude $(\theta)$ on the Earth's surface:

$$
g_{\theta}=978049\left(1+0.0052884 \sin ^{2} \theta-0.0000059 \sin ^{2} 2 \theta\right) \mathrm{mGal}
$$

\subsubsection{Gravity variations with elevation}

\section{Free-air correction}

The force of gravity varies inversely with the square of distance (equation 2.1) and so variation in the elevation of gravity observations will increase or decrease the measured force of gravity. To reduce the observations of gravity to that expected on the geoid, a correction for elevation is required. The free-air correction accounts for the difference in gravity between an observation point and the corresponding point on the geoid, due to a difference in elevation, $h$ (Gerkens, 1989).

In Figure 2.3 the observed gravity at point $P$ differs from the gravity expected at the geoid because of both an increase in radial distance $h$ and the gravitational effect of additional mass between the point $P$ and the geoid (Gerkens, 1989). The free-air correction does not account for any additional 
mass situated between the observation point and the geoid, and this must be corrected for separately. The simplest form of the free-air correction can be determined through differentiation of equation 2.3 with respect to the radial distance $R$, giving a rate of change in gravity with elevation, also known as the free-air gradient (Burger et al., 2006):

$$
\frac{\delta g}{\delta R}=-2 \frac{G M}{R^{3}}=-g \frac{2}{R}
$$

As the Earth's gravity $(g)$ and radial distance $(R)$ vary with latitude, the derivation of the Earth's free-air gradient yields a more complex equation (the derivation of which is omitted):

$$
\frac{\delta g}{\delta R}=-0.3086-0.00023 \cos 2 \theta+0.00000002 h
$$

where $\theta$ is latitude, $h$ is the elevation above the geoid and the units are in $\mathrm{mGal} / \mathrm{m}$. In most scenarios the second and third terms are negligible, leaving the leading term of $-0.3086 \mathrm{mGal} / \mathrm{m}$ to be used for the free-air gravity correction $\left(\mathrm{FA}_{\text {Corr }}\right)$ (Burger et al., 2006):

$$
\mathrm{FA}_{\text {Corr }}=-0.3086 \mathrm{mGal} / \mathrm{m} \times h
$$

\section{Bouguer correction}

The second consequence of an elevation difference between an observation point and the geoid (Figure 2.3) is the gravitational effect of additional mass between the two points (Gerkens, 1989). To reduce the free-air-corrected gravity observation to the expected gravity at point $P$ on the geoid, the gravitational effect of a laterally infinite slab of thickness $h$ and density $\rho$ is removed. This correction is known as the Bouguer correction (Gerkens, 1989; Burger et al., 2006). Derivation of the gravitational effect due to an infinite slab can be found in Beck (1981); Burger et al. (2006); Gerkens (1989), with the final Bouguer correction reducing to: 


$$
B_{\text {Corr }}=2 \pi G \rho h
$$

where $G$ is the gravitational constant, $\rho$ is the density of the material and $h$ is the elevation difference between the observation point and the geoid (Beck, 1981; Gerkens, 1989).

\subsubsection{Gravity variation due to topography}

The obvious problem with the Bouguer correction described above, is the assumption that an infinite slab represents the topography above the geoid (Burger et al., 2006). In Figure 2.3, shaded areas represent topography above and below the level of the Bouguer slab. The topography above the plane of the Bouguer slab represents a mass excess, while topography below the plane of the Bouguer slab represents a mass deficit (Gerkens, 1989; Beck, 1981).

The gravitational effect of these mass excesses and deficits are unaccounted for in the observed gravity and require a topographic correction. Both the topography above and below the plane of the Bouguer slab act to reduce the value of the observed gravity (Gerkens, 1989; Beck, 1981). In Figure 2.4, the topography above and below the plane of the Bouguer slab both reduce the observed gravity by equal amounts (Gerkens, 1989; Beck, 1981; Burger et al., 2006). A positive topography correction must therefore be added to the observed gravity to get a representative value at the geoid. The correction for undulations in topography is known as the terrain correction (Beck, 1981; Telford et al., 1990; Gerkens, 1989; Burger et al., 2006). Ideally gravity observations are be made in areas with limited topography to reduce the errors associated with determining terrain corrections (Gerkens, 1989).

A systematic method for estimating terrain corrections was developed by Hammer (1939). Hammer's method divides the surrounding topography into segmented rings of increasing radius surrounding an observation point, as can be seen in Figure 2.5. These rings are assigned a letter according to their 


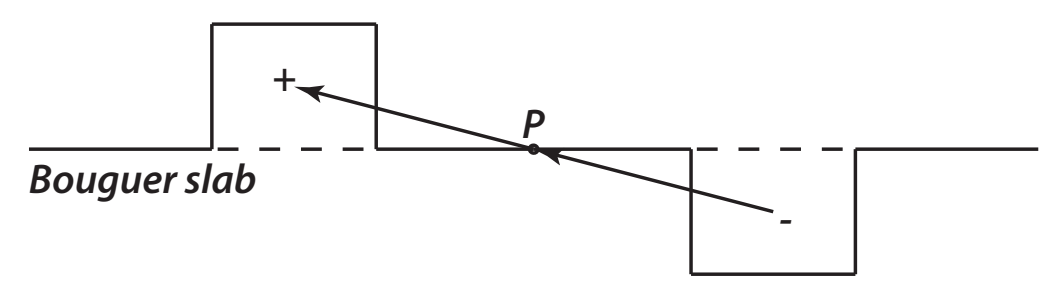

Figure 2.4: Topography both above and below the plane of the Bouguer slab has the effect of reducing the observed gravity at observation point $P$.

increasing radii size. Zone $\mathrm{A}$ is the ring with radius $0-2 \mathrm{~m}$, Zone $\mathrm{B}$ extends from $2-16.6 \mathrm{~m}$, Zone $\mathrm{C}$ extends from 16.6 - $53.3 \mathrm{~m}$ and so on (Dobrin and Savit, 1988).

The average elevation of topography lying in each ring sector around the observation point must be estimated. The absolute difference between the average elevation in a ring sector and the observation point elevation is used to compute the gravitational effect of topography in that ring sector (Telford et al., 1990; Gerkens, 1989; Burger et al., 2006). For the details of these calculations, see texts Telford et al. (1990) or Burger et al. (2006).

In this study, the elevation of the Hammer zones B $(2-16.6 \mathrm{~m}), \mathrm{C}$ $(16.6-53.3 \mathrm{~m})$ and $\mathrm{D}(53.3-170.1 \mathrm{~m})$ were estimated in the field for new gravity observations, with Hammer zone A $(0-2 \mathrm{~m})$ assumed to be level. These field observations were converted to $\mathrm{mGal}$ values using Hammer charts, giving the inner terrain corrections $\left(T_{\text {inner }}\right)$ for each gravity observation. Outer terrain corrections, between $170.1 \mathrm{~m}$ and $22 \mathrm{~km}$, were determined using Davies (2005) terrain correction software TopCor. TopCor utilises 25 $\mathrm{m}$ digital elevation models and the spatial location of each gravity observation to calculate the gravitational acceleration due to topography in a ring between $170.1 \mathrm{~m}$ and $22 \mathrm{~km}$ around each observation point. TopCor returns an outer terrain correction $\left(T_{\text {outer }}\right)$ in $\mathrm{mGal}$ for each observation location.

The total terrain correction for each gravity observation is given by: 


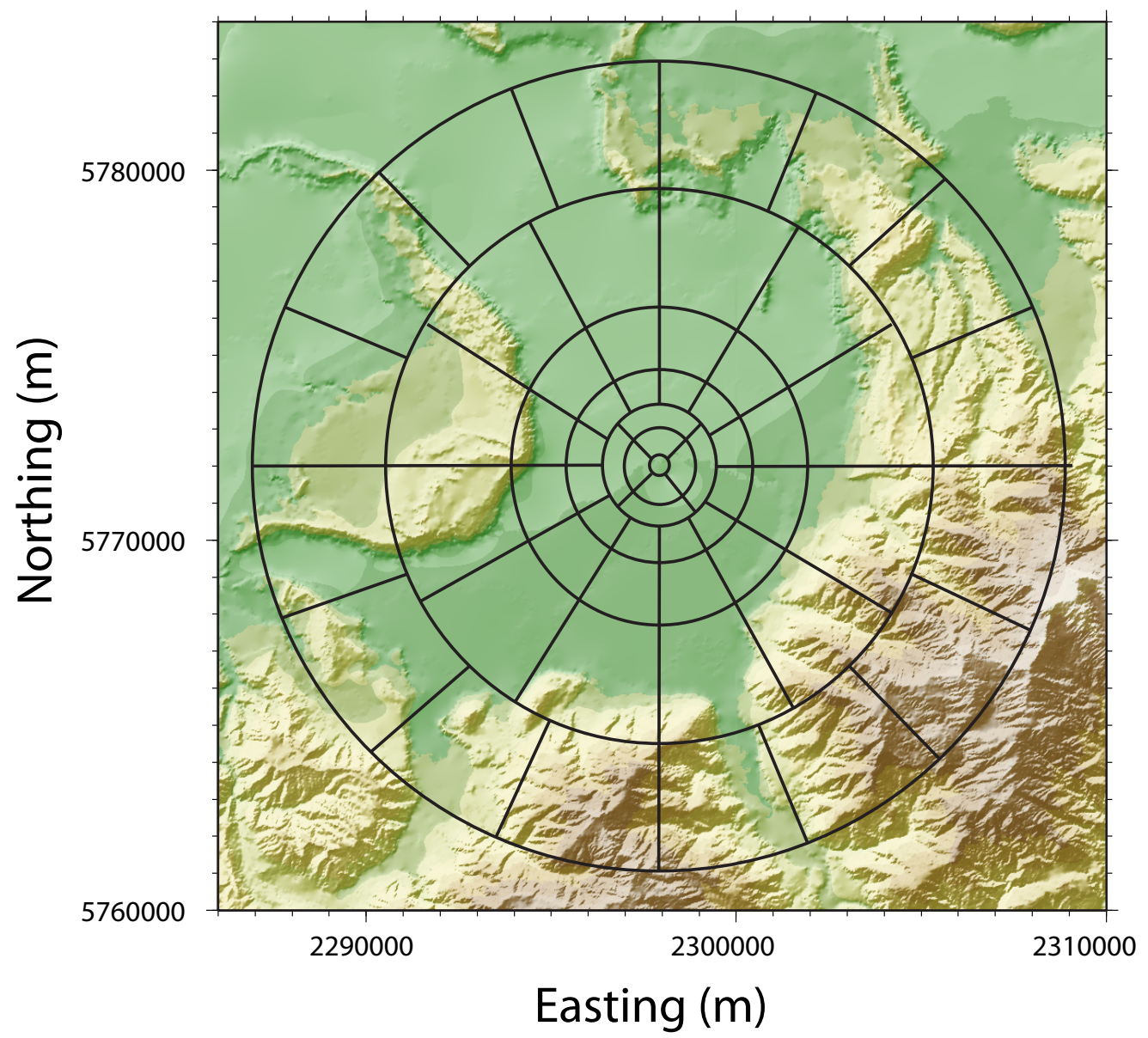

Figure 2.5: The Hammer zones used to divide and calculate the gravitational effects of topography surrounding an observation point. In this figure the template has been illustrated around a site in the Whataroa river valley.

$$
T_{\text {corr }}=T_{\text {inner }}+T_{\text {outer }}
$$

\subsubsection{The Bouguer gravity anomaly}

Gravity anomalies are discrepancies between the observed gravity and the gravity expected at a given location. Four of the five factors which determine the magnitude of gravity at the Earth's surface have been discussed 
above. The expected value of gravity $\left(g_{\text {exp }}\right)$ at an observation location can be determined by combining the approximations and corrections for these factors:

$$
g_{\text {exp }}=g_{\theta}+B_{\text {Corr }}+F A_{\text {Corr }}-T_{\text {Corr }}
$$

where $g_{\text {exp }}$ is the expected value of gravity at the observation location, $g_{\theta}$ is the expected gravity at latitude $\theta, B_{\text {Corr }}$ is the Bouguer correction, $F A_{C o r r}$ is the free-air correction and $T_{C o r r}$ is the terrain corrections. $g_{\exp }$ is sometimes referred to as the Bouguer model.

The difference between the observed gravity and expected gravity at an observation point is due to density variations within the Earth's subsurface and is known as the Bouguer gravity anomaly $\left(g_{B A}\right)$ :

$$
g_{B A}=g_{o b s}-g_{e x p}
$$

Substituting Equation 2.16 into Equation 2.17 yields:

$$
g_{B A}=g_{o b s}-g_{\theta}-B_{C o r r}-F A_{C o r r}+T_{C o r r}
$$

The Bouguer gravity anomaly enables the modelling and interpretation of the Earth's subsurface.

\subsection{New gravity observations}

This section outlines the acquisition, processing and error estimates of new gravity observations collected for this study.

\subsubsection{Instrumentation and field procedure}

\section{Instrumentation}

Gravity observations were made using a Lacoste and Romberg model G gravimeter (G179), which can measure relative gravity to an accuracy of 
$0.01 \mathrm{mGal}$. The readings of gravity recorded from the LaCoste and Romberg gravity meter are in units unique to the meter. These readings are converted to relative $\mathrm{mGal}$ values, $\mathrm{gm}_{\text {relative }}$, using the K-factor conversion table provided by LaCoste and Romberg.

The location and elevation of each observation was recorded using a Trimble R8 GNSS Global Position System (GPS) receiver, which in ideal conditions can reach a horizontal accuracy of $<5.0 \mathrm{~cm}$ and vertical accuracy of $<7.5 \mathrm{~cm}$. The location and elevation of all gravity observations were calculated relative to the World Geodetic Service 1984 ellipsoid (WGS84) as well as the New Zealand Map Grid (NZMG) using the collected GPS data. The relative GPS locations and elevations are tied to the WGS84 ellipsoid by occupying the LINZ second order survey mark B8C9 in Whataroa. Existing gravity data from the New Zealand primary gravity network are observed in the New Zealand Geodetic Datum of 1949 (NZGD49) (Reilly, 1972). To ensure consistency between all data utilised, the NZGD49 locations were converted to both the WGS84 and NZMG datums.

\section{Field procedure}

Details of the basic field procedure for collecting new gravity observations are omitted from this document, but can be found in many standard texts (eg: Milsom (2003) and Dobrin and Savit (1988)). 


\subsubsection{Data reduction}

In order to produce meaningful maps, models and interpretations of the central West Coast subsurface, the relative gravity observations must be reduced to Bouguer gravity anomalies. The process of obtaining Bouguer gravity anomalies is described in the sections above and summarised below:

1. Relative gravity measurements, $\mathbf{g m}_{\text {relative }}$, are converted to absolute gravity observations, $\mathbf{g}_{\text {abs }}$, through the looping procedure expressed in equation 2.7 .

2. Drift corrections, $\mathbf{g}_{\text {drift }}$, are calculated for all gravity observations using equation 2.8 .

3. Observed gravity values, $\mathbf{g}_{\text {obs }}$, are obtained using equation 2.9.

4. The expected gravity at latitude, $\mathbf{g}_{\boldsymbol{\theta}}$, is calculated for all gravity observations using GPS determined latitudes $(\theta)$ and equation 2.10.

5. Free-air corrections, $\mathbf{F A}_{\mathbf{C o r r}}$, are estimated using GPS determined elevations $(h)$ and equation 2.13 .

6. Bouguer corrections, $\mathbf{B}_{\mathbf{C o r r}}$, are estimated using GPS determined elevations $(h)$, a mass density $(\rho)$ of $2670 \mathrm{~kg} / \mathrm{m}^{3}$ and equation 2.14 .

7. Terrain corrections, $\mathbf{T}_{\mathbf{C o r r}}$, are estimated as described in section 2.2.5 above.

8. Bouguer gravity anomalies, $\mathbf{g}_{\mathbf{B A}}$ for all observations are calculated using equation 2.18:

$$
g_{B A}=g_{o b s}-g_{\theta}-B_{C o r r}-F A_{C o r r}+T_{C o r r}
$$

\subsubsection{Uncertainty in the Bouguer gravity anomaly}

Four sources contribute to the uncertainty in any single gravity measurement: reader error, drift calculations, terrain correction estimates, and the error associated with determining position and elevation. 


\section{Reader error}

At each observation point the gravity meter was read three times to get concurrent measurements within 0.03 meter units $(\sim 0.03 \mathrm{mGal})$. During the survey, it was sometimes not possible to obtain consistent readings within 0.03 meter units. In these situations, factors such as wind, unstable ground and recent seismic activity (surveying was abandoned for several days after the 2010 magnitude 7.1 Canterbury earthquake) contributed to inconsistent meter readings. These gravity readings were either rejected or re-measured at a later date. The reading error is considered to be \pm 0.03 meter units $( \pm 0.03 \mathrm{mGal})$ for all gravity measurements.

\section{Drift calculations}

The maximum amount of instrument and tidal drift, determined through repeat base station measurements, was $0.26 \mathrm{mGal}$ over a five hour period on the $15^{\text {th }}$ of March 2011. On all other survey days, the total measured drift was less than $0.15 \mathrm{mGal}$. Care was taken to ensure that no mechanical or thermal tares occurred over the course of the survey, with no evidence to suggest that any took place. Uncertainty in the calculated drift is introduced when interpolating between repeated base station readings (measured every two hours), and is estimated to be $\pm 0.05 \mathrm{mGal}$ for all gravity observations.

\section{Terrain corrections}

Observation sites were consciously selected in areas with low-lying topography within a $170 \mathrm{~m}$ radius. This minimises the contribution of uncertainty associated with the calculation of the inner terrain corrections, which is estimated to be $\pm 10 \%$. Of the calculated inner terrain corrections $92 \%$ were less than $0.1 \mathrm{mGal}$ and $99 \%$ were less than $0.25 \mathrm{mGal}$. The average uncertainty of the inner terrain corrections was $\pm 0.003 \mathrm{mGal}$, with a maximum uncertainty of $\pm 0.04 \mathrm{mGal}$.

Uncertainty in the outer terrain corrections is dependent on the resolution 
of the Digital Elevation Models (DEMs) used to calculate them. In this study, $25 \mathrm{~m}$ DEMs were utilised. However, the uncertainty associated with outer terrain corrections is expected to be negligible compared with that of the inner terrain corrections.

\section{Uncertainty in elevation and latitude}

Elevation is one of the most critical factors in calculating the Bouguer gravity anomaly; an elevation uncertainty of $\pm 1 \mathrm{~m}$ results in a $\pm 0.42 \mathrm{mGal}$ uncertainty in the Bouguer gravity anomaly. Conversely, a latitude uncertainty of $\pm 1 \mathrm{~m}$ results in a $\pm 0.00078 \mathrm{mGal}$ uncertainty in Bouguer gravity anomaly, and is a negligible error.

In recent years, differential GPS techniques have significantly reduced the error in elevation and lateral position determination, which results in reduced error in the free-air correction, Bouguer correction and the IGF30. Modern GPS survey instruments can achieve lateral uncertainties $<5 \mathrm{~cm}$ and elevation uncertainties $<7.5 \mathrm{~cm}$. The differential Trimble R8 GNSS GPS unit used in this study returns the uncertainty associated with each determination of spatial location. The average uncertainty in elevation for the survey was $\pm 0.03 \mathrm{~m}$, reaching maximum uncertainty of $\pm 0.49 \mathrm{~m}$. Equation 2.19 shows that the average elevation uncertainty contributes $0.013 \mathrm{mGal}$ to the uncertainty of the Bouguer gravity anomaly, while the maximum elevation uncertainty contributes $0.206 \mathrm{mGal}$.

$$
U_{H}=U_{h}(0.3086+200000 \pi \rho G)=0.42 U_{h}
$$

where $U_{h}$ is the uncertainty in elevation $(\mathrm{m})$ at a station and $U_{H}$ is the resulting uncertainty in the Bouguer gravity anomaly (mGal).

The average error in latitude for the survey was $\pm 0.02 \mathrm{~m}$, reaching maximum error of $\pm 0.23 \mathrm{~m}$. As stated above, these errors in the latitude contributed a negligible amount to the uncertainty of the Bouguer gravity anomaly. 


\section{Total uncertainty}

Combining the reader, drift, terrain correction and location uncertainties estimated for each site yields the maximum uncertainty for each gravity observation:

$$
U=U_{R}+U_{D}+U_{T}+U_{E}
$$

where $U$ is the maximum uncertainty at a site, $U_{R}$ is the reader uncertainty, $U_{D}$ is drift uncertainty, $U_{T}$ is terrain correction uncertainty and $U_{E}$ is elevation uncertainty, all in units of mGal.

The average maximum uncertainty in the new Bouguer gravity anomalies is $\pm 0.09 \mathrm{mGal}$, with the largest uncertainty reaching $\pm 0.30 \mathrm{mGal}$. The uncertainty of each gravity observation made in this study can be seen in Appendix A.

\subsection{Regional-residual separation}

The Bouguer gravity anomaly is the superposition of anomalies due to subsurface geological features, from small localised structure to large regional structure. Some of the anomalous structures lie at depths of interest, while others may lie at shallower or deeper depths. Anomalies due to deep largescale features have smoothly varying shapes over large distances and are commonly referred to as regional features. Localised structure produces sharper and spatially more restricted anomalies (Beck, 1981; Dobrin and Savit, 1988; Telford et al., 1990; Burger et al., 2006).

Removal of a regional trend from observed gravity data yields what is known as the residual anomaly, caused by smaller localised structure. In some cases, where large scale features are of interest, the contribution of smaller structures is thought of as noise. To remove a regional trend the data set of gravity observations must be dense enough to resolve local anomalies and extensive enough to correctly identify and describe regional trends (Burger 
et al., 2006). This process is, however, non-unique. There is no unequivocal partition of the observed gravity into regional and local anomalies, with spectral overlap of the different anomaly scales (Dobrin and Savit, 1988).

There are several methods of identifying and removing regional trends. The choice of method depends on the complexity of the regional trend and any prior knowledge of the subsurface geology.

\subsubsection{Numerical regional removal}

Numerical methods are appropriate where regional trends are complex or unobvious to an interpreter. Numerical methods provide an unbiased estimate of the regional trend, however, any geological information of the area is not taken into consideration (Burger et al., 2006).

One numerical method of representing a regional trend is to determine a surface of best fit through the spatially varying gravity data. These surfaces are fitted to the data distributed in $x-y-g$ space. Surfaces are defined by polynomial functions and are fit to the gravity data using a method of least squares. Subtracting such regional trend surfaces from gravity data will result in residual gravity data. The order of the polynomial used to define the surface should be selected based on the complexity of the regional gravity trend (Stern, 1979; Dobrin and Savit, 1988; Burger et al., 2006). First order polynomials (equation 2.21) represent inclined planes

$$
g_{T S}=A x+B y+C
$$

where $g_{T S}$ is the gravity value of the trend surface at a spatial position $x$, $y$. The coefficients $A, B$ and $C$ are determined through the method of least squares to reduce the residual value between the regional surface and the gravity data. Second order polynomials (equation 2.22) represent paraboloid surfaces

$$
g_{T S}=A x^{2}+B y^{2}+C x y+D x+E y+F
$$


Increasing orders of polynomial represent increasingly complex regional trend surfaces. It is the role of the interpreter to select which order of polynomial best represents the regional trend (Dobrin and Savit, 1988). If the order of the polynomial surface removed is too low, then the residual data will still be influenced by regional effects. If the order of the polynomial surface fitted is too high, the surface will also be fit to localised changes in gravity and removal of this surface will also remove the residual data of structures of interest.

Stern (1979) uses gravity observations on known basement rock surrounding the local structure of interest to calculate a regional surface trend. The regional surface is then extended over the area of local interest to reduce Bouguer gravity anomalies to residual gravity anomalies. Building a trend surface from data on areas with little or no subsurface density variation ensures that the surface fit is uninfluenced by localised gravity anomalies, which results in a more accurate regional removal from the gravity data.

\subsubsection{Modelling}

Polynomial fitting methods often do not utilise physical information which may be available, and hence suffer from mathematical subjectivity. These methods can introduce artifacts to the residual data which restricts its the ability for quantitative interpretation (Dobrin and Savit, 1988).

An alternative method to avoid these problems involves the utilisation of geological and geophysical information to build computer generated gravitational models of the regional density distributions. One particularly useful method is the use of deep-seismic data to infer regional density distributions. This inference is possible as the seismic velocity of rock is related to its density. Using the regional density distribution determined through seismic measurements, a gravitational model can be built. Other geophysical methods can be used to constrain and construct these regional density models. The gravitational effects of these models are used to represent the regional gravity trend and are removed to give residual gravity data (Dobrin 


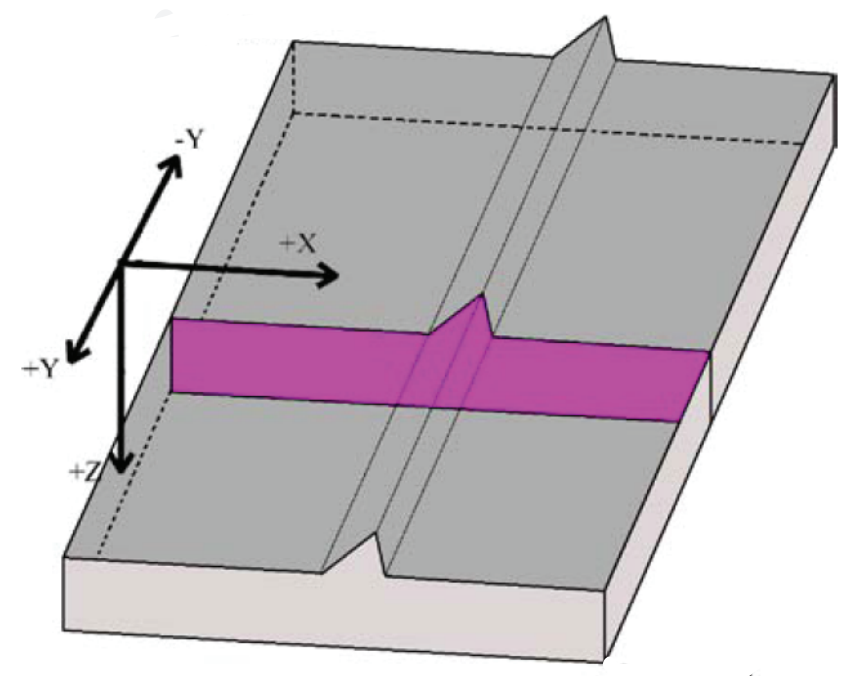

Figure 2.6: A schematic showing a basic two dimensional model and the relative coordinate system used for the modelling process. Pink highlighted cross-section is extended to infinity in the y-axis. Figure adapted from Northwest Geophysical Associates (2004).

and Savit, 1988).

\subsection{Gravity modelling}

Gravity modelling performed for this study is done with Geosoft's GM-SYS, using a combination of 2D, $21 / 2 \mathrm{D}$ and $23 / 4 \mathrm{D}$ modelling techniques.

\subsubsection{Two dimensional modelling}

Two-dimensional (2D) gravity models assumes the modelled structure is two dimensional in nature, i.e. it changes with depth (along the z-axis) and in the profile direction (along the $\mathrm{x}$-axis). 2D models do not change in the strike direction (y-axis) and are assumed to extend to infinity. Figure 2.6 shows a schematic of a 2D model and the relative coordinate system. The pink cross-section shows a one layer $2 \mathrm{D}$ model, nominally extending to infinity 


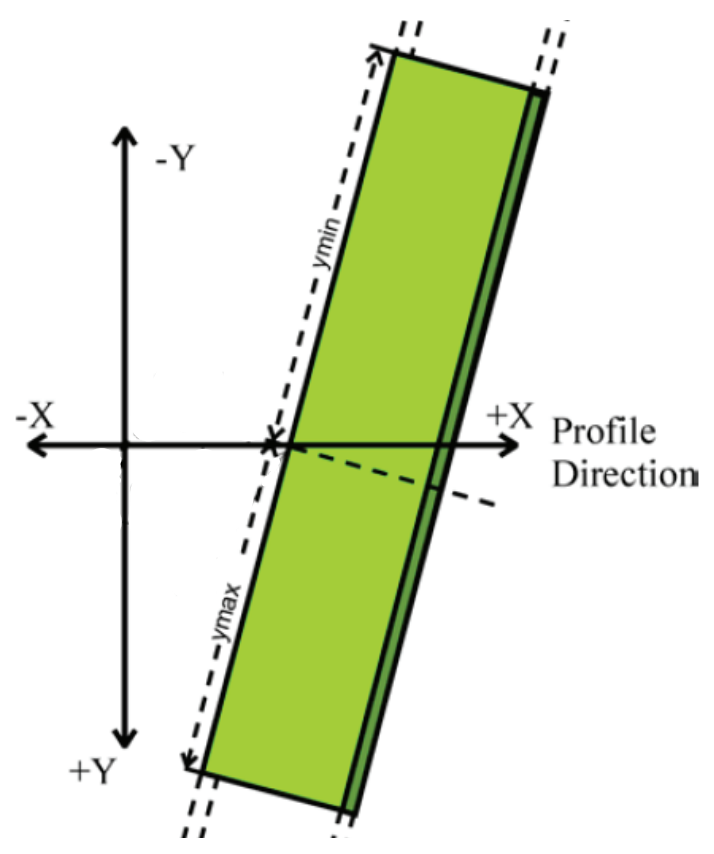

Figure 2.7: A schematic showing a plan view of a 23/4D gravity model and the relative coordinate system used for the modelling process. The model is skewed at an angle between the $\mathrm{x}$-axis and $\mathrm{y}$-axis. Figure adapted from Northwest Geophysical Associates (2004).

in the y-plane. Various software packages may approximate the infinite $y$ extent by using a very large y extent relative to the $\mathrm{x}$-axis and $\mathrm{z}$-axis model extents. 2D models are typically built up of different polygonal units of varying density. The gravitational response of the constructed $2 \mathrm{D}$ polygonal model is calculated and compared at the location of the observed gravity to gauge the fit of the model.

\subsubsection{Two and a half dimensional modelling}

Rather than infinite y-axis model extents, $21 / 2 \mathrm{D}$ modelling allows for the polygonal units in the model to extend to specified distances in both the $y$ positive and y negative direction. 


\subsubsection{Two and three quarter dimensional modelling}

As seen in plan view in Figure 2.7, 2 3/4D modelling allows for an arbitrary angle between the plane of observation (x-plane) and the strike plane of the modelled bodies (y-plane). 


\section{Chapter 3}

\section{Gravity of the central West Coast}

\subsection{Introduction}

This chapter presents the spatial data coverage over the central West Coast, the resulting gravity anomaly maps and the methods of regional-residual separation.

One of the primary objectives in this study is to produce Bouguer and residual gravity anomaly maps over the central West Coast. Such maps will enable the modelling and interpretation of both regional scale features such as the South Westland Basin and localised features including structures formed as the result of erosional processes. Another of the study objectives is to quantify the simple kinematics of the central Alpine Fault including the rate of strike-slip movement. This is achieved by identifying the gravity signature of local erosional channels which have been offset close to the Alpine Fault.

In order to achieve these objectives the data coverage over the study area must be widely spread in order to identify regional gravity trends, while at the same time being sufficiently dense to resolve localised structures of interest. 


\subsection{Existing data}

Areas of the central West Coast have been surveyed in gravity studies preceding this study. These existing data sets provide a basis for which further gravity surveying is designed around.

\subsubsection{New Zealand Gravity Network}

Existing gravity observations from the New Zealand Gravity Network (discussed in Chapter 2) have an average spacing of $\sim 5 \mathrm{~km}$ over the West Coast of the South Island (Reilly and Whiteford, 1979). The New Zealand Gravity Network observations used in this study can be observed in Figure 3.1.

\subsubsection{Whataroa gravity data}

Additional to the New Zealand Gravity Network observations, gravity observations from Brikke (2007) are incorporated into this study. Brikke (2007) observed gravity along a 2-dimensional transect running sub-parallel to the Alpine Fault in the Whataroa flood plain, with an average observation spacing of $750 \mathrm{~m}$, see Figure 3.3.

\subsubsection{Existing coverage}

The combined datasets of the New Zealand Gravity Network and Brikke (2007) provide a sparse coverage of gravity data over the Wanganui, Whataroa and Waiho flood plains, which can be seen in Figures 3.2, 3.3 and 3.4 respectively. 


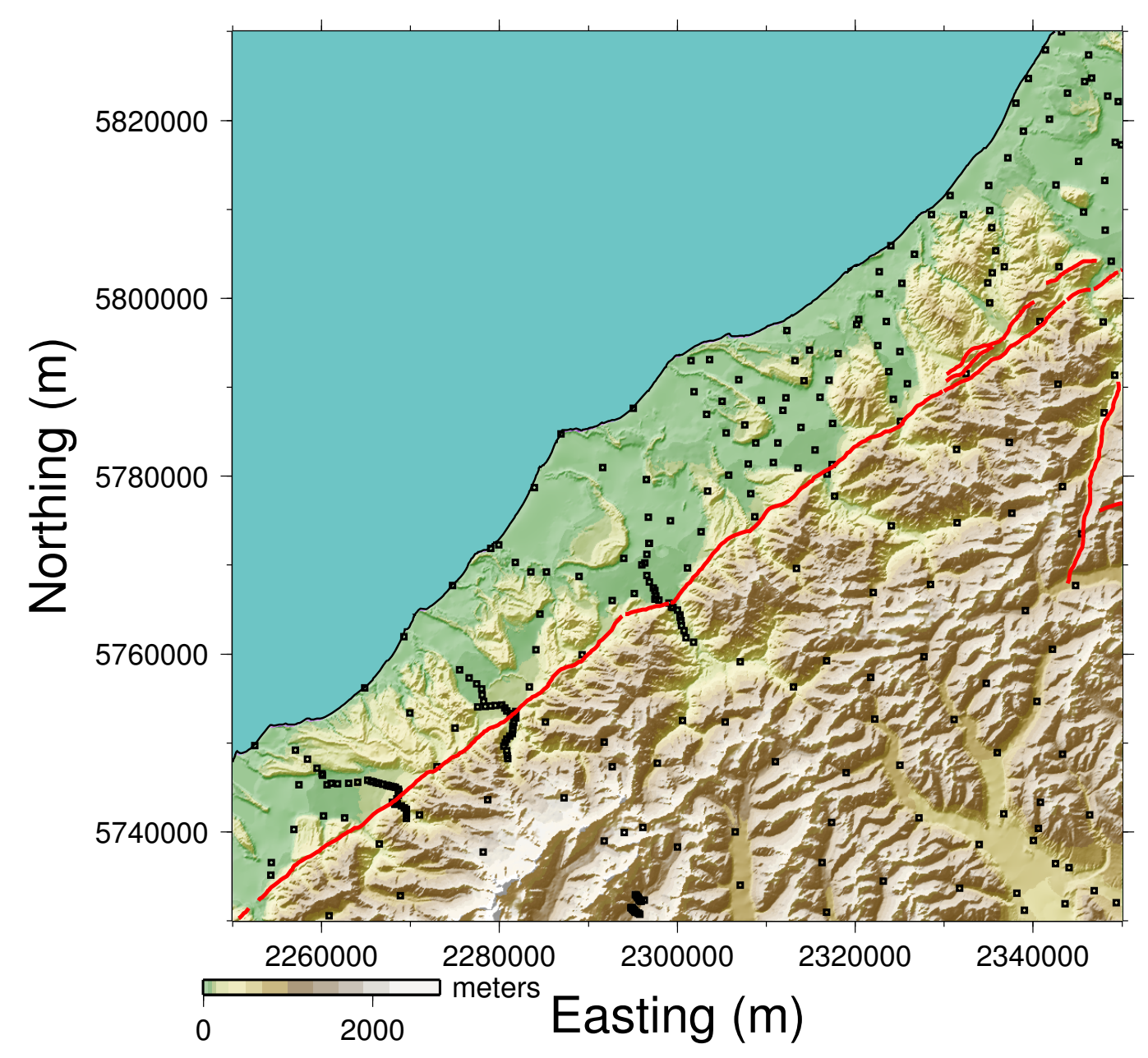

Figure 3.1: New Zealand Gravity Network observations over the central West Coast, represented by black squares. 


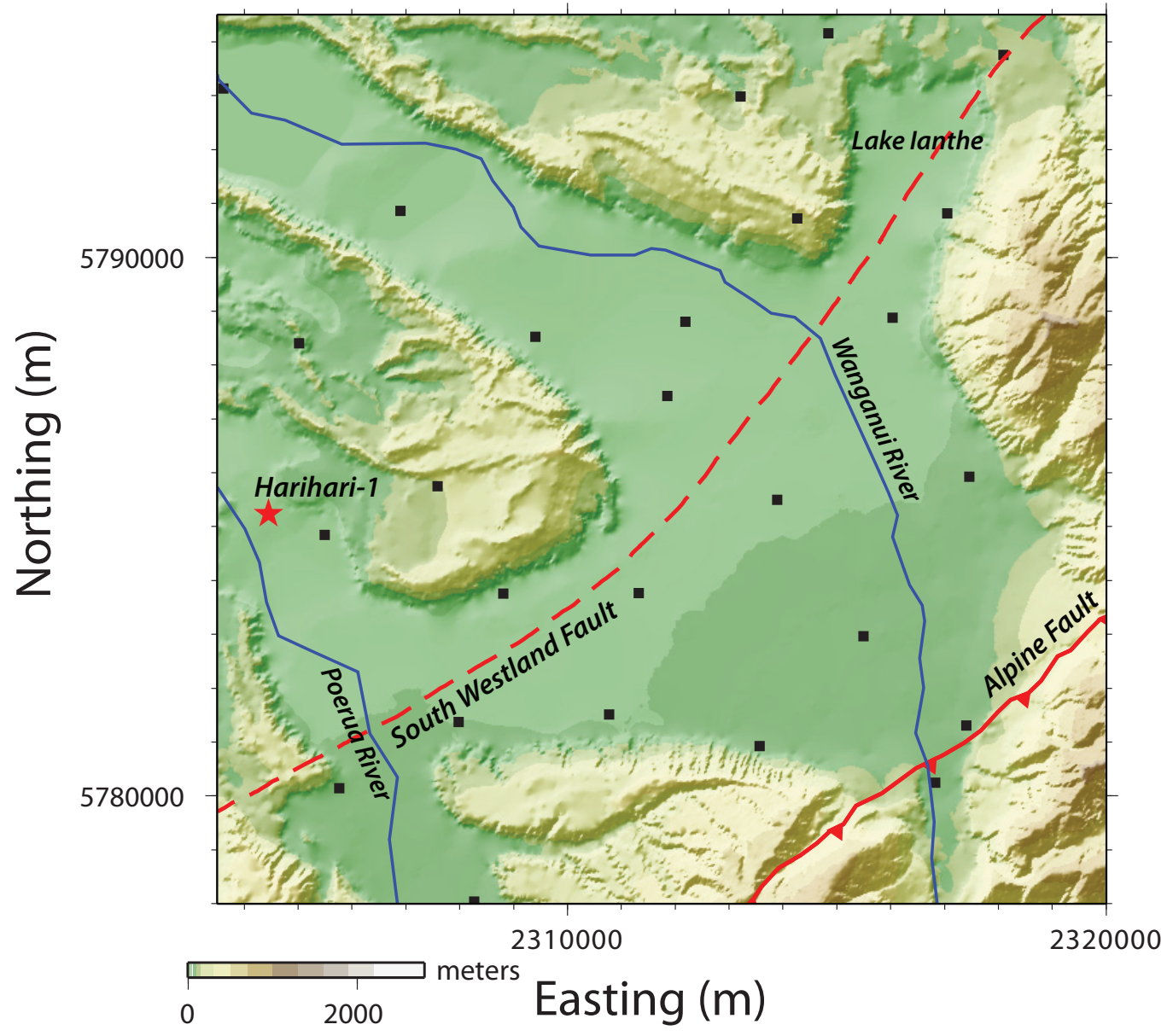

Figure 3.2: Existing New Zealand Gravity Network observations over the Wanganui flood plain represented by black squares; the red star represents the location of the Harihari-1 borehole. 


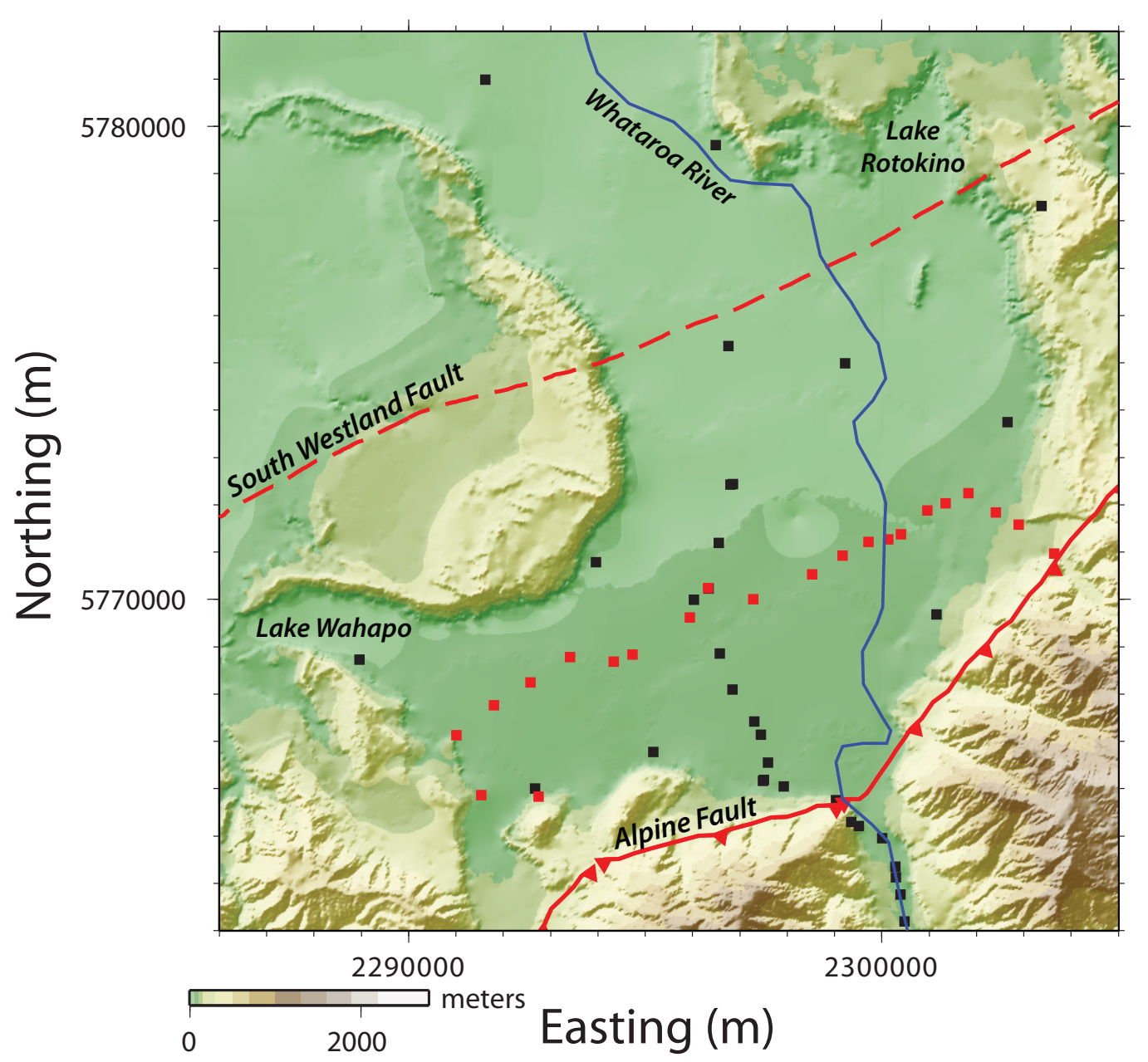

Figure 3.3: Existing gravity observations over the Whataroa flood plain. Black squares represent New Zealand Gravity Network observations; red squares are observations from Brikke (2007) 


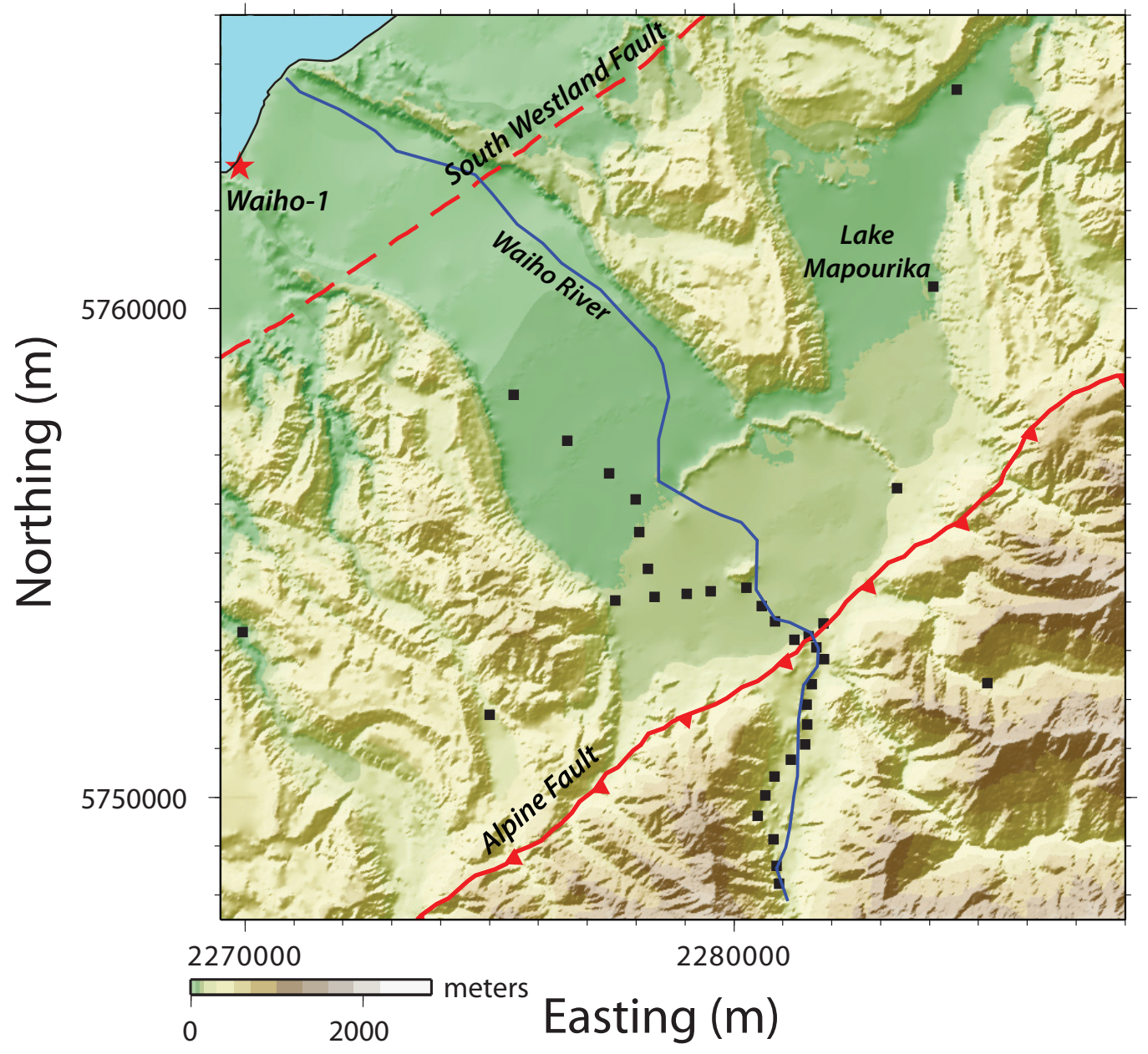

Figure 3.4: Existing New Zealand Gravity Network observations over the Waiho flood plain represented by black squares; the red star represents the location of the Waiho-1 borehole. 


\subsection{New gravity data}

A total of 361 new gravity observations were made over the central West Coast study area for the purpose of this study. These gravity observations were collected in February, September and December of 2010 and March of 2011.

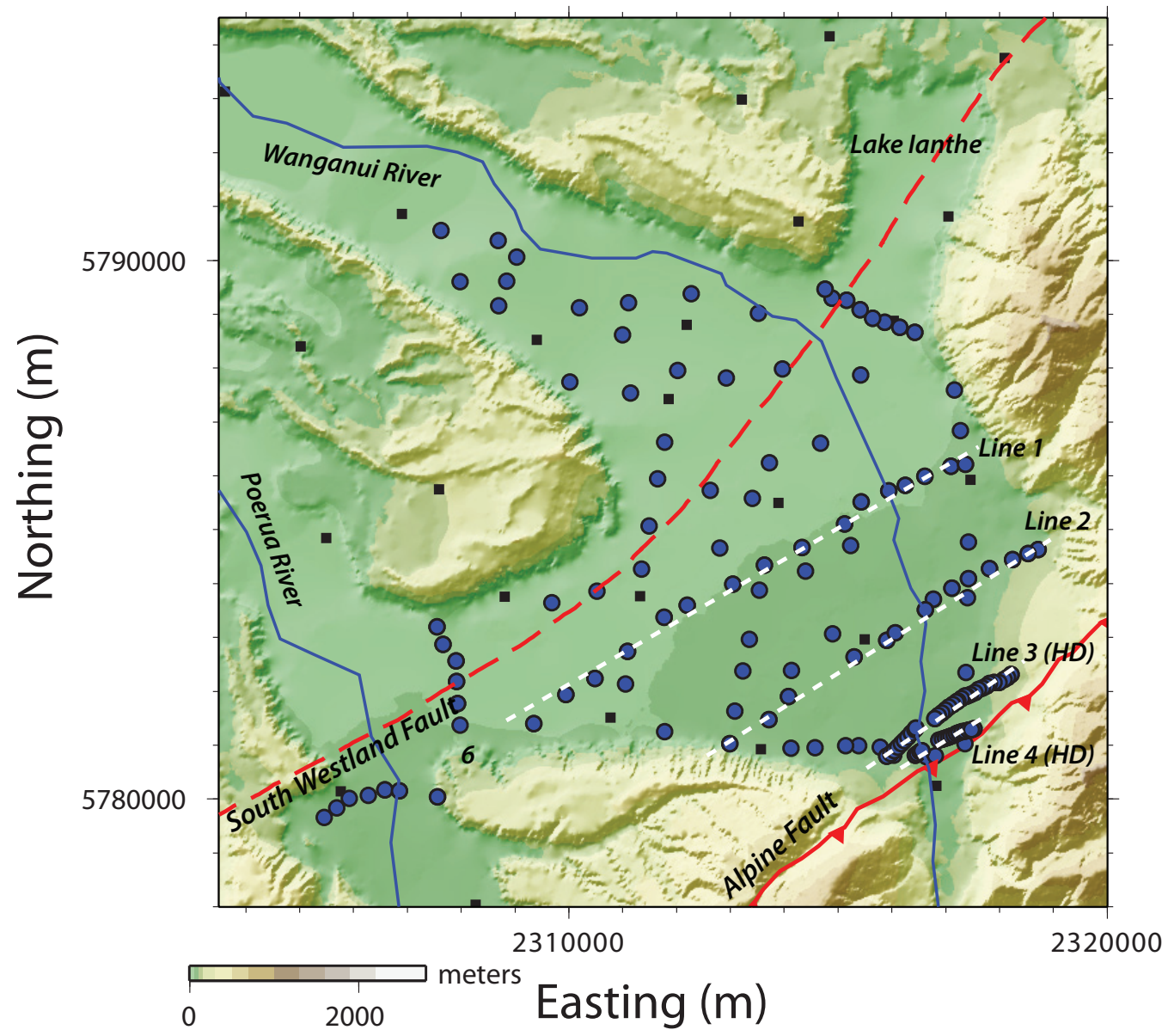

Figure 3.5: Gravity observations over the Wanganui flood plain. Black squares represent existing data, blue circles are new gravity observations and white dashed lines indicate 2-D profiles. 


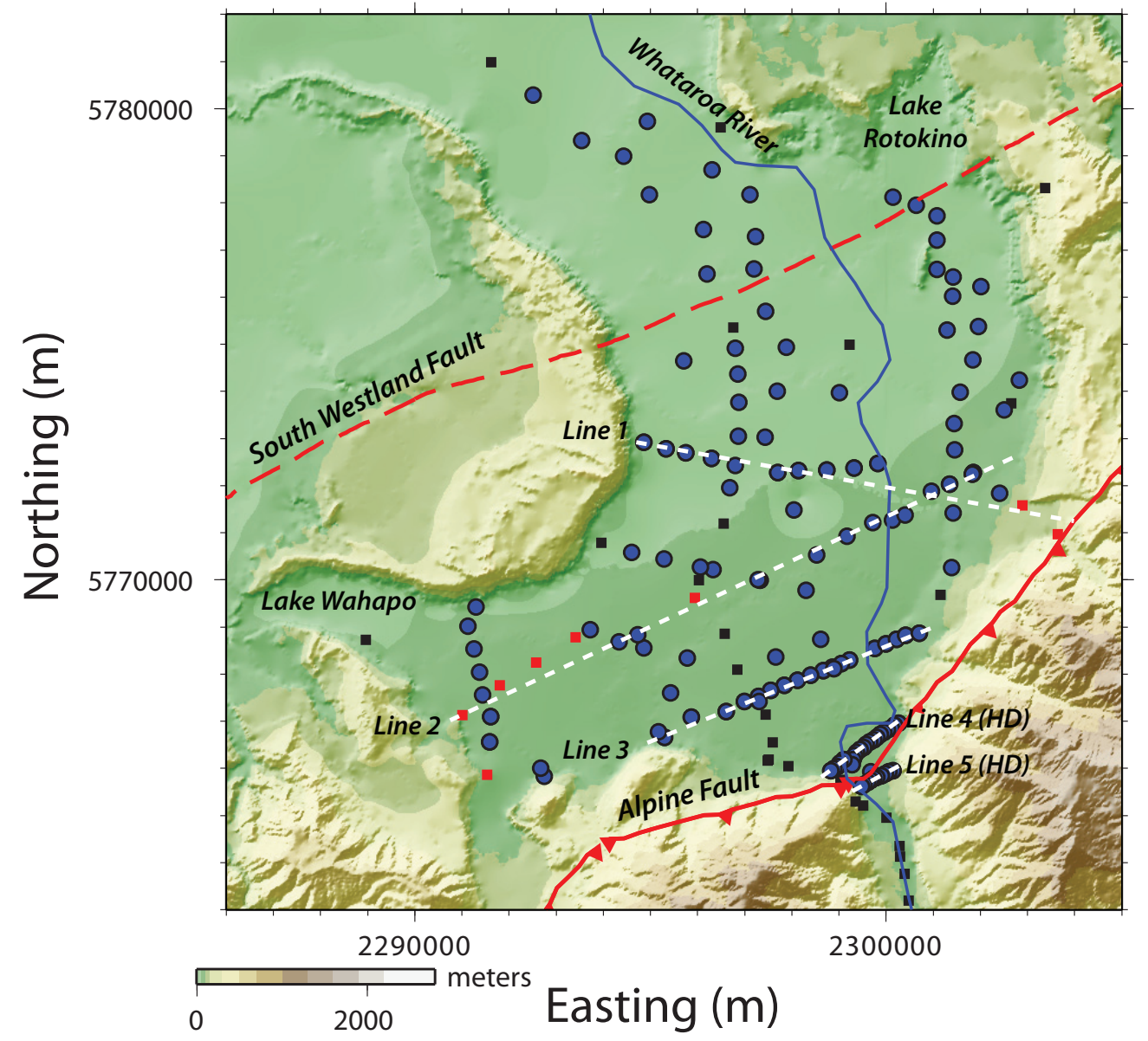

Figure 3.6: Gravity observations over the Whataroa flood plain. Black and red squares represent existing data, blue circles are new gravity observations and white dashed lines indicate 2-D profiles.

\subsubsection{Survey design}

Gravity surveying was designed to maximise the data coverage over each of the three flood plains, while taking into consideration the limited time and land access for data collection. The coverage achieved in the surveying aimed to resolve features of both short and broad wavelength. To resolve features on both scales, two styles of surveying were undertaken (Dobrin and Savit, 1988). 


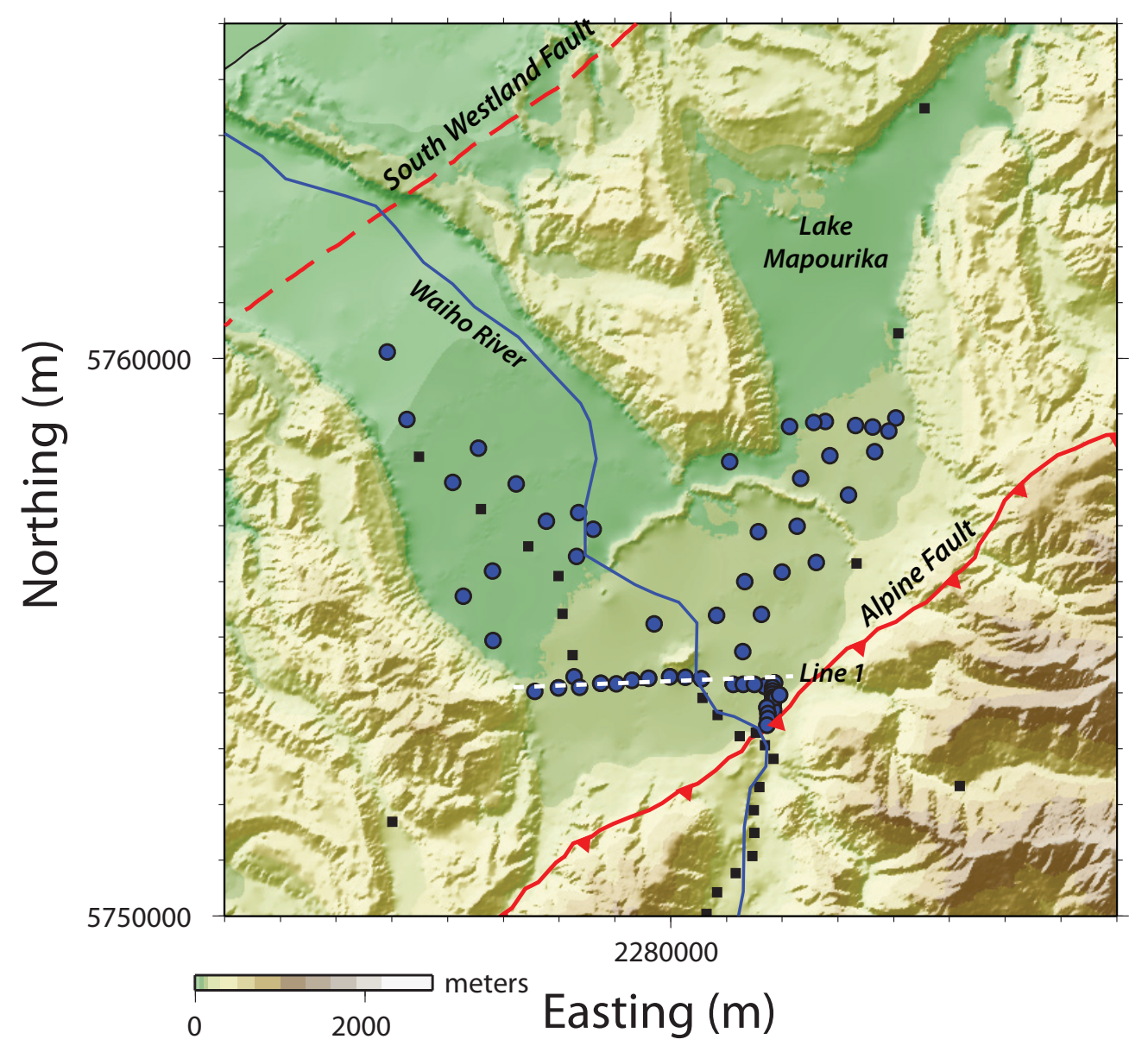

Figure 3.7: Gravity observations over the Waiho flood plain. Black squares represent existing data, blue circles are new gravity observations and white dashed lines indicate $2-\mathrm{D}$ profiles.

\section{Regional scale surveying}

To resolve regional scale features such as the onshore sections of the South Westland Basin and the broader patterns of erosion along the coast, a uniform spread of gravity observations over each flood plain was measured. Observations of gravity were made along existing roads and farm tracks, with the aim of obtaining an average observation density of one observation per $1 \mathrm{~km}^{2}$. The resulting data coverage is biased to easily accessible areas. The spread 
of data obtained over the Wanganui, Whataroa and Waiho flood plains can be seen as blue circles in Figures 3.5, 3.6 and 3.7, respectively.

\section{Local scale surveying}

To resolve the gravity signature of localised structures of interest, such as incised glacial troughs, a series of closely spaced 2-dimensional gravity profiles were measured in each flood plain. A significant number of these transects run sub-parallel to the Alpine Fault in order to resolve structures oriented at high angles to the fault trace. The 2-dimensional profiles are illustrated in Figures 3.5, 3.6 and 3.7. The profiles which are not denoted by a "HD", have an average observation spacing of $400 \mathrm{~m}$. The gravity observations along these lines are also used in the spatial data coverage across each flood plain. Profiles denoted with a "HD" are closely spaced lines located close to the Alpine Fault for the purpose of determining the offset of buried glacial channels. These closely spaced profiles have an average observation spacing of $80 \mathrm{~m}$. Data along these closely spaced lines are not used in the spatial data spread, and are discussed in detail in Chapter 5.

\subsection{Gravity maps}

The new gravity observations were reduced to Bouguer gravity anomalies, as described in Chapter 2.3.2.

\subsubsection{Bouguer gravity}

The new Bouguer gravity anomaly data are combined with the existing datasets. Unix based software Generic Mapping Tools (Wessel and Smith, 2011) is used to grid the combined gravity dataset at both a local scale (individual flood plains) and a regional scale (central West Coast study area) and to subsequently illustrate this gridded data. The Bouguer gravity anomaly 
maps for both the existing and combined datasets are shown to illustrate the improvement in resolution achieved in this study.

\section{Regional Bouguer gravity maps}

Figures 3.8 and 3.9 show the improvement in resolution of Bouguer gravity anomaly maps between the existing and combined datasets, for the central West Coast study area. The map based on existing gravity data shows poorly resolved anomaly structures, with contour lines that vary smoothly over the study area.

With the addition of new gravity observations the anomalies become more defined in their shape, indicating that greater resolution of localised structure within the flood plains is being achieved. Two near elliptical negative anomalies centered over the Whataroa and Wanganui flood plains in existing Bouguer gravity anomaly map become much more defined with the addition of the new gravity data. With the additional data coverage the anomalies now appear to be elongate in the direction of the northwestern and northeastern splays of both the Wanganui and Whataroa flood plains.

The regional Bouguer gravity anomaly map (Figure 3.9) highlights several important features:

- A large NE-SW trending elongate negative Bouguer gravity anomaly, centered at location 1, extends over the Wanganui and Whataroa flood plains, and further to the northeast. This negative anomaly is connected between the two flood plains by the $-32 \mathrm{mGal}$ contour, reaching minimums of $-40 \mathrm{mGal}$ in the Wanganui flood plain and $-38 \mathrm{mGal}$ in the Whataroa flood plain.

- In the Wanganui flood plain at location 2, the prominent negative anomaly results in a positive gravity trend heading both northwest and southeast of the mapped South Westland Fault. The increasingly positive Bouguer gravity field toward the Southern Alps is opposite to what an interpreter might expect given the geological setting of the area. A 


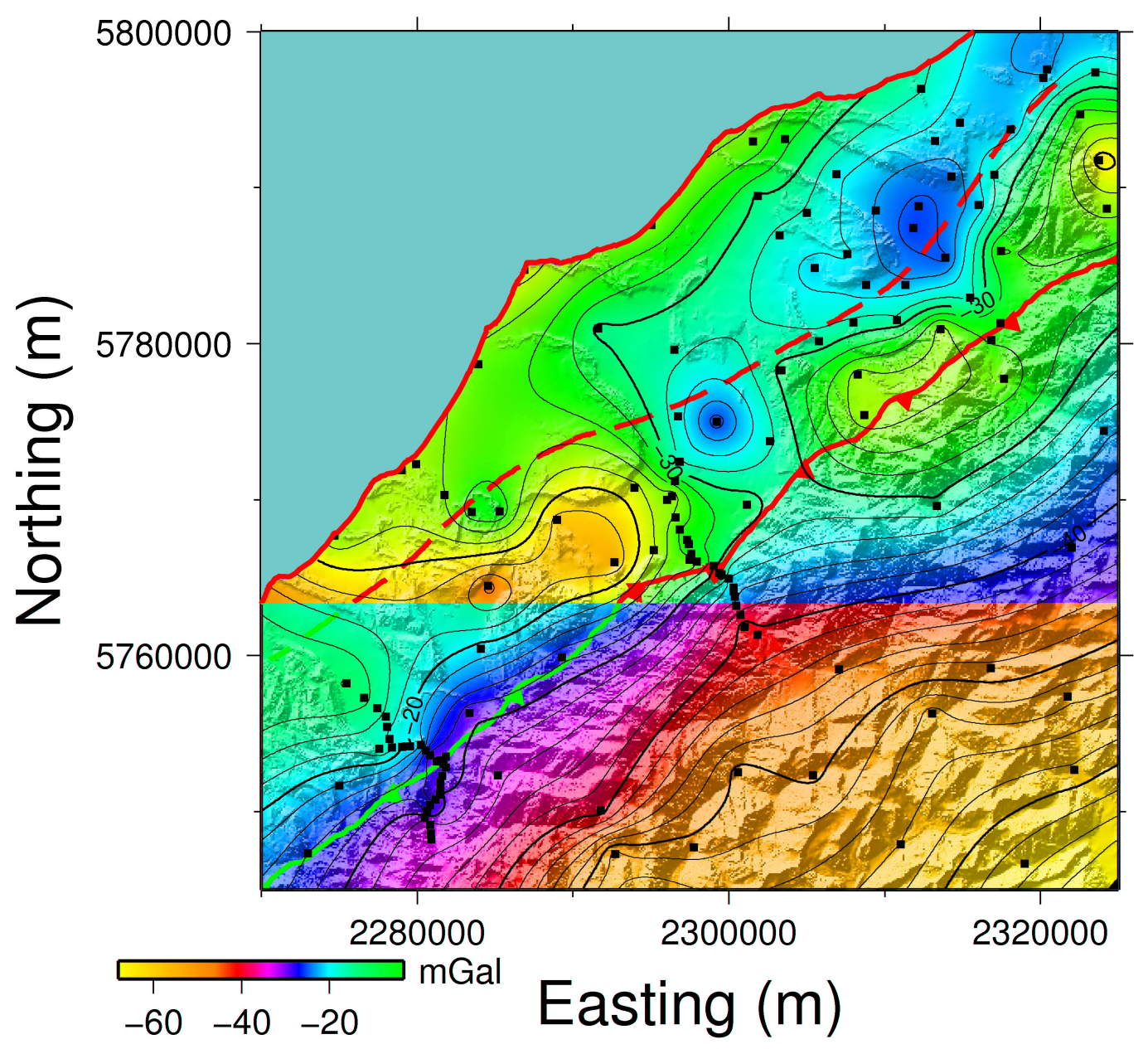

Figure 3.8: Regional Bouguer gravity anomaly map illustrated from the existing datasets. The red dashed line represents the South Westland Fault while the solid red line shows the Alpine Fault. 


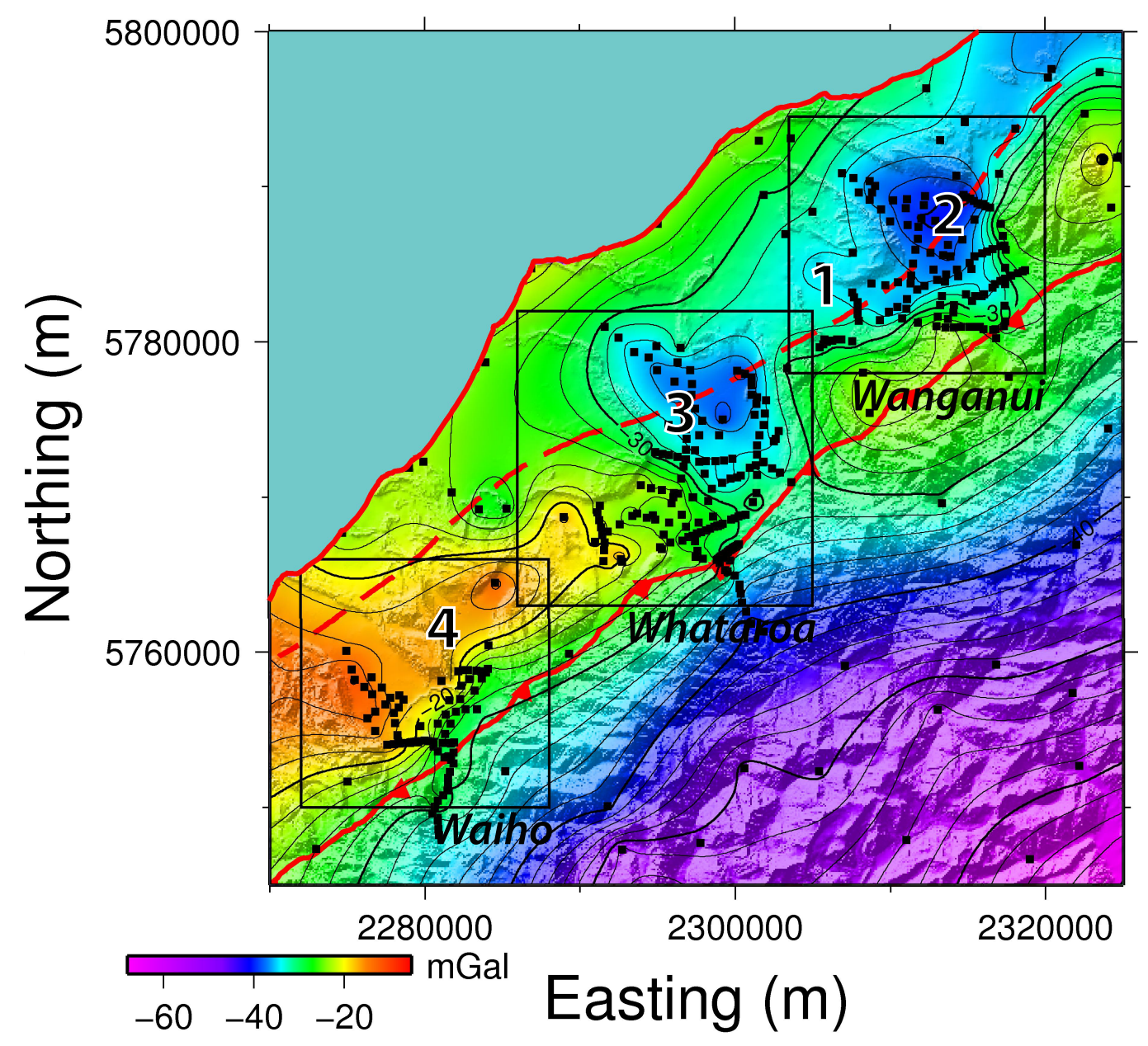

Figure 3.9: Regional Bouguer gravity anomaly map illustrated from the combined datasets. The Bouguer gravity map shows a significant increase in resolution from Figure 3.8. Numbers on the map show features of interest, which are described in the text. Boxes show the respective field areas. The red dashed line represents the South Westland Fault while the solid red line shows the Alpine Fault. 
long-wavelength negative anomaly is associated with the crustal root of the Southern Alps mountain range (Stern et al., 2000; Brikke, 2007), therefore it could be expected that the dominant regional trend would be an increasingly negative Bouguer gravity field toward the Southern Alps in all of the West Coast river plains.

- As a result of the large negative anomaly terminating in the Whataroa flood plain at location 3, the Bouguer gravity field expresses a strong positive trend in the southwest direction.

- The Bouguer gravity field at location 4 in the Waiho flood plain expresses a local gravity trend consistent with the negative field associated with the crustal root of the Southern Alps mountain range. In the Waiho flood plain, the Bouguer gravity field becomes increasingly negative toward the Alpine Fault.

- There is what appears to be a boundary between location 3 and 4 , which could suggest a significant change in erosional and/or tectonic processes between the two locales.

\section{Wanganui Bouguer gravity maps}

Figure 3.10 shows the Bouguer gravity anomaly maps for the Wanganui flood plain. When viewing the Bouguer gravity map at a local scale, the improvement in resolution between the existing and combined datasets becomes much more apparent.

There are several features of interest in the Bouguer gravity anomaly map of the Wanganui flood plain, constructed using the combined dataset:

- The Bouguer gravity field shows indication of elongation in multiple directions. The $-40 \mathrm{mGal}$ contour interval in the centre of the flood plain extends northeast toward location 1. At location 2, contour intervals between $-40 \mathrm{mGal}$ and $-35 \mathrm{mGal}$ are elongate toward the coast. The $-35 \mathrm{mGal}$ contour exhibits a particularly geometric elongation to the 
southwest at location 3, toward the Poerua river. Finally the contour intervals between $-34 \mathrm{mGal}$ and $-28 \mathrm{mGal}$ are strongly elongated to the southeast at location 4 .

- The Bouguer gravity field becomes increasingly positive southeast of the mapped South Westland Fault, toward the Southern Alps. This is opposite to the trend that might be expected given the tectonic setting, as was discussed earlier.

- The elongate contour intervals $(-34$ to $-28 \mathrm{mGal})$ at location 4 appear to resemble the gravity signature of an erosional channel structures. It appears that the buried erosional channels have been dextrally offset to the northeast, along the Alpine Fault, by $1-2 \mathrm{~km}$ from the fault intersection of Wanganui river valley.

- There appears to be a reasonable correlation between the geometry of both the topography and the Bouguer gravity field, particularly along the range front, where the gravity field runs near parallel with topography. A weaker correlation exists between the gravity field and the topography of glacial moraines bordering the north and west of the flood plain.

- In the southwest of the flood plain the Bouguer gravity field appears to run parallel with the South Westland Fault.

\section{Whataroa Bouguer gravity maps}

Figure 3.11 shows the Bouguer gravity anomaly maps for the Whataroa flood plain. There is an observable increase in the resolution of the gravity field between the existing and combined datasets.

There are several features of interest in the Bouguer gravity anomaly map of the Whataroa flood plain, constructed using the combined dataset: 


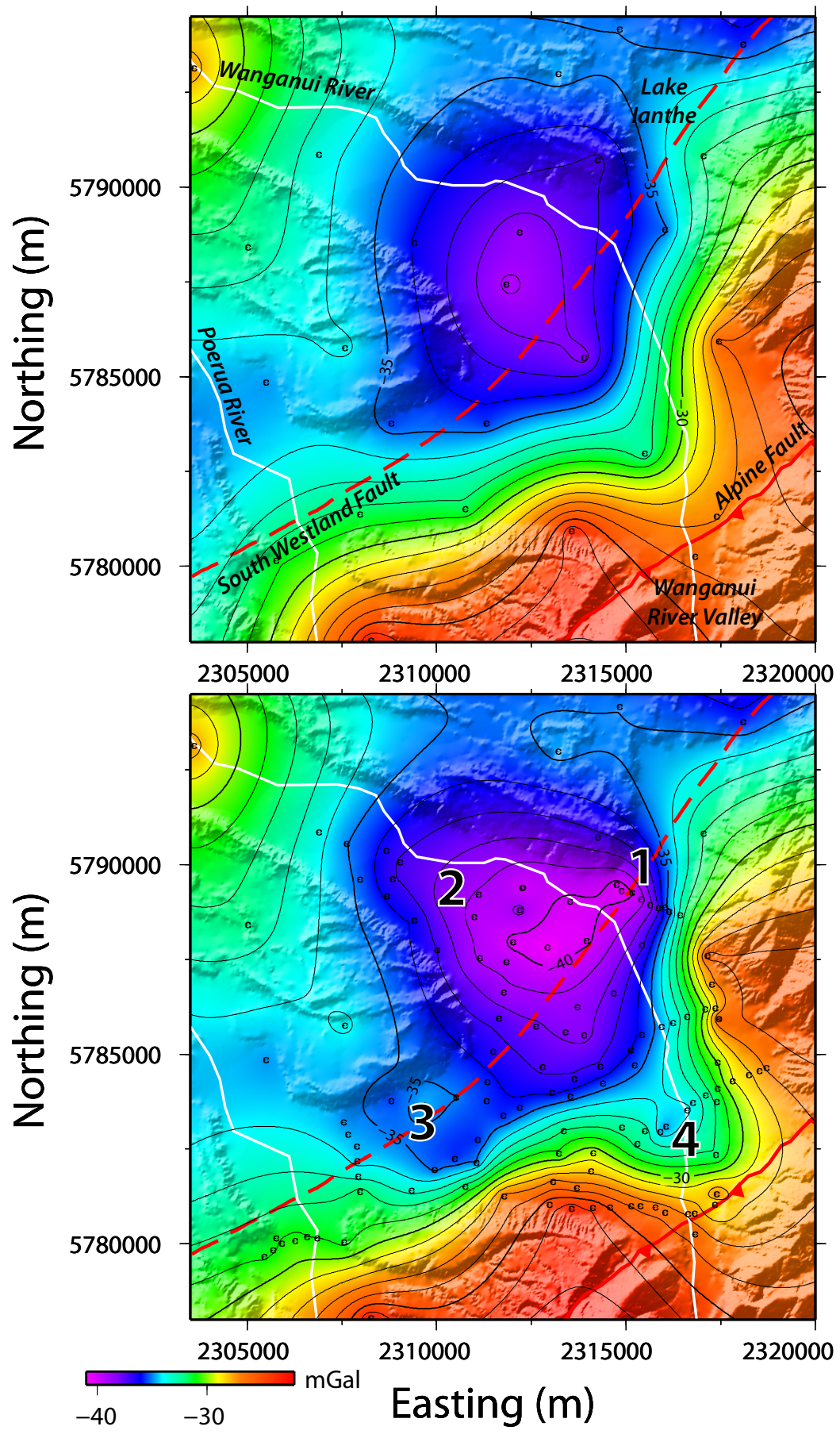

Figure 3.10: Bouguer gravity anomaly maps of the Wanganui flood plain. The top map illustrates data from existing datasets, the lower map illustrates data from the combined datasets. Numbers on the map show features of interest, which are described in the text. White lines mark river systems, red line mark mapped faults. 
- The $-35 \mathrm{mGal}$ contour centered around location 1 in the middle of the flood plain becomes much more defined, going from a poorly constrained elliptical anomaly to an anomaly exhibiting significant structure.

- Like the Wanganui flood plain, there is evidence of elongation in the structure of the Bouguer gravity field. Contour intervals between -34 and $-36 \mathrm{mGal}$ become elongated toward Lake Rotokino at location 2, and are also strongly elongate toward the coast in the northwest splay at location 3 . South of the anomaly centre, at location 4 , the $-34 \mathrm{mGal}$ contour interval expresses strong elongation toward the Whataroa river valley.

- There appears to be less correlation between the gravity field and the local topography than is observed in the Wanganui flood plain. The elongation of the negative gravity anomaly in the centre of the flood plain roughly correlates to the topography of the splays which extend northwest and northeast. Contour lines of the gravity field along the range front appear to have little correlation with the topography.

- At location 5, there is a strong trend in the Bouguer gravity field perpendicular to the Alpine Fault, becoming increasingly positive in the southwest direction. This could be marking the boundary between two areas of different tectonic and/or erosional properties. Increased basement uplift and/or lower amounts of erosion southeast of location 5 could result in the relative increase of the Bouguer gravity field. Surface outcrops of Buller terrane basement rock, in areas surrounding the Waiho flood plain (see Figure 1.6), support the suggestion of increased tectonic uplift. 


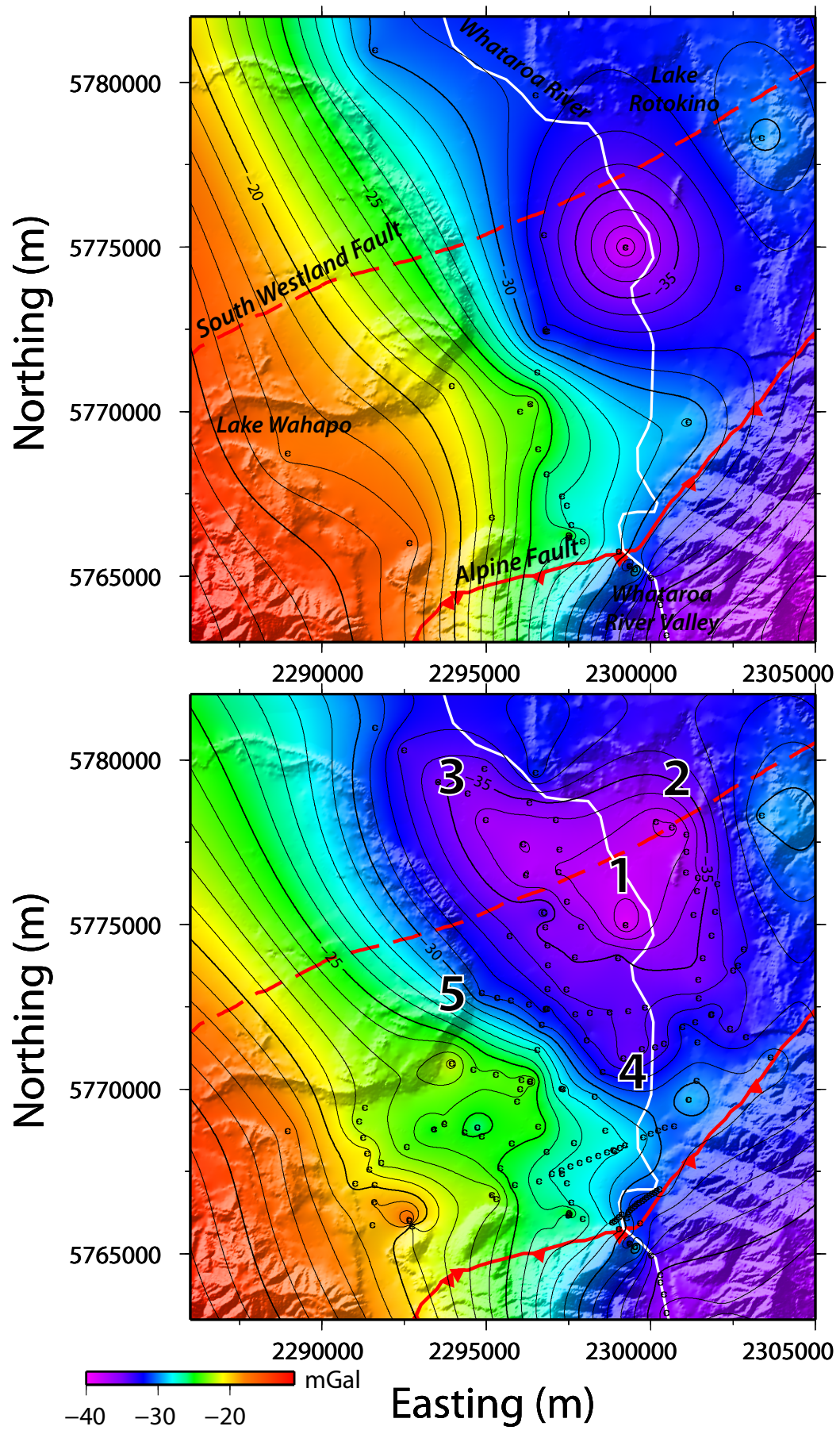

Figure 3.11: Bouguer gravity anomaly maps of the Whataroa flood plain. The top map illustrates data from existing datasets, the lower map illustrates data from the combined datasets. Numbers on the map show features of interest, which are described in the text. White lines mark river systems, red line mark mapped faults. 


\section{Waiho Bouguer gravity maps}

Figure 3.12 shows the Bouguer gravity anomaly maps for the Waiho flood plain. Land access in the Waiho flood plain was much more restricted than that of the Wanganui and Whataroa flood plains, and so the additional coverage of gravity observations was limited. There is only a slight increase in resolution between the datasets, primarily in the north and northwest splays of the flood plain.

There are several features of interest in the Bouguer gravity anomaly map of the Waiho flood plain constructed using the combined dataset:

- The increase in data coverage over the flood plain reveals the presence of elongation in the negative gravity anomaly. There is only one obvious instance of elongation in the Waiho dataset, seen at location 1, with the -15 to $-10 \mathrm{mGal}$ contours extending toward the northwest splay of the flood plain.

- In the Bouguer gravity anomaly map of existing data, the contours between $-17 \mathrm{mGal}$ and $-26 \mathrm{mGal}$ run smoothly to the northeast. With the addition of new observations, an S-shaped curve in these contours has been resolved at location 2 .

- The local trend in gravity is an increasingly negative Bouguer gravity field toward the Southern Alps mountain range. This trend is what would be expected given the tectonic setting, where the crustal root of the Southern Alps generates a long-wavelength negative gravity anomaly.

- Contours of the Bouguer gravity field run parallel to the range front and the Alpine Fault. There are also indications of correlation between the gravity field and the topography of the northern splay in the flood plain, north of location 2 . 


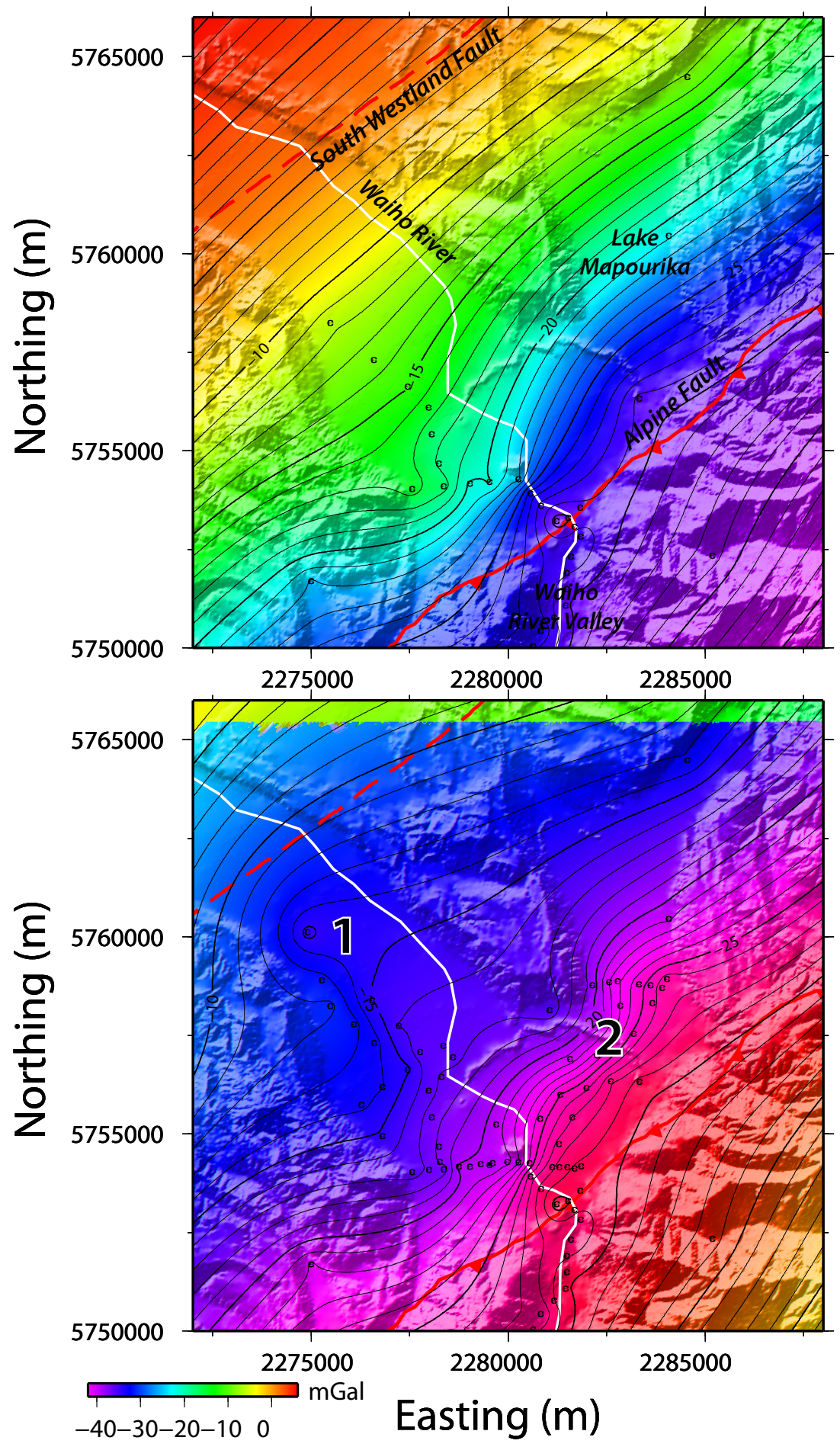

Figure 3.12: Bouguer gravity anomaly maps of the Waiho flood plain. The top map illustrates data from existing datasets, the lower map illustrates data from the combined datasets. Numbers on the map show features of interest, which are described in the text. White lines mark river systems, red line mark mapped faults. 


\subsection{Regional correction methods}

The Bouguer gravity field of the central West Coast is strongly influenced by the crustal root associated with the Southern Alps. A crustal root results in a mass deficit below the Alps and a long-wavelength negative gravity anomaly associated with this deficit, which will affect observations along the West Coast (Stern et al., 2000). In order to resolve features of interest along the central West Coast, this dominant regional trend must be removed from the dataset.

\subsubsection{Numerical method}

The first approach to removing a regional gravity trend was to fit low order polynomial surfaces to all the spatial gravity data, through a method of least squares fitting. A fitted lower order polynomial surface approximates the regional gravity trend, and removing this surface from the dataset should leave only the gravity anomalies due to localised features of interest. Mathworks Matlab $^{T M}$ was used to fit and subsequently remove $2^{\text {nd }}$ order polynomial surfaces from the Bouguer gravity data, regionally correcting the gravity dataset. Surfaces were fit at a regional scale (one surface to represent the regional gravity anomaly over all three flood plains) and at a local scale (surfaces to represent the regional gravity anomaly in each flood plain).

\section{Regional residuals}

Figure 3.13 shows the regionally fitted surface and the regional residual gravity map; equation 3.1 is that of the surface fitted to the regional gravity trend.

$$
g_{s}(x, y)=\left(0.014 x^{2}-0.035 y^{2}+0.024 x y-0.263 x+0.111 y-30.519\right) \mathrm{mGal}
$$

where $g_{s}(x, y)$ is the regional surface value at some $\mathrm{x}$ and $\mathrm{y}$ relative to the surface centre at 2301000 Easting, 5772400 Northing. 


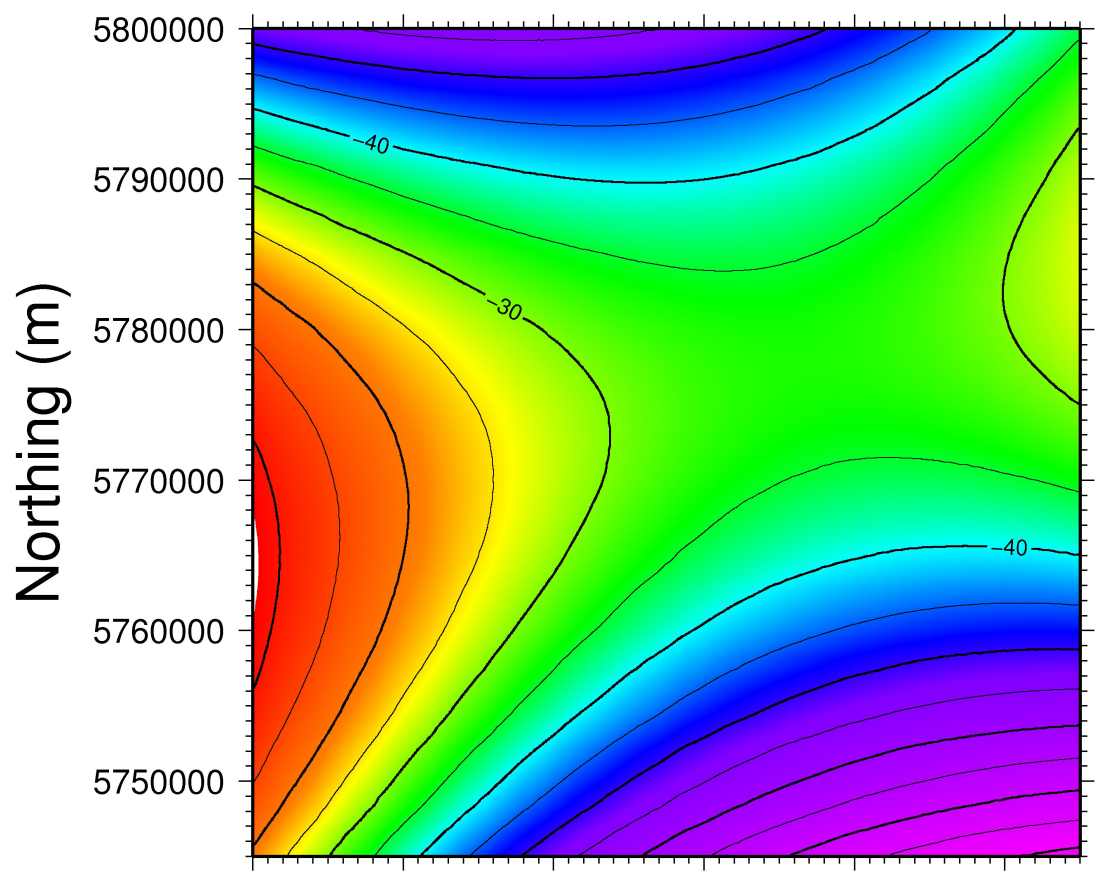

227000022800002290000230000023100002320000

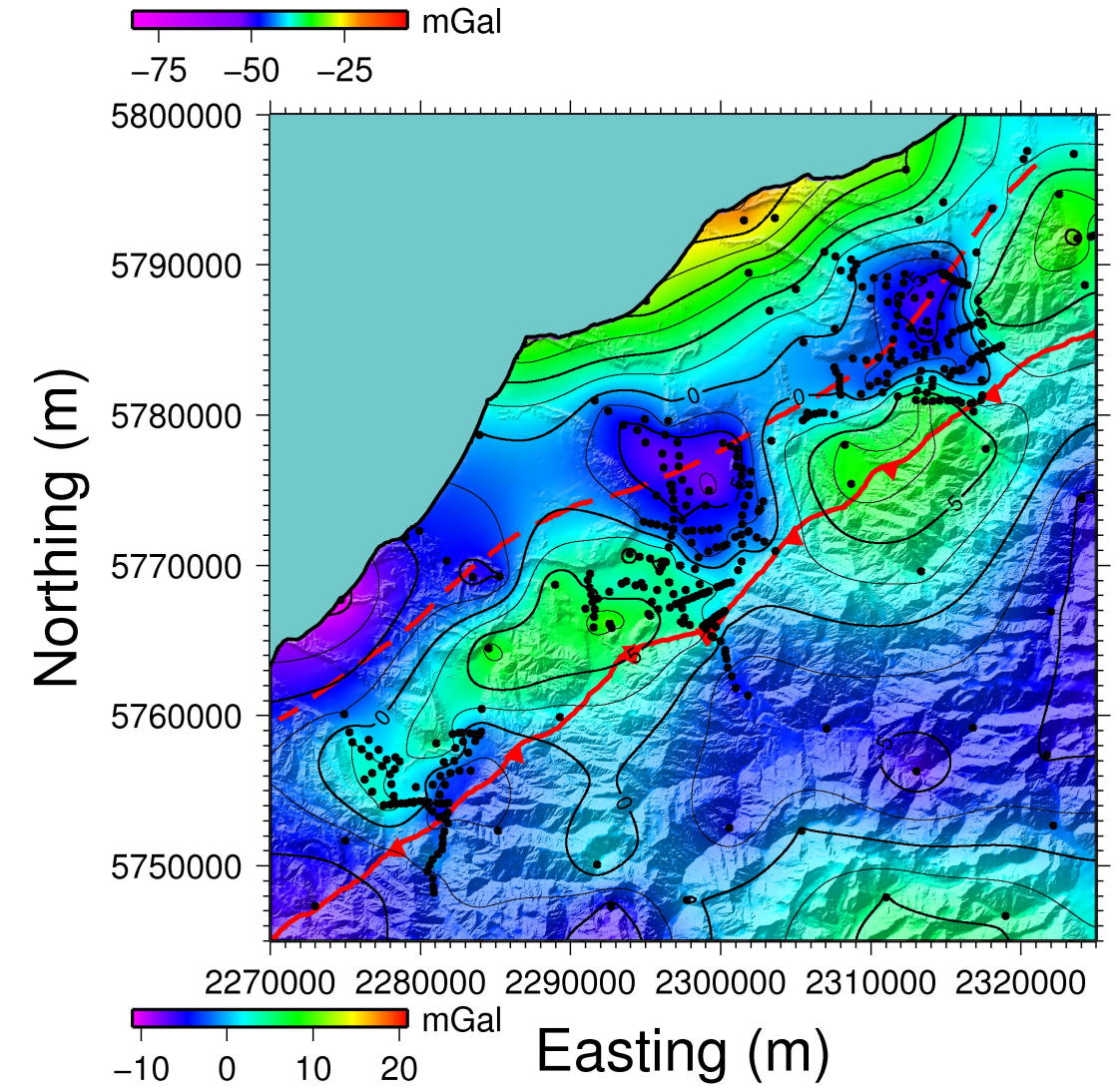

Figure 3.13: The central West Coast with a regional trend removed via surface fitting methods. The surface fit and removed from the dataset is at the top and the residual gravity map is below. 
The surface fitted to the data (Figure 3.13) is not a good approximation of the gravity trend due to the crustal root of the Southern Alps. The southeast corner of the fitted surface shows that an increasingly negative trend in gravity toward the Southern Alps is being removed, which is to be expected given the crustal root. However, the north-northwest section of the fitted surface is removing an in increasingly negative trend toward the coast; a trend which corresponds to the negative anomaly associated with the South Westland Basin. This numerical method is over-fitting the data and removing not only the gravitational effect of the crustal root but also the gravity signature of structures of interest, such as the South Westland Basin.

\section{Local residuals}

Instead of fitting one surface to the entire region, surfaces are fit to the data in the individual flood plains. A consequence of removing a trend surface from each individual flood plain is that the residual gravity between the flood plains is not consistent.

\section{Wanganui residuals}

Figure 3.14 shows the surface fitted to spatial Bouguer gravity data over the Wanganui flood plain and the resulting residual gravity map; equation 3.2 is that of the surface fitted to the overall gravity trend in the Wanganui flood plain.

$$
g_{s}(x, y)=\left(0.078 x^{2}+0.120 y^{2}-0.053 x y+0.648 x-1.261 y-34.474\right) \mathrm{mGal}
$$

where $g_{s}(x, y)$ is the surface value at some $\mathrm{x}$ and $\mathrm{y}$ relative to the surface centre at 2314000 Easting, 5784000 Northing.

The fitted surface possess elliptical contours around the centre of the flood plain, reaching a minimum value of approximately $-31 \mathrm{mGal}$. This surface 


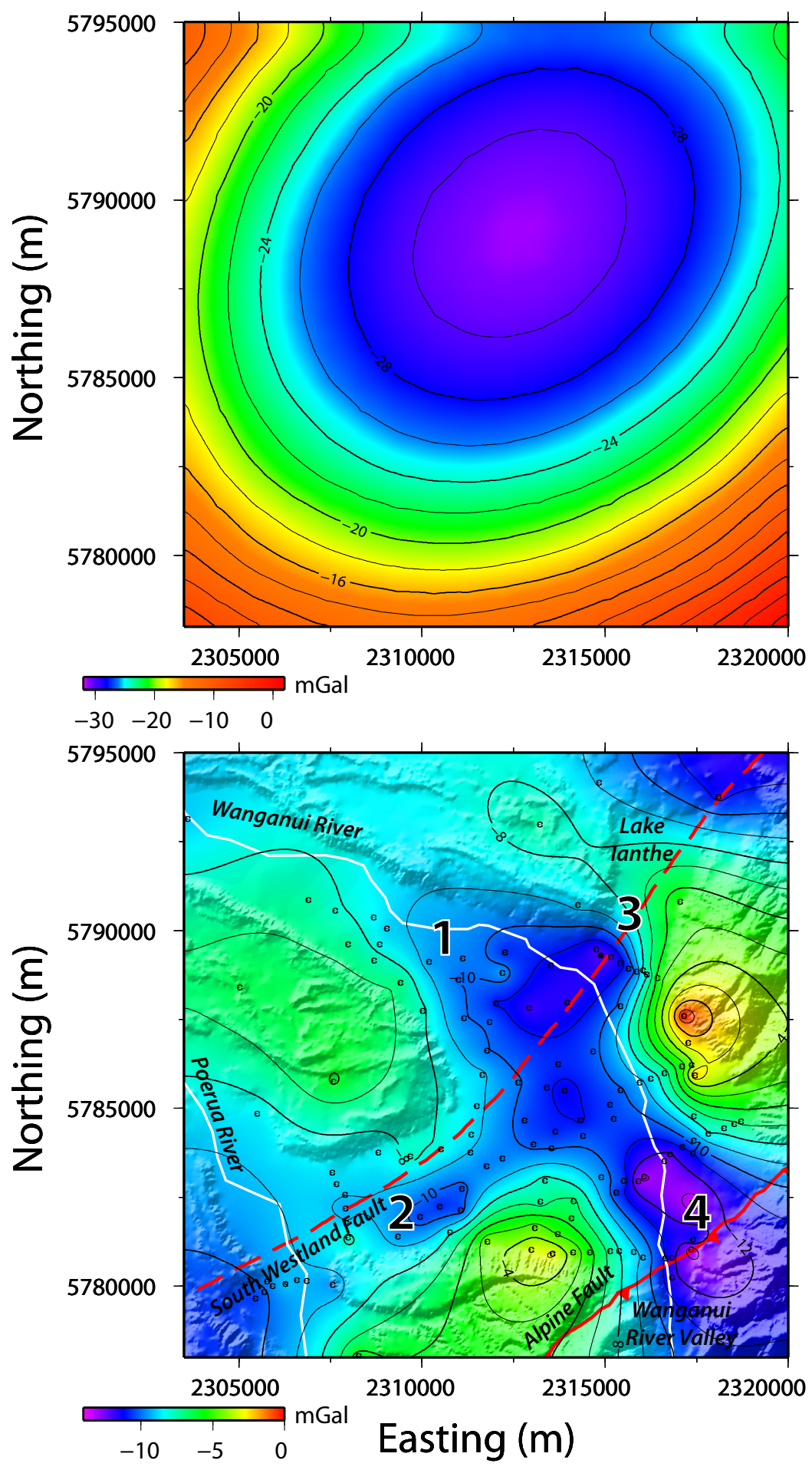

Figure 3.14: Numerical regional correction of the Wanganui flood plain. Best fit surface at the top and residual gravity map on the bottom. Numbers on the map show features of interest, which are described in the text. White lines mark river systems. 
is not a geologically reasonable representation of the gravity anomaly associated with the crustal root of the Southern Alps, and appears to be fit to the gravity field of both the crustal root and South Westland Basin. However, the resulting residual gravity field exhibits strongly defined structure, which appears to correspond with the topography of the flood plain. This residual gravity field can be used as a representation of the localised subsurface structure in the flood plain.

Prominent features of the Wanganui residual gravity map include:

- A large, elongate, sub-rectangular negative anomaly extending northwest from the Alpine Fault, through the centre of the flood plain and toward the northwest splay of the flood plain. This northwest extending anomaly is primarily defined by the $-10 \mathrm{mGal}$ contour. The anomaly extends into the northwest splay of the flood plain at location 1, with the $-9 \mathrm{mGal}$ contour stretching toward the coast. To the southwest, at location 2 , the $-9 \mathrm{mGal}$ contour line defines $\mathrm{a} \sim 6 \mathrm{~km}$ extension of the anomaly into the western splay of the flood plain. Toward Lake Ianthe at location 3 , the $-11 \mathrm{mGal}$ contour interval is elongate in the northeast/southwest direction, perpendicular to the trend of the larger anomaly, with the $-11 \mathrm{mGal}$ contour interval branching into the northeastern splay.

- The minimum value of the residual gravity field is defined by the -12 mGal contour interval and is juxtaposed against the Alpine fault at location 4 , on the axis of extension of the large negative anomaly. The centre of this minimum is dextrally offset from the centre of the Wanganui river valley by $\sim 1.7 \mathrm{~km}$. This is consistent with a dextrally offset erosional structure.

- The structure observed in the residual gravity field is strongly correlated with the topography of the flood plain. This indicates that the processes which have formed the surface features are the same ones which formed sub-surface features. 
- The South Westland Fault runs directly though the northeast anomaly branch and just northwest of the western anomaly branch. The interaction between the fault and erosional processes could potentially play a role in how the splays of the flood plain were formed.

\section{Whataroa residuals}

Figure 3.15 shows the surface fitted to spatial Bouguer gravity data over the Whataroa flood plain and the resulting residual gravity map; equation 3.3 is that of the surface fitted to the overall gravity trend in the Whataroa flood plain.

$$
g_{s}(x, y)=\left(0.056 x^{2}-0.037 y^{2}+0.071 x y-0.907 x-0.516 y-29.944\right) \mathrm{mGal}
$$

where $g_{s}(x, y)$ is the surface value at some $\mathrm{x}$ and $\mathrm{y}$ relative to the surface centre at 2297900 Easting, 5770200 Northing.

The surface representing the regional gravity trend over the Whataroa flood plain has a field which becomes increasingly positive in the southwest direction. Again, the surface fitted to the data is an unreasonable approximation of the gravity anomaly due to the crustal root below the Southern Alps. However, the resulting residual gravity field has significant structure, similar to that observed in the Wanganui flood plain, which can be used to describe the localised sub-surface structure of the flood plain.

Prominent features of the Whataroa residual gravity map include:

- A large, sub-rectangular, negative gravity anomaly extending northwest into the northwestern splay of the flood plain. This anomaly is defined by the -8 to $-9 \mathrm{mGal}$ contour intervals. The negative anomaly appears to branch into the northeast and northwest splays of the flood plain, at location 1 and 2 respectively. However, unlike the Wanganui flood plain, there is no evidence of the anomaly extending into the western splay of the flood plain. 

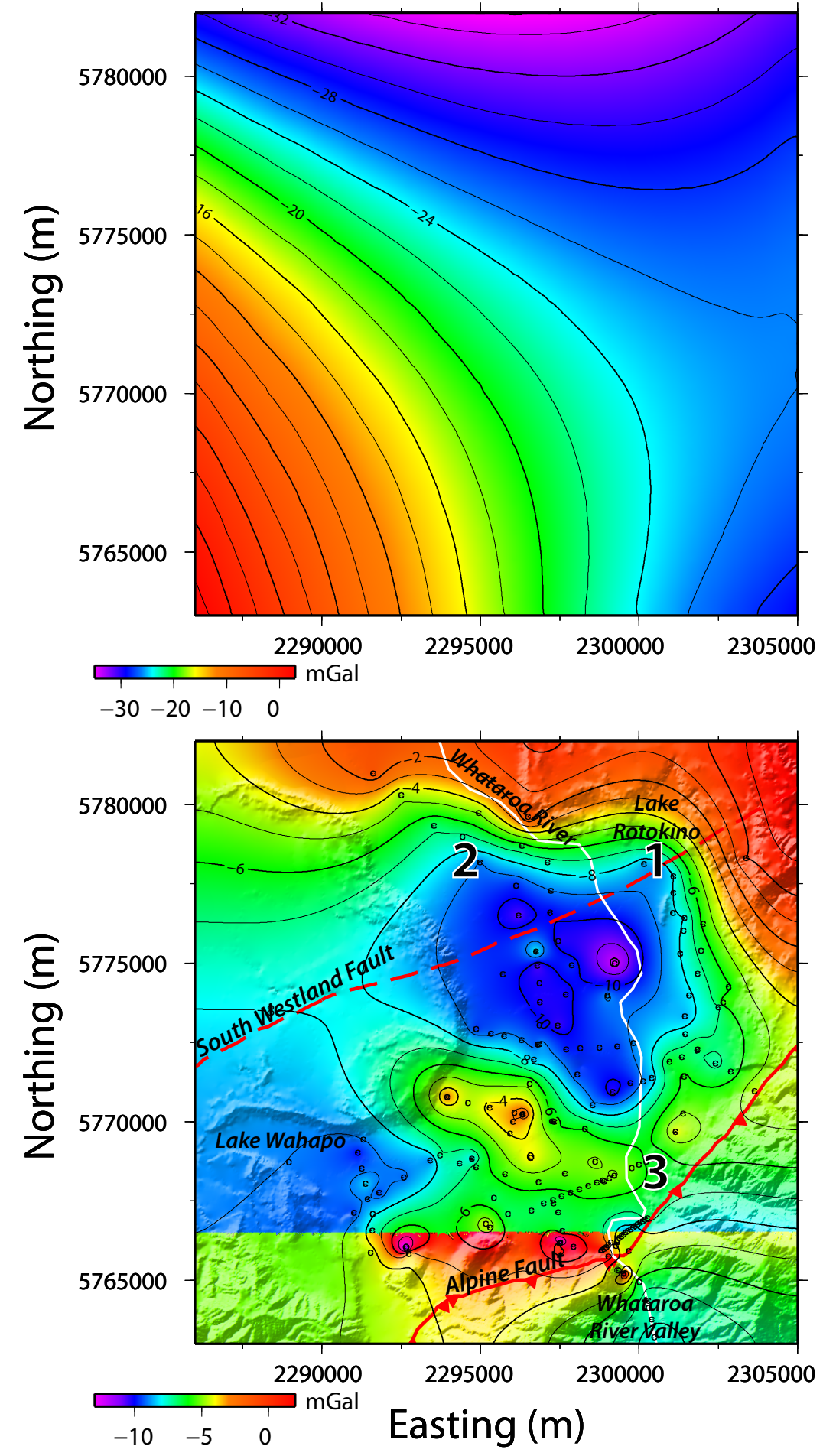

Figure 3.15: Numerical regional removal of the Whataroa flood plain. Best fit surface at the top and residual gravity map on the bottom. Numbers on the map show features of interest, which are described in the text. White lines mark river systems. 
- The northwest striking anomaly can be traced back to the Alpine fault through the $-6 \mathrm{mGal}$ contour interval at location 3. As with the negative residual anomaly in the Wanganui flood plain, it appears that this anomaly has been dextrally offset from the river valley by a distance of $\sim 2 \mathrm{~km}$, consistent with a dextrally offset erosional structure.

- The South Westland Fault bisects the northeastern branch of the large residual gravity anomaly. However, the fault appears to have no correlation with the residual gravity field in the west of the flood plain, or the western splay of the flood plain topography.

\section{Waiho residuals}

Figure 3.16 shows the surface fitted to spatial Bouguer gravity data over the Waiho flood plain and the resulting residual gravity map; equation 3.4 is that of the surface fitted to the overall gravity trend in the Waiho flood plain.

$g_{s}(x, y)=\left(-0.146 x^{2}+0.053 y^{2}+0.113 x y-2.186 x-1.291 y-22.817\right) \mathrm{mGal}$

where $g_{s}(x, y)$ is the surface value at some $\mathrm{x}$ and $\mathrm{y}$ relative to the surface centre at 2280500 Easting, 5755300 Northing.

The surface fitted to the spatial gravity data in the Waiho flood plain approximates a regional gravity field that would be expected given the tectonic setting of the study area. The surface fitted to represent the regional gravity trend shows an increasingly negative field in the direction of the Southern Alps and its crustal root. The residual gravity field reveals anomalies which appear to have relatively random structure.

Prominent features in the Waiho residual gravity map include:

- An elongate, relative, negative residual gravity anomaly at location 1 extends northeast over a distance of $\sim 5 \mathrm{~km}$ from the Waiho river valley. This anomaly is defined by the -6 to $-8 \mathrm{mGal}$ contour intervals. The 

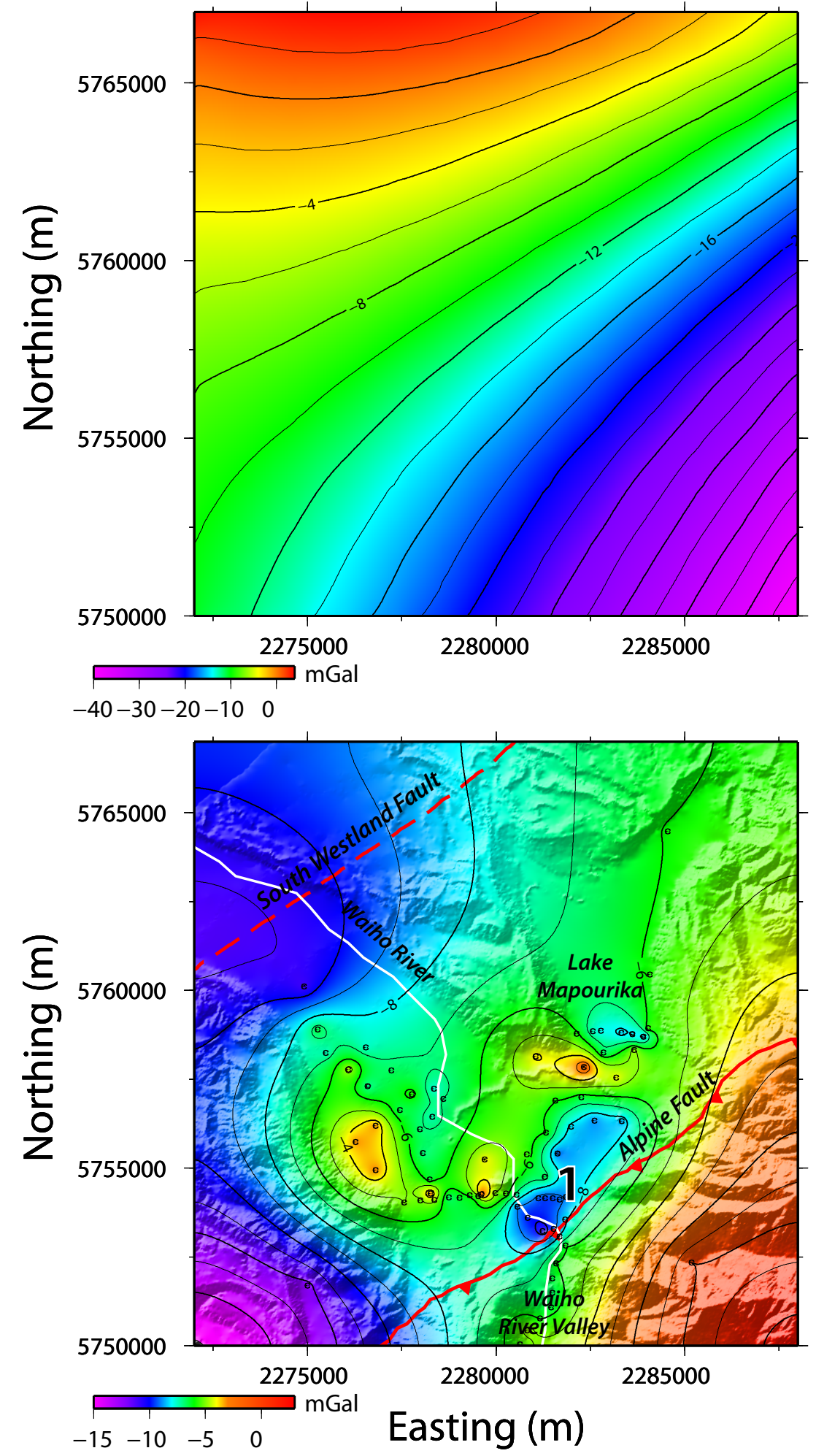

Figure 3.16: Numerical regional removal of the Waiho flood plain. Best fit surface at the top and residual gravity map on the bottom. Numbers on the map show features of interest, which are described in the text. White lines mark river systems. 
termination of this elongate anomaly appears to be coincident with the topographic expression of the Waiho loop. Unlike the residual anomalies present in the two northern flood plains, this anomaly does not branch in multiple directions.

- The remainder of the residual gravity field appears to have little relation to the topography of the flood plain. Most notably there is little evidence of anomaly extension toward the coast through the northwestern splay of the flood plain.

\section{Drawbacks of surface fitting}

Most of the surfaces fit to the gravity data are not good approximations of the regional gravity trend resulting from the Southern Alps crustal root. The sub-surface geology of the central West Coast is complex, with the wavelength of gravity anomalies due to the Southern Alps crustal root and the South Westland Basin overlapping. This overlap results in the polynomial surfaces being over fit to the data and removing the gravity signature of features of interest (i.e the South Westland Basin). Therefore, this method is unreasonable for the interpretation and modelling of sub-surface structure along the central West Coast.

However, the residual anomaly maps produced through this method provide insight into the localised structure of erosion over the central West Coast.

\subsubsection{Regional modelling}

A more direct approach to obtain regionally corrected gravity data is to utilise previous knowledge and data on the area to build a model of the unwanted regional structure, and remove the associated gravity trend from the dataset.

The Southern Alps mountain range and its crustal root is the dominant regional gravity feature of the central West Coast region. By modelling the mantle-lithosphere structure and its variation along the West Coast, a reasonable and constrained regional trend can be established and used to 
correct the dataset, without removing the gravity signature of the geological features of interest.

\section{Model constraints}

The mantle-lithosphere structure below the Southern Alps has been a focus of many geophysical studies, most notably the SIGHT project in 1996. These studies provide constraints used to model the crustal thickening below the Southern Alps.

- Henrys et al. (2004) found the crustal root is pronounced over a width of $80 \mathrm{~km}$ and reaches a maximum depth of $\sim 45 \mathrm{~km}$ below SIGHT transect 2 .

- Brikke (2010) proposed that the Moho interface was smoothly varying in depth, increasing from $35 \mathrm{~km}$ depth below SIGHT transect 1, to 42 km depth below SIGHT transect 2 .

- Stern et al. (2000) proposed the presence of a high-speed mantle body below the Southern Alps. Although relatively unconstrained, this study indicates that the the body is centered below the Southern Alps at a depth of $\sim 120 \mathrm{~km}$ with a width of $80 \mathrm{~km}$ and depth extent of $100 \mathrm{~km}$. Scherwath et al. (2006) produced gravity models, based on Stern et al. (2000), indicating that this anomalous mantle body increases in size to the south of the central Southern Alps.

- Reasonable densities and dimensions of the mantle-lithosphere structure below SIGHT transect 2 are taken from the gravity modelling of Stern et al. (2000) and Scherwath et al. (2006). This study used a density of $2900 \mathrm{~kg} / \mathrm{m}^{3}$ for oceanic crust, $3350 \mathrm{~kg} / \mathrm{m}^{3}$ for the mantle and $3380 \mathrm{~kg} / \mathrm{m}^{3}$ for the high-speed mantle body. 


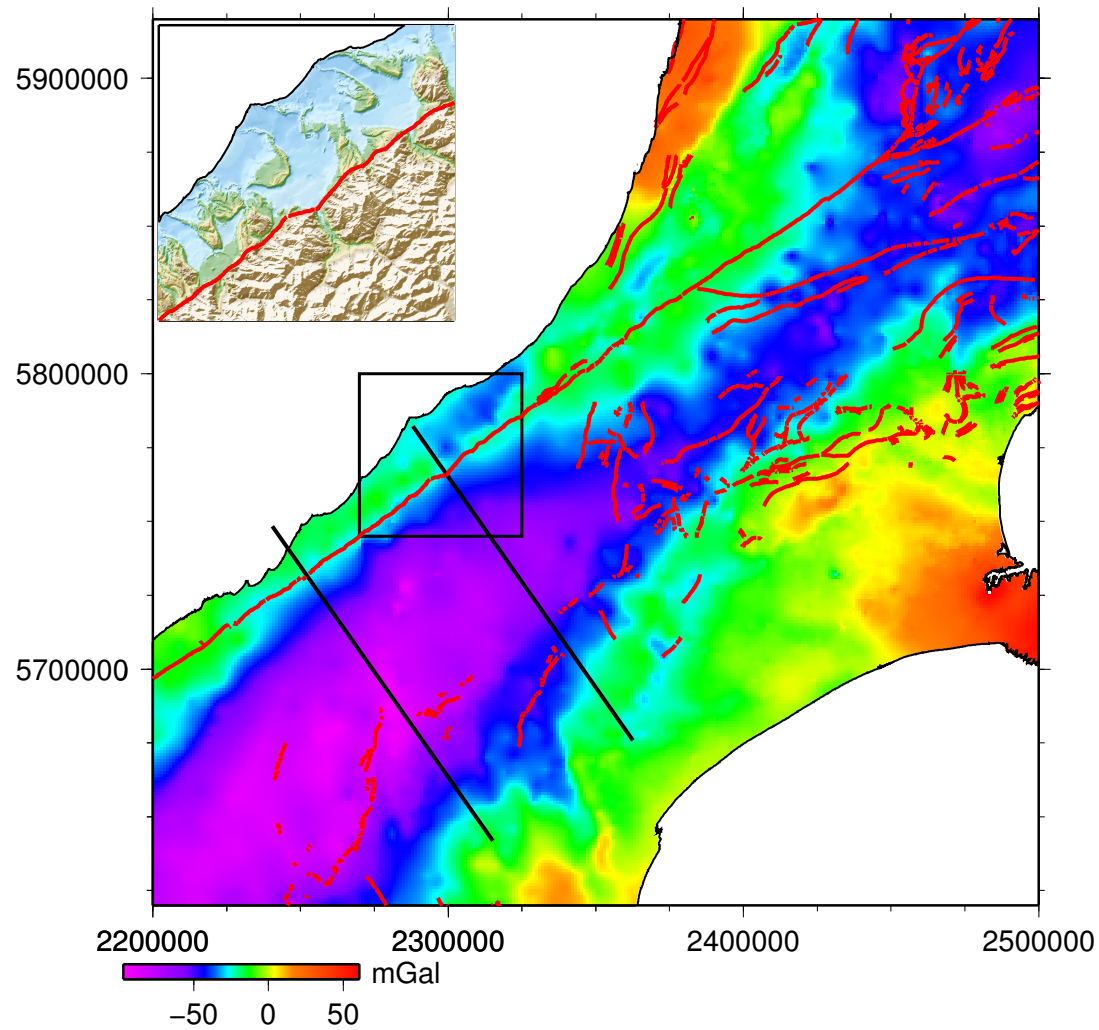

Figure 3.17: Gravity profiles across the Southern Alps for the purpose of regional trend modelling. The profiles follow SIGHT transects 1 and 2. The inset figure shows the topography of the study area, indicated by the black box.

\section{Two line model}

Figure 3.17 shows a Bouguer gravity map of the central South Island, gridded and displayed using data from GNS Science's National Gravity Network. Shown on the map are two profiles, each running $130 \mathrm{~km}$ in length, perpendicular to the trace of the Alpine Fault. These two profiles follow where SIGHT transects 1 and 2 crossed the Southern Alps.

Gravity modelling of the mantle-lithosphere structure below these two profiles is used to produce calculated gravity anomalies over the study area, which can subsequently be used to remove the regional gravity trend from 
the dataset.

Figure 3.18 shows gravity models of the mantle-lithosphere structure below the northern and southern gravity profiles and the resulting gravity anomalies. The dashed lines indicate the gravity anomaly over the West Coast study area, northwest of the Alpine Fault. Linear trends are fitted to the calculated gravity anomalies between these dashed lines, representing the regional gravity over the West Coast along each profile, the equations of which can be seen in Table 3.1 .

\begin{tabular}{ccc}
\hline Profile & Fitted anomaly equation & $\delta g_{\text {regional }}$ \\
\hline Northern profile & $g_{\text {regional }}=-0.000928 \times d+14.5$ & $0.93 \mathrm{mGal} / \mathrm{km}$ \\
Southern profile & $g_{\text {regional }}=-0.00111 \times d-3.03$ & $1.11 \mathrm{mGal} / \mathrm{km}$ \\
\hline
\end{tabular}

Table 3.1: Linear trends fitted to modelled gravity anomalies along the central West Coast and the rate of change in the regional field $\delta g_{\text {regional }}$. $d$ is distance measured in metres.

The gradient of the fitted lines are used to represent the change in regional gravity moving away from the Alpine Fault. Heading toward the coast, perpendicular to the trace of the Alpine Fault, the modelled value of the regional gravity increases at a rate of $0.93 \mathrm{mGal} / \mathrm{km}$ along the northern profile and $1.11 \mathrm{mGal} / \mathrm{km}$ along the southern profile.

The rate of change in the perpendicular regional gravity field also varies along the length of the Alpine Fault, due to the varying depth and dimensions of the crustal root below the Southern Alps. To account for this, a linear change in the regional gradient between the two profiles is assumed. The perpendicular distance between the two profiles is $58.3 \mathrm{~km}$ and so the rate in change of the modelled regional gravity gradient between the two profiles is:

$$
\Delta \delta g_{\text {regional }}=\frac{\text { Southern } \delta g_{\text {regional }}-\text { Northern } \delta g_{\text {regional }}}{d_{\text {perpendicular }}}=0.003 \frac{\mathrm{mGal} / \mathrm{km}}{\mathrm{km}}
$$

A regional gravity gradient which varies smoothly between the two profiles 

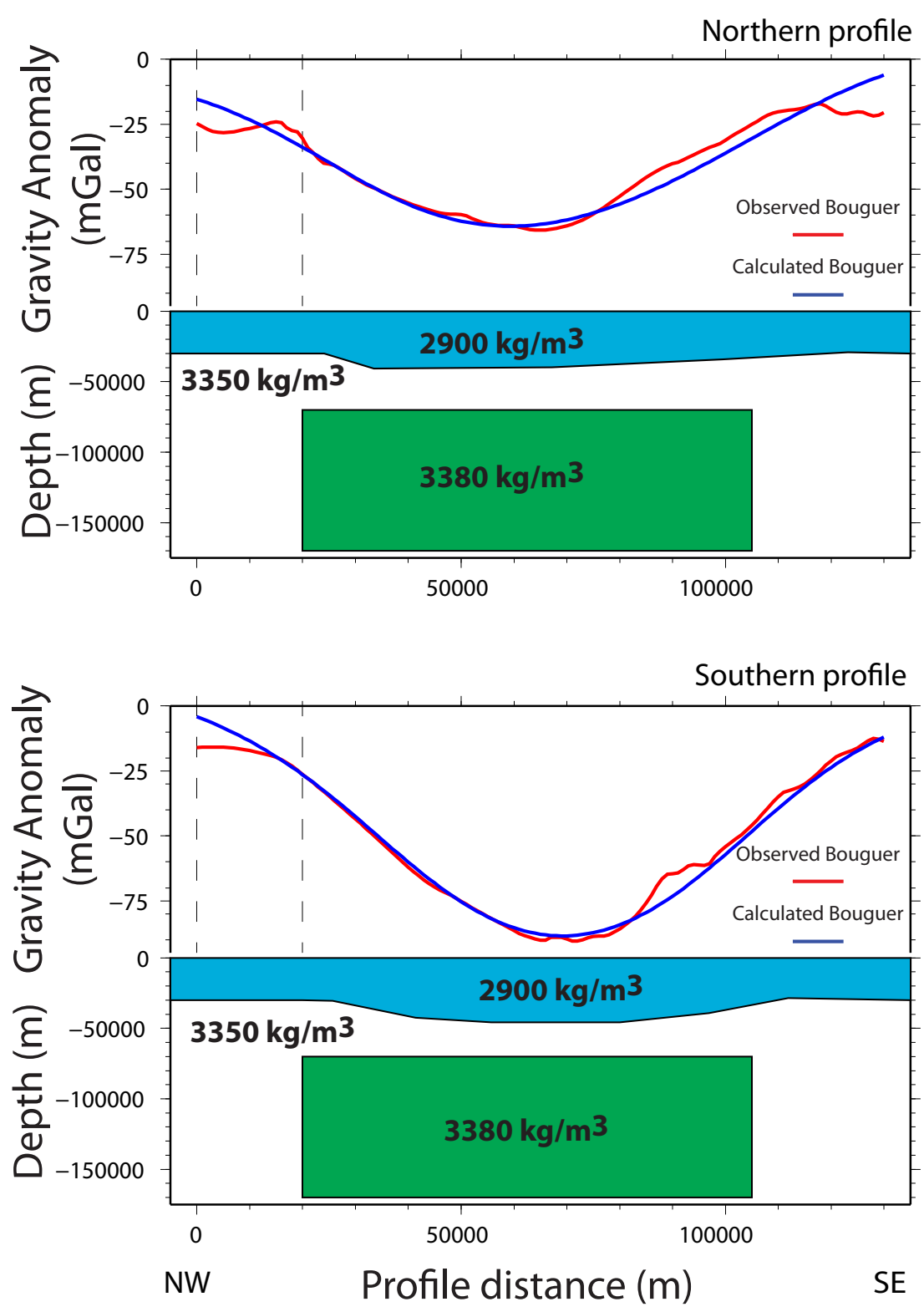

Figure 3.18: Gravity modelling of the two gravity profiles. Above is the northern line which runs over SIGHT transect 1, below is the southern line which runs over SIGHT transect 2. The dashed lines indicates where lines of best fit are applied to the modelled anomaly to establish regional trends over the central West Coast. 
has been established, however there are data which lie outside these two profiles, most notably data within the Wanganui flood plain. Given that these two gravity profiles are the only constrained transects across the Southern Alps, the change in the regional gravity gradient must be extrapolated. The extrapolation of the model assumes that the change in the regional gradient continues to vary smoothly north of the northern profile and south of the southern profile. That is to say that the change in the regional gravity gradient parallel to the Alpine fault is constant along the length of the fault, at a rate of $0.003(\mathrm{mGal} / \mathrm{km}) \mathrm{km}^{-1}$.

This regional model is consistent with the findings of Scherwath et al. (2006), whose 3-D gravity model of the lithosphere structure shows an increase (from north to south) in both the width and depth of the crustal thickening below the Southern Alps. The model of Scherwath et al. (2006) also shows an increase (to the south) in the size of the anomalous mantle blob.

\section{Model application and results}

In order to apply this model to data across the central West Coast, the faultperpendicular distance of each data point must be established, as well as the relative fault-parallel distance. To determine these distances, the southern gravity profile is used as a reference line for the fault-parallel distances, while a line representing the trace of the Alpine fault is used to establish fault-perpendicular distances, see Figure 3.19. The modelled regional gravity gradient at any point is given by:

$$
\delta g_{\text {point }}=\delta g_{\text {southern }}-\Delta \delta g_{\text {regional }} \times d_{\text {parallel }}
$$

While the value of the regional gravity at any point is given by:

$$
g_{\text {regional }}=\delta g_{\text {point }} \times d_{\text {perpendicular }}
$$

With these two distances established for all points in the dataset, the value of the modelled regional gravity field can be calculated at each data 


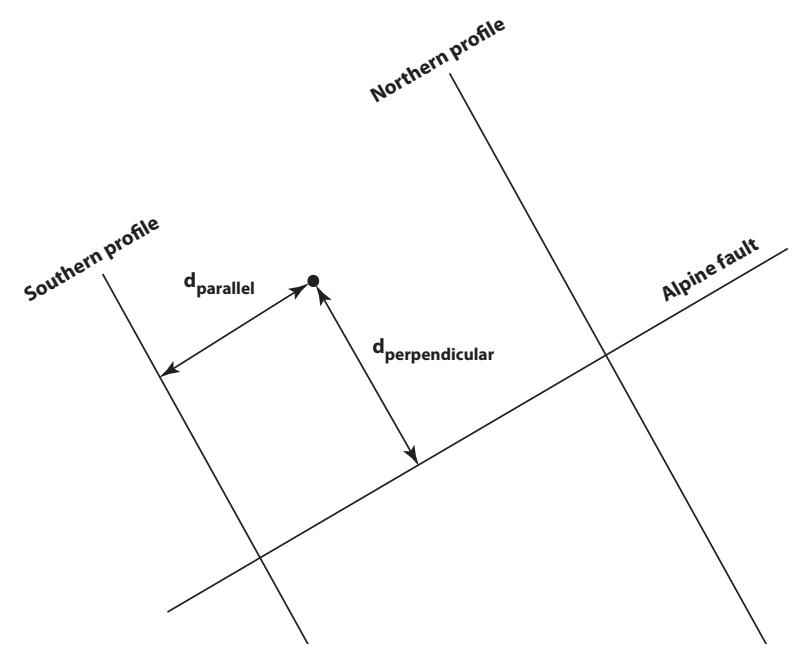

Figure 3.19: Diagram showing the set up of the two line regional model. The southern gravity line is used as the fault-parallel distance reference line, while a line representing the trace of the Alpine fault is used as the faultperpendicular distance reference line.

point and is subsequently removed from the data. Once the regional gravity value has been removed, the dataset is tied to a rock outcrop, where it is expected that the residual gravity value at that point is $0 \mathrm{mGal}$.

Figure 3.20 shows the regionally corrected residual gravity map using this two profile model.

There are several features in this residual gravity map which are of importance:

- There is less obvious erosional structure in the residual gravity field within the flood plains than that of the numerically corrected datasets. This is because the large negative gravity field associated with the South Westland Basin, northwest of the South Westland Fault, has not been removed and "drowns out" the gravitational effects of smaller structures.

- There is a small correlation between the corrected gravity field and 

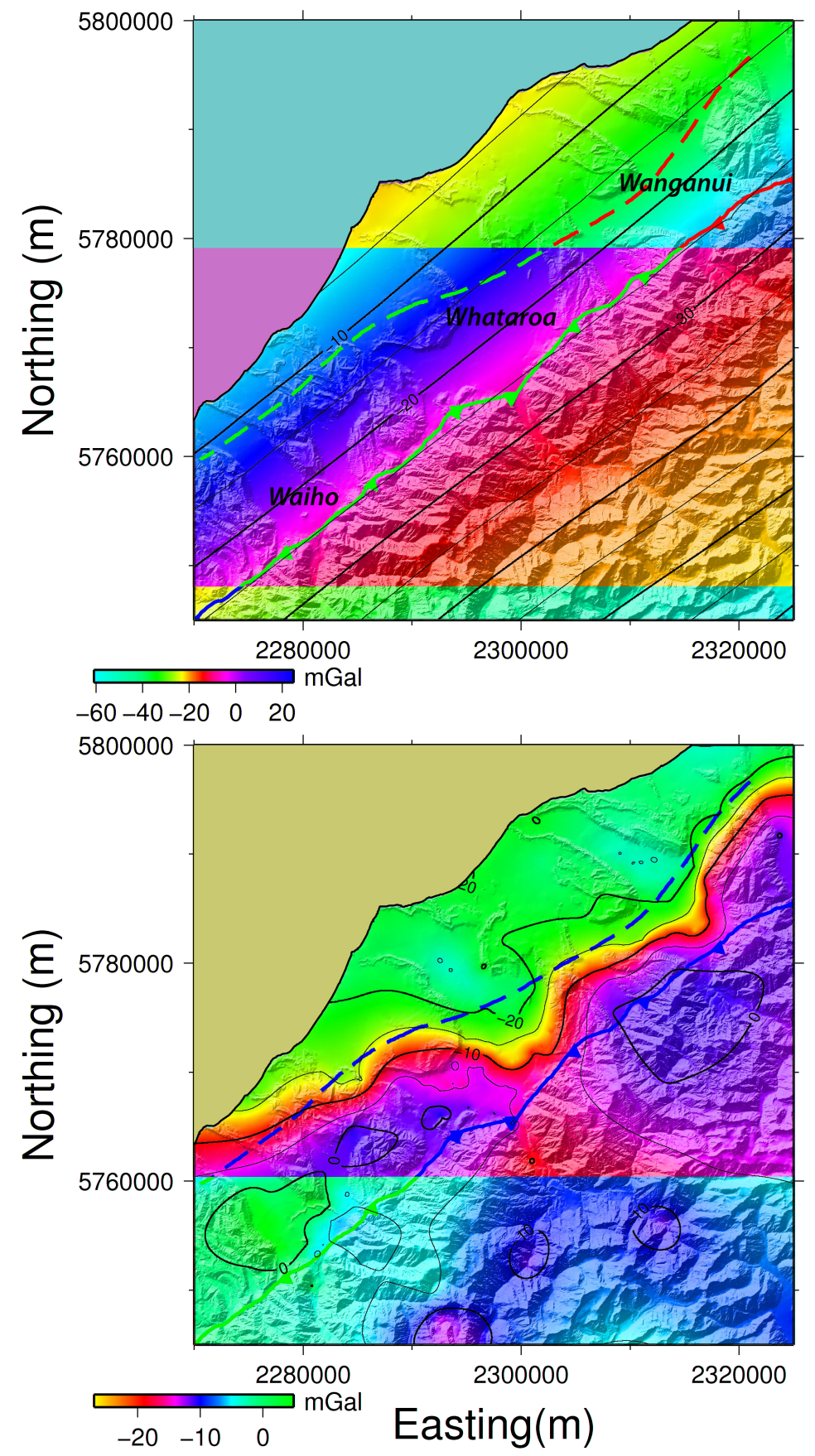

Figure 3.20: Residual gravity map of the central West Coast resulting from the removal of the simple mantle-lithosphere model. 
the mapped South Westland Fault as far south as the Whataroa flood plain. The -15 to $-20 \mathrm{mGal}$ contour intervals loosely parallel the fault, with the contour intervals deviating from the fault in the centre of the flood plains. The deviation of contours in the centre of the flood plains is to be expected as this is where erosional processes are focused. South of the Whataroa flood plain, the residual gravity field and the fault appear to have little relation to each other, with the fault cutting across the contours of the residual gravity field.

- There are lobes of positive residual gravity, two situated in the Waiho flood plain and another in the western splay of the Whataroa flood plain. It is an unlikely possibility that there is dense material below these areas which results in positive values of gravity, it is more likely that the regional model of gravity has not correctly removed the regional trend in these areas.

\subsubsection{Detailed regional model}

The two profile regional model provides a simple, yet well constrained model of the crustal root below the Southern Alps. The resulting residual gravity map shows that there is a significant correlation between the South Westland Fault and the residual gravity field in the Wanganui and Whataroa flood plains, which is to be expected as the fault defines the boundary of the South Westland Basin. However, the correlation ceases south of the Whataroa flood plain, and lobes of positive gravity over the Waiho flood plain indicate that the regional model may be too simple.

Instead of relying on just the two gravity profiles to define the regional model, ten gravity profiles spaced $10 \mathrm{~km}$ apart, across the Southern Alps are used to develop a detailed regional model. These profiles are less constrained than the two gravity profiles used in the previous model, but enable nonlinear variations in the crustal structure to be modelled. The ten new gravity profiles completely encompass the study area, which reduces the need for 


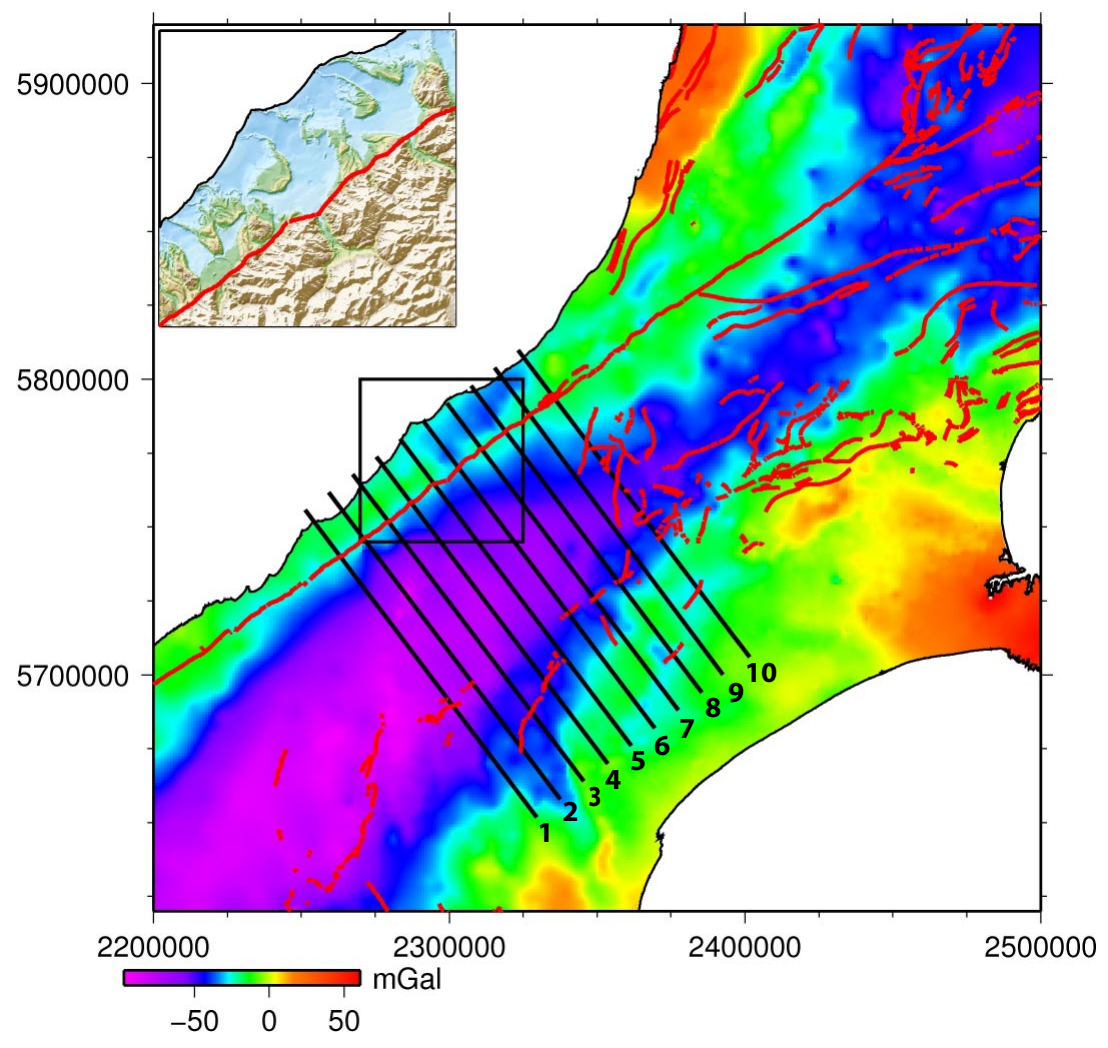

Figure 3.21: Gravity profiles across the Southern Alps for the purpose of modelling the regional trend in gravity. The black box indicates the relative location of the study area.

trend extrapolation.

Figure 3.21 provides an overview of the gravity profiles used in building a detailed regional model.

The constraints of SIGHT transects 1 and 2 are maintained in the modelling of the new profiles, which can be seen in Appendix B. Table 3.2 gives the equations of the lines fitted to the modelled gravity along the West Coast and their regional gradients. 


\begin{tabular}{ccc}
\hline Profile & Fitted anomaly equation & $\delta g_{\text {regional }}$ \\
\hline 1 & $g_{\text {regional }}=-0.00250 \times d+33.48 \mathrm{mGal}$ & $2.50 \mathrm{mGal} / \mathrm{km}$ \\
2 & $g_{\text {regional }}=-0.00335 \times d+40.16 \mathrm{mGal}$ & $3.35 \mathrm{mGal} / \mathrm{km}$ \\
3 & $g_{\text {regional }}=-0.00350 \times d+44.10 \mathrm{mGal}$ & $3.50 \mathrm{mGal} / \mathrm{km}$ \\
4 & $g_{\text {regional }}=-0.00217 \times d+15.61 \mathrm{mGal}$ & $2.17 \mathrm{mGal} / \mathrm{km}$ \\
5 & $g_{\text {regional }}=-0.00165 \times d+6.89 \mathrm{mGal}$ & $1.65 \mathrm{mGal} / \mathrm{km}$ \\
6 & $g_{\text {regional }}=-0.00169 \times d-9.38 \mathrm{mGal}$ & $1.69 \mathrm{mGal} / \mathrm{km}$ \\
7 & $g_{\text {regional }}=-0.00153 \times d-11.99 \mathrm{mGal}$ & $1.53 \mathrm{mGal} / \mathrm{km}$ \\
8 & $g_{\text {regional }}=-0.00135 \times d-5.76 \mathrm{mGal}$ & $1.35 \mathrm{mGal} / \mathrm{km}$ \\
9 & $g_{\text {regional }}=-0.00138 \times d+8.59 \mathrm{mGal}$ & $1.38 \mathrm{mGal} / \mathrm{km}$ \\
10 & $g_{\text {regional }}=-0.00117 \times d+17.89 \mathrm{mGal}$ & $1.17 \mathrm{mGal} / \mathrm{km}$ \\
\hline
\end{tabular}

Table 3.2: Linear trends fitted to modelled gravity anomalies on the ten profiles along the central West Coast and the rate of change in the regional field $\delta g_{\text {regional }}$. $d$ is distance measured in metres.

\section{Model application and results}

The implementation of the detailed model is similar to that of the two line model. However, instead of interpolating between just two profiles, interpolation is done between all sets of neighbouring gravity profiles. The regional trend at any data point will be an interpolation of the gradients resulting from the gravity models on profiles either side of that point.

In order to determine what two gravity profiles each data point sits between, a series of conditional programming statements within Microsoft Excel $^{T M}$ is used. Tables 3.3 and 3.4 shows how the total fault-parallel distance is used to determine what gravity profiles the data points sit between. The fault-parallel distance between the data point and the closest gravity profile to the south-west determines the interpolation of the regional trend between the two neighbouring gravity profiles, see Figure 3.22.

For example, if a data point is $19.1 \mathrm{~km}$ fault-parallel from the southern most gravity profile, then the point lies between profile 2 and 3 (see Figure 


\begin{tabular}{ccccccc}
\hline Parallel distance & $>0 \mathrm{~km}$ & $>10 \mathrm{~km}$ & $>20 \mathrm{~km}$ & $\ldots$ & $>100 \mathrm{~km}$ & Total \\
\hline $19.1 \mathrm{~km}$ & 1 & 1 & 0 & $\ldots$ & 0 & 2 \\
$63.9 \mathrm{~km}$ & 1 & 1 & 1 & $\ldots$ & 0 & 7 \\
\hline
\end{tabular}

Table 3.3: Example of determining what two profiles a data point sits between using if statements.

\begin{tabular}{ccc}
\hline Distance total & Southern profile & Northern profile \\
\hline 0 & - & Profile 1 \\
1 & Profile 1 & Profile 2 \\
2 & Profile 2 & Profile 3 \\
$\ldots$ & $\ldots$ & $\ldots$ \\
10 & Profile 9 & Profile 10 \\
11 & Profile 10 & - \\
\hline
\end{tabular}

Table 3.4: Example of determining what two profiles a data point sits between using if statements.

3.22 ) and the regional trend used at this point would be given by:

$$
\delta g_{\text {point }}=\frac{\delta g_{\text {profile } 3}-\delta g_{\text {profile } 2}}{10 \mathrm{~km}} \times \Delta d_{\text {parallel }}+\delta g_{\text {Profile } 2}
$$

The modelled value of gravity at this point would be:

$$
g_{\text {regional }}=\delta g_{\text {point }} \times d_{\text {perpendicular }}
$$

For any points south of profile 1 and north of profile 10 the change in regional trend is extrapolated from the two nearest gravity profiles.

The value of regional gravity at each data point in the study area is calculated using the detailed model and removed from the dataset to give a new regionally corrected dataset. As with the simple model, the corrected residual gravity values are tied to a rock outcrop where the expected residual gravity anomaly is $0 \mathrm{mGal}$.

Figure 3.23 shows the resulting residual gravity field over the central West Coast once the detailed regional model of gravity has been removed from the dataset. 


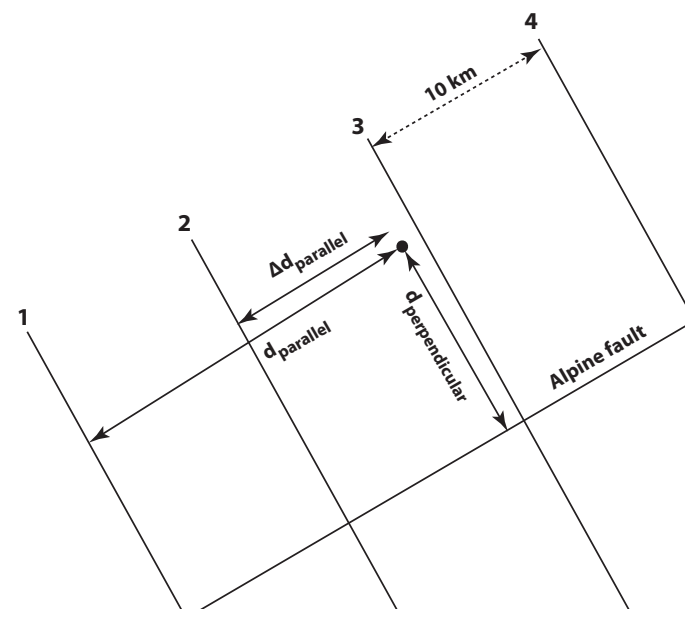

Figure 3.22: Diagram showing the set up of the ten line regional model. The southern most gravity line is used as the fault-parallel distance reference line, $\Delta d_{\text {parallel }}$ is the fault-parallel distance between a point and the closest gravity profile to the south-west.

It is apparent that this new detailed regional model is an improvement on the simpler regional model. The features of the residual map which show significant improvement include:

- A strong correlation between the South Westland Fault and the residual gravity field over the entire central West Coast. This correlation is due to the gravity expression of the fault bound South Westland Basin. The peak of the gravity gradient will broadly correspond to the steepest part of the fault offset. This correlation deviates slightly in the centre of the flood plains, which is likely to be the result of extensive erosion within the flood plains.

- The lobes of positive gravity residual along the northwest side of the Alpine Fault have nearly been completely removed, leaving the residual gravity field dominated by negative anomalies along the West Coast.

This detailed regional model of the mantle-lithosphere thickening below the Southern Alps mountain range provides the best approximation of the 

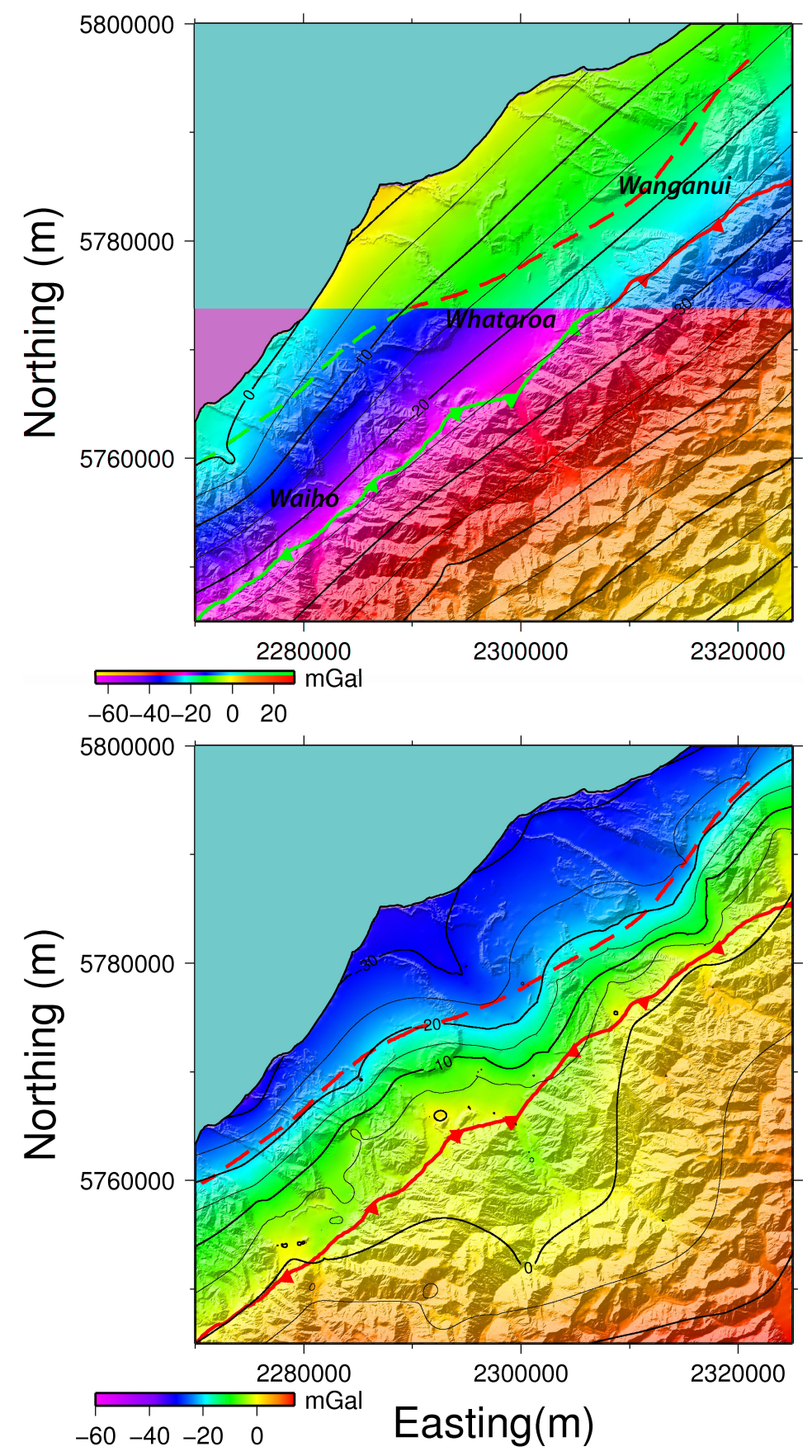

Figure 3.23: Residual gravity map of the central West Coast. This is the result of removing the modelled regional field from the dataset. 
regional gravity trend. The dataset which is regionally corrected using this detailed model can now be used for the modelling of smaller and more localised features such as the South Westland Basin and erosional features of interest. 


\section{Chapter 4}

\section{Gravity modelling and interpretation}

The Bouguer and residual gravity anomaly fields described in the previous chapter are used to infer the subsurface structure of the West Coast.

\subsection{Gravity/geology map}

Figure 4.1 shows contours of the residual gravity field, superimposed over a geological map in order to highlight correlations between the residual gravity field and local geological features (Cox and Barrell, 2007a).

Several features of interest are evident:

- The dominant gradient in the residual gravity field runs NW-SE, perpendicular to the South Westland Fault, the southeastern bound of the South Westland Basin (Sircombe and Kamp, 1998; Davey, 2010). The residual anomaly field becomes increasingly negative to the northwest, where the South Westland Basin has been mapped by previous studies (Nathan et al., 1986; Sircombe and Kamp, 1998).

- Elongation of the residual gravity field toward the Alpine valleys is the result of glacial and fluvial processes eroding channels in the base- 
ment rock and sedimentary layers of the onshore South Westland Basin (Korup et al., 2005).

- Small lobes of positive residual gravity are present in both the Whataroa and Waiho flood plains near the mapped locations of granitic intrusions (Cox and Barrell, 2007a). The likely cause for these lobes of positive residual anomaly is the positive density contrast between granite and basement and/or sediments.

- The 0 mGal contour extends southeast up the Whataroa river valley, with the contour broadly mimicking the shape of the river valley. The lack of readings north and south of the valley will, with gridding, broaden what may have been a more valley-focused anomaly. At the coast the $-30 \mathrm{mGal}$ contour is strongly elongated southeast. The same contour extensions are not observed in either the Wanganui or Waiho valleys. This raises the question of whether the Whataroa area is exposed to increased erosion or whether the contour elongations are a result of mis-fit in the regional gravity model.

- The residual gravity field changes most rapidly between the $-10 \mathrm{mGal}$ and $-20 \mathrm{mGal}$ contours, which lie southeast and sub-parallel to the mapped South Westland Fault. This supports the suggestion of Davey (2010) that the South Westland Fault is situated closer to the Alpine Fault than is inferred by GNS Science's Aoraki QMAP (Cox and Barrell, 2007a). Gravity changes rapidly over fault structure, with the maximum rate of change occurring over the centre of a fault structure. 


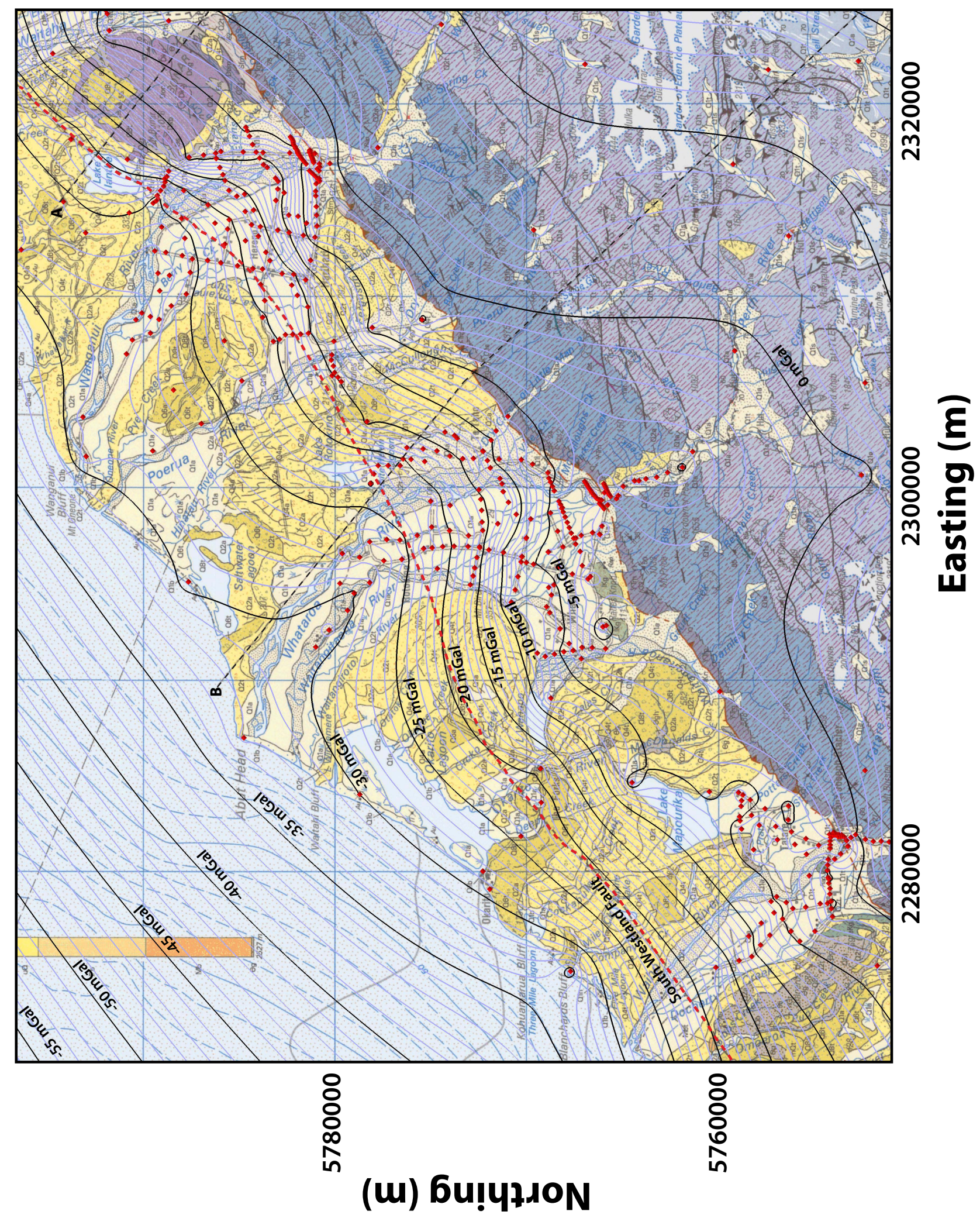

Figure 4.1: Contours of the residual gravity field are superimposed over the Aoraki QMAP in order to observe correlations between the residual gravity field and surface geology (Cox and Barrell, 2007a). The black dashed lines labelled A and B are geological cross-sections which can be seen in Figure 1.8, the red dashed line is the South Westland Fault and red diamonds are gravity observations. 


\subsection{Gravity gradient}

Gravity interpretation has been used for many years to research basin and fault structures. In more recent years derivatives of the gravity field have been used to supplement gravity analysis and interpretation (Bierlein, 2006). Significant geological features can be observed in a Bouguer gravity field by calculating the field's maximum directional derivative (Ben-Avraham et al., 1996). Plots of the field's maximum spatial derivative can highlight sharp changes in geological structure such as faulting which commonly causes rapid spatial changes in the gravity field (Ben-Avraham et al., 1996; Bierlein, 2006).

The maximum directional derivative of the Bouguer gravity anomaly field is calculated over the central West Coast to highlight fault structures additional to the Alpine Fault.

Figure 4.2 shows a plot of the maximum horizontal spatial gravity gradient over the central West Coast with the GNS Science's QMAP faults illustrated over top (Cox and Barrell, 2007a).

East of the Alpine Fault, there is a large amount of faulting which supports the idea that a significant amount of interplate motion is accommodated as deformation in the Southern Alps (Beavan et al., 1999; Sutherland et al., 2006; Boese et al., 2011).

Between 5-20 km west of the Alpine Fault there is a long, semi-continuous, linear high in the gravity gradient. This high is coincident with the South Westland Fault Zone bounding the southeastern flank of South Westland Basin (Sircombe and Kamp, 1998; Cox and Barrell, 2007a). South of the Hope Fault this high runs sub-parallel to the Alpine Fault, while north of the Hope Fault the linear high splits into two separate linear features. The first extends north-northeast parallel the coast, exhibiting a strong and continuous high in the gradient of the Bouguer gravity field and is coincident with the Kumara Fault (Cox and Barrell, 2007b). The second extends northeast parallel to the Alpine Fault for a short distance, but is not as continuous or well-defined, and is coincident with the Hohonu Fault (Cox and Barrell, 2007b). This split in the South Westland Fault Zone is mapped in GNS 


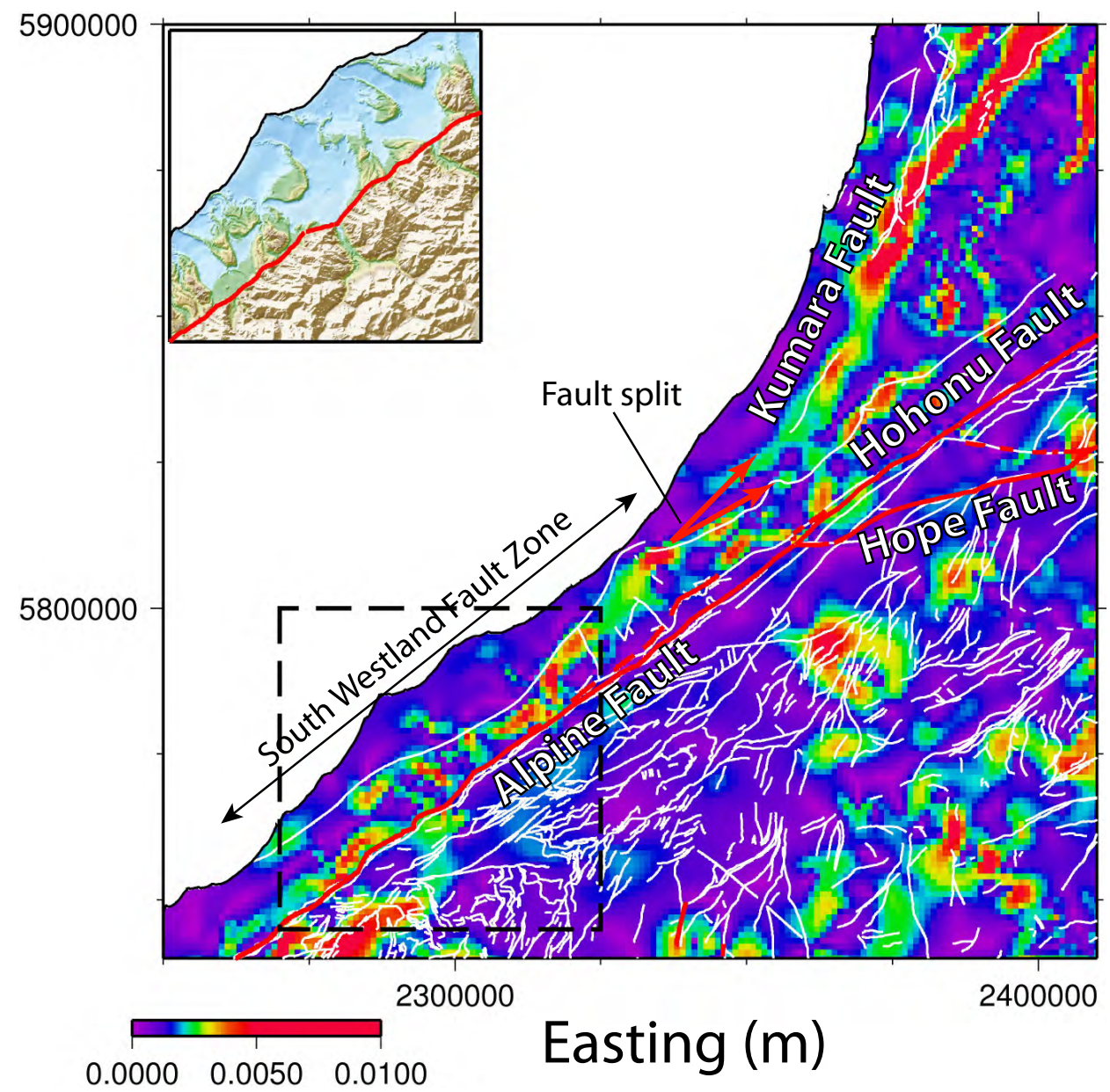

Figure 4.2: Maximum directional gradient plot of the central West Coast Bouguer gravity field, compiled from the data illustrated in Figure 3.21. Units are $\mathrm{mGal} / \mathrm{m}$. Red lines show the location of the Alpine Fault as well as the Hope Fault, which splays east from the Alpine Fault. White lines represent faults mapped in GNS Science's Aoraki and Greymouth QMAP series. The location of a possible split in the South Westland Fault Zone is indicated on the plot. The dashed box is the study area seen in Figure 4.1, and shown as the topography inset (top left). 
Science's QMAP series and is shown in Figure 1.7 (Cox and Barrell, 2007a; Sircombe and Kamp, 1998).

This fault structure identified in Figure 4.2 is consistent with the results of Kamp et al. (1992), discussed in Chapter 1.

Within the study area, the maximum linear gravity gradient is slightly southeast of the mapped South Westland Fault (Cox and Barrell, 2007a). This positioning could reveal information on the fault's orientation or could simply indicate that the South Westland Fault is closer to the Alpine Fault as stated by Davey (2010).

\subsection{Modelling}

In this section gravity profiles have been modelled partially as $2 \mathrm{D}, 21 / 2 \mathrm{D}$ and $23 / 4 \mathrm{D}$ models using Geosoft ${ }^{\circledR}$ GM-SYS v7.3. A description on the differences between the three modelling techniques can be found in Chapter 2 .

Rock densities used in the following models can be found in Table 1.3.

Uncertainties for the gravity observations used in these models are in the order of $\sim 0.1 \mathrm{mGal}$, which is insignificant compared with the size of the full gravity anomalies, and are omitted from the modelling.

\subsubsection{Fault-perpendicular models}

Gravity transects perpendicular to the Alpine Fault enable the forward modelling of regional gravity features including the South Westland Basin, the South Westland Fault, regional-scale erosion and the Alpine Fault.

Six fault-perpendicular transects are established over the three flood plains with four in the Whataroa flood plain and one in both the Wanganui and Waiho flood plains. Multiple gravity transects in the Whataroa flood plain enables variation parallel to the Alpine Fault to be examined. 


\section{Whataroa flood plain interpretations}

Figure 4.3 shows the gravity observations used to form the four fault-perpendicular transects in the Whataroa flood plain. Land access toward both the coast and Alpine Fault is limited, which has resulted in common gravity observations between the transects. Data points are projected onto best-fitting transects, which progress in the northeast direction in order to observe dextrally offset erosion.

The SIGHT gravity transect directly follows the SIGHT seismic line, making it the best-constrained gravity transect in this study. The initial dimensions for the gravity model are taken directly from the seismic model of Davey (2010) and were adjusted in order to fit the observed residual anomaly. The adjustments of the model dimensions are small and generally do not exceed $\pm 100 \mathrm{~m}$. A fourth layer was added to distinguish between the Pleistocene layer of the South Westland Basin and overlying Quaternary/fluvioglacial sediment. The SIGHT transect gravity model can be seen at the top of Figure 4.4. The out of plane extent along the y-axis is limited by basement rock in the river valley and $1 \mathrm{~km}$ northwest of the Alpine Fault, as indicated by red-dashed arrows in Figure 4.3 (y+ direction is southwest, y- direction is northeast). As this is the most constrained model it is used as the basis for the gravity models along all the remaining transects.

It is assumed that the difference in gravity between transects is due to dextrally offset subsurface erosional features which have been buried below Quaternary sediments. To satisfy the observed gravity anomalies along gravity transects 0, 1 and 2, the SIGHT transect gravity model is modified where gravity observations are non-common. The depth of the Quaternary sediment along the length of each gravity model is adjusted so that the modelled gravity anomalies fit with the observed residual gravity anomalies, minimising the fit error. The error in fit between the modelled and observed gravity is shown as a red line of misfit relative to a zero line (shown as a blue dashed line). 


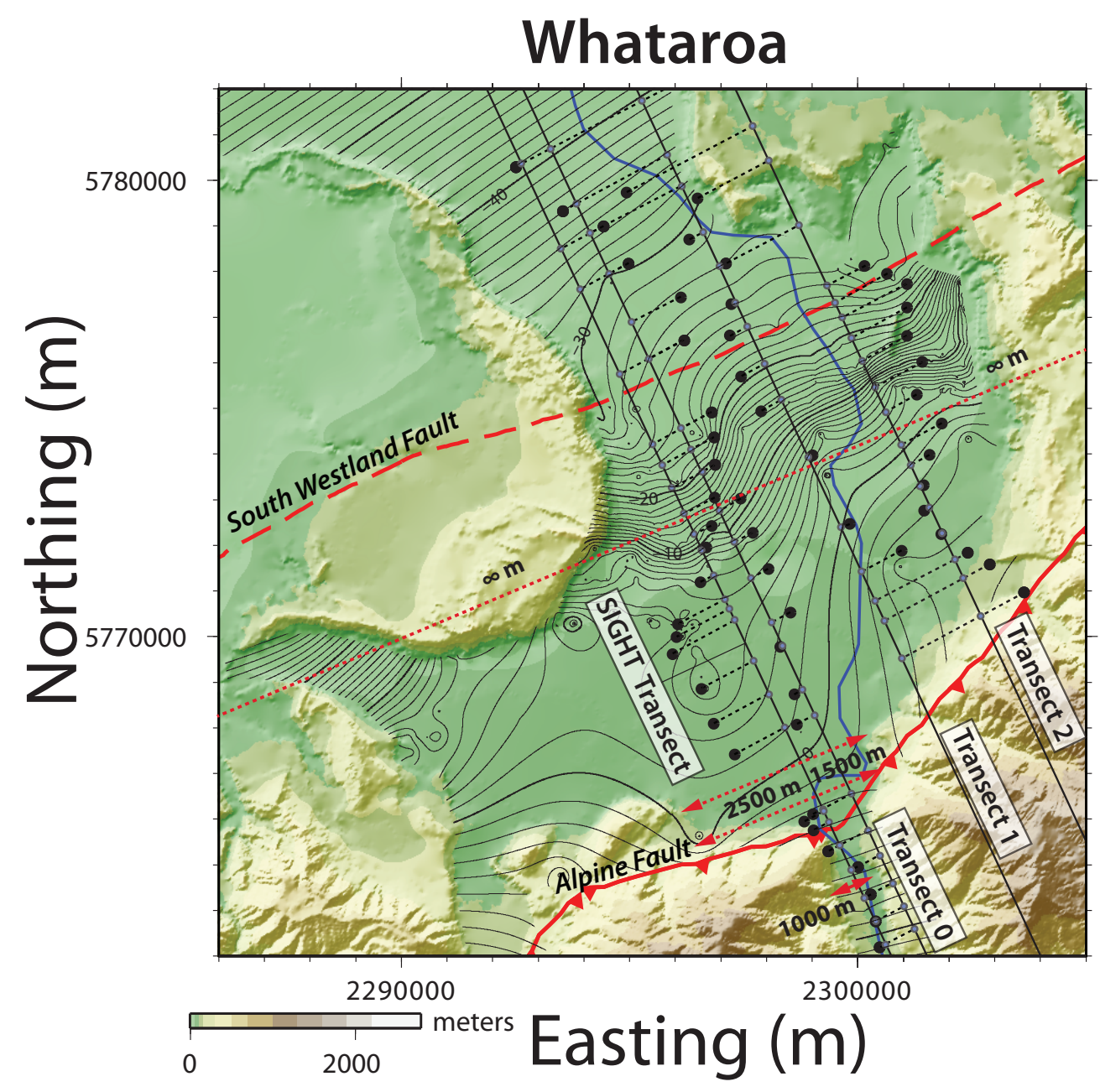

Figure 4.3: Four gravity transects in the Whataroa flood plain perpendicular to the Alpine Fault. Transects progress northeast to observe dextrally offset erosion. Neighbouring transects share common gravity observations toward the coast and the Alpine Fault. Black dashed lines and grey circles illustrate the projection of data onto the transects. The y-axis dimensions of the gravity models are shown as red dashed lines, with the $y+$ direction to the southwest and the y-direction to the northeast. 

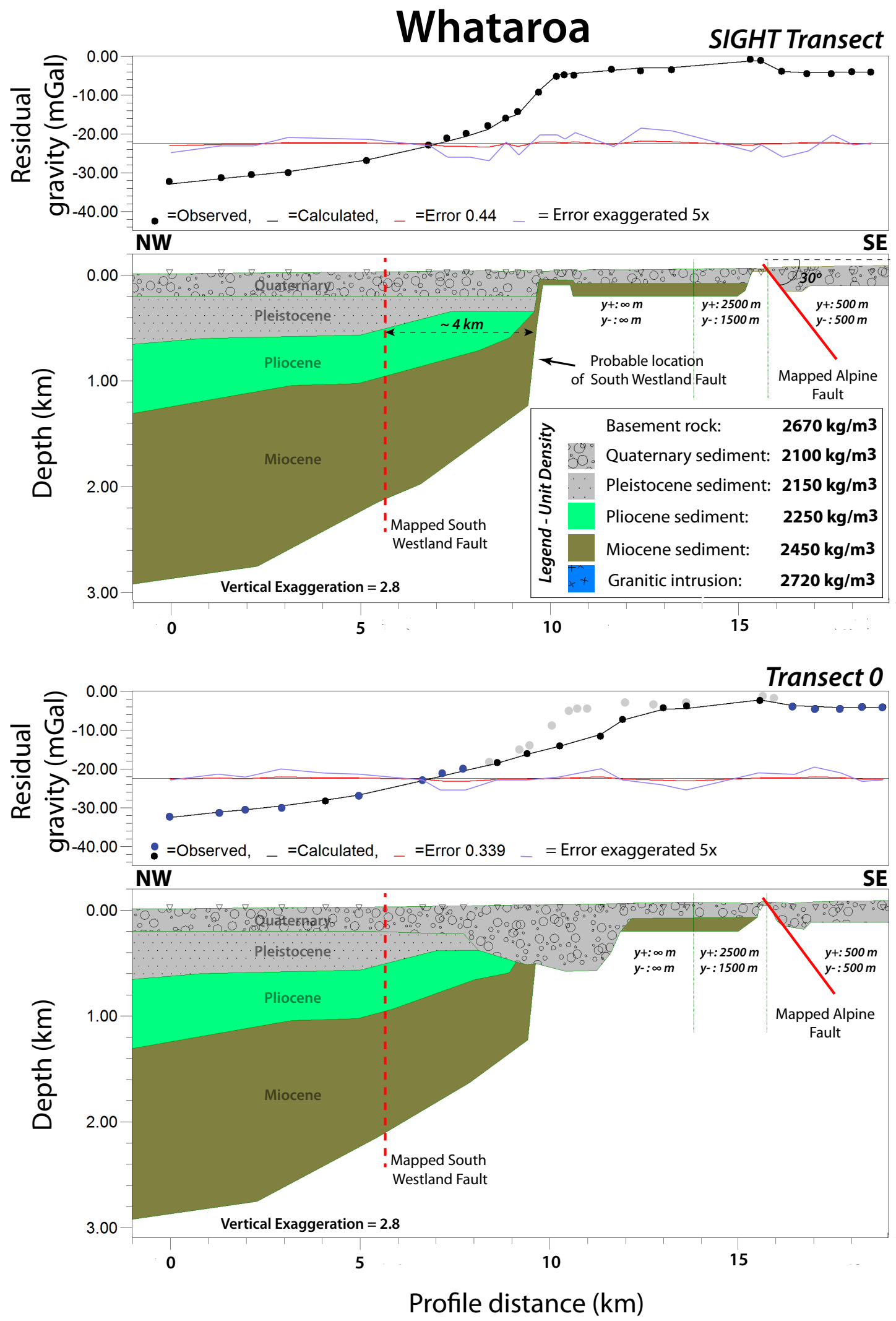

Figure 4.4: Forward gravity models in the Whataroa flood plain. The SIGHT gravity transect is above and gravity transect 0 is below. Black circles represent the observed residual gravity anomaly, the black line represents the modelled anomaly and the red line indicates the error between the two. Light grey circles show the gravity anomaly along the SIGHT transect relative to that observed along transect 0 , while blue observations are common between the two transects. The $\mathrm{y}+$ and $\mathrm{y}$ - distances show the y-axis limits of each model. 

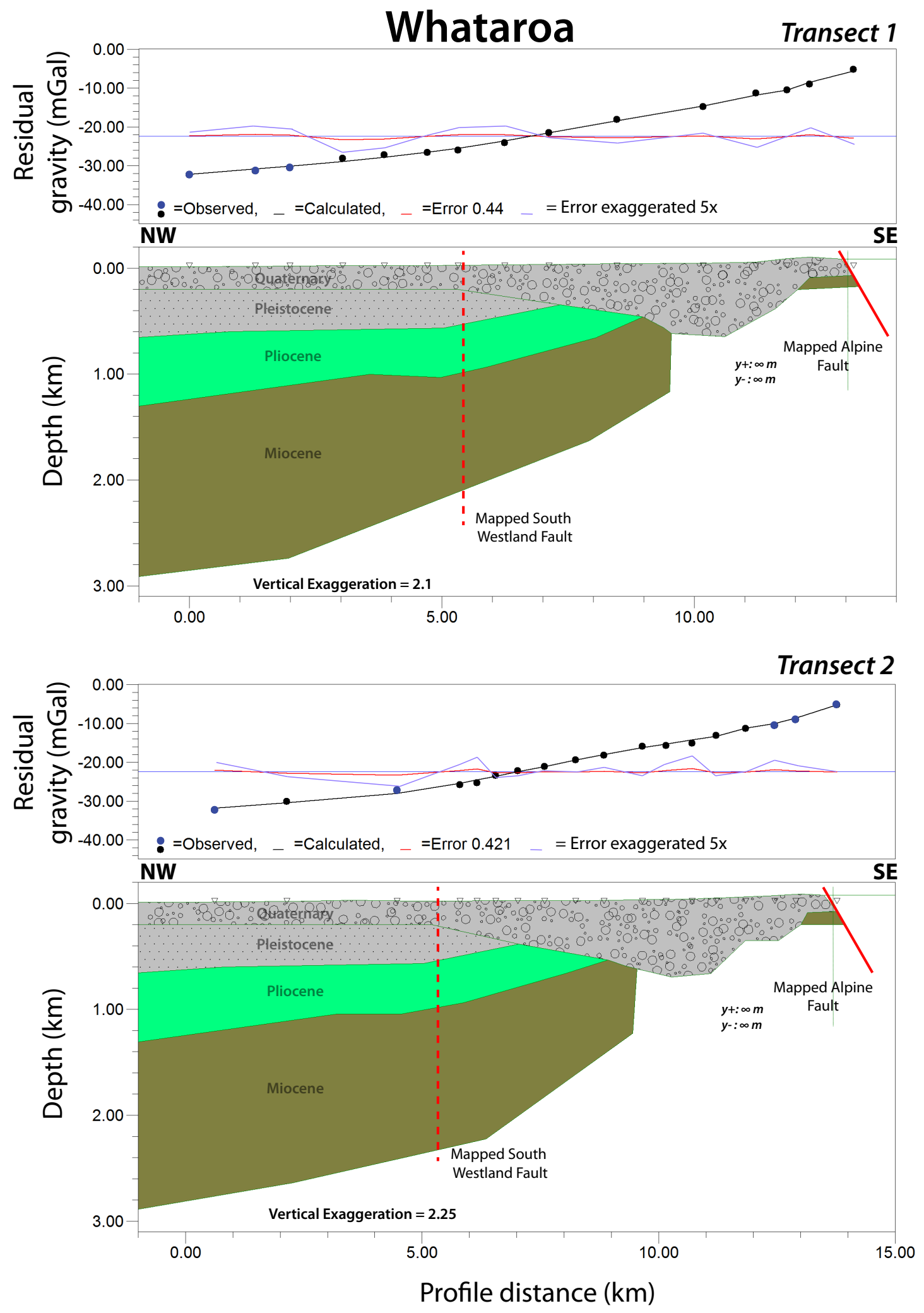

Figure 4.5: Forward gravity models in the Whataroa flood plain. Gravity transect 1 is above and gravity transect 2 is below. Black circles represent the observed residual gravity anomaly, the black line represents the modelled anomaly and the red line indicates the error between the two. Blue gravity observations are common with the previous transect. The $\mathrm{y}+$ and $\mathrm{y}$ - distances show the $\mathrm{y}$-axis limits of each model. 
Gravity models for fault perpendicular transects 0,1 and 2 can be seen in Figures 4.4 and 4.5. These gravity models show the interpreted appearance of a large erosional feature, infilled with Quaternary sediment, which lies across the modelled South Westland Fault. This interpreted size of this large erosional feature increases between transect 0 and transect 2 , with the width increasing from approximately $4.0 \mathrm{~km}$ to $6.5 \mathrm{~km}$ and depth from $0.6 \mathrm{~km}$ to 0.8 $\mathrm{km}$. The erosional feature is modelled as a 2D feature, extending the y-axis to infinity, as there are no pre-existing geological constraints. However, the erosional feature is likely to be of limited extent in the y-axis, which would likely result in a deeper erosional feature and a larger density contrast.

\section{Wanganui flood plain interpretations}

Figure 4.6 shows the gravity observations used to form the best-fit fault perpendicular transect in the Wanganui flood plain.

There are no existing geophysical models of the Wanganui flood plain subsurface; the basic structure for the fault perpendicular model is derived from the SIGHT transect gravity model.

The layer depths of the South Westland Basin are constrained by the stratigraphy of the Harihari-1 borehole in the Wanganui flood plain (location can be seen in Figure 4.6). The location of the South Westland Fault is modelled $\sim 3 \mathrm{~km}$ southeast of the mapped fault in order to fit the modelled anomaly to the observed residual anomaly. Evidence from the plot of the gravity fields' maximum directional derivative (Figure 4.2) supports the closer fault location. The structure of the South Westland Fault itself is modelled to match the structure in the SIGHT transect gravity model. Figure 4.7 shows the forward gravity model for the fault perpendicular gravity transect in the Wanganui flood plain. 


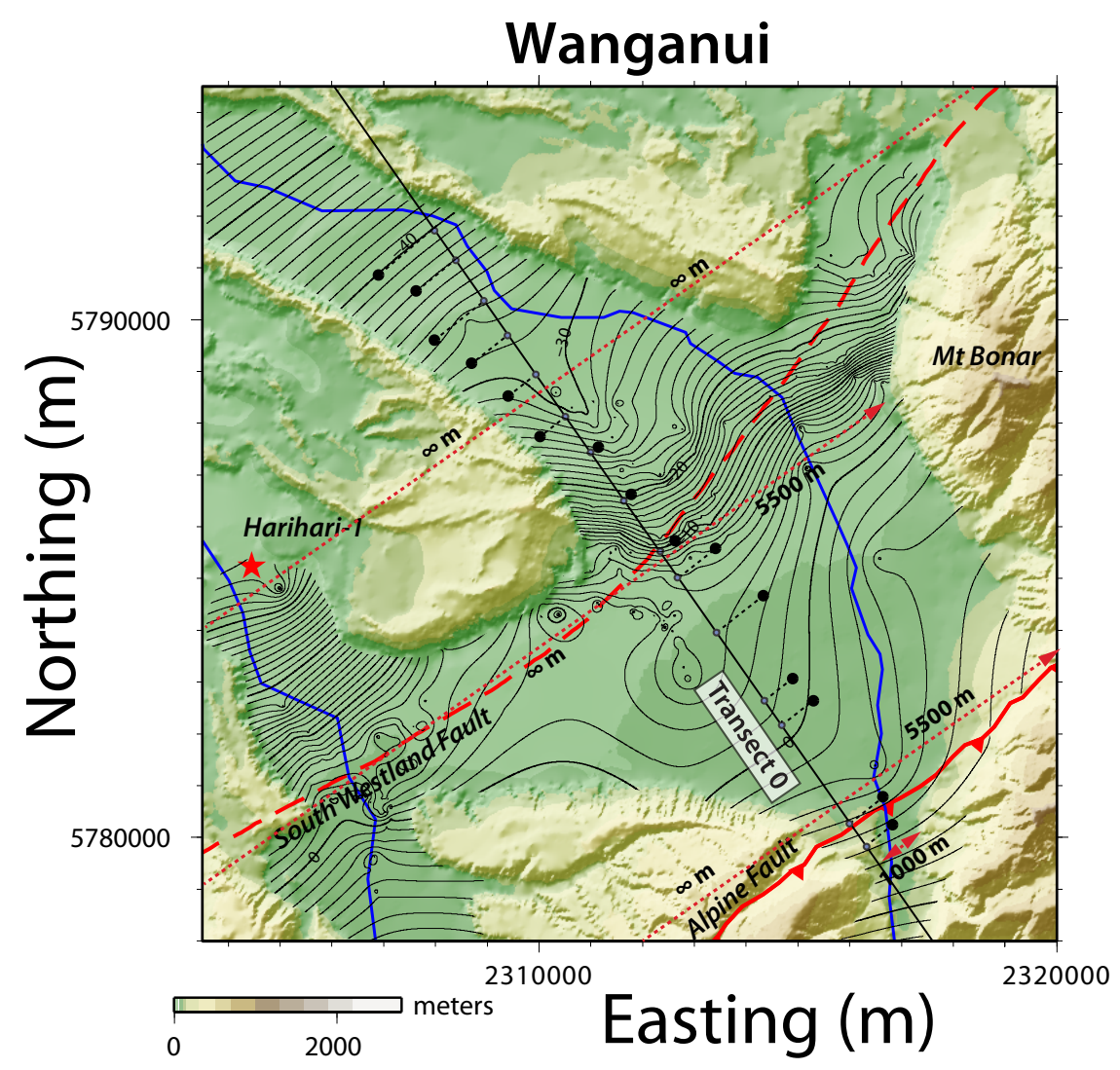

Figure 4.6: Gravity observations are projected onto a transect perpendicular to the Alpine Fault in the Wanganui flood plain. Black dashed lines and grey circles illustrate the projection of data onto the transect. The y-axis dimensions of the gravity model are shown as red dashed lines, with the $\mathrm{y}+$ direction to the southwest and the $\mathrm{y}$ direction to the northeast.

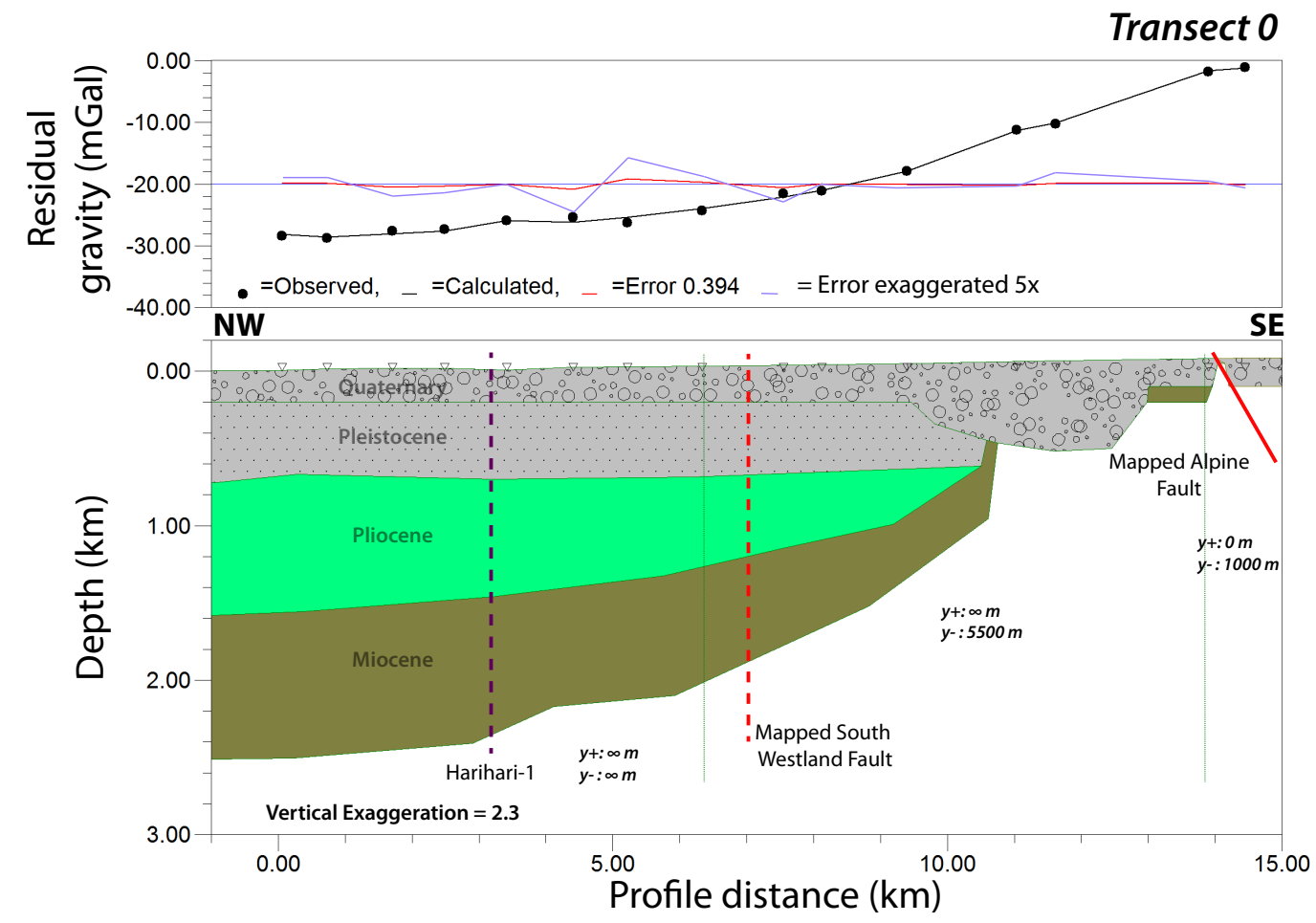

Figure 4.7: Forward gravity model of gravity transect 0 in the Wanganui flood plain. Black circles represent the observed residual gravity anomaly, the black line represents the modelled anomaly and the red line indicates the error between the two. The y+ and y-distances show the y-axis limits the model. 
The width of the model in the river valley is limited by basement rock 0 $\mathrm{m}$ in the $\mathrm{y}+$ direction (southwest) and $1000 \mathrm{~m}$ in the $\mathrm{y}$ - direction (northeast) in the river valley. Basement rock of Mt Bonar limits the model width to $5500 \mathrm{~m}$ in the $\mathrm{y}$ - direction (northeast) for $7.5 \mathrm{~km}$ northwest of the Alpine Fault.

The structure of the subsurface interpreted in this model is similar to the fault-perpendicular models in the Whataroa flood plain. As with the models from the Whataroa flood plain, a large low density body is interpreted to lie across the South Westland Fault. This low density body has an along profile length of $\sim 3 \mathrm{~km}$ and a depth extent of $\sim 0.6 \mathrm{~km}$.

\section{Waiho flood plain interpretations}

Figure 4.8 shows the projection of gravity observations onto the fault perpendicular transect in the Waiho flood plain.

Constraints in the Waiho flood plain are limited. The Waiho-1 borehole is situated on the coastline $\sim 6 \mathrm{~km}$ from the nearest gravity observation and the mapped location of the South Westland Fault is $2 \mathrm{~km}$ northwest of the gravity transect. The transect crosses an outcrop of granitic rock $\sim 2.5 \mathrm{~km}$ northwest of the Alpine Fault, the depth dimensions of which is unknown.

The gravity model of this fault-perpendicular transect is seen in Figure 4.9. The basic model dimensions are based on the SIGHT transect gravity model. The South Westland Fault is modelled at the northwest extreme of the transect, $2 \mathrm{~km}$ southeast of the mapped fault trace. The width of the model in the flood plain is limited by basement rock $2500 \mathrm{~m}$ in the $\mathrm{y}+$ direction (southwest), while the granitic intrusion is modelled with a a width of $500 \mathrm{~m}$ in both the $\mathrm{y}+$ and $\mathrm{y}$ - direction. 


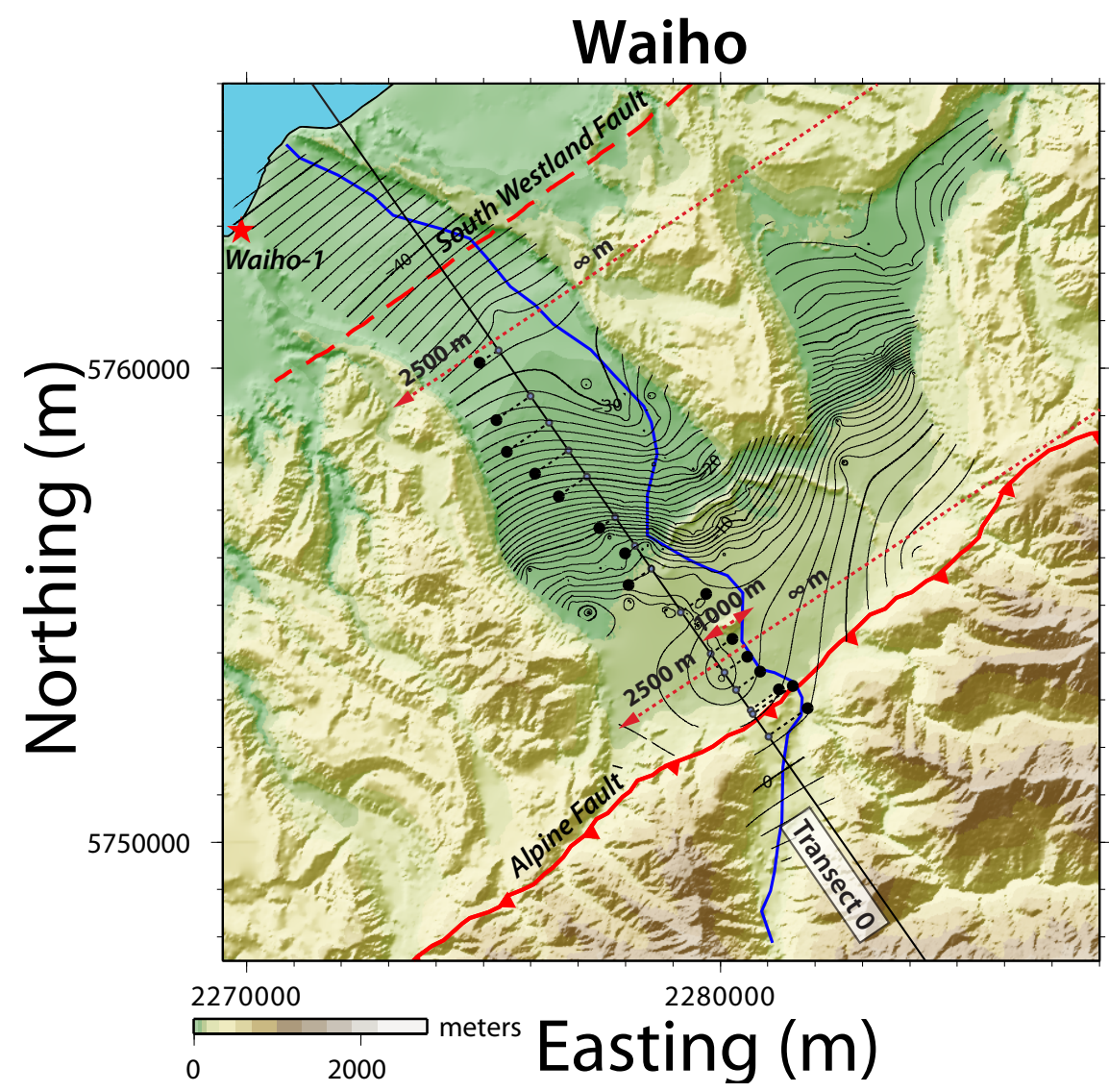

Figure 4.8: Gravity observations are projected onto a transect perpendicular to the Alpine Fault in the Waiho flood plain. Black dashed lines and grey circles illustrate the projection of data onto the transect. The y-axis dimensions of the gravity model are shown as red dashed lines, with the $\mathrm{y}+$ direction to the southwest and the $\mathrm{y}$ direction to the northeast.

Transect 0

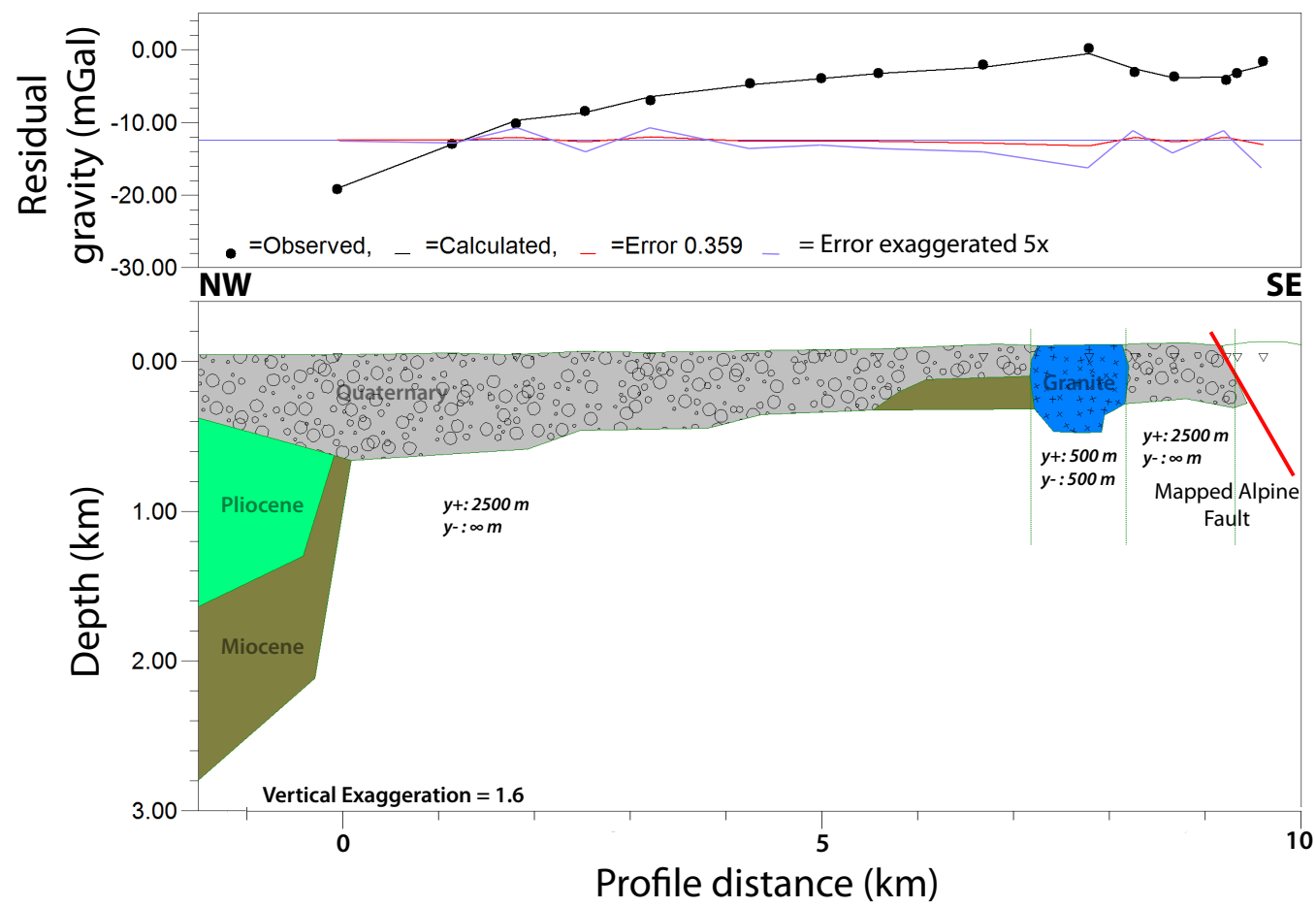

Figure 4.9: Forward gravity model of gravity transect 0 in the Waiho flood plain. Black circles represent the observed residual gravity anomaly, the black line represents the modelled anomaly and the red line indicates the error between the two. The y+ and $y$-distances show the y-axis limits of the model. 


\section{Common features of the fault-perpendicular models}

Common features between the fault-perpendicular gravity transects include:

- The modelled location of the South Westland Fault is consistently 2-4 $\mathrm{km}$ southeast of the mapped fault location.

- Layer depths and dimensions of the South Westland Basin are taken from the Harihari-1 and Waiho-1 boreholes as well as the seismic model of Davey (2010).

- A dip of $30^{\circ}$ southeast on the Alpine Fault is modelled along each transect. This dip is assumed and consistent with previous studies of the Alpine Fault (Davey et al., 1995).

- The modelled low-density features increase in size as the transects progress to the northeast, indicative of dextral offset.

- The large low-density features are consistently situated across the modelled South Westland Fault in each flood plain.

The nature of the South Westland Fault is discussed in detail in Chapter 6.

\subsubsection{Fault-parallel/oblique models}

Gravity profiles oriented parallel to the Alpine Fault aim to resolve the pattern of subsurface erosion in each flood plain. Modelling of fault-parallel gravity profiles provide cross-sections of the erosional channels and should reveal dextral offset consistent with the offset of erosion seen in the faultperpendicular gravity transects.

Constraints for the fault-parallel models are limited and require the faultperpendicular gravity models to act as depth constraints. General channel location and direction can be loosely inferred from the polynomial residual gravity maps determined in Chapter 3 (Figures 3.14, 3.15 and 3.16). 


\section{Whataroa flood plain interpretations}

Three gravity profiles in the Whataroa flood plain are seen in Figure 4.10. Line 1 is oblique to the Alpine Fault and strikes $103^{\circ}$, while line 2 and 3 strike $55^{\circ}$ which is parallel to the overall trace of the Alpine Fault, although the fault trace in the Whataroa area contains an obvious fault jog. Line 2 and line 3 are $5.0 \mathrm{~km}$ and $1.5 \mathrm{~km}$ northwest of the Alpine Fault, respectively. Gravity models for lines 1, 2 and 3 are seen in Figure 4.11 and 4.12.

All three models are limited in the $\mathrm{y}+$ (south/southeast) direction by basement rock of the Southern Alps mountain range.

Line 1 obliquely crosses the modelled location of the South Westland Fault, which can be seen in the gravity model (Figure 4.11) as the introduction of South Westland Basin layers. Three erosional channels filled with Quaternary sediments are modelled east of the South Westland Basin. From west to east these three channels reach depths of $800 \mathrm{~m}, 880 \mathrm{~m}$ and $500 \mathrm{~m}$.

The same three erosion channels are modelled east of the SIGHT transect in the gravity model of line 2, reaching depths of $440 \mathrm{~m}, 700 \mathrm{~m}$ and $500 \mathrm{~m}$ respectively. Two channels with depths of $\sim 370 \mathrm{~m}$ are also present west of the SIGHT transect and appear to be correlated to the topography and location of Lake Wahapo and the Waitangitoana River.

The gravity model of line 3 shows little channel structure, with one channel reaching a depth of $350 \mathrm{~m}$ at the western extreme of the profile. A granitic rock intrusion is modelled at the western end of the gravity model. The granite outcrops at the surface and is mapped by GNS Science's Aoraki QMAP (Cox and Barrell, 2007a). 


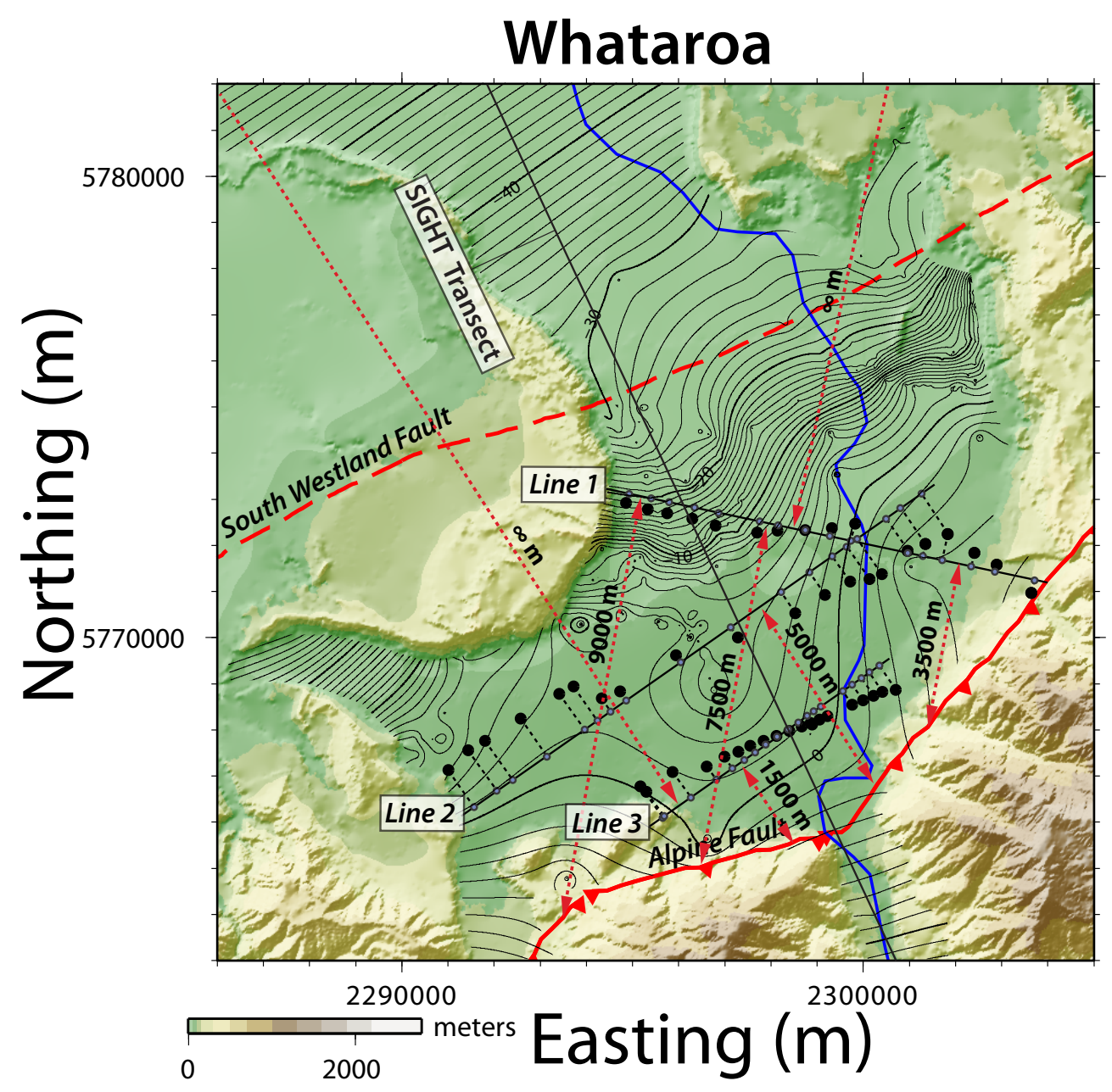

Figure 4.10: The projection of gravity observation onto three profiles oriented both parallel and oblique to the Alpine Fault. Black dashed lines and grey circles illustrate the projection of data onto the transects. The y-axis dimensions of the gravity models are shown as red dashed lines, with the $\mathrm{y}+$ direction to the south and the $y$ - direction to the north. 

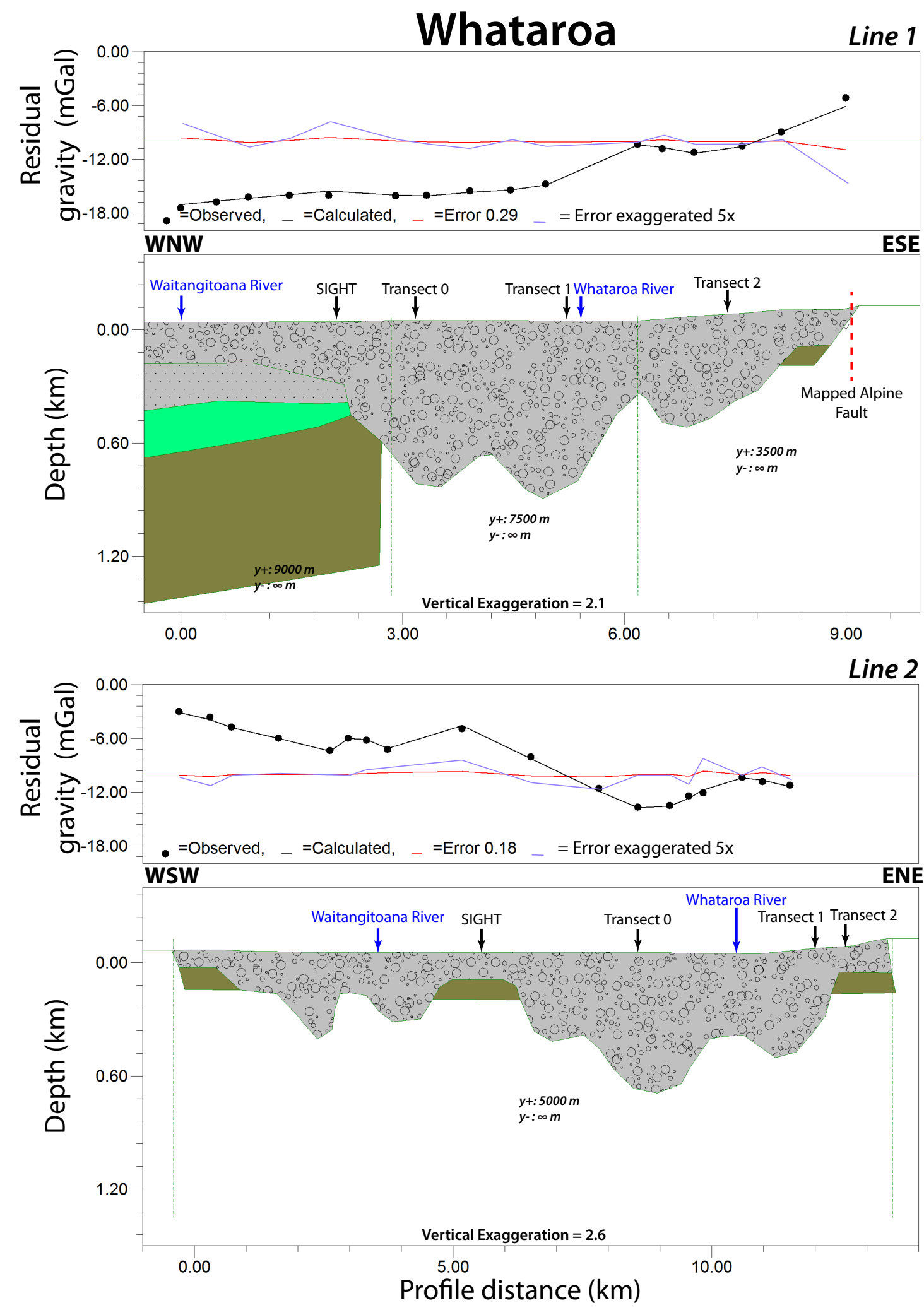

Figure 4.11: Forward gravity models of line 1 above and line 2 below. Black circles represent the observed residual gravity anomaly, the black line represents the modelled anomaly and the red line indicates the error between the two. The intersect location of rivers and fault-perpendicular gravity transects are indicated on the surface of the gravity models. The $\mathrm{y}+$ and $\mathrm{y}$ - distances show the $\mathrm{y}$-axis limits of each model. 


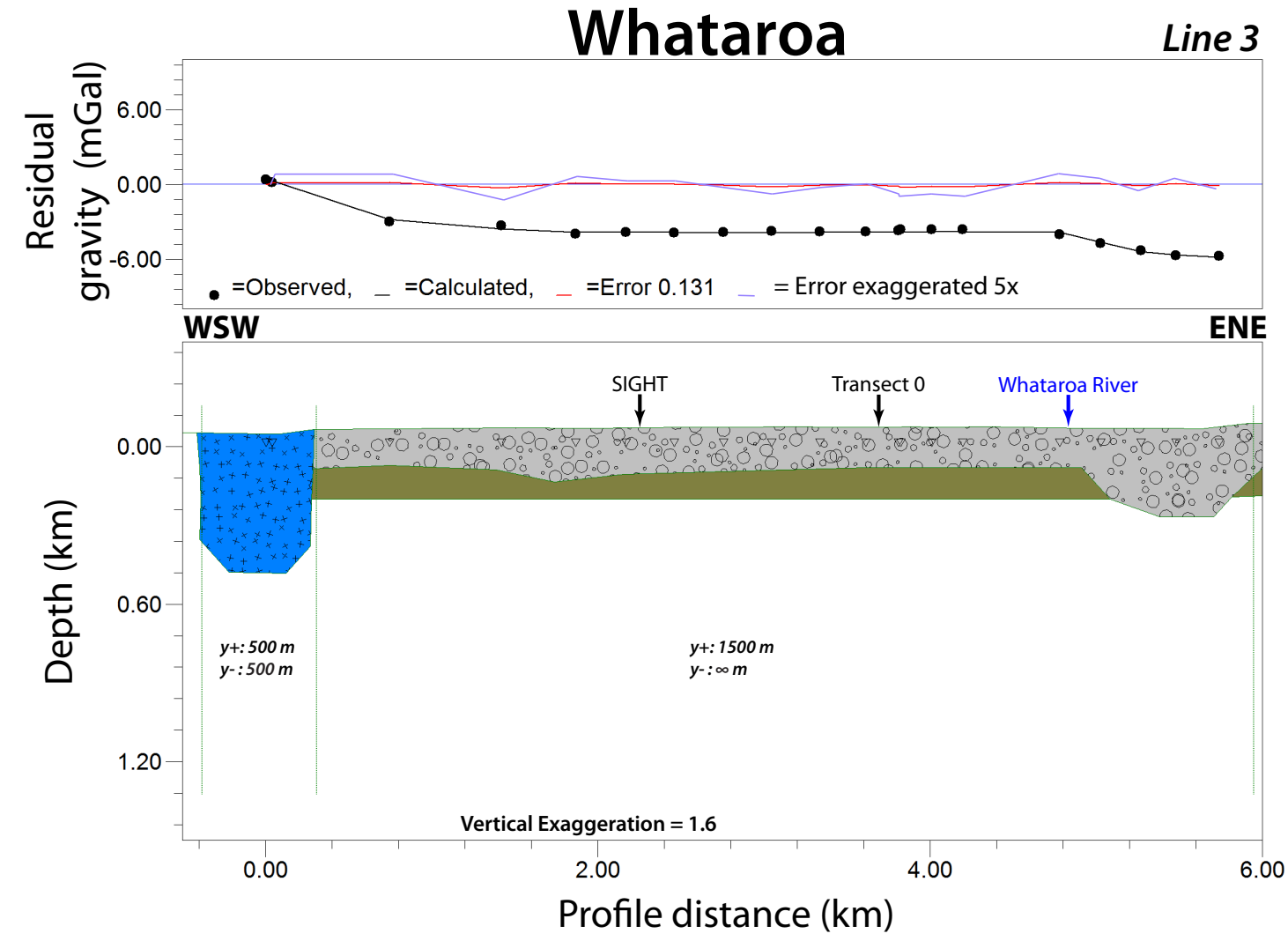

Figure 4.12: Forward gravity model of line 3. Black circles represent the observed residual gravity anomaly, the black line represents the modelled anomaly and the red line indicates the error between the two. The intersect location of rivers and faultperpendicular gravity transects are indicated on the surface of the gravity models. The $\mathrm{y}+$ and $\mathrm{y}$ - distances show the $\mathrm{y}$-axis limits of the model. 


\section{Wanganui flood plain interpretations}

Two fault-parallel gravity profiles striking $55^{\circ}$ are established across the Wanganui flood plain and can be seen in Figure 4.13. Line 1 and line 2 are situated $\sim 5.0 \mathrm{~km}$ and $\sim 2.5 \mathrm{~km}$ northwest of the Alpine Fault respectively. Gravity models of these profiles can be seen in Figure 4.14. The two models are limited in the $\mathrm{y}+$ (southeast) direction by basement rock of the Southern Alps mountain range, while the layers of the South Westland Basin in the model of line 1 are constrained in the $\mathrm{y}+$ direction by the fault-perpendicular model.

Line 1 crosses the modelled location of the South Westland Fault, similar to how line 1 in the Whataroa flood plain does. Layer structure of the South Westland Basin is modelled between $0 \mathrm{~km}$ and $7 \mathrm{~km}$ along the profile. Three erosional channels are modelled in the basement rock and sedimentary layers of the South Westland Basin. From west to east these channels have depths of $760 \mathrm{~m}, 680 \mathrm{~m}$ and $880 \mathrm{~m}$.

In the gravity model of line 2 , three pronounced channels are modelled and reach depths of $720 \mathrm{~m}, 840 \mathrm{~m}$ and $750 \mathrm{~m}$ from west to east. Line 2 is situated closer to the Alpine Fault and does not cross the modelled South Westland Fault, with the gravity model exhibiting a single density contrast between the Quaternary sediment and basement rock. 


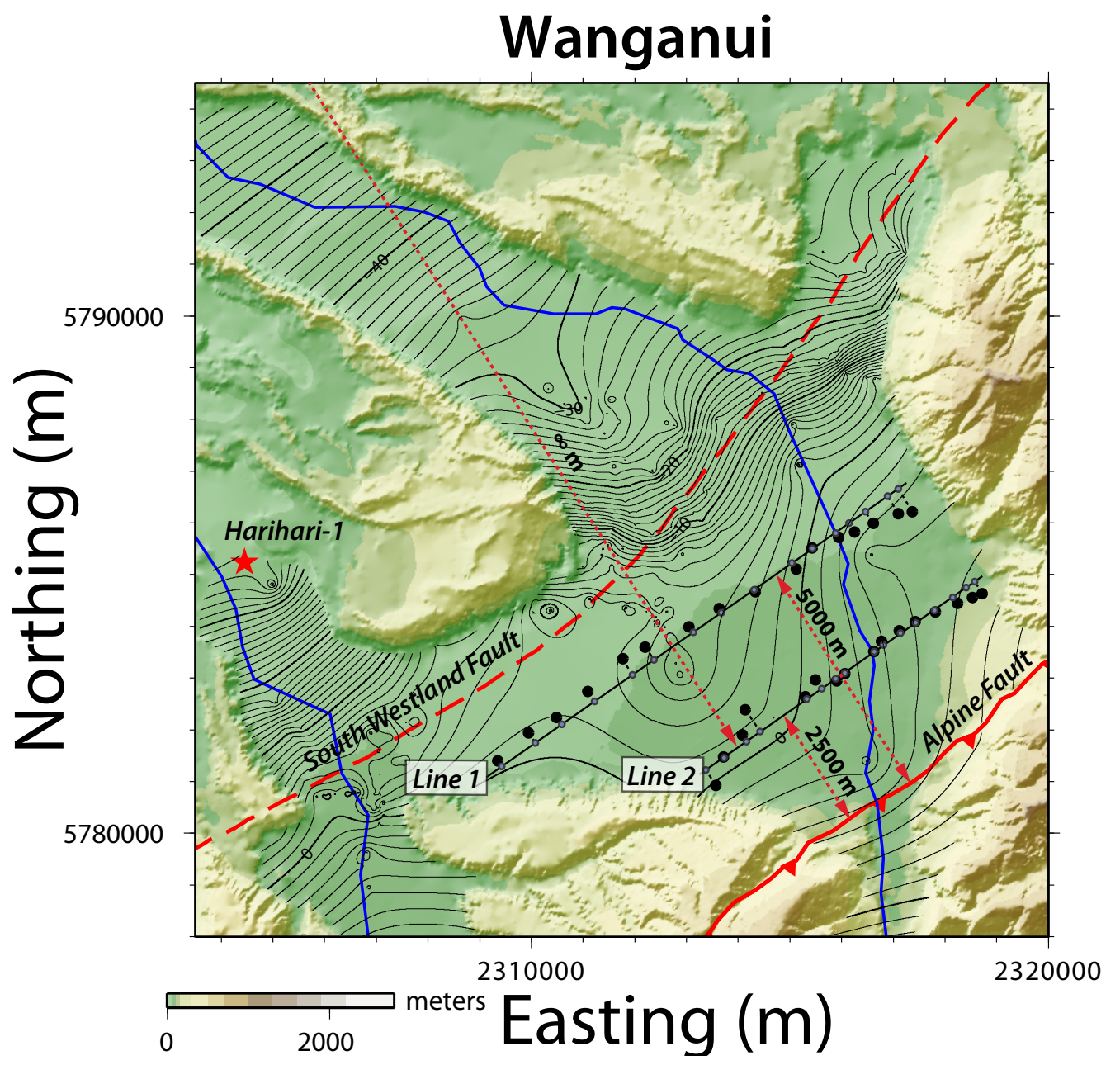

Figure 4.13: The projection of gravity observations onto two profiles oriented parallel to the Alpine Fault. Black dashed lines and grey circles illustrate the projection of data onto the transects. The y-axis dimensions of the gravity models are shown as red dashed lines, with the $\mathrm{y}+$ direction to the south and the $y$ - direction to the north. 

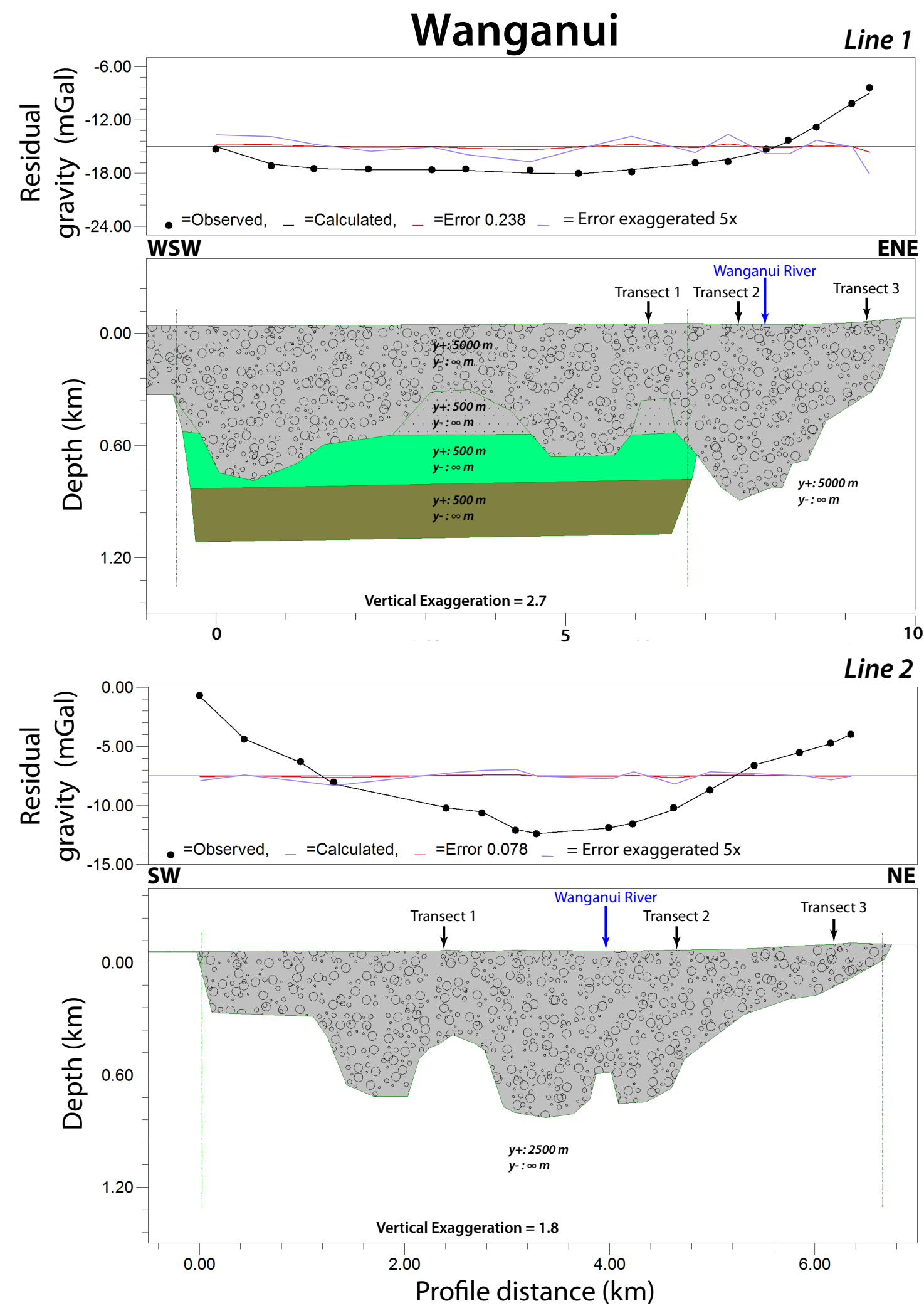

Figure 4.14: Forward gravity models of line 1 above and line 2 below. Black circles represent the observed residual gravity anomaly, the black line represents the modelled anomaly and the red line indicates the error between the two. The intersect location of rivers and fault-perpendicular gravity transects are indicated on the surface of the gravity models. The $\mathrm{y}+$ and $\mathrm{y}$ - distances show the $\mathrm{y}$-axis limits of each model. 


\section{Waiho flood plain interpretations}

A single fault-oblique gravity profile is established in the Waiho flood plain. The profile strikes $90^{\circ}$ and can be seen in Figure 4.15.

The model for this gravity profile is seen in Figure 4.16 and is constrained by only the fault-perpendicular gravity model and the location of a granitic outcrop mapped by GNS Science's Aoraki QMAP (Cox and Barrell, 2007a). It is assumed that variation in the residual gravity along the profile is due to sediment filled structure.

Several erosional channels are modelled along the profile as well as the same granitic intrusion that is seen along the fault perpendicular model in the Waiho. The general depth of the Quaternary sediment along the profile is $\sim 200 \mathrm{~m}$ reaching depths of $\sim 350 \mathrm{~m}$ in the channels. The $\mathrm{y}+$ and $\mathrm{y}-$ limit of the granitic body is limited to $500 \mathrm{~m}$ in each direction, consistent with the width of the same granite body in the fault perpendicular model. The model is limited in the $\mathrm{y}+$ (south) direction by basement rock of the Southern Alps mountain range. 


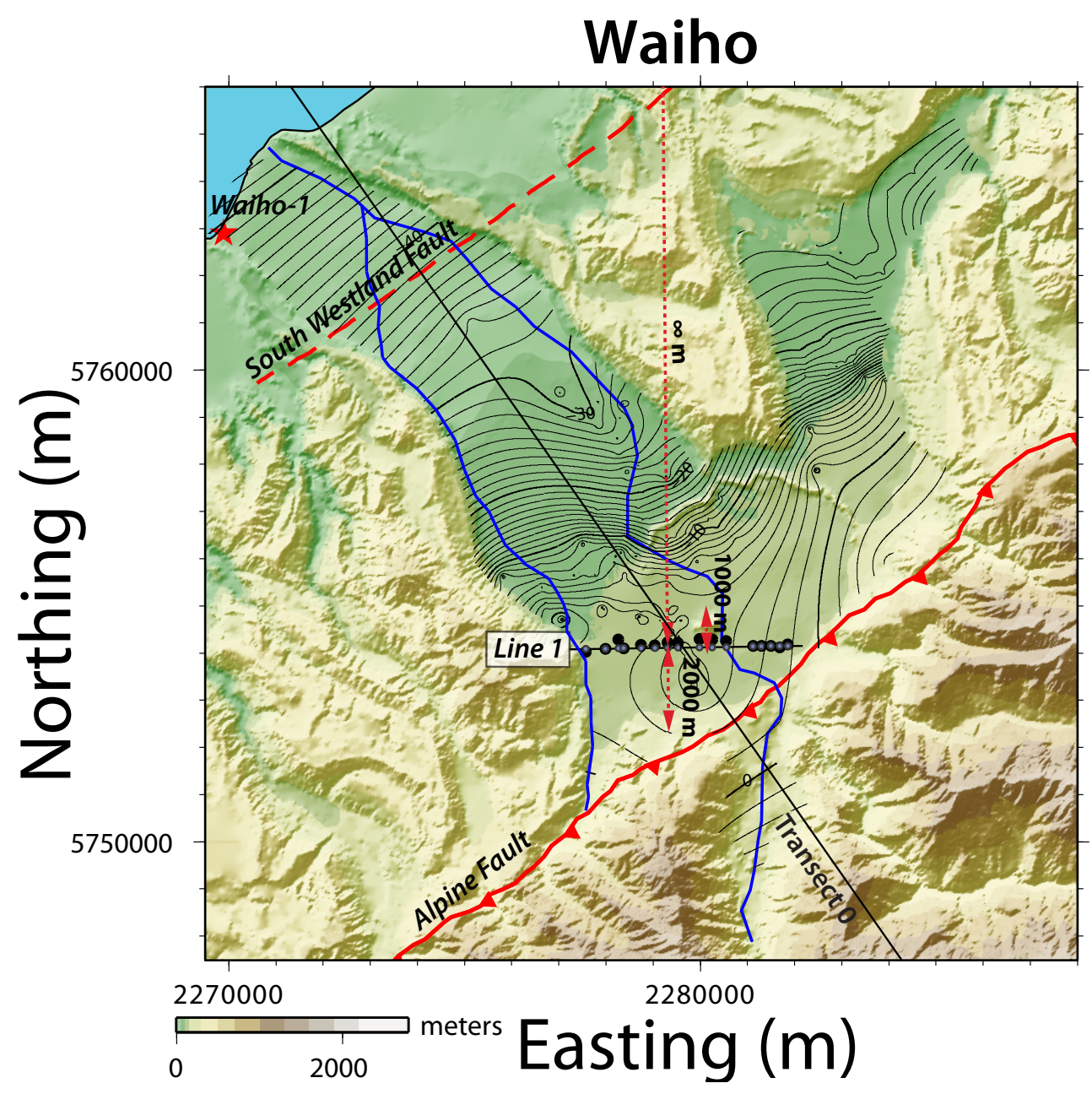

Figure 4.15: The projection of gravity observations onto a fault-oblique profile. Black dashed lines and grey circles illustrate the projection of data onto the transects. The y-axis dimensions of the gravity models are shown as red dashed lines, with the $\mathrm{y}+$ direction to the south and the $\mathrm{y}$ - direction to the north. 


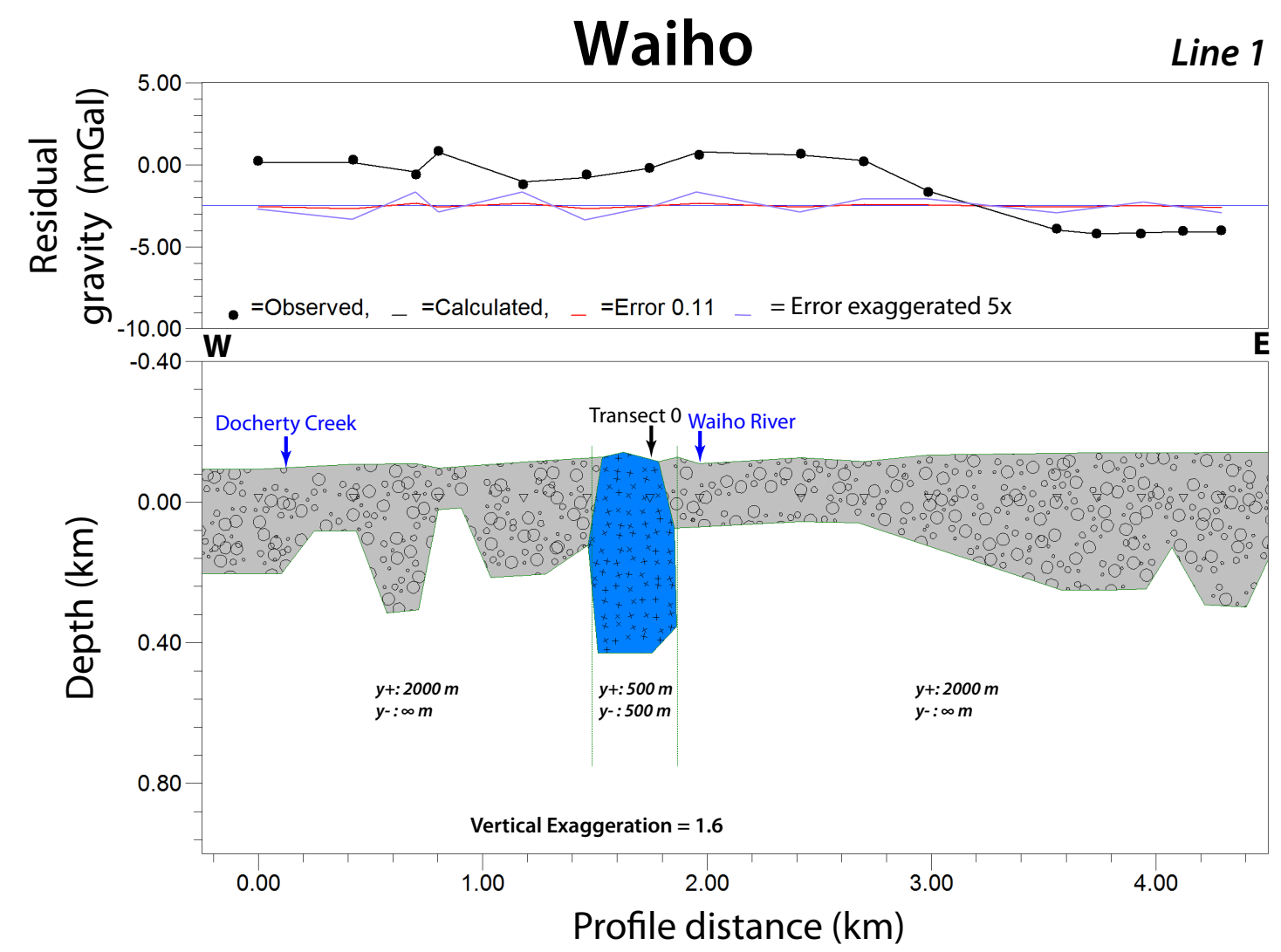

Figure 4.16: Forward gravity models of line 1. Black circles represent the observed residual gravity anomaly, the black line represents the modelled anomaly and the red line indicates the error between the two. The intersect location of rivers and faultperpendicular gravity transects are indicated on the surface of the gravity models. The $\mathrm{y}+$ and $\mathrm{y}$ - distances show the $\mathrm{y}$-axis limits of the model. 


\section{Common features of the fault-parallel models}

Common features between the fault-perpendicular gravity transects include:

- Lines $>1.5 \mathrm{~km}$ northwest of the Alpine Fault show the presence of three or more U-shaped channels formed through glacial erosion.

- These glacial channels become significantly deeper and wider within the area $6.0 \mathrm{~km}$ southeast of the South Westland Basin.

- Surface topography conforms strongly with the modelled locations of buried channel structures. Buried glacial channels are situated in areas of low topography, which is expected given the surrounding elevated surface topography is comprised of glacial moraines deposited by glacial advance (Almond et al., 2001).

- The modelled location of the central glacial channels, which extend to the coast, are dextrally offset from the hanging wall river valleys. As the rivers cross the fault they preferentially follow these sediment filled channels. 


\section{Chapter 5}

\section{Offset and slip rates}

\subsection{Offset on the Alpine Fault and slip rates}

Harold Wellman was the first person to observe offset on the Alpine Fault in 1948, measuring a $\sim 480 \mathrm{~km}$ dextral offset of the Dun Mountain Ophiolite Belt across the Alpine Fault (Nathan, 2005, see Figure 5.1). Since this discovery there have been many studies into the offset and rate of movement along the Alpine Fault and how it has evolved through time (Norris and Cooper, 2007). Understanding the past and present displacement rates along the fault is important for understanding the fault's evolution through time, as well as its present day kinematics and earthquake potential (Sutherland et al., 2006).

In order to determine the strike-slip movement rate of a fault, an observable offset feature and the time since its formation is required. The rate of movement is simply:

$$
\text { Slip rate }=\frac{\text { Offset }}{\text { Time }}
$$

A slip rate represents an average rate of movement over the time since the formation of an observed feature. Quaternary slip rates are determined for features formed within the last $\sim 2.5$ Ma. Quaternary strike-slip rates have been determined along the length of the Alpine Fault using the offset of various Quaternary surface features (Norris and Cooper, 2001). Typically 


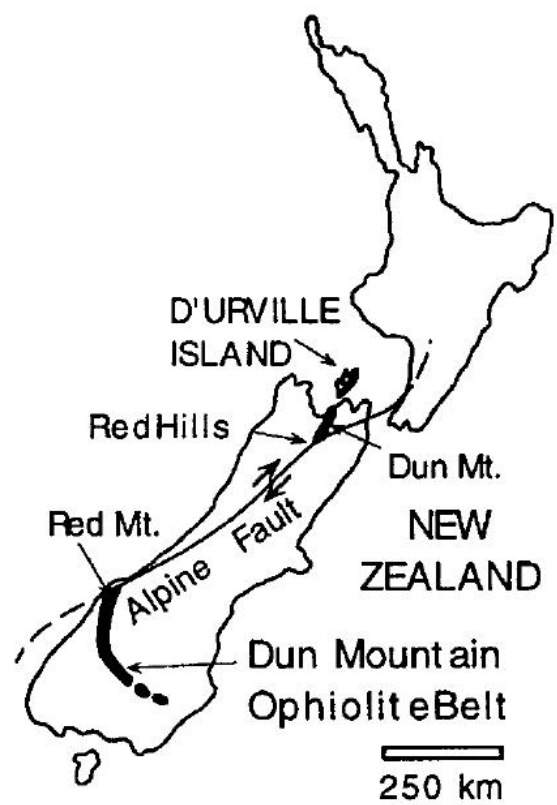

Figure 5.1: The observed dextral offset of the Dun Mountain Ophiolite Belt across the Alpine Fault. Figure from Sivell and McCulloch (2000)

the surface features used to determine Quaternary offsets along the Alpine Fault include:

- Offset glacial moraines.

- Offset river channels and terraces.

- Offset glacial valley walls.

Norris and Cooper (2007) compiled and recalculated both strike-slip and dip-slip rates from published research dating back to 1990. A significant number of these rates were determined using the offset of glacial features formed during the last glacial maximum, known as the Otira Glaciation, which culminated $\sim 19 \mathrm{ka}$ (Suggate and Almond, 2005). The southern onshore fault section, south of the Haast River, has offsets of $400 \pm 100 \mathrm{~m}$ since the Otira Glaciation (Sutherland, 1995b). An overview of the collated Quaternary strike-slip rates along the fault can be seen in Figure 1.5. 
One limitation of using the offset of surface features to determine a fault's strike-slip offset and movement rate is that in areas of high erosion, offset features at the surface can be erased. With little or no offset surface features in a given area, it is difficult to obtain well constrained slip rates using traditional geological methods. Such is the case in areas of the central Alpine Fault. With rainfall in the order of $\sim 15 \mathrm{~m} / \mathrm{yr}$, glacial surface features have been significantly eroded or erased completely (Henderson and Thompson, 1999). This has resulted in a lack of well constrained slip-rates for the central section of the Alpine Fault (Norris and Cooper, 2007; Sutherland et al., 2006).

\subsection{Offset estimates from gravity and topog- raphy}

Instead of relying on the offset of surface features it is conceptually possible to use geophysical means to quantify offset, using displaced subsurface features.

Channel structures below the central West Coast flood plains have formed as a result of glacial erosion and are observed in the gravity data collected, processed and presented in the previous chapters. It is possible to use the gravity anomalies of these buried channels to detect and quantify the dextral channel offset within each flood plain.

In order to quantify the offset of buried glacial channels, the following needs to be determined:

- Where these buried glacial channels are currently situated below the flood plains.

- Where the glaciers responsible for carving these channels were located at the time of their formation.

Figure 5.2 provides a schematic diagram of how the channel offset is found. 


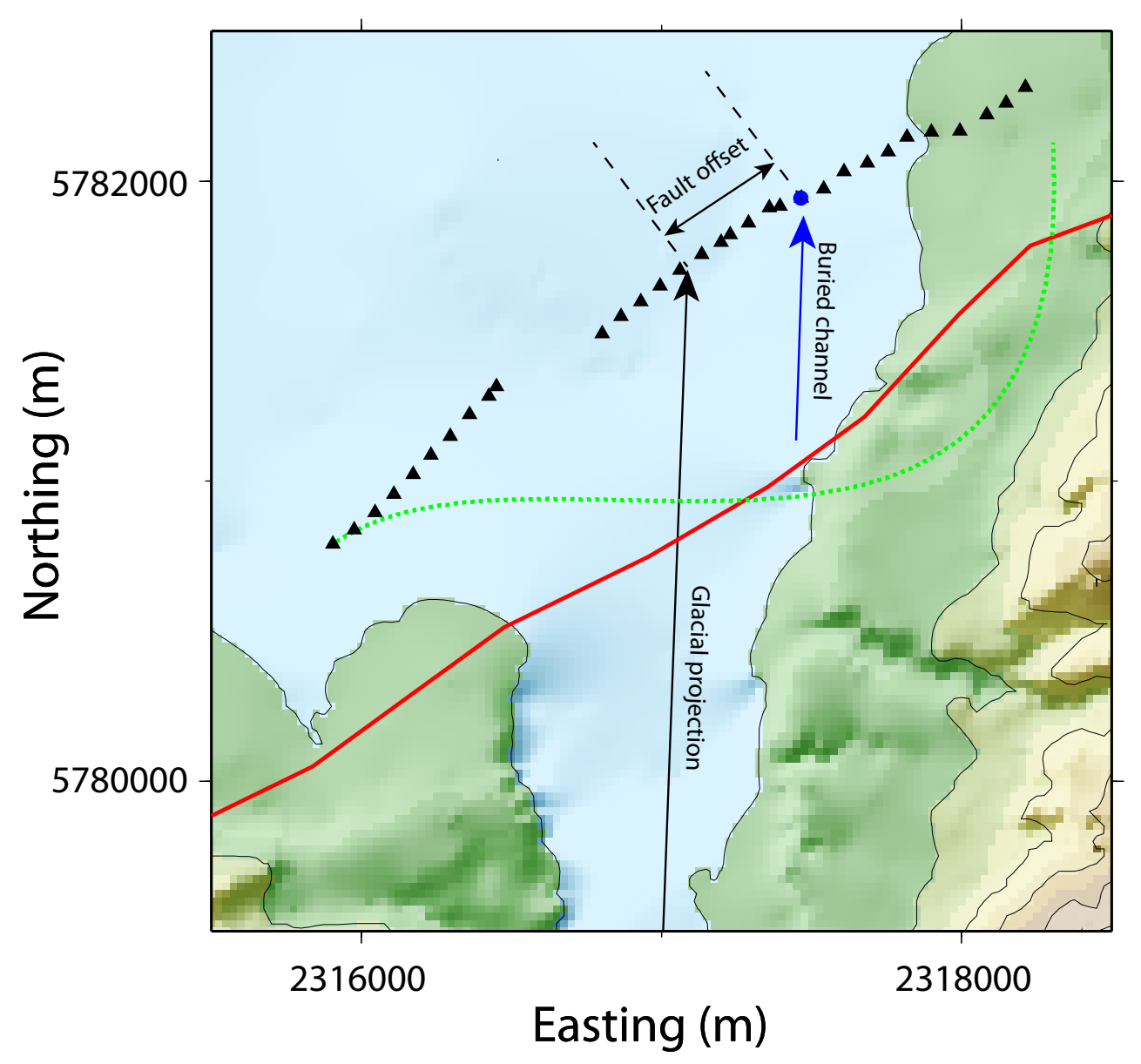

Figure 5.2: Overview of how channel offset is determined by projecting past glacial trajectory onto the closely spaced gravity profile. Black triangles are gravity observations of the closely spaced transect; the green dashed line represents the residual gravity anomaly along the closely spaced transect; the blue circle represents the location of the gravity minimum along the transect. 


\subsubsection{Glacial channel location}

\section{Gravity transects}

Closely spaced gravity transects with an average spacing of $80 \mathrm{~m}$ were measured parallel to the trace of the Alpine Fault. To obtain the best representation of the true channel offset, these gravity transects were situated in close proximity to the Alpine Fault. These transects are much closer to the fault and shorter in length than the fault parallel transects in the previous chapter. These transects are looking to resolve the gravity signature of the most recently formed glacial channel and its' offset from the hanging wall glacial valley. Transects situated close to the fault will have a reduced error associated with the projection of past glacial trajectories. To ensure that these gravity transects covered the offset buried channels, the transects extended for distances $>1000 \mathrm{~m}$ northeast of the hanging wall valleys.

Closely spaced gravity transects for the purpose of determining channel offset were measured in the:

- Wanganui flood plain.

- Whataroa flood plain.

- Fox flood plain.

A closely spaced gravity transect in the Waiho flood plain was not possible due to dense tree coverage impeding GPS measurements. In lieu of a gravity transect in the Waiho flood plain, an additional gravity transect was measured in the Fox flood plain, situated $\sim 20 \mathrm{~km}$ southwest of the Waiho flood plain.

The closely spaced gravity transects are illustrated in Figures 5.4 and 5.6. Table 5.1 gives the equations of the best fit straight line through stations, the average station spacing and average fault-perpendicular distance for each of the closely spaced transects. 


\begin{tabular}{cccc}
\hline Flood plain & $\begin{array}{c}\text { Closely spaced } \\
\text { line equation }\end{array}$ & $\begin{array}{c}\text { Mean station } \\
\text { spacing }(\mathrm{m})\end{array}$ & $\begin{array}{c}\text { Mean fault } \\
\text { perp. distance }(\mathrm{m})\end{array}$ \\
\hline Wanganui & $N=0.70 \times E+4159193$ & 80 & 400 \\
Whataroa & $N=0.50 \times E+4619327$ & 85 & 185 \\
Fox & $N=1.075 \times E+3305771$ & 70 & 75 \\
\hline
\end{tabular}

Table 5.1: Details of the closely spaced gravity transects including best-fit transect equation, average station spacing and average perpendicular distance from the fault trace. $N$ is Northing and $E$ is Easting in the New Zealand Map Grid reference system.

\section{Gravity of the transects}

Gravity measurements were processed as described in Chapter 3 and were reduced to Bouguer gravity anomalies. A regional gravity trend was removed from the profile data. This was done using the numerical method of representing the regional gravity trend in each of the flood plains as a second order polynomial surface fit to the data and subsequently removed using $M A T L A B^{T M}$. Both the Bouguer and residual gravity anomalies along the closely spaced transects can be seen for the three valleys in Figure 5.3.

\section{Gravity profile minimum}

In order to determine where the centres of the buried glacial channels are located, it has to be assumed that the minimum value of residual gravity along each transect represents the centre of the buried footwall channel. Research by Greenwood and Humphrey (2002) discusses the use of different mathematical models to represent the cross-sectional shape of glacial. It was found that for valley profiles with 17 or more observations, a quartic polynomial fit was the best approximation of the cross-sectional glacial valley shape. To determine the location of the gravity minimum along each transect in an unbiased manner, a quartic polynomial was fit to each of the residual gravity profiles. The location where these polynomials reach a minimum along each 


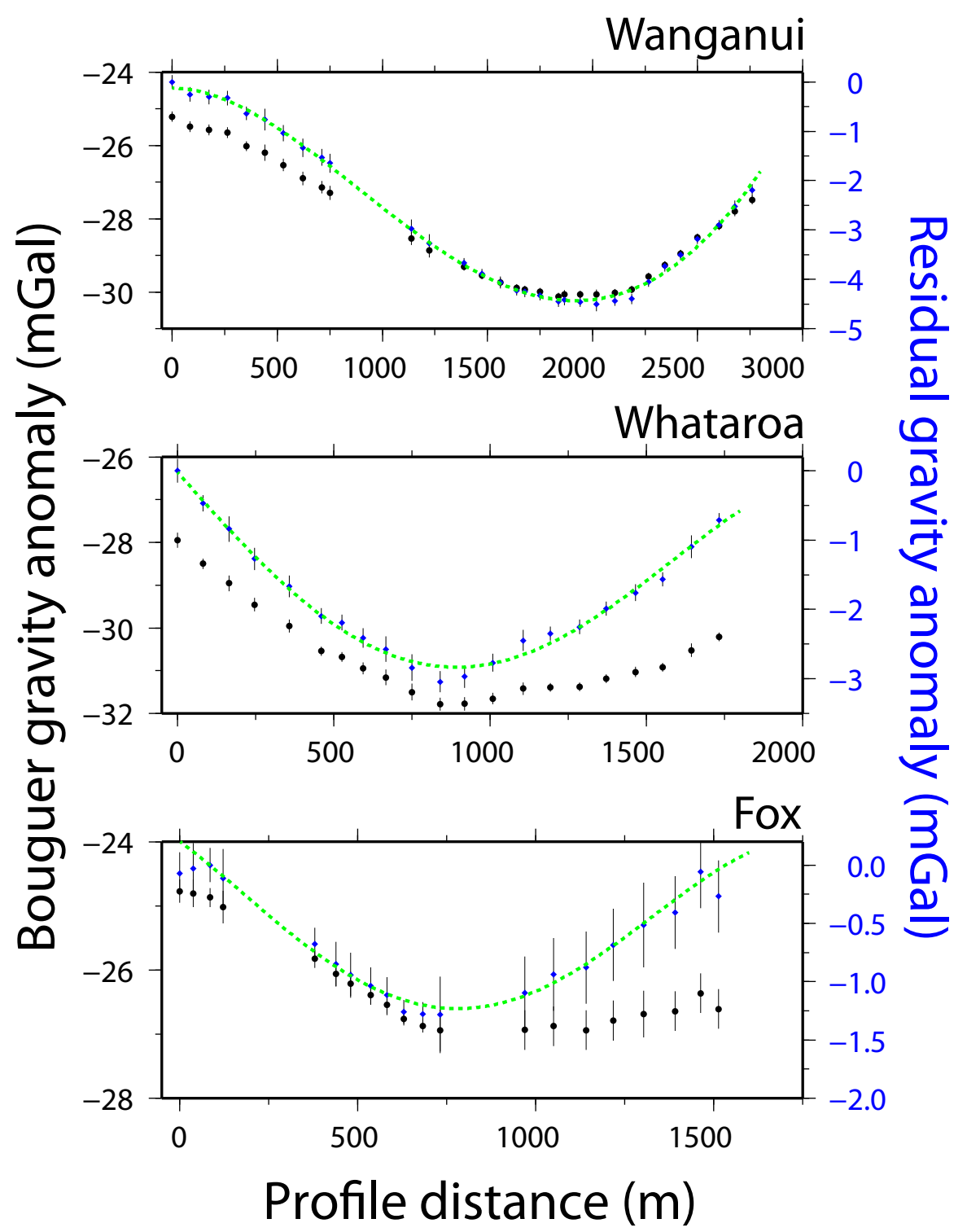

Figure 5.3: Gravity profiles from the closely spaced transects. Black circles show the Bouguer gravity anomaly along each profile; blue circles show the residual gravity anomaly along each profile; green dashed lines show the polynomial fitted to the residual gravity anomalies. 


\begin{tabular}{cc}
\hline Flood plain & Distance $(\mathrm{m})$ \\
\hline Wanganui & $1906 \pm 47$ \\
Whataroa & $901 \pm 6$ \\
Fox & $678 \pm 39$ \\
\hline
\end{tabular}

Table 5.2: Location of the residual gravity anomaly minimums along the closely spaced gravity transects. Distance is measured from the southwest end of each transect.

transect represents where the centre of the buried channels are situated. The uncertainty in the location of the channel minimum is the taken to be the difference between the minimum determined using a third and fourth order polynomial.

Figure 5.3 shows the quartic polynomials fit to the residual gravity anomalies along each profile, with the locations of the gravity minima listed in Table 5.2. Figure 5.6 shows maps of the closely spaced gravity transects, the residual gravity anomalies along the closely spaced profiles and the location of channel minimums.

\subsubsection{Projected glacial trajectory and channel offsets}

With the location of the buried glacial channels established, the relative location of where these channels were formed must be determined in order to estimate channel offsets. Collecting reliable gravity data on the hanging wall side of the fault was not possible, and so the following assumptions were made to determine the trajectory of past glacial advances as they moved across the fault and into the flood plains:

- Over small distances $(\sim 1 \mathrm{~km})$, glaciers move linearly, with negligible deviation.

- As glaciers cross the Alpine Fault, they maintain the same linear trajectory which they possess on the hanging wall of the fault. 
- The surface topography of the hanging wall valley has formed through glacial erosion and can be used to determine the past glacial trajectory.

Using these assumptions, the trajectory of past glacial advances is projected on to the closely spaced gravity transects by:

1. Picking the glacial valley walls of each hanging wall valley at regular intervals in order to establish a set of topography centre points for each valley.

2. Applying best-fit lines to these centre point sets, through a method of least squares. These best-fit lines represent the trajectories of past glacial advance.

3. The glacial trajectories are projected onto the closely spaced gravity transects. The location where these projected trajectories intersect with the closely spaced gravity transects represent the relative location of channel formation.

\section{Picking glacial topography}

To determine the trajectory of past glacial advances, the topography of the hanging wall is assumed to represent the erosional path of past glaciers. Thus the topography of the hanging wall is used to project the trajectory of the past glacial movements.

To pick the glacial topography a $25 \mathrm{~m}$ digital elevation model (DEM) of the central West Coast region was imported into the $3 D$ imaging software, Fledermaus ${ }^{T M}$. Ten profiles oriented parallel to the fault trace and at regular intervals of $250 \mathrm{~m}$ were established across the hanging wall valley in each area. Figure 5.4 gives an overview of the topography profiles for each valley. 


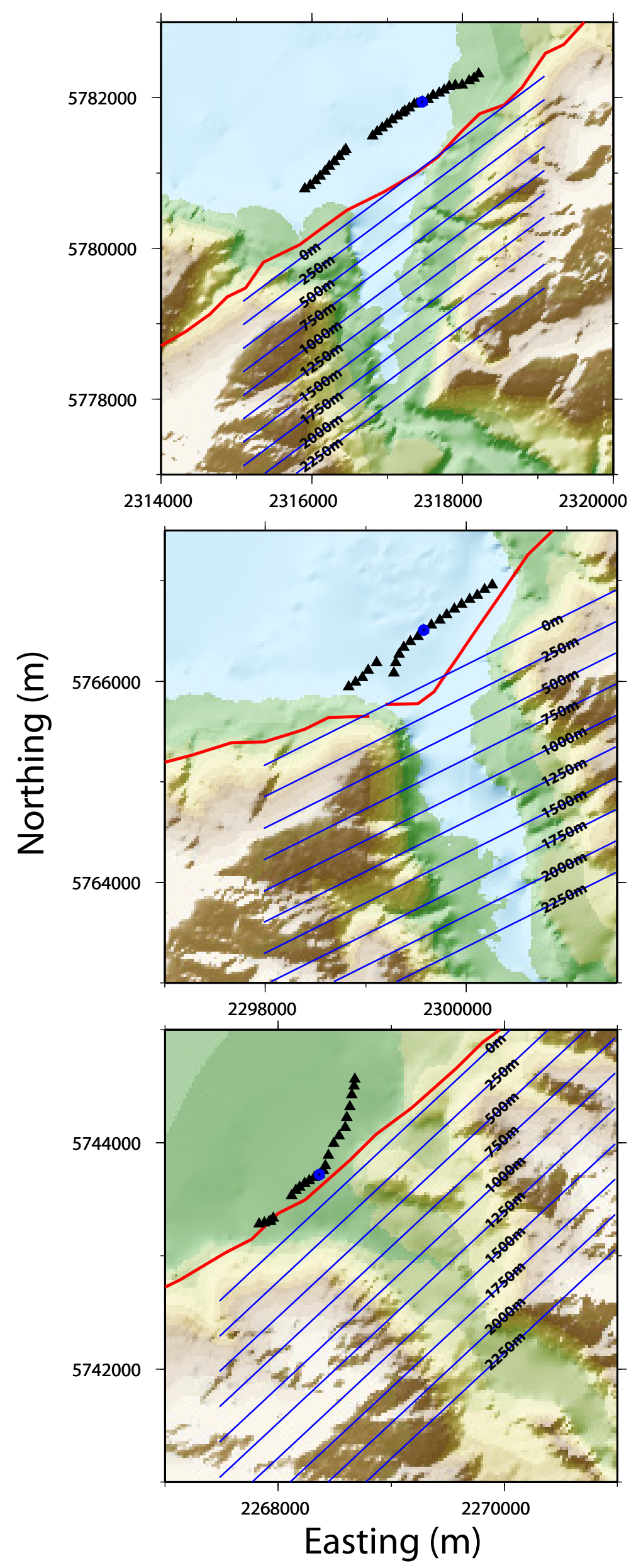

Figure 5.4: Topographic profile lines across the hanging wall valleys for determining glacial trajectory. Top to bottom: Wanganui, Whataroa and Fox river valley. 


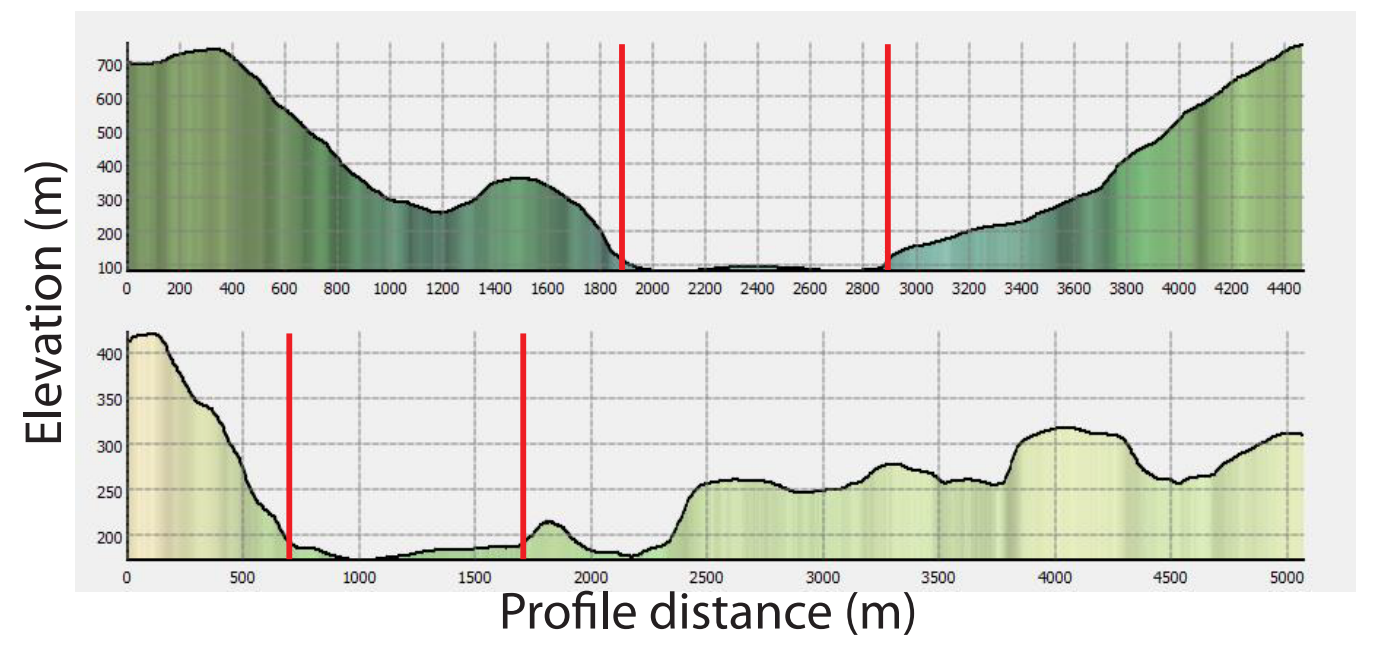

Figure 5.5: Picking glacial walls with Fledermaus. The top profile is the $1500 \mathrm{~m}$ profile in the Whataroa river valley, and is simple to pick. The lower profile is the $0 \mathrm{~m}$ profile in the Fox river valley, and is more ambiguous

Using the profile viewer within Fledermaus ${ }^{T M}$, the glacial walls of the hanging wall valleys were picked along each profile. Some of the topography profiles have obvious glacial walls and are simple to pick while other profiles present ambiguous topography and require the judgment of the interpreter. Figure 5.5 gives an example of both a simple and an ambiguous topography pick. The centre point of each profile is found by averaging the location of the two glacial walls along each profile. Topography centre point sets for the three study valleys along with the topography picks can be found in Appendix C.

Figure 5.6 shows the established topography centres for all three study areas, as well as the channel minima of the buried channels. 


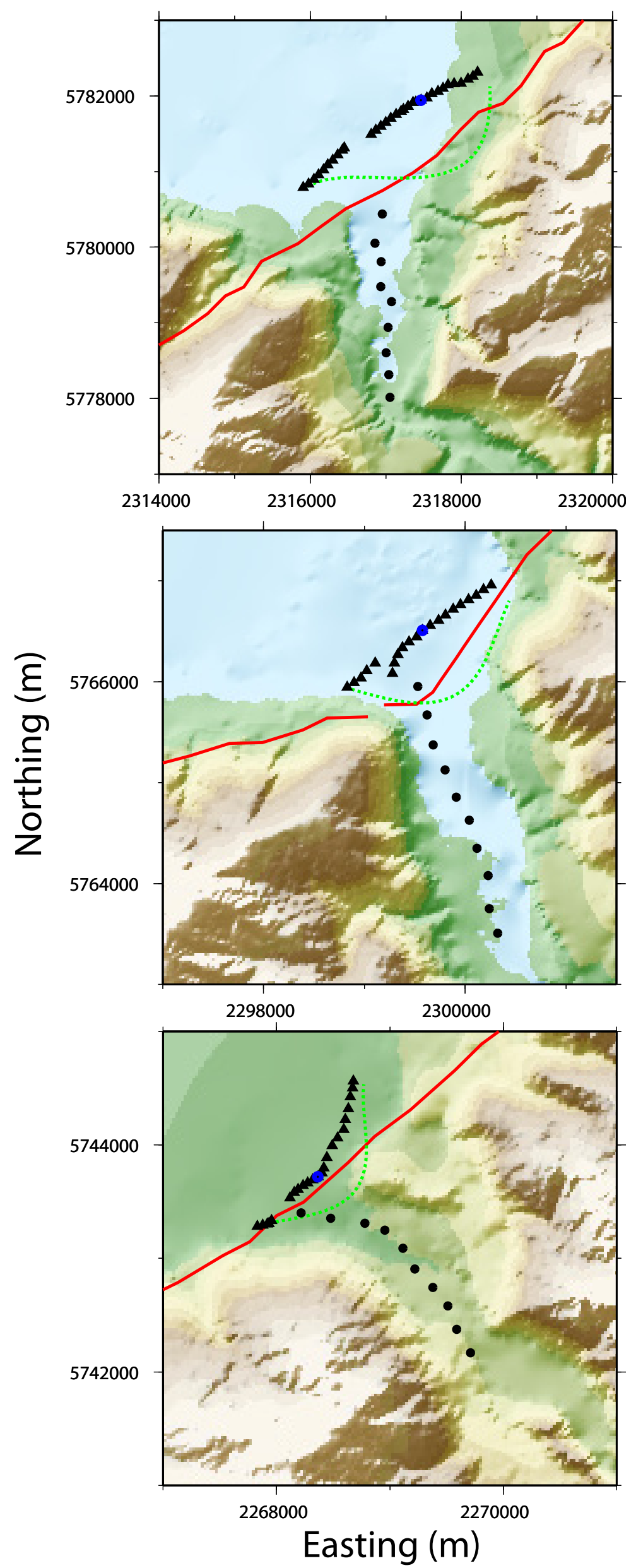

Figure 5.6: Closely spaced gravity transects and the topography picked valley centres. Black triangles represent gravity observations; black circles represent topography centres; the green dashed lines are the residual anomalies. Top to bottom: Wanganui, Whataroa and Fox river valley. 
5.2. OFFSET ESTIMATES FROM GRAVITY AND TOPOGRAPHY 141

\begin{tabular}{cc}
\hline Area & Trajectory equations \\
\hline Wanganui & $N=-14.22 \times E+38726812$ \\
Whataroa & $N=-2.92 \times E+12489103$ \\
Fox & $N=-0.884 \times E+7747795$ \\
\hline
\end{tabular}

Table 5.3: Glacial trajectories established from valley centres picked along topography profiles. $N$ is Northing and $E$ is Easting in the New Zealand Map Grid reference system.

\section{Establishing past glacial trajectory}

Lines of best-fit are applied to each of the topography centre point sets through a method of least squares using $M A T L A B^{T M}$. The resulting bestfit lines represent the trajectory of past glacial advances in each glacial valley. Table 5.3 gives the best-fit lines / equations of glacial trajectory.

\section{Projection of glacial trajectory}

The established glacial trajectories are projected onto the closely spaced gravity transects, see Figure 5.7. The intersection of the projected trajectories and the closely spaced gravity profiles represent where the centre of glaciers would have been at the time the channels were formed, given the assumptions made earlier in this section.

The current and formation location of the glacial channels in the footwall have now been established, enabling the calculation of channel offset.

\subsubsection{Glacial channel offsets}

Table 5.4 gives the distance along each of the closely spaced gravity profiles where the projected glacial trajectories intersect and the amount of offset between the buried channel and the projected glacial movement. The uncertainty associated with the intersect distance is the $95 \%$ confidence interval for the trajectory projection. Figure 5.7 shows an example of a projection 


\begin{tabular}{cccc}
\hline Area & $\begin{array}{c}\text { Projection } \\
\text { intersect }(\mathrm{m})\end{array}$ & $\begin{array}{c}\text { Buried channel } \\
\text { centre }(\mathrm{m})\end{array}$ & $\begin{array}{c}\text { Channel } \\
\text { offset }(\mathrm{m})\end{array}$ \\
\hline Wanganui & $1208 \pm 253$ & $1906 \pm 47$ & $698 \pm 300$ \\
Whataroa & $672 \pm 76$ & $901 \pm 6$ & $229 \pm 82$ \\
Fox & $563 \pm 248$ & $678 \pm 39$ & $115 \pm 287$ \\
\hline
\end{tabular}

Table 5.4: The distances along the closely spaced gravity transects where the topography picked projections intersect. Offsets are the difference between the channel minimum location and the intersection location of the projected glacial trajectories.

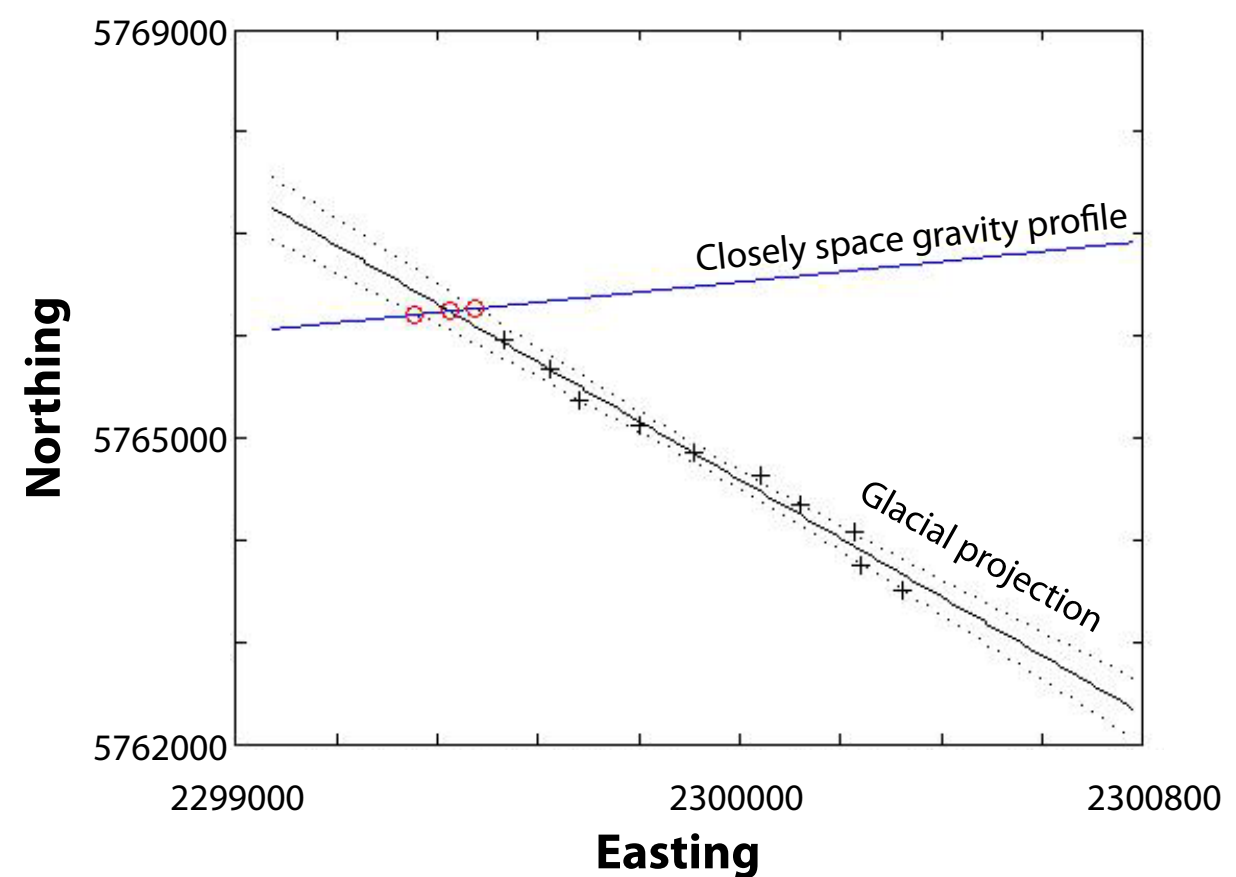

Figure 5.7: The projection of glacial trajectory onto the closely spaced gravity transect in the Whataroa flood plain. The dotted lines represent the $95 \%$ confidence interval for the best-fit line.

and the $95 \%$ confidence interval.

These offsets appear to misrepresent the true offset of the glacial channels 
as they do not agree with each other within uncertainty. As the channels were formed concurrently it would be expected that the offsets are comparable to one another, within the calculated error. This indicates that the projected glacial trajectories are subject to uncertainty due to factors related to the picking of glacial topography, which could include:

- Fluvial erosion acting on the glacial valley walls.

- Increased erosion of an asymmetric nature in close proximity to the fault trace.

- Picking topography too far up the hanging wall valley.

- Poor topography picks resulting from ambiguous topography.

\subsubsection{Proximal data projections}

From Figure 5.6 it can be seen that there are several significant factors which might produce poor representations of the glacial trajectories:

- The set of topography centres in the Fox hanging wall valley exhibit a clear curvature away from the fault trace.

- In the Whataroa valley there is pronounced asymmetric erosion of the valley walls close to the fault trace. Also, the topography centre closest to the fault trace is on the footwall side of the mapped fault trace.

- The set of topography centres in the Wanganui hanging wall valley appear to be much less linear than that of the Whataroa hanging wall valley.

Centre points affected by these factors needed to be removed from the topography centre sets in a consistent manner across the three valleys. New projections of the glacial trajectory can then be calculated with the cleaned topography centre point sets. 


\begin{tabular}{cc}
\hline Area & Trajectory equations \\
\hline Wanganui & $N=9.92 \times E--17199119$ \\
Whataroa & $N=-2.13 \times E+10673081$ \\
Fox & $N=-0.20 \times E+6189154$ \\
\hline
\end{tabular}

Table 5.5: Refined glacial trajectories established from topography centres picked along topography profiles. $N$ is Northing and $E$ is Easting in the New Zealand Map Grid reference system.

In the Wanganui and Fox valleys the four centre points proximal to the fault are kept, while the rest of the centre points are rejected. In the Whataroa, the two centre points closest to the fault are rejected, the four subsequent centre points are kept, and the rest of the points are rejected. Figure 5.8 shows the remaining topography centres used to recalculate the glacial trajectories.

The recalculated glacial trajectories are listed in Table 5.5, while the resulting channel offsets are listed in Table 5.6.

\begin{tabular}{cccc}
\hline Area & $\begin{array}{c}\text { Projection } \\
\text { intersect }(\mathrm{m})\end{array}$ & $\begin{array}{c}\text { Buried channel } \\
\text { centre }(\mathrm{m})\end{array}$ & $\begin{array}{c}\text { Channel } \\
\text { offset }(\mathrm{m})\end{array}$ \\
\hline Wanganui & $1523 \pm 388$ & $1906 \pm 47$ & $383 \pm 435$ \\
Whataroa & $529 \pm 88$ & $901 \pm 6$ & $372 \pm 94$ \\
Fox & $228 \pm 99$ & $678 \pm 39$ & $450 \pm 138$ \\
\hline
\end{tabular}

Table 5.6: The distances along the closely spaced gravity transects where refined glacial trajectories intersect. Offsets are the difference between channel minimum location and the intersection location of projected glacial trajectories. Top to bottom: Wanganui, Whataroa and Fox river valley.

The recalculated offsets now sit within each others uncertainty range. 


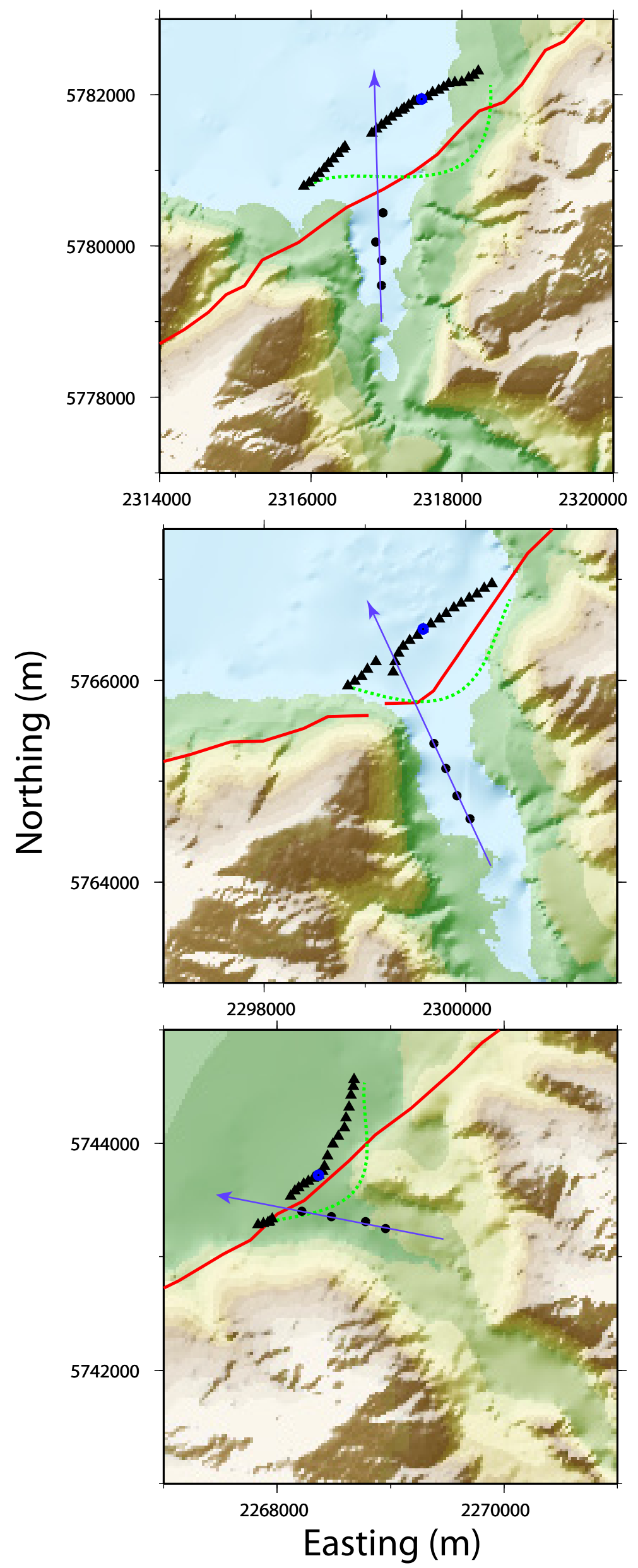

Figure 5.8: Refined glacial topography centres for the three valleys from the faultparallel topography picks. Black triangles represent gravity observations; black circles represent topography centres; the green dashed lines are the residual anomalies. 


\subsection{Slip rates}

\subsubsection{Channel age}

With glacial channel offsets established for each valley all that is required to obtain fault slip rates is an age of formation for the buried glacial channels. The channels have been formed by glacial advance and retreat during the Otira glacial period, also referred to by many as the Last Glacial Maximum (LGM) (Suggate and Almond, 2005). During this period there were three primary ice advances in the Westland region. These ice advances culminated $\sim 28, \sim 21.5$ and $\sim 19 \mathrm{ka}$, with the period $28-19$ ka representing the New Zealand LGM (Suggate and Almond, 2005). These three separate ice advances during the LGM are not individually responsible for the three different channel structures observed in the fault parallel models from the previous chapter. All three ice advances will have contributed to the formation and widening of the single channel observed in close proximity to the Alpine Fault, as well as the three erosional channels away from the fault.

It could be assumed that the localised fault movement and rates of erosion are consistent over the LGM. Given this assumption the centre of the buried footwall channel would have been formed at the midpoint of the LGM. Sutherland et al. (2006) dealt with this issue when determining a fault slip rate using the offset of an aggradation fan on the southern fault section. To obtain a slip rate for the offset to the centre of the aggradation fan, Sutherland et al. (2006) used an age of $22 \pm 2$ ka to represent the peak of the LGM period.

However, it is not clear whether correlating the centre of the erosional channels with the mid-point of the LGM is reasonable. The local fault movement and erosion rates are not constant over the LGM. Local fault movements are not as uniform in time as movements along the entire fault, and occur less frequently (Wells et al., 1999). The three separate ice advances differed in their extent, with the first two being similar in extent and the third advance being smaller in extent (Suggate and Almond, 2005). Major changes 


\begin{tabular}{cccc}
\hline & \multicolumn{3}{c}{ Area } \\
Age & Wanganui & Whataroa & Fox \\
$(\mathrm{ka})$ & $(\mathrm{mm} / \mathrm{yr})$ & $(\mathrm{mm} / \mathrm{yr})$ & $(\mathrm{mm} / \mathrm{yr})$ \\
\hline $28 \pm 1$ & $13.7 \pm 16.0$ & $13.3 \pm 3.8$ & $16.1 \pm 5.5$ \\
$21.5 \pm 1$ & $17.8 \pm 21.1$ & $17.3 \pm 5.2$ & $20.9 \pm 7.4$ \\
$19 \pm 1$ & $20.2 \pm 24.0$ & $19.6 \pm 6.0$ & $23.7 \pm 8.5$ \\
\hline
\end{tabular}

Table 5.7: The range of possible strike-slip movement rates for the three primary ice advances during the LGM (Suggate and Almond, 2005).

in glacial erosion rates can be significant between glacial and interglacial periods, as well as between ice advances and retreat (Hallet et al., 1996). Therefore, with no direct dating of the buried erosional channels in the footwall only a range of slip rates can be investigated for different formation ages during the LGM.

\subsubsection{Strike-slip rates}

Strike-slip rates are explored for three different formation ages. The formation ages used are $28 \pm 1,21.5 \pm 1$ and $19 \pm 1 \mathrm{ka}$, corresponding to the culmination dates of the three ice advances in the Westland region during the LGM (Suggate and Almond, 2005). Table 5.7 show the range of calculated slip rates on the fault at Wanganui, Whataroa and Fox.

The Wanganui flood plain has uncertainty as large as the physical value of the strike-slip movement rate. The uncertainty is large as the Wanganui gravity profile is $\sim 0.5 \mathrm{~km}$ from the fault trace and the topography centre set is particularly non-linear, which results in larger uncertainty in the glacial trajectory projection.

The rates vary between $13.3-23.7 \mathrm{~mm} / \mathrm{yr}$ over the range of formation dates. The channel formation ages of 28 and 19 ka give the extreme values for which the strike-slip rates could be. For the formation ages of 21.5 and $19 \mathrm{ka}$, the rates over all three of the areas agree, within uncertainty, with the 
rates determined by Sutherland et al. (2006) on the southern onshore fault section. This suggests that the strike-slip movement rate over at least the last two glacial periods has remained relatively constant along the length of the onshore fault, south of the Hope Fault.

\subsubsection{Alternative slip rate method}

Instead of projecting past glacial movements it is possible to determine fault slip rates using the difference in width between the channels in the hanging wall and the channels in the footwall. As the Alpine Fault is thought to rupture in large earthquakes (magnitude $\sim 8$ ) every $\sim 200-300$ yrs, there could have been as many as 45 large fault ruptures along the length of fault during the LGM (Wells et al., 1999; Korup et al., 2005). Successive fault movements act to expose the footwall to more glacial erosion, which results in the widening of the footwall channel. The total width of the foot wall channel becomes the sum of localised fault movement and the width of the hanging wall channel (Sutherland et al., 2006). The difference in width between the foot wall channel and the hanging wall valley will represent the channel offset over the period of the glaciation.

To determine slip rates in this manner the following is required:

- The width of the hanging wall glacial valley.

- The width of the buried foot wall channel.

- The period of time over which the footwall channel was glacially eroded.

The width of the hanging wall glacial valleys can be determined using the $250 \mathrm{~m}$ fault-parallel topography profiles, used earlier in the chapter to pick glacial topography. The time over which the foot wall was glacially eroded is simply the period of the LGM, which occurred between 28-19 ka ago, a total period of $9 \pm 2 \mathrm{ka}$ (Suggate and Almond, 2005). In order to determine the width of the buried foot wall channels, the residual gravity anomaly along 


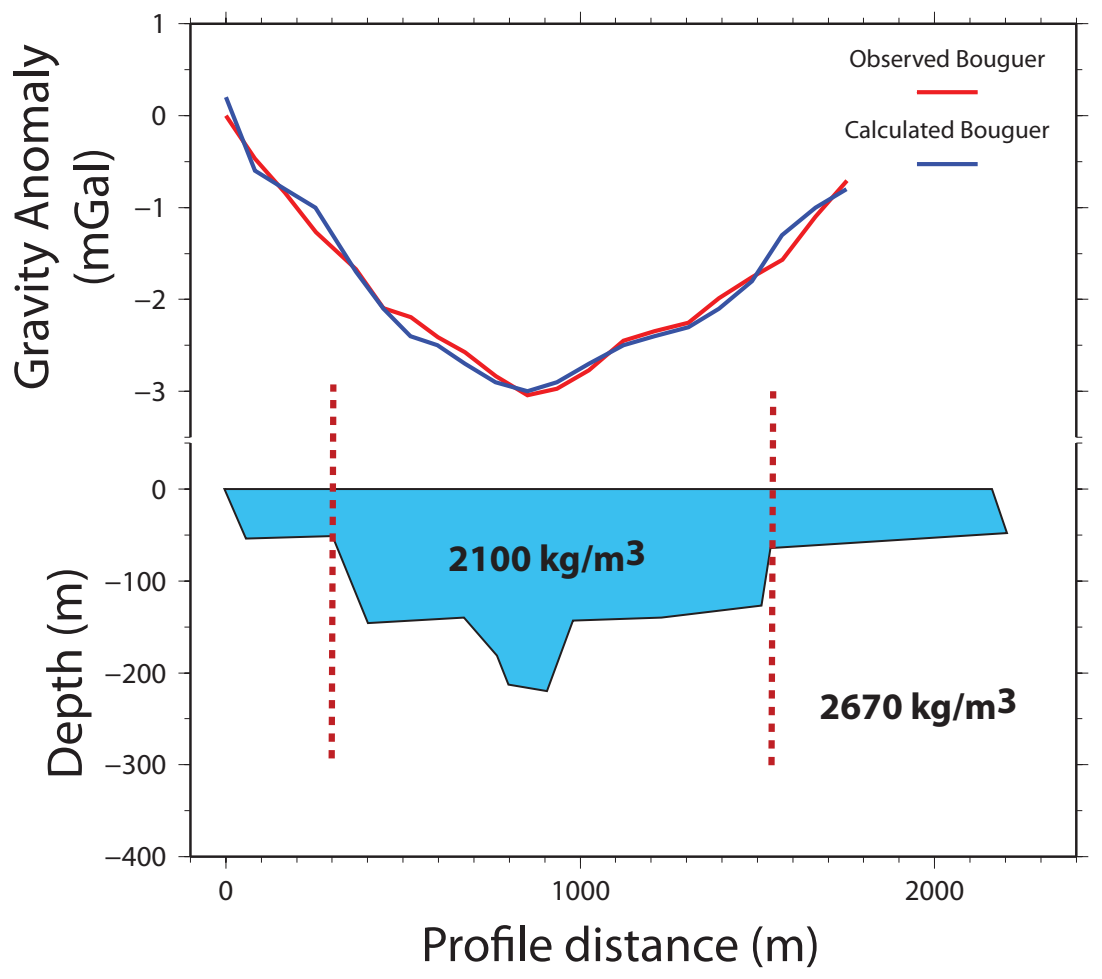

Figure 5.9: Gravity model of the buried Whataroa foot wall channel. The observed and modelled gravity is at the top, while the channel is modelled below with an infill density of $2100 \mathrm{~kg} / \mathrm{m}^{3}$ The red dashed lines indicate the model-determined walls of the buried channel.

each closely spaced gravity transect must be modelled. Once the width of the footwall channel has been modelled the calculation of the slip rate is simply:

$$
\text { Slip rate }=\frac{\Delta \text { Channel width }}{\text { LGM duration }}
$$

The 2-D modelling of the foot wall channels was done using Grav-2D ${ }^{T M}$. As there is no physical sample of the sediments infilling the channels, a range of densities were modelled to enable uncertainty to be determined. Figure 5.9 shows the gravity model for Whataroa using a sediment density of 2100 $\mathrm{kg} / \mathrm{m}^{3}$. All gravity models for the three flood plains can be found in Appendix 


\begin{tabular}{|c|c|c|c|c|}
\hline $\begin{array}{l}\text { Infill density } \\
\qquad\left(\mathrm{kg} / \mathrm{m}^{3}\right)\end{array}$ & $\begin{array}{l}\text { Hanging wall } \\
\text { channel width } \\
(\mathrm{m})\end{array}$ & $\begin{array}{c}\text { Modelled } \\
\text { channel width } \\
(\mathrm{m})\end{array}$ & $\begin{array}{c}\text { Difference } \\
(\mathrm{m})\end{array}$ & $\begin{array}{l}\text { Slip rate } \\
(\mathrm{mm} / \mathrm{yr})\end{array}$ \\
\hline \multicolumn{5}{|c|}{ Wanganui } \\
\hline 2100 & 1215 & 1414 & 199 & $22.1 \pm 2.5$ \\
\hline 2200 & 1215 & 1414 & 199 & $22.1 \pm 2.5$ \\
\hline 2300 & 1215 & 1491 & 276 & $30.7 \pm 3.4$ \\
\hline Model aver & age: & & & $25.0 \pm 9.1$ \\
\hline \multicolumn{5}{|c|}{ Whataroa } \\
\hline 2100 & 1080 & 1236 & 156 & $17.3 \pm 1.9$ \\
\hline 2200 & 1080 & 1298 & 218 & $24.2 \pm 2.7$ \\
\hline 2300 & 1080 & 1257 & 177 & $19.7 \pm 2.2$ \\
\hline Model aver & age: & & & $20.4 \pm 6.5$ \\
\hline \multicolumn{5}{|c|}{ Fox } \\
\hline 2100 & 920 & 1186 & 266 & $29.6 \pm 3.3$ \\
\hline 2200 & 920 & 991 & 71 & $7.9 \pm 0.9$ \\
\hline 2300 & 920 & 1006 & 86 & $9.6 \pm 1.1$ \\
\hline Model aver & age: & & & $15.7 \pm 17.2$ \\
\hline
\end{tabular}

Table 5.8: Strike-slip movement rates determined from the modelling of the buried footwall channels.

B. The results of the modelling and slip rate calculations are summarised in Table 5.8.

Results of this modelling technique provide reasonable results for both the Wanganui and Whataroa flood plains. In these valleys the modelled gravity anomaly is sensitive to the location of the modelled channel walls, making it straight forward to determine the width of the channels. The results for the Fox channel varied drastically from one model to another, leading to a large uncertainty in the average rate. Unlike the Wanganui and Whataroa channel models, the Fox channel gravity model produced an ambiguous channel structure, making it difficult to confidently determine the width of the buried channel. 
The modelled slip rate results agree with the glacial projection slip rates, within the uncertainty. However, the uncertainties associated with the glacial projection slip rates are lower and therefore are the preferred rates.

\subsubsection{Rate comparison}

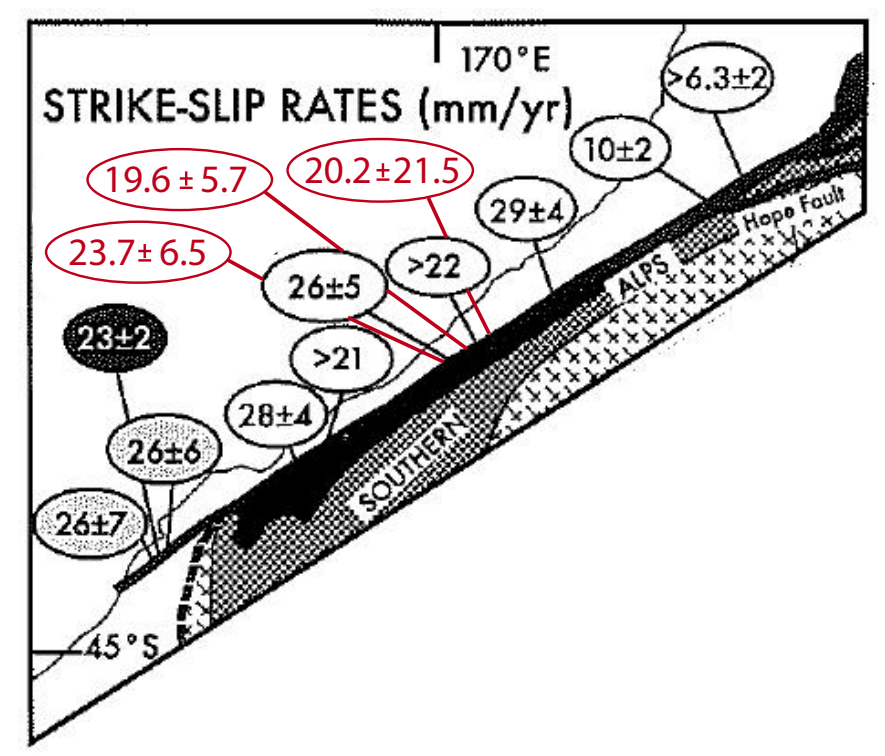

Figure 5.10: Updated Quaternary strike-slip rates along the length of the onshore Alpine Fault (mm/yr) (Norris and Cooper, 2007). Strike-slip rates determined in this study are shown in red.

The strike-slip movement rates found using the most recent glacial advance age of 19 ka are the most comparable to previously established rates along the Alpine Fault. The strike-slip movement rates for this formation age are $20.2 \pm 24.0,19.6 \pm 6.0$ and $23.7 \pm 8.5 \mathrm{~mm} / \mathrm{yr}$, for the Wanganui, Whataroa and Fox river valleys respectively. All three of 19 ka strike-slip rates fall within the uncertainty ranges of previously determined rates, which can be seen in Figure 5.10 and Table 5.9. However, these new rates are in the lower bounds of the previously determined slip rates, with the movement rates for formation ages of 21.5 and $28 \mathrm{ka}$ being significantly lower. 


\begin{tabular}{ll}
\hline \multicolumn{1}{c}{ Location } & \multicolumn{1}{c}{$\begin{array}{c}\text { Strike-slip rate } \\
(\mathrm{mm} / \mathrm{yr})\end{array}$} \\
\hline Kakapotahi River & $29 \pm 6$ \\
Wanganui River & $20.2 \pm 24.0$ \\
Whataroa River & $19.6 \pm 6.0$ \\
Gaunt Creek & $>22$ \\
Waikukupa River & $27 \pm 5$ \\
Fox River & $23.7 \pm 8.5$ \\
North Bank, Haast River & $>21$ \\
South Bank, Haast River & $28 \pm 4$ \\
Hakuri Creek & $26 \pm 6$ \\
Webb Creek & $23 \pm 2$ \\
Lake McKerrow & $26 \pm 7$ \\
Southern onshore fault & $23 \pm 2$ \\
\hline
\end{tabular}

Table 5.9: New and previously determined strike-slip rates on the Alpine Fault (Norris and Cooper, 2007; Sutherland et al., 2006). Rates from this study are shown in red.

The nearest location of a previously determined strike-slip rate is at Gaunt Creek, which is situated between the Whataroa and Waiho flood plains. The strike-slip rate here is $>22 \mathrm{~mm} / \mathrm{yr}$, which is a highly unconstrained rate, but agrees with the slip rates for a formation age of $19 \mathrm{ka}$.

Chapter 6 contains discussion on these slip rates and what they reveal about the accommodation of inter-plate convergence in the central Alpine Fault. 


\section{Chapter 6}

\section{Discussion and conclusions}

\subsection{Discussion}

\subsubsection{Structure}

\section{Regional erosion}

The effects of extensive erosion along the central West Coast is observable in the Bouguer gravity, residual gravity and gravity gradient maps (Figures 3.9, 4.1 and 4.2, respectively). Large negative Bouguer gravity anomalies are observed in the centre of both the Whataroa and Wanganui flood plains, and to a much lesser extent in the Waiho flood plain. These negative anomalies are inferred to be the result of large subsurface erosional structures formed primarily through glacial erosion during cyclic glaciations, which have since been infilled with sediment (Korup et al., 2005; Suggate and Almond, 2005).

One of the primary factors contributing to the extent of erosion in each valley and flood plain is the size of the respective catchments. Ice and river volume is proportional to catchment size and larger volumes of ice will in turn erode larger erosional structures (Korup et al., 2005). The catchment areas for the Wanganui, Whataroa and Waiho flood plains are $342.7 \mathrm{~km}^{2}$, $452.9 \mathrm{~km}^{2}$ and $163.8 \mathrm{~km}^{2}$ respectively (Korup et al., 2005). The catchment area of the Waiho valley is half that of the Wanganui valley and nearly a 
third of the Whataroa valley. Therefore it would be assumed that the ice volume in the Waiho valley during glacial periods is also significantly less than the other two areas. This would result in less glacial erosion in the Waiho flood plain, and a smaller associated gravity anomaly when compared to the two northern flood plains.

Korup et al. (2005) infers the volume of "missing rock" in each catchment by interpolating surfaces using DEM's surrounding each catchment. It would be a reasonable assumption that the extent of erosion below the flood plains is proportional to the volume of missing rock. The inferred missing rock volumes for the Wanganui, Whataroa and Waiho catchments are $216 \mathrm{~km}^{3}$, $325 \mathrm{~km}^{3}$ and $89 \mathrm{~km}^{3}$, respectively (Korup et al., 2005). From this study it can be seen that the volumes of missing rock in the catchments is consistent with the size of the catchment areas and the relative magnitude of the negative residual gravity anomalies over the flood plains, which reach around -10 $\mathrm{mGal},-12 \mathrm{mGal}$ and $-6 \mathrm{mGal}$ in the Wanganui, Whataroa and Waiho respectively.

The locus of the two large negative Bouguer gravity anomalies in the Wanganui and Whataroa flood plains straddle the mapped trace of the South Westland Fault (see Figure 3.9), which indicates that erosion becomes more pronounced over the fault and sedimentary basin structure. The sedimentary layers of the South Westland Basin are far less lithified than basement rock and therefore provide less erosional resistance (Hallet et al., 1996). As glaciers advance over the fault and into the sediment filled basin, the rate of erosion below the glaciers increases, which in turn increases the width and depth extent of the erosional structure (Hallet et al., 1996).

As the glaciers cross the South Westland Fault they erode the leading edge of the (thrust) fault structure, bringing the contours of the gravity field and trace of the fault back toward the Alpine Fault. These deviations, focused in the flood plains (particularly the Whataroa), are seen in Figure 4.1 as the bending of residual gravity field contours toward the Alpine Fault.

In the Waiho flood plain, the mapped trace of the South Westland Fault 
is further northwest of the Alpine Fault $(\sim 12 \mathrm{~km})$ than in the Whataroa $(\sim 10 \mathrm{~km})$ and Wanganui $(\sim 7.5 \mathrm{~km})$ flood plains, while the nearest gravity observation to the fault is $\sim 4 \mathrm{~km}$ southeast in the Waiho flood plain, due to restricted land access. This means that the erosional structure observed in gravity over the Waiho flood plain is purely in basement rock or mid-Miocene sediment, both which possess a higher erosional resistance than the upper sedimentary layers of the South Westland Basin. Therefore, the erosional structures in this flood plain are smaller in both depth and width extent, producing a smaller negative gravity anomaly than that of the Whataroa or Wanganui flood plains (Hallet et al., 1996).

\section{Glacial erosion}

Several U-shaped erosional channels are observable in the fault-parallel/oblique 2-3/4D gravity models presented in Chapter 4 (e.g: Figures 4.11 and 4.14). U-shaped erosional channels form in response to glacial erosion as opposed to V-shaped channels, formed through fluvial erosion (Adams, 1980; Herman et al., 2007). Three glacial channels are seen along lines 1 and 2 in the Wanganui flood plain, while five are seen along line 2 and three along line 5 in the Whataroa flood plain. The additional two channels in the Whataroa flood plain are likely to be the result of smaller glacial advance from the Waitangitoana river valley, and will be ignored for this discussion. Along strike of the river valleys, these glacial channels appear to have been dextrally offset from the originating river valleys.

The three channels in the Wanganui flood plain and in the northeast of the Whataroa flood plain correlate with surface moraines, which define the topography of the flood plains (Almond et al., 2001). Glacial advance has eroded and pushed these moraines to the terminal positions of the most recent ice advance (Suggate and Almond, 2005). Figure 6.1 shows white arrows connecting the location of modelled channel centres, while illustrating the correlation between these glacial channels, topography and the residual gravity field of the glacial erosion in the Wanganui flood plain (residuals 


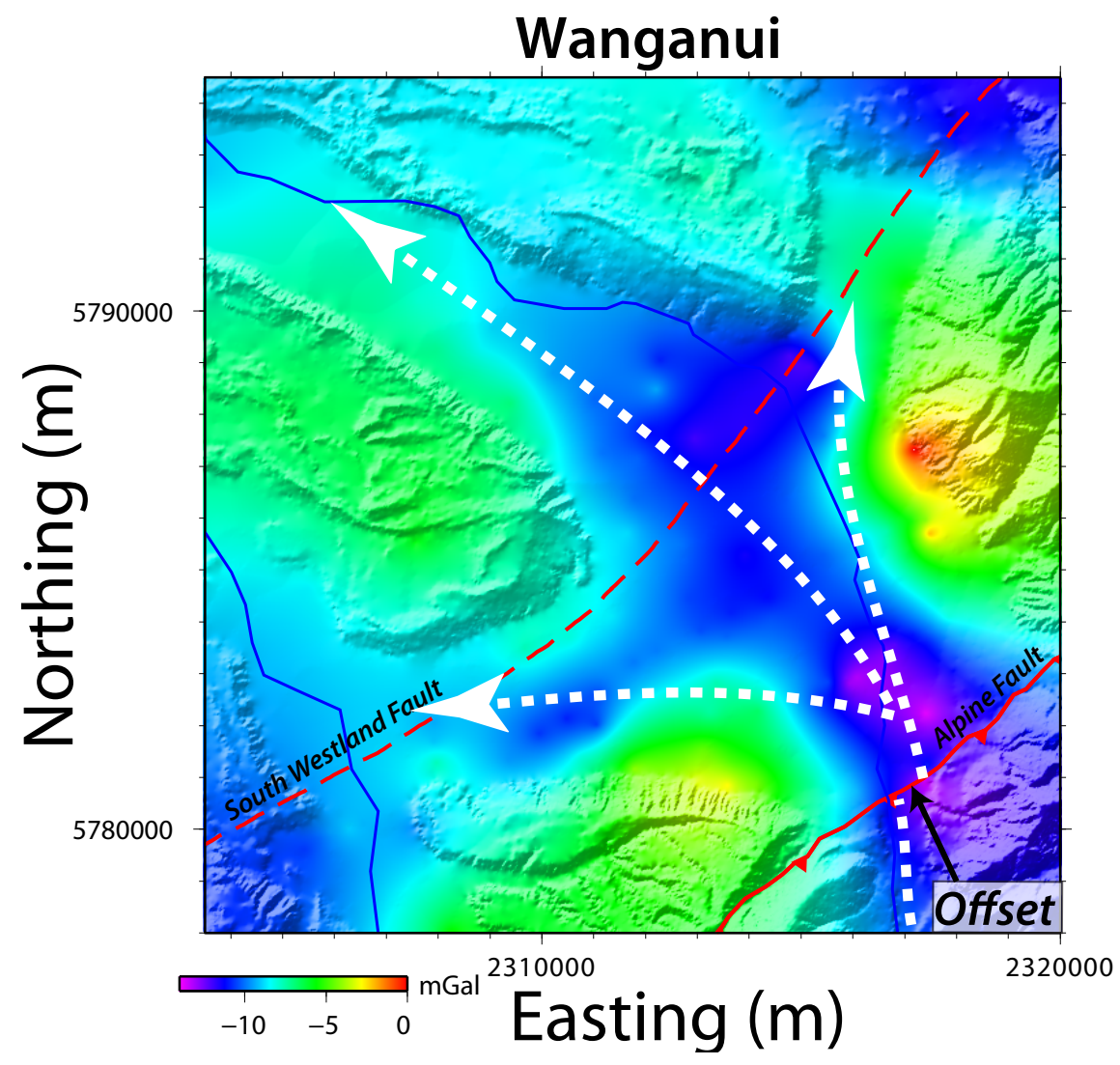

Figure 6.1: Schematic showing the possible paths of glacial advance in the Wanganui flood plain. The white dashed lines connect the location of glacial channel centres, while the residual gravity field shows glacial structure through numerical regional removal.

determined through numerical regional gravity trend removal, see Chapter 3 Section 6.1).

This correlation implies that glaciers occupied all of these subsurface channels during the last ice advance (Almond et al., 2001). However, whether these channels were formed concurrently or whether ice advance has reoccupied existing erosional structure is not immediately clear.

In the last $0.35 \mathrm{Myr}$ there have been four significant glaciations, each presumably eroding U-shape channels in the foot wall of the Alpine Fault 
(Suggate and Almond, 2005). Assuming a dextral strike-slip movement rate on the Alpine Fault of $\sim 25 \mathrm{~mm} / \mathrm{yr}$ over this period, erosion from these four glaciations should be observed in a zone $\sim 8.75 \mathrm{~km}$ northeast of the river valleys. All observed or modelled glacial channels contained ice during the last glacial maximum, and therefore it is proposed that glaciers override and continue to erode glacial structure formed in preceding glaciations.

The average fault-parallel distance between the centres of the three northeast glacial channels along line 2 in the Whataroa flood plain is $\sim 2.5 \mathrm{~km}$. Assuming this distance between neighbouring channels represents the amount of fault offset between major glaciations and a strike-slip movement rate of $\sim 25 \mathrm{~mm} / \mathrm{yr}$, then the time between channel formations is $\sim 100,000$ yrs, which approximately the period of glacial maximums governed by Milankovitch cycles (Imbrie et al., 1993). This is further evidence that ice reoccupies past erosional structure and forms new channels with continuing dextral offset. Glaciers reoccupy past erosional channels as the sediment infill is poorly lithified and provides less erosional resistance compared to that of basement rock and more lithified sediment (Hallet et al., 1996). Figure 6.2 shows an idealised schematic of how ice advance in glacial maximums might preferentially flow into past erosional structures.

The path of the glacial advances do not perfectly conform to this proposed erosional process, with deviation of the glacial channels becoming more pronounced with distance northwest of the Alpine Fault. As discussed above, the width and depth extent of these glacial channels increases as they approach and cross the South Westland Fault, transitioning from the more lithified mid-Miocene sediment and basement rock, to the less lithified upper layers of the South Westland Basin.

It is evident that existing subsurface glacial structure in the flood plain and the location of the South Westland Fault are significant factors determining the path taken by glaciers, and hence the formation of surface topography, as well as the dimensional extent of these ice bodies. 


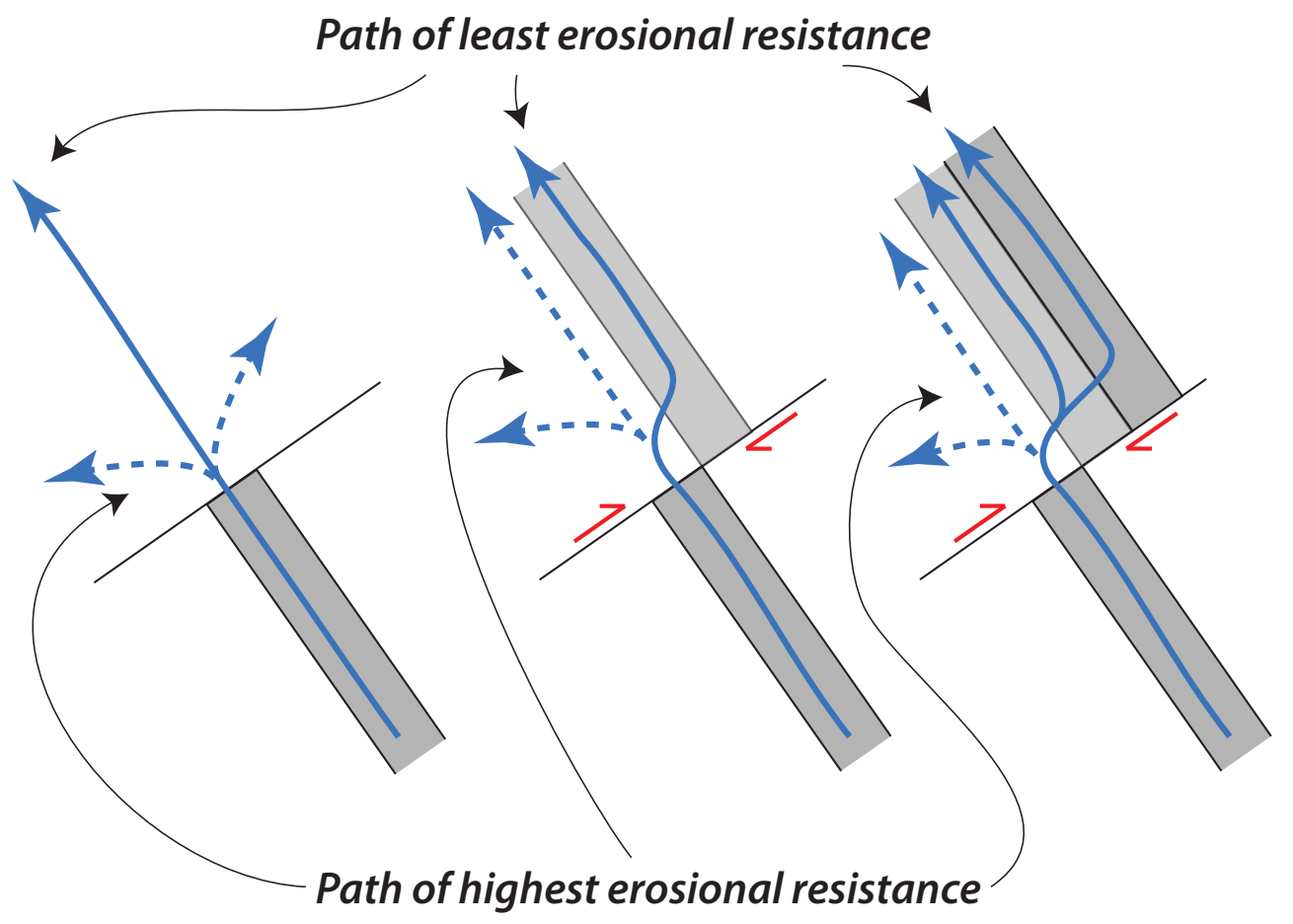

Figure 6.2: Schematic showing the preferential paths of ice flow through previously formed channel structure. This process could explain the geomorphology of South Westland flood plains.

\section{South Westland Fault}

With limited research into the South Westland Fault and a lack of surface outcrops, the nature of the fault in central Westland remains relatively unclear. Geological profiles across the fault in the Aoraki QMAP illustrate the fault as an unknown structure (Cox and Barrell, 2007a,b). Nathan et al. (1986) and Sutherland (1996) identify the entirety of the South Westland Fault Zone as a continuous zone of thrust faulting that developed during the mid-Miocene, with a total throw of $>3.5 \mathrm{~km}$. This thrust faulting has resulted in the formation of the South Westland Basin and a coastal monocline that outcrops in south Westland (Sutherland, 1996; Walcott, 1998; Sircombe and Kamp, 
1998). Davey (2010) states that several basement offsets observed in seismic reflection and refraction profiles could be documenting either normal or thrust faulting in the Whataroa flood plain, and that the South Westland Fault may be a fault zone with multiple strands resulting from convergence on the leading edge of the Australian plate.

In the Greymouth area, north of the central West Coast study area, there are several thrust faults west of the Alpine Fault. The Hohonu Fault (mentioned in Chapter 3), is inferred to be a steeply dipping reverse fault from outcrop patterns and seismic profiles (Waight, 1995). Seismic surveying indicates a down throw of $2.5 \mathrm{~km}$ west of the Hohonu Fault, which is comparable to the $\sim 3.0 \mathrm{~km}$ down throw west of the South Westland Fault in the seismic model of Davey (2010) and the gravity models presented in this study (Ghisetti and Sibson, 2006).

The continuous linear high in the gravity gradient seen in Figure 4.2 suggests that the Hohonu Fault is a northern continuation of the South Westland Fault. This is supported by Sircombe and Kamp (1998), who conclude from exposed steeply dipping Late Cretaceous and Cenozoic beds, that the coastal monocline, observed in South Westland, develops into the steeply dipping reverse Hohonu Fault to the northwest and along strike of the monocline. The structure of the South Westland Fault in the central Westland region could therefore be exhibiting a transition between the thrust fault driven monocline in the south and the steeply dipping Hohonu thrust fault to the north.

However, the residual gravity anomaly and modelled structure of the South Westland Fault are not characteristic of thrust faulting. Fault-perpendicular models in Chapter 4 show a structure which resembles normal or near vertical faulting. Figure 6.3 shows the gravity anomalies associated with idealised thrust, normal and vertical faulting. The residual gravity anomalies along fault-perpendicular transects have hard to distinguish anomalies (e.g Figure 4.4), but it could be argued that they appear to have concave gravity anomalies which are characteristic of normal faulting. However, the erosional structures below the flood plains affects the observed gravity anomaly of the 


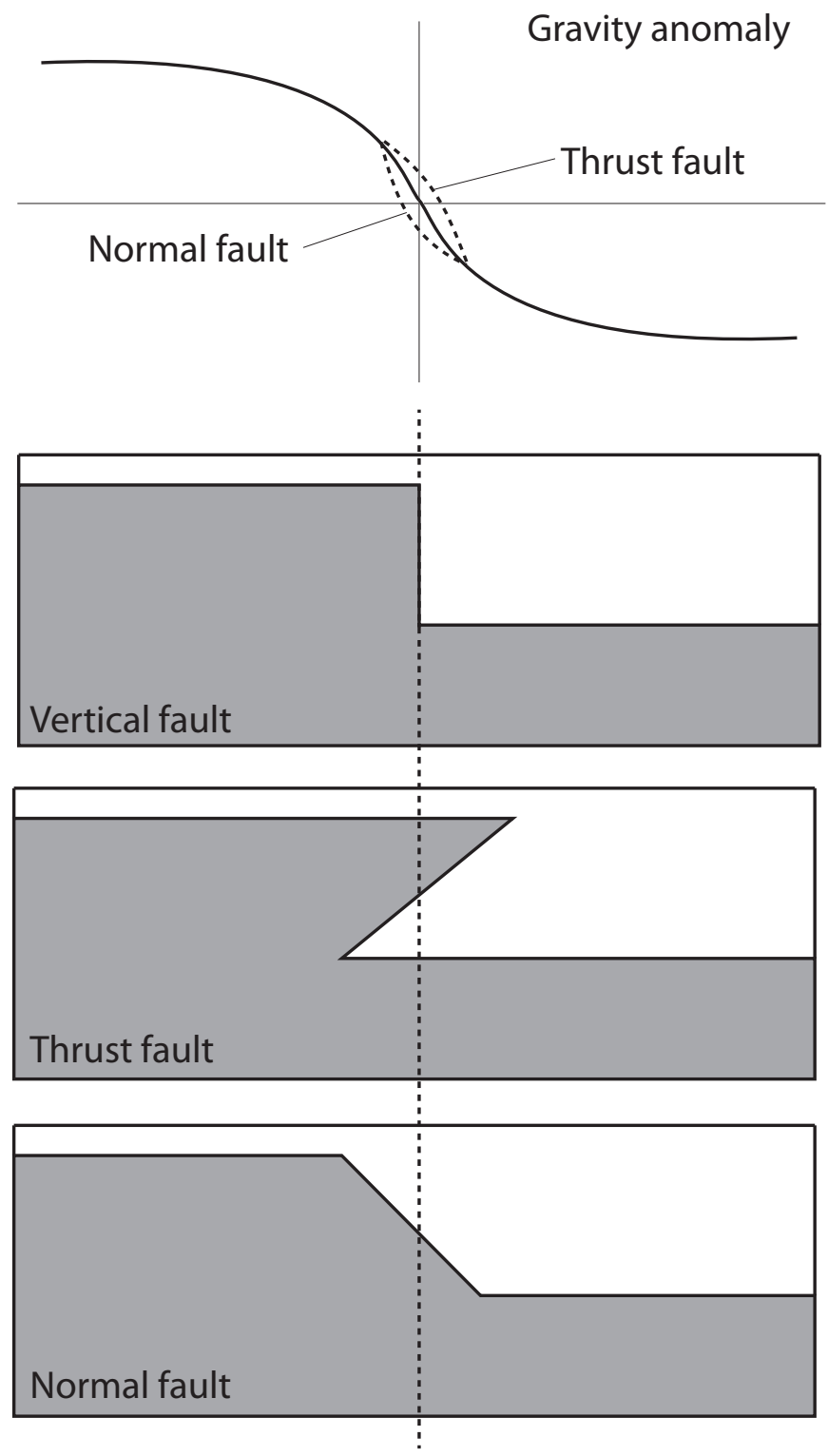

Figure 6.3: Gravity anomalies associated with vertical, thrust and normal faulting.

fault, meaning that the fault type cannot be picked in this manner with any level of confidence.

One possibility is that extensive erosion over the South Westland Fault in 


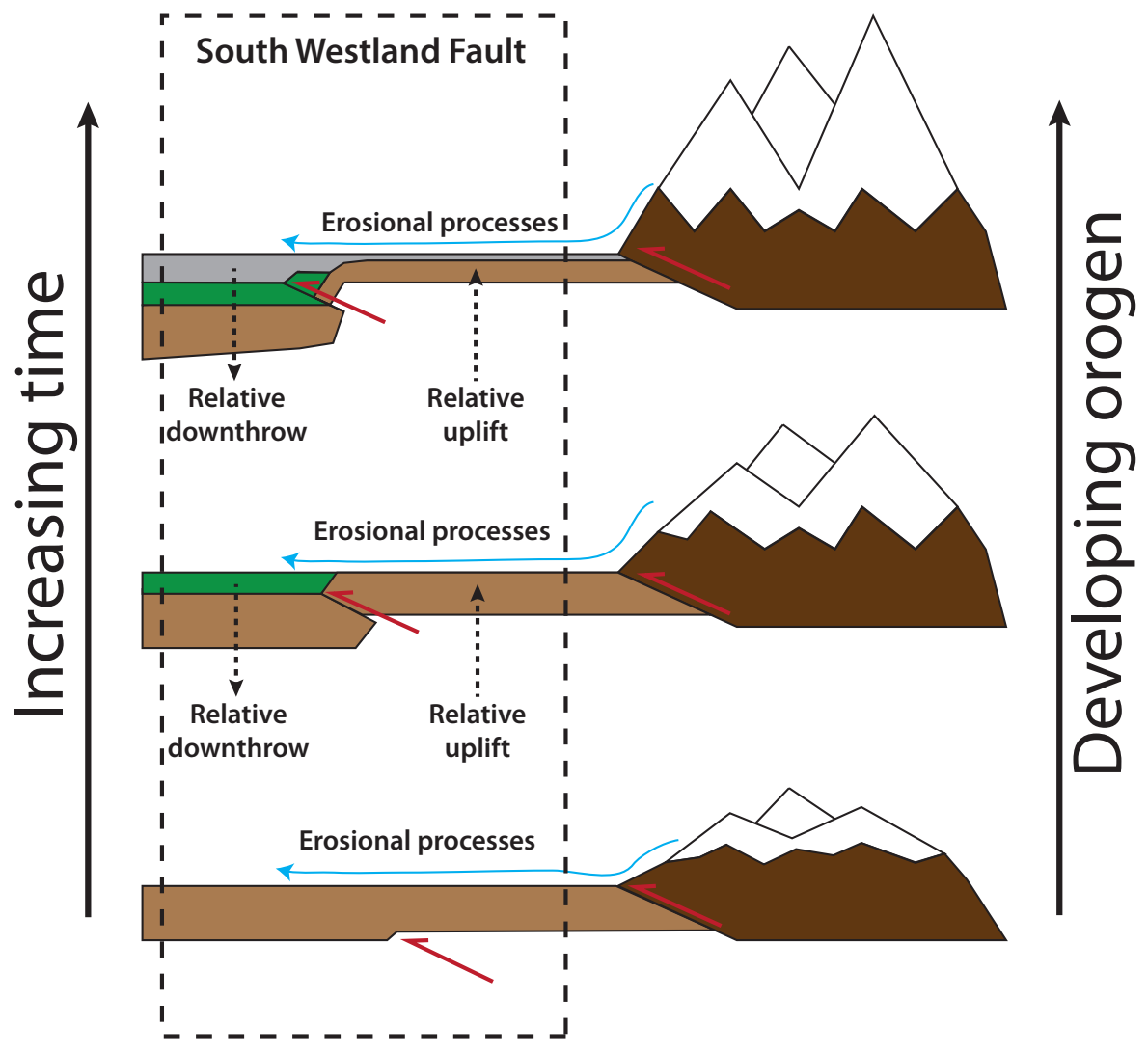

Figure 6.4: Schematic showing the possible processes responsible for the current structure of the South Westland Fault and Basin.

the flood plains continually erodes the thrust segment back toward the Alpine Fault, while thrust faulting warps the stratigraphy of the South Westland Basin into a monoclinal structure, giving the South Westland Fault and Basin its present day structure. Figure 6.4 provides a schematic of how this process may have resulted in the present day structure observed in both seismic and gravity models (Davey, 2010).

The effect of erosion on the South Westland Fault is observable in both the residual gravity map (Figure 4.1) and the gravity gradient map (Figure 4.2). In the flood plains, where erosional processes are focused, the field of the residual gravity and maximum gravity gradient deviates toward the 
Alpine Fault.

There is evidence in the Bouguer gravity field (Figure 3.9) to suggest a possible increase in the rate of uplift south of the Whataroa river flood plain, between the South Westland and Alpine Fault. A relative increase in the Bouguer gravity field, south of the Whataroa flood plain, combined with the outcropping of Buller terrane (see Figure 1.6) around the Waiho flood plain, could indicate that any remnant South Westland Basin, between the South Westland and Alpine Fault, has been completely uplifted and eroded down. Conversely, in the Wanganui and Whataroa flood plains, it has been inferred that the lower section of the Miocene layer belonging to the South Westland Basin still lies between the South Westland and Alpine Fault, and is uplifted relative to the current basin (see Figures 4.4, 4.5 and 4.7). An increase in uplift rate on the South Westland Fault, south of the Whataroa flood plain, is consistent with the results of Kamp et al. (1992), who interpreted an increase in uplift rate going from North to South Westland.

Given the extensive research into inter-plate convergence along the central Alpine Fault in the South Island it is a wonder that comparatively little focus has been put on the South Westland Fault. In order to fully understand the kinematics of the inter-plate convergence on and around the central Alpine Fault, more research focused on the fault structures both east and west of the Alpine Fault needs to be undertaken.

\subsubsection{Offset and slip rates}

\section{Dextral offset and slip rates}

The channel offsets and strike-slip movement rates estimated in the Wanganui, Whataroa and Fox river valleys fill important gaps along the Alpine Fault and assist in understanding the nature of deformation distribution on and around the fault.

The estimated offset of glacial channels since the Last Glacial Maximum are $383 \pm 435 \mathrm{~m}, 372 \pm 94 \mathrm{~m}$, and $450 \pm 138 \mathrm{~m}$ for Wanganui, Whataroa 
and Fox river valleys respectively. The estimated channel offset in the Fox river valley is consistent with published offsets along the central and southern section of the Alpine Fault since the LGM (Sutherland et al., 2006; Norris and Cooper, 2007). Channel offsets observed in the Wanganui and Whataroa river valleys are $\sim 15 \%$ lower, but still agree within the ranges of uncertainty. However, the uncertainties of $\pm 119 \%, \pm 31 \%$ and $\pm 36 \%$ (for the Wanganui, Whataroa and Fox river valleys, respectively) are larger than those of previously published offsets.

The age of channel formation is crucial for obtaining slip rates representative of the true fault movement rate. However, determining the formation age of an offset glacial channel observed through gravity is a difficult task. The only reasonable approach was to investigate a range of formation ages corresponding to primary ice advances at 28,21.5 and 19 ka during the LGM (Suggate and Almond, 2005). Over the three river valleys the slip rates determined for a formation age of 28 ka range between $13.3-16.1 \mathrm{~mm} / \mathrm{yr}$ and between $17.3-20.9 \mathrm{~mm} / \mathrm{yr}$ for a formation age of $21.5 \mathrm{ka}$. These slip rates are considerably lower than previously determined rates along the central Alpine Fault. A formation age of 19 ka produces slip rates ranging between $19.6-23.7 \mathrm{~mm} / \mathrm{yr}$ over the three flood plains, consistent with previously determined movement rates.

Using a channel formation age of $19 \mathrm{ka}$ is logical in the fact that it corresponds to the last of the major ice advances which shaped and defined the present day structure of not only the offset glacial channels, but the topography of the hanging wall valleys. This is important as the projection of past glacial movements are based on the topography of the hanging wall river valleys, which were last glacially modified by the major ice advance at $19 \mathrm{ka}$. This means that the age of channel formation used in the slip rate determination is consistent with the age of topography used to determine the channel offset. For this reason 19 ka is the preferred formation age for the offset channels observed in gravity.

Figure 6.5 shows a plot of the compiled Quaternary strike-slip rates along 


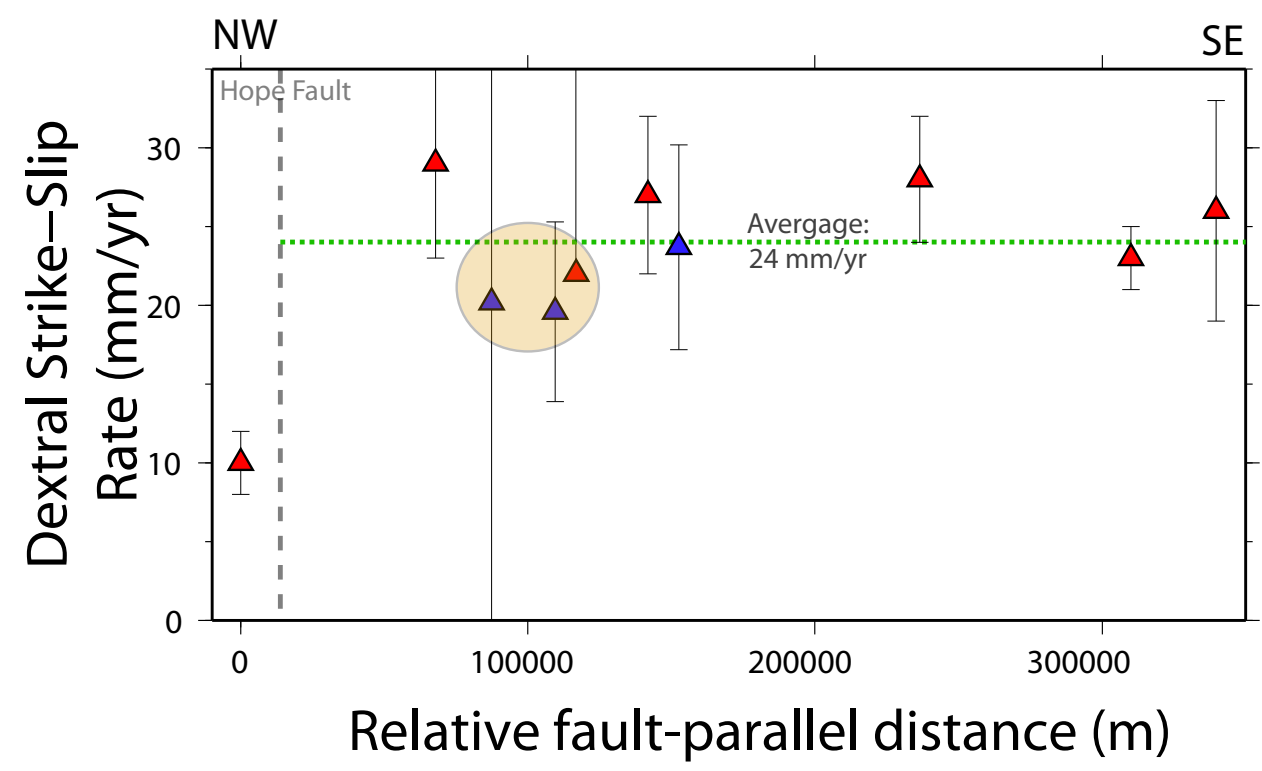

Figure 6.5: Compiled strike-slip movement rates on the Alpine Fault, south of the Hope Fault. Red triangles are previously compiled strike-slip movement rates from Norris and Cooper (2007); blue triangles are the preferred strikeslip movement rates from this study, using a formation age of 19 ka. The green dotted line represents the combined average of rates south of the Hope Fault, which is $24.4 \mathrm{~mm} / \mathrm{yr}$.

the Alpine Fault, from this study and those presented by Norris and Cooper (2007). The average of all strike-slip rates south of the Hope Fault is 24.0 $\mathrm{mm} / \mathrm{yr}$, which falls within the uncertainty of all individual slip rates, and has a standard deviation of $3.4 \mathrm{~mm} / \mathrm{yr}$. The strike-slip movement rate estimated the Fox river valley is $23.7 \pm 8.5 \mathrm{~mm} / \mathrm{yr}$ which is consistent with this average, suggesting that this rate is well determined.

From Figure 6.5 it would reasonable to suggest that strike-slip movement rates along the central and southern Alpine Fault are largely constant. It could be argued that the circled slip rates in Figure 6.5 show an slight decrease between the Kakapotahi river and Franz Josef, an area where the fault trace is serially partitioned into thrust and strike-slip fault segments (Norris 
and Cooper, 2007). The pattern of serial partitioning could increase the resistance to strike-slip movement along the trace of the fault, resulting in a portion of the stress deformation being released on structure away from the fault, reducing the strike-slip rate observed. However two of the circled rates have the highest associated uncertainties, making it unreasonable to draw conclusions from them.

\section{Uncertainty and method improvement}

It has been shown that gravity surveying can be used to effectively quantify the offset of subsurface features, providing an alternative option in areas which lack traditional offset markers. As seen above, the uncertainties associated with the offset and slip-rates estimated with this technique, can be significant. The primary sources of uncertainty include:

- The inability to accurately determine the age of subsurface features. As seen above, a range of ages were investigated resulting in a large uncertainty in the true strike-slip movement rate of each area.

- Gravity profiles further from the fault trace may not estimate the true fault offset, as glacial paths may deviate between the fault and gravity profile. Additionally, any uncertainty associated with the projection of glacial trajectory onto the closely spaced line will increase accordingly.

- The trajectories of glaciers crossing the Alpine Fault are estimated using the surface topography of the hanging wall river valley. It is assumed that the walls of these river valleys are shaped primarily by the last glacial advance. However, since the LGM the valley walls have been exposed to fluvial erosion, which increases the uncertainty in the trajectories determined by their topography.

There are several ways that this method could be improved in order to yield lower uncertainties. Figure 6.6 gives a schematic diagram of a suggested survey setup which would produce more constrained channel offsets. 
By measuring two fault-parallel gravity profiles on each side of the fault, the glacial path could be projected onto the fault trace through the gravity minima along each profile. This removes the reliance on topography to determine the glacial trajectory, and also allows for any deviation in the trajectory of a glacier as it crosses the fault.

This method would also be improved by supplementing it with other geophysical techniques, such as seismic reflection/refraction and aeromagnetic surveying. These techniques would help reveal the shape and path of the offset channel structure, refining the offsets determined.

\section{Accommodation of convergence}

Strike-slip rates determined in this study reinforce the argument that the rate of strike-slip movement on the central and southern Alpine Fault is largely constant (Norris and Cooper, 2007). In the central Alpine Fault a strikeslip movement rate of $24 \mathrm{~mm} / \mathrm{yr}$ accounts for $68 \%$ of the relative strike-slip movement between the Pacific and Australian continental plates, supporting arguments that $2 / 3$ of inter-plate strain is accommodated as deformation on the Alpine Fault and that the distribution of deformation is constant along the fault, south of the Hope Fault. The remaining $1 / 3$ of strain deformation is accommodated by structures east and west of the Alpine Fault (Sutherland et al., 2006; Beavan et al., 1999). 


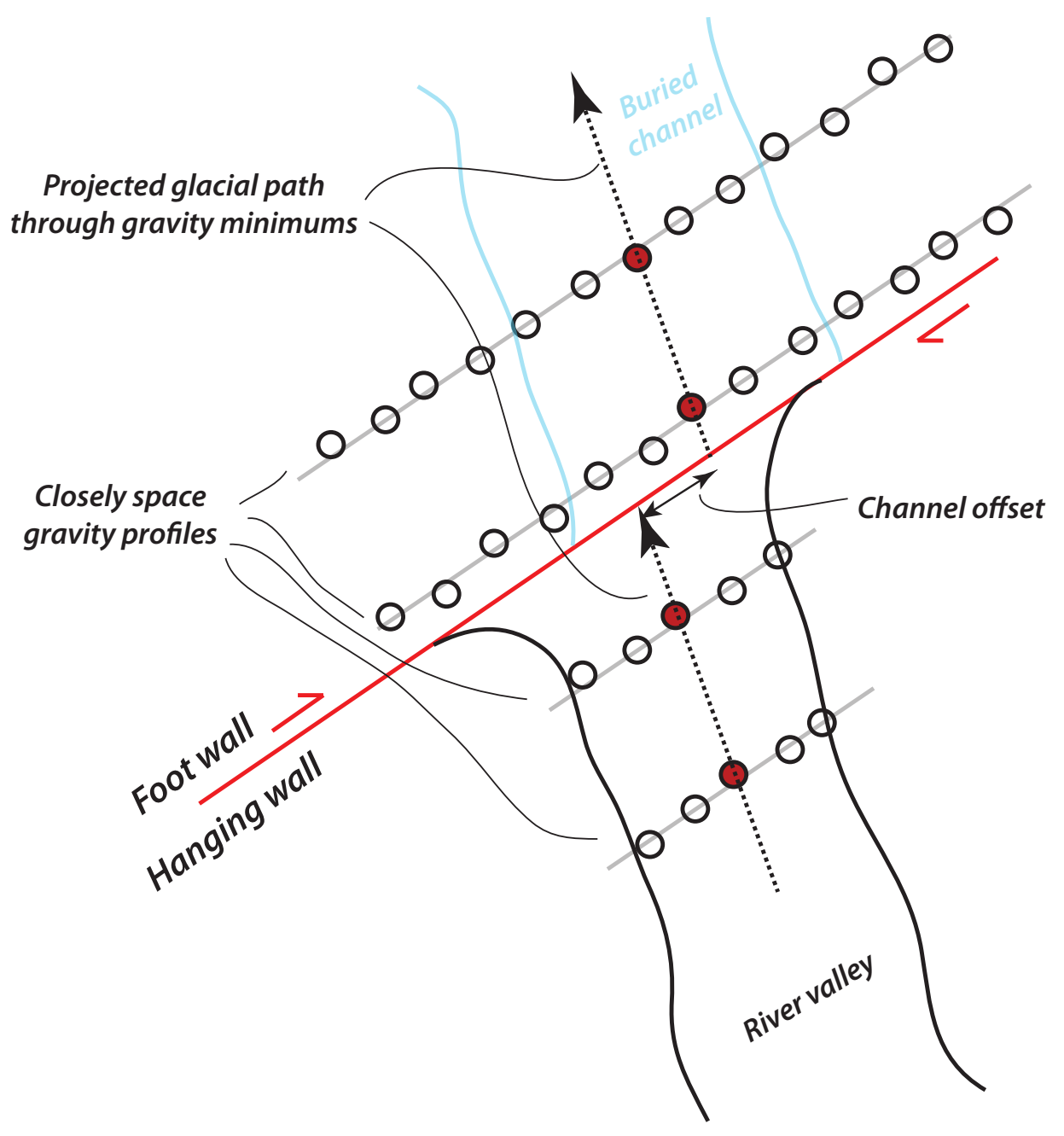

Figure 6.6: Schematic diagram of the suggested survey design in order to yield channel offsets with lower uncertainty. Two fault-parallel gravity profiles on each side of the fault enables the historic glacial path to be projected onto the fault trace through gravity minima along each profile. Red circles are the location of channel/gravity minimums along each profile. 


\subsection{Conclusions}

The key findings of this study are summarised below:

- Extensive dextrally offset fluvioglacial erosion is recorded in gravity data over the central West Coast. Glacial channels within the flood plains are interpreted to reach depths of $>800 \mathrm{~m}$. The pre-existing erosional structure appears to have controlled further glacial advance and the formation of surface topography in the central West Coast flood plains. Continuing dextral offset and erosional processes give rise to the continually stretching "lazy Z" shape of the flood plains.

- Gravity models of the structure of the South Westland Fault and Basin are consistent with the seismic model of Davey (2010). The 2-3/4D models reveal uplifted basement rock and monoclinal basin structure associated with the South Westland Fault, suggesting the fault is a transition between a thrust-fault driven monocline structure to the south and the steeply-dipping Hohonu thrust fault, north of the field area.

- Erosional processes focused in the flood plains have eroded the trace of the South Westland Fault back toward the Alpine Fault. This is seen as deviations of the residual gravity field to the southeast. This indicates that the trace of the fault may lie closer to the Alpine Fault than depicted in the Aoraki QMAP.

- Alpine Fault offset since the Last Glacial Maximum is estimated to be $383 \pm 435 \mathrm{~m}, 372 \pm 94 \mathrm{~m}$, and $450 \pm 138 \mathrm{~m}$ for the Wanganui, Whataroa and Fox river valleys, respectively. These offsets yield dextral strike-slip movement rates of $20.2 \pm 24.05,19.6 \pm 6.0$ and $23.7 \pm 8.5$ $\mathrm{mm} / \mathrm{yr}$, assuming a LGM date of $19 \mathrm{kyr}$.

- Strike-slip movement rates reinforce the widely published observation that the Alpine Fault accommodates $2 / 3$ of relative strike-slip interplate motion as deformation. 
Appendix A

Appendix A 


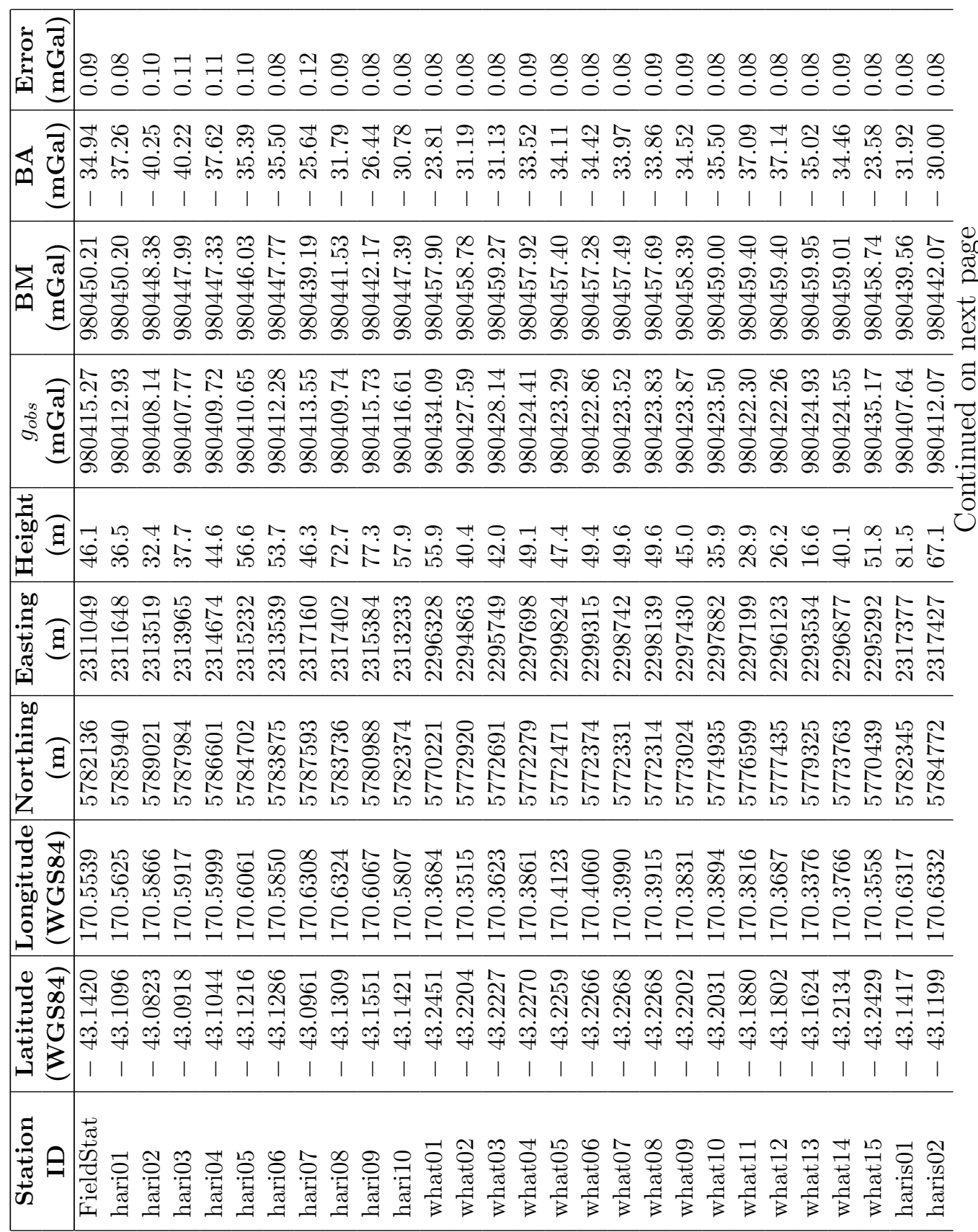


กี่

苟

สิ

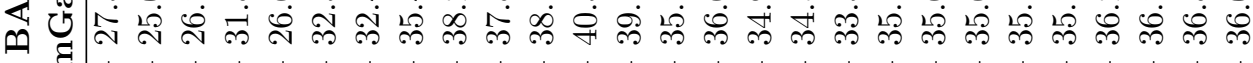

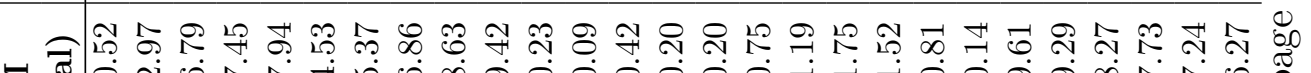

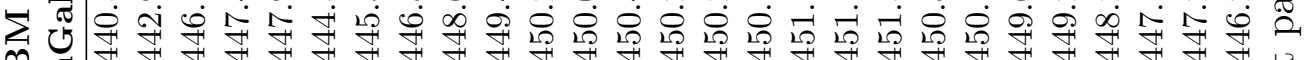

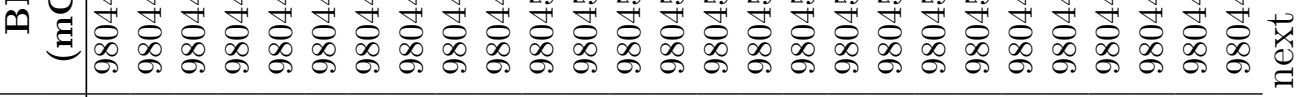

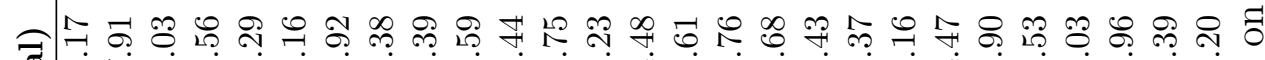

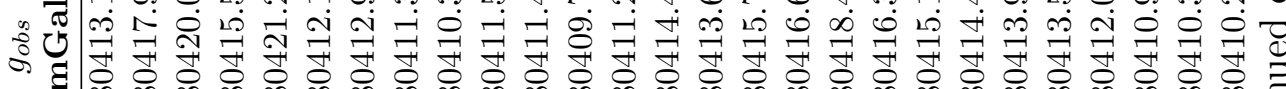

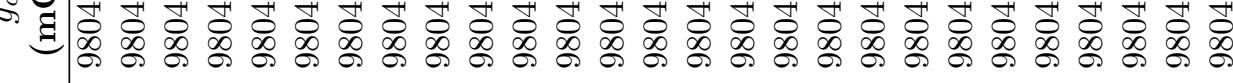

:

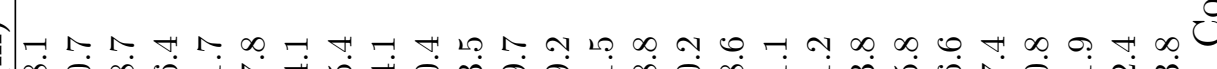

60 ก

N

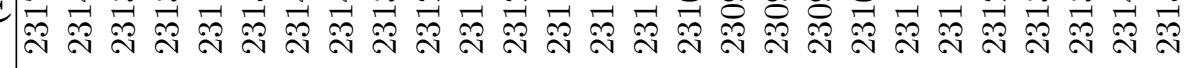

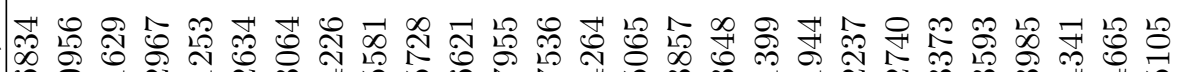

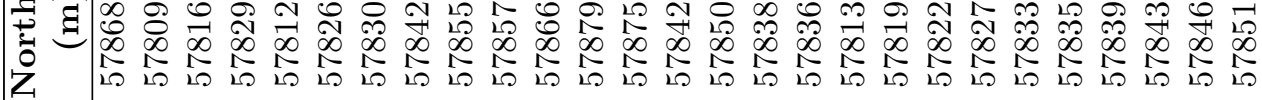

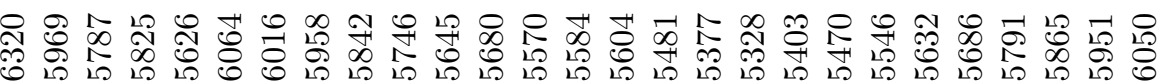

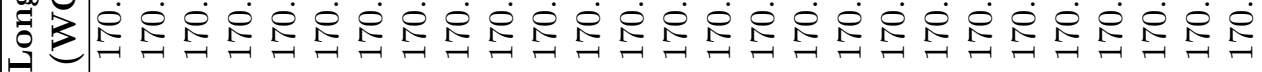

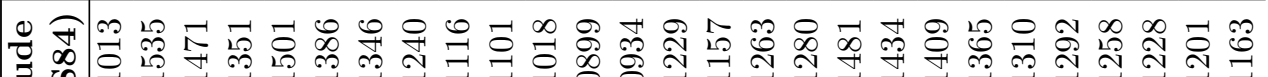

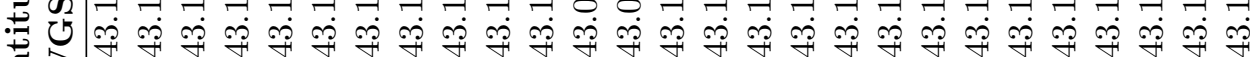

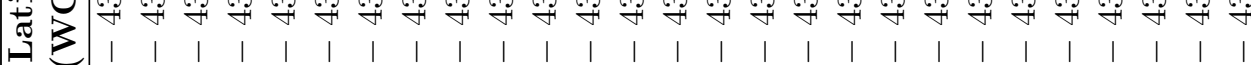

$\approx$

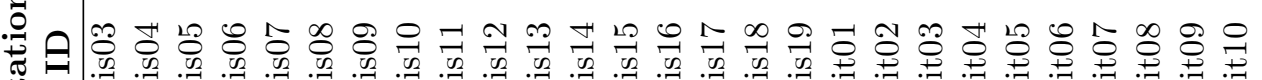

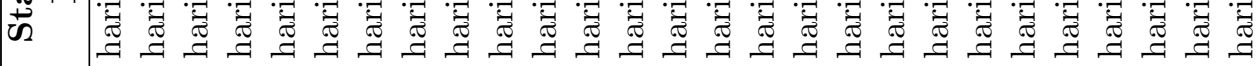




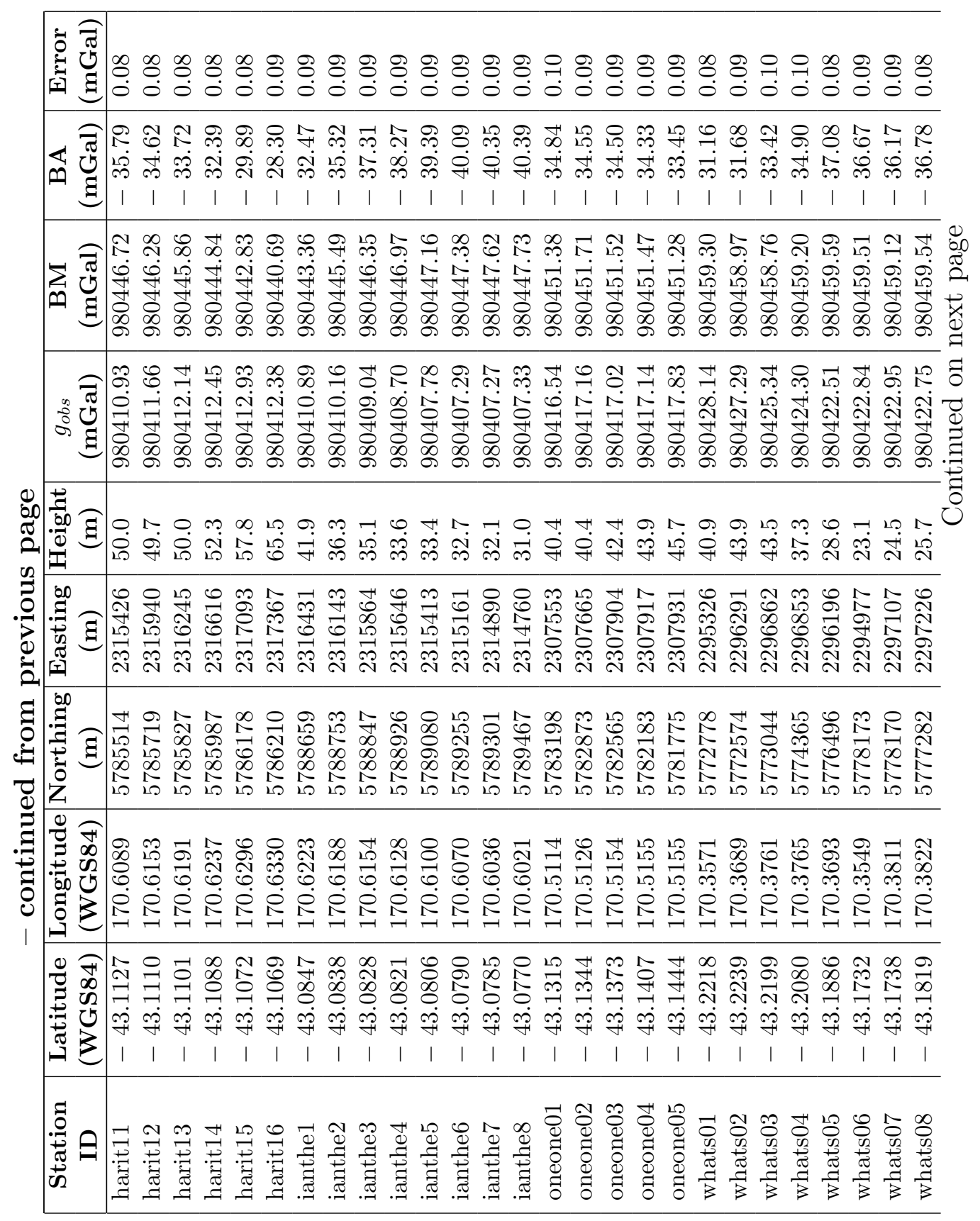




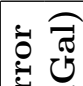

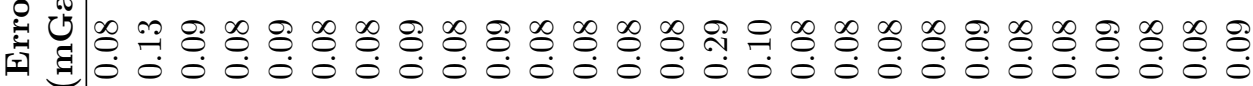

สิษ

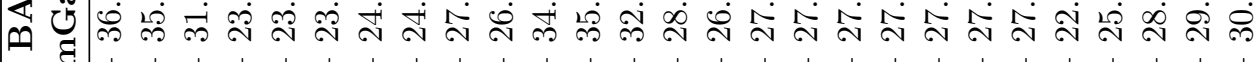

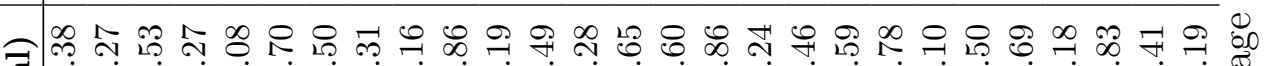

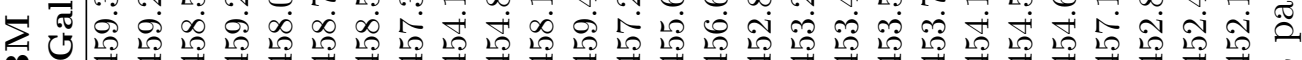

ص

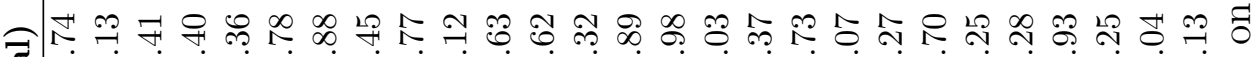

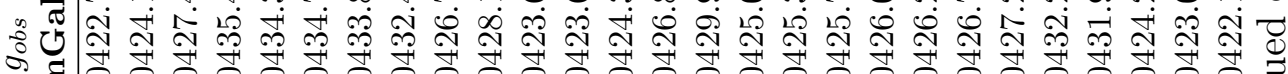

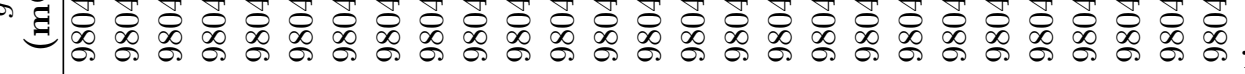

$\frac{10}{20}$

.

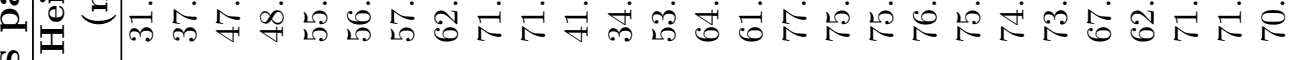

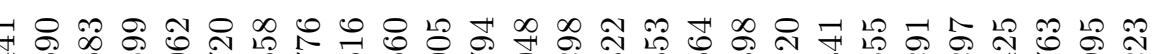

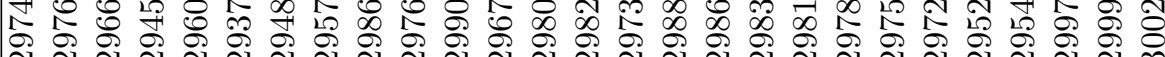

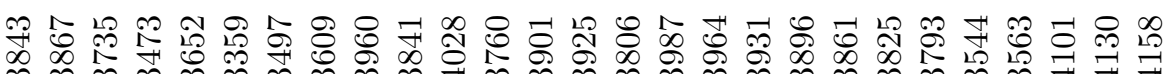

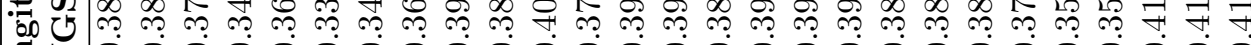

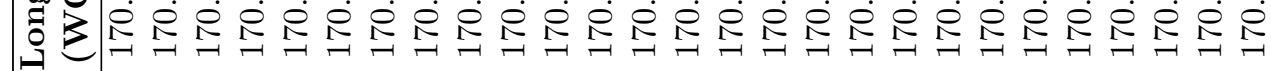

ช

Đo

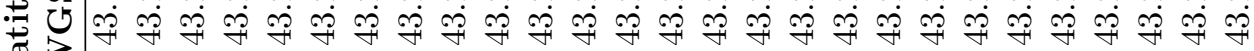

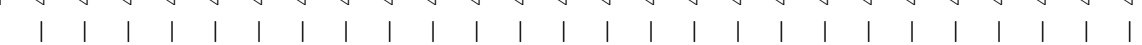

$\approx$

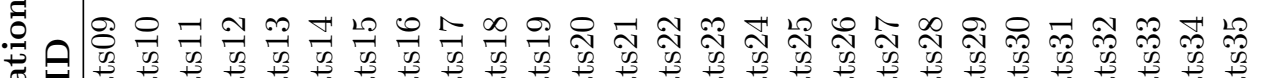

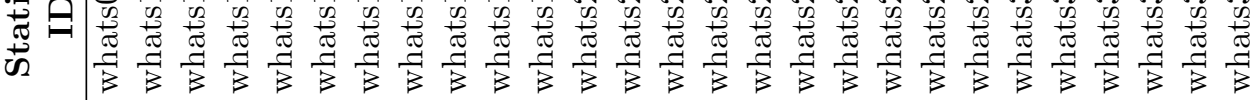




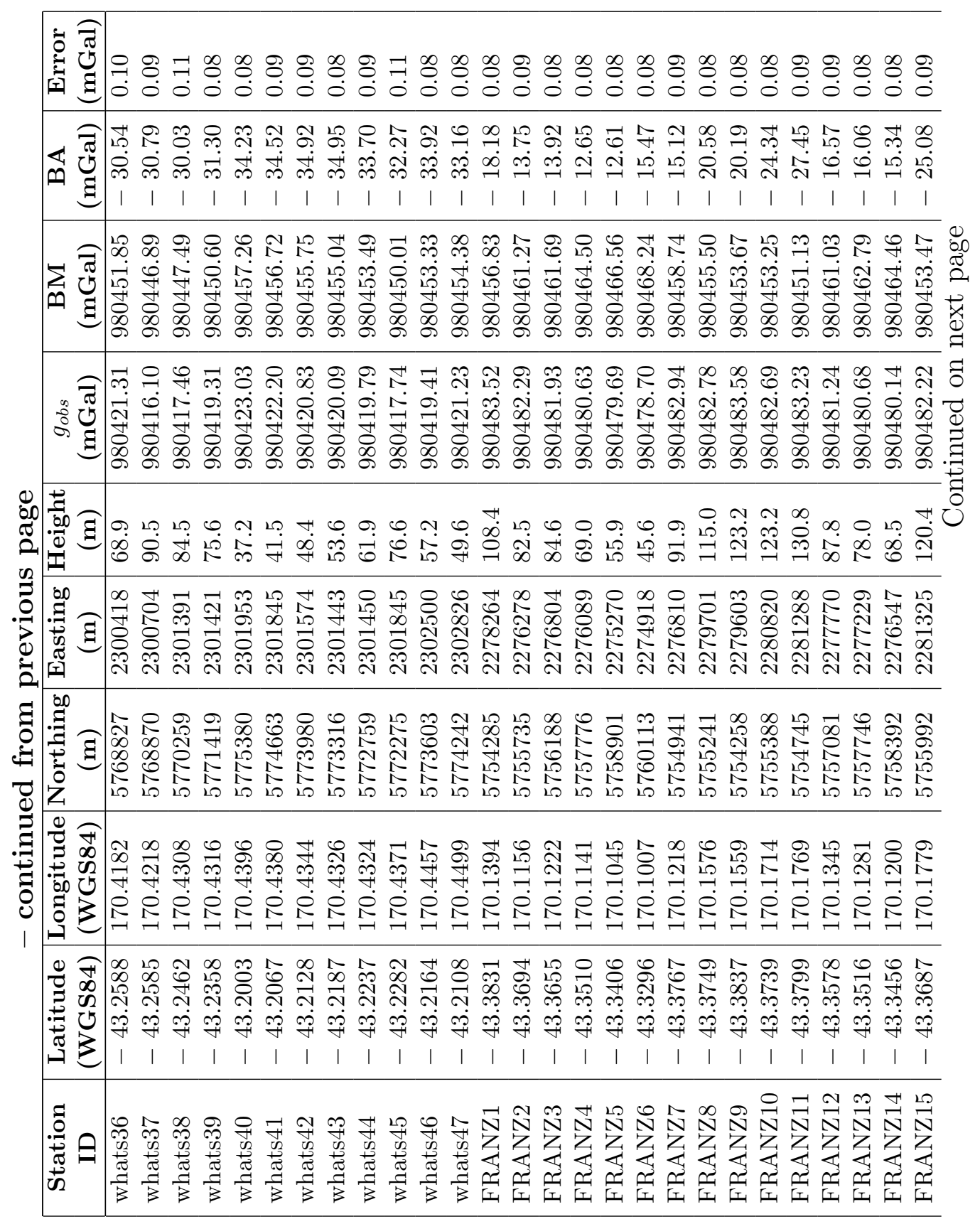




\section{דิ}

武 岁

สิ

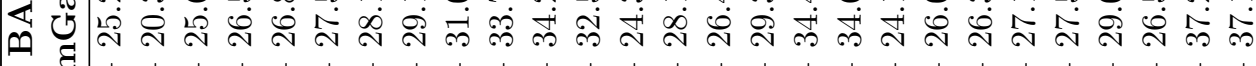

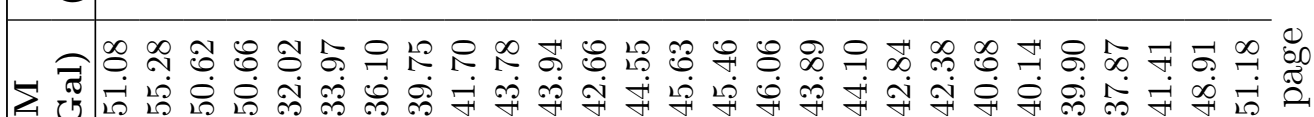

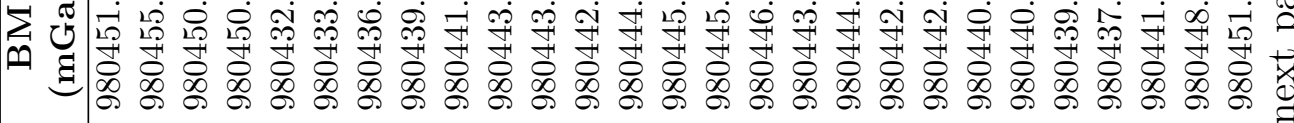

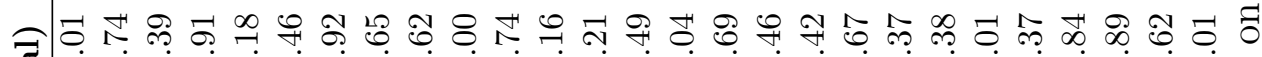

类

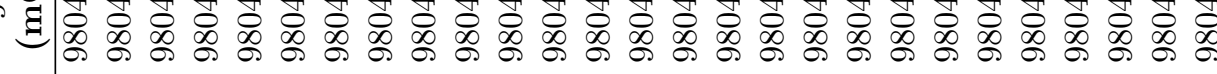

80

$\frac{10}{00} \bigcirc 0.0 .0$

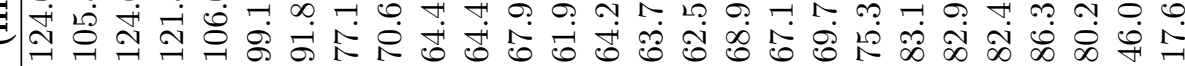

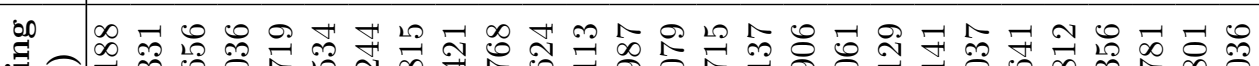

可

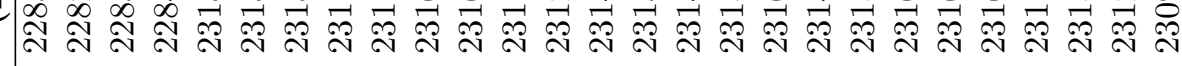

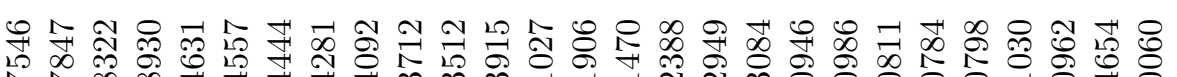

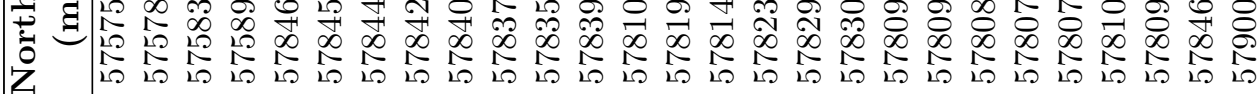

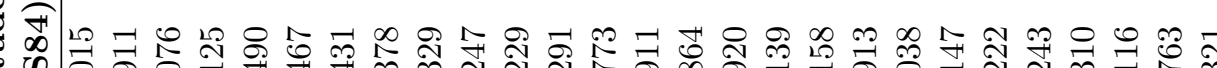

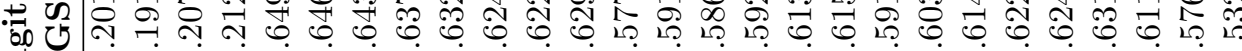

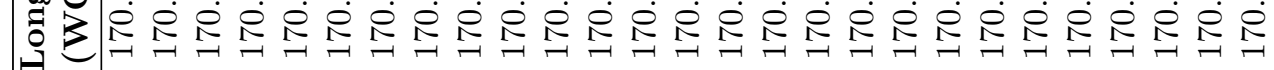

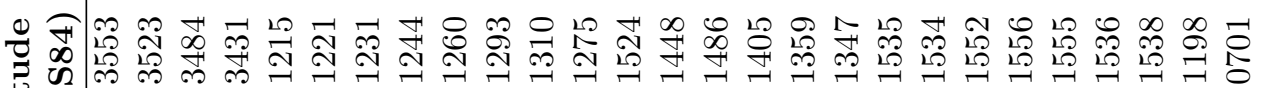

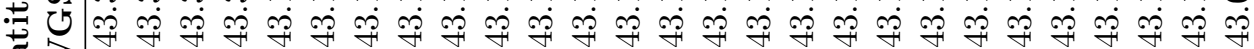

$=\stackrel{0}{\sim} \sim \infty$

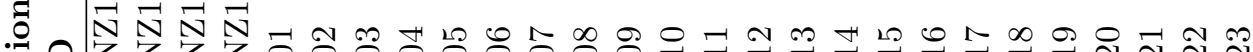

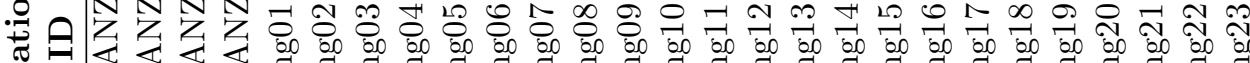

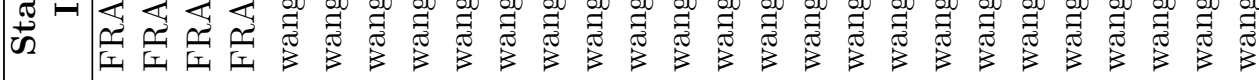




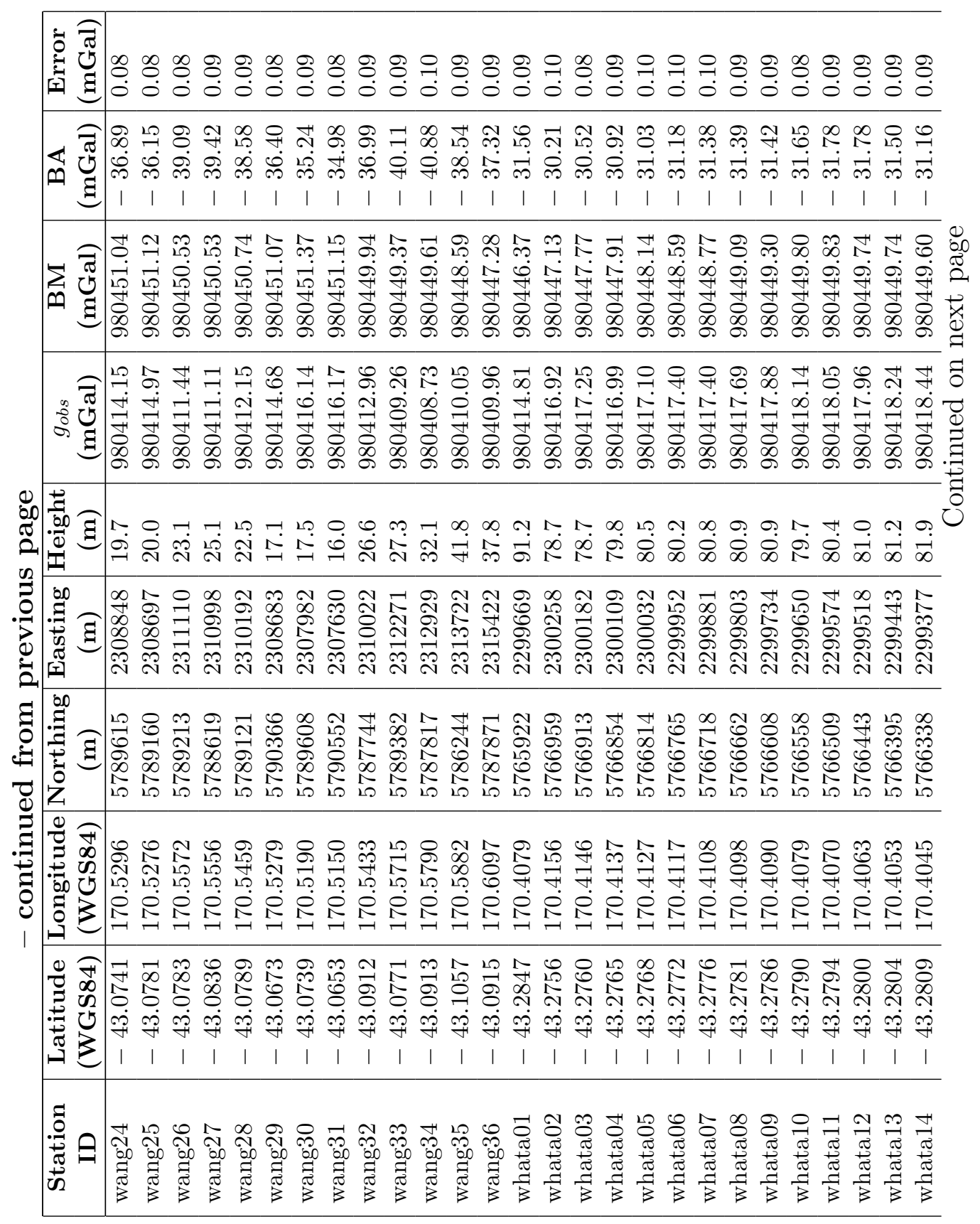


๑ึ

类

สิ

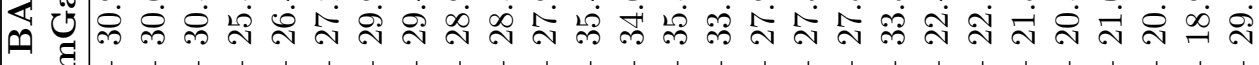

حึ

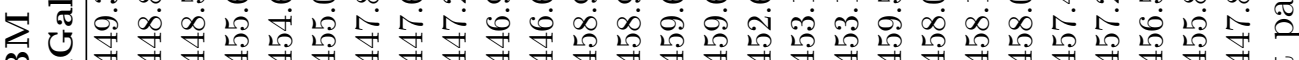

ص

ภิ่

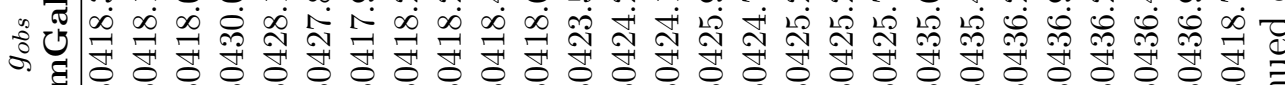

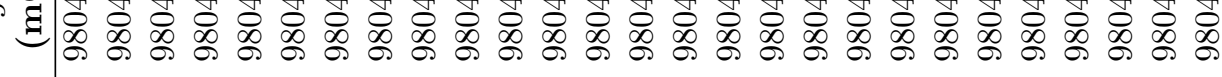

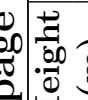

N N N N N

舟

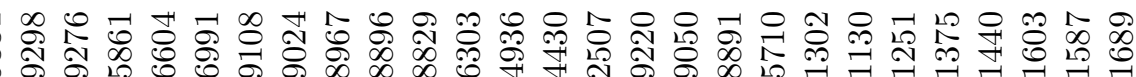
令 令 ৯

융

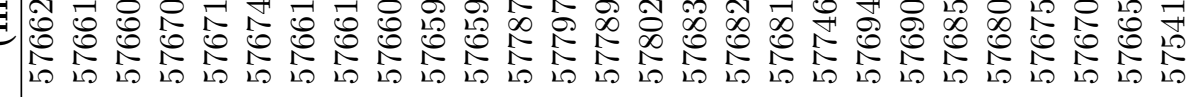

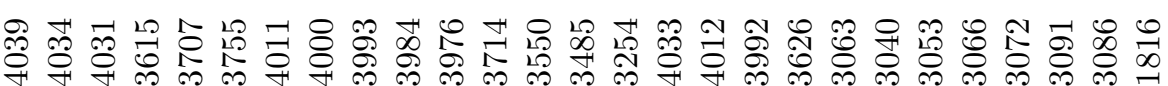

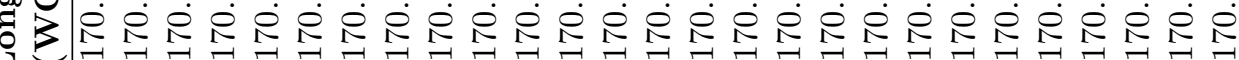

๑ ح

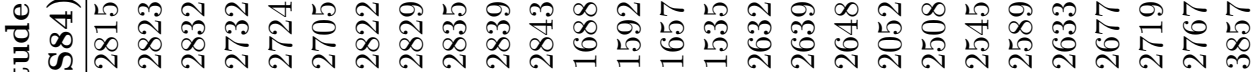

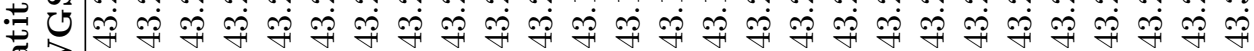

문 票 


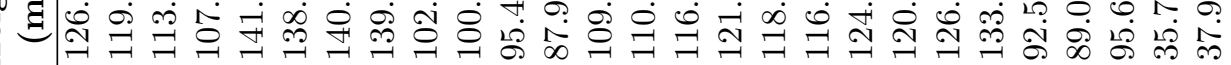

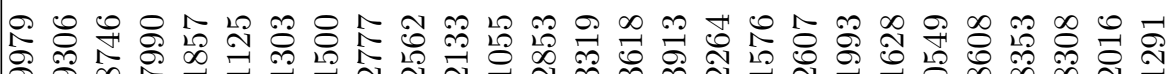

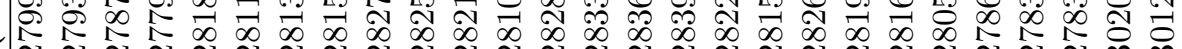

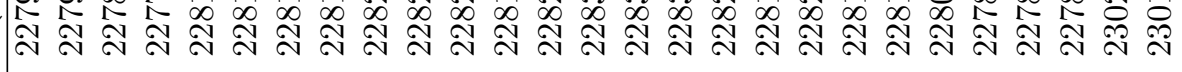

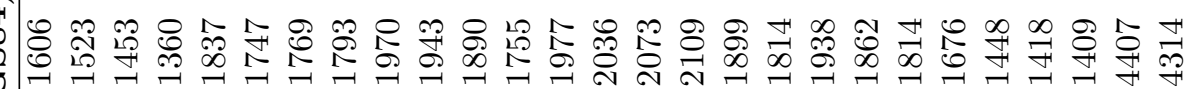

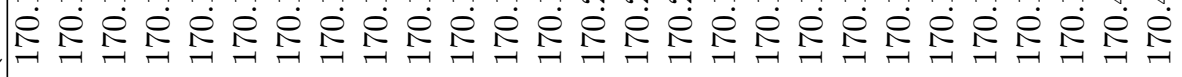

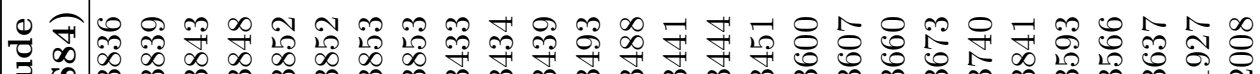
U

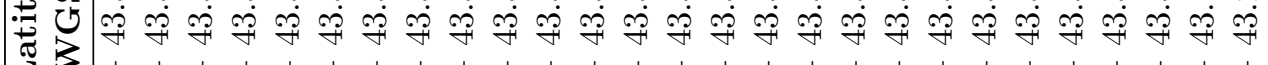


กิ สำ

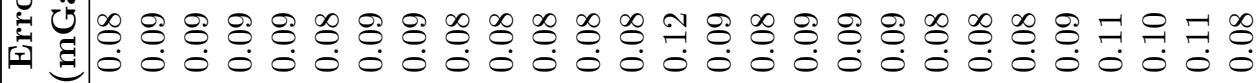

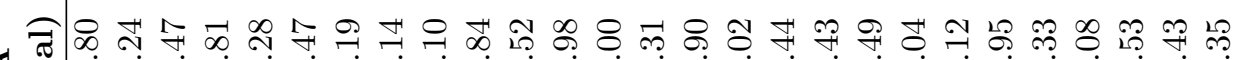

ब

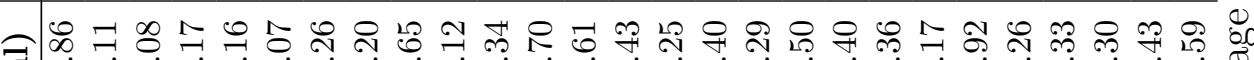

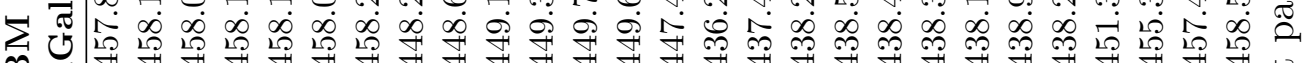

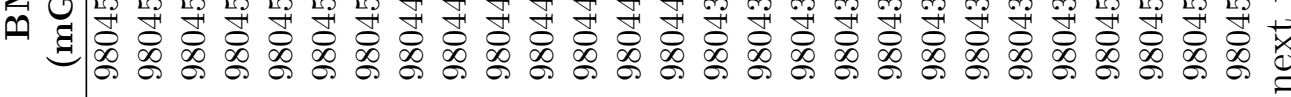

|

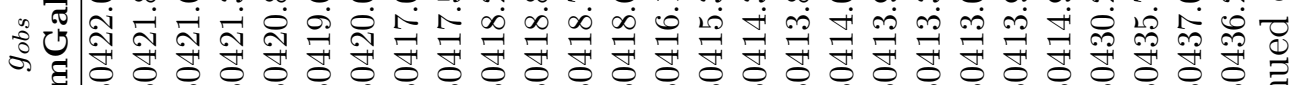

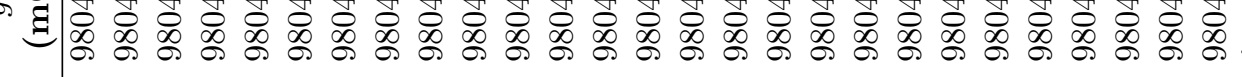

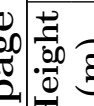

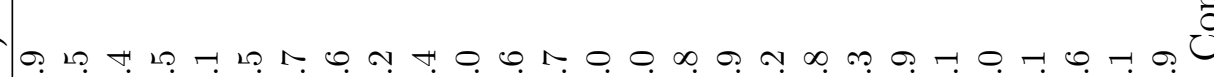

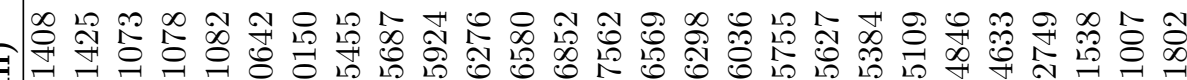

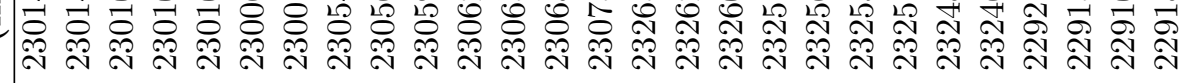

60

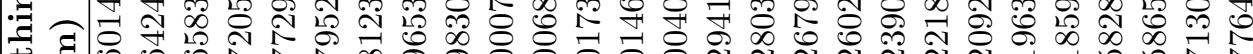

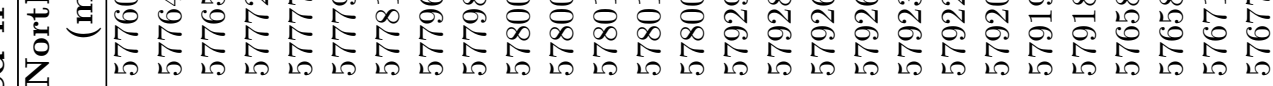

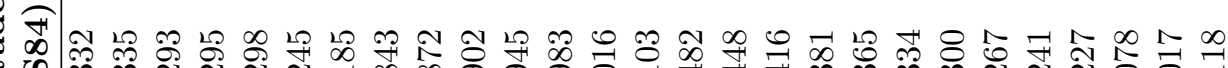

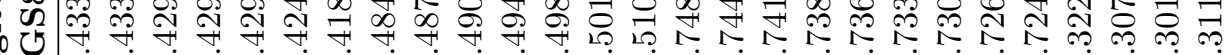

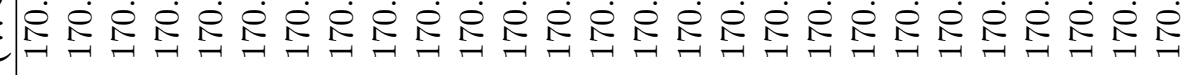

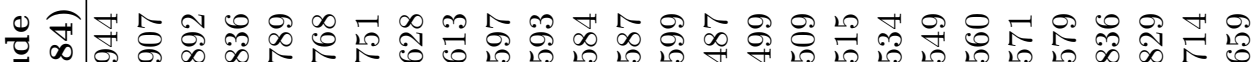

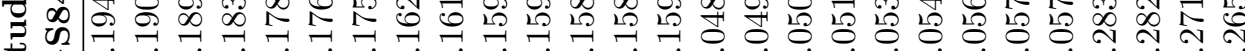

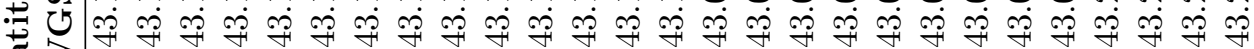

$\approx$

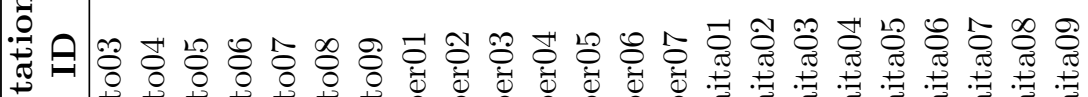

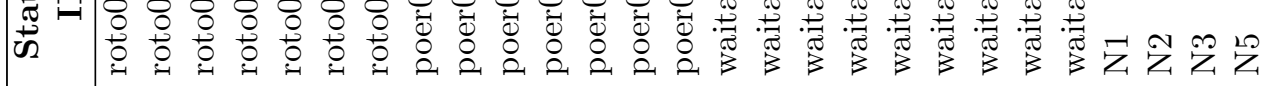




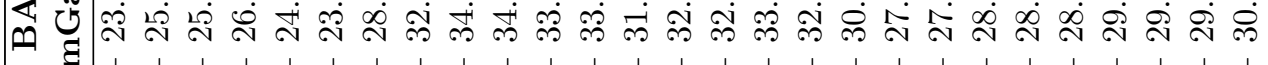

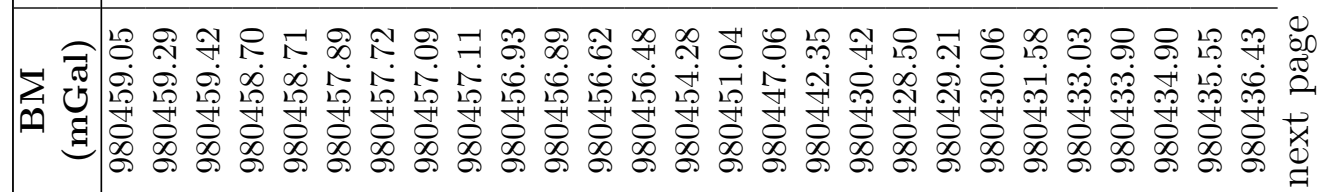

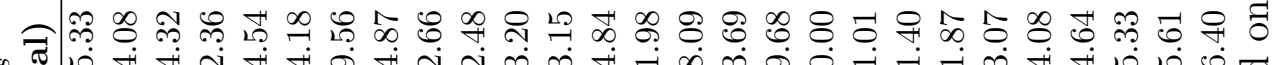

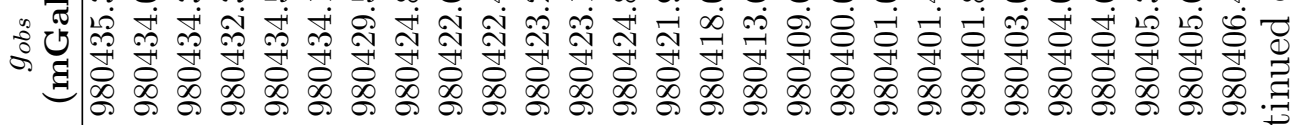

녁

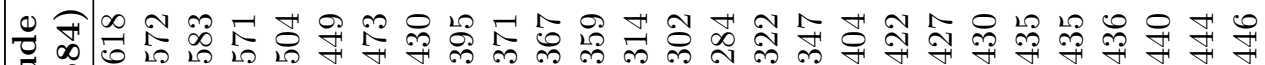

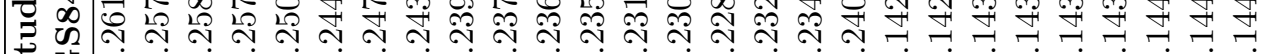

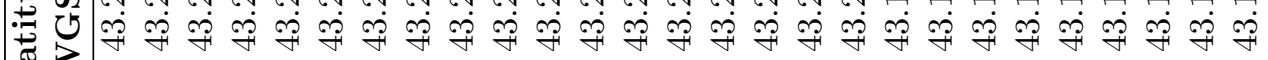

I 蕞

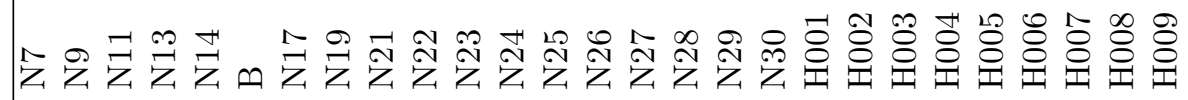




\section{จิ สิ}

武

สิธี

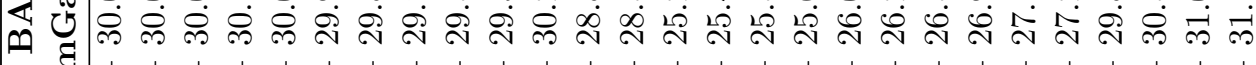

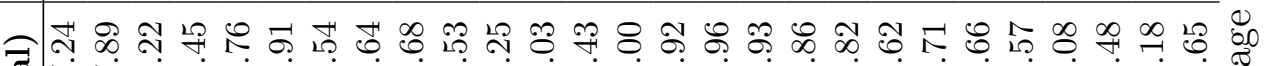

之

m

드

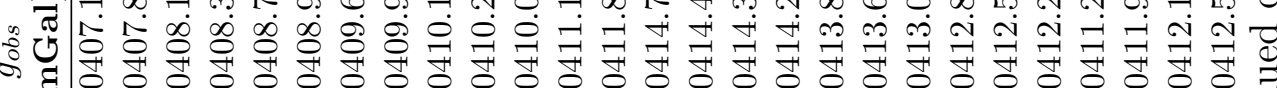

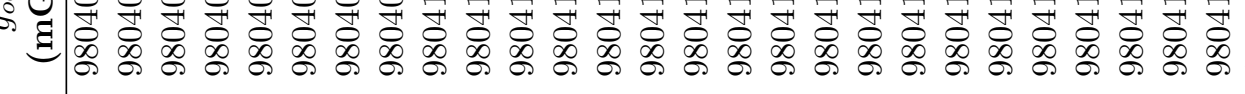

80

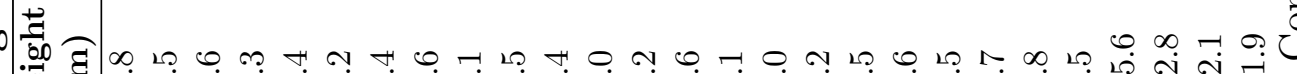

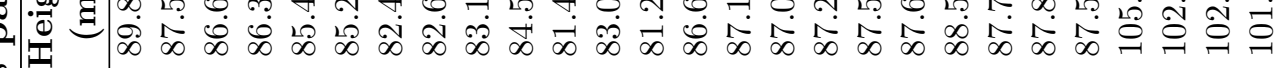

20.

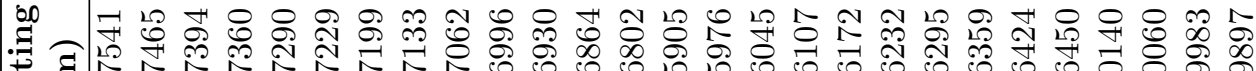

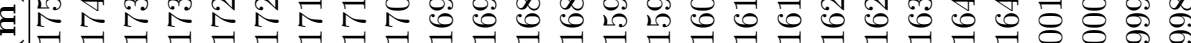

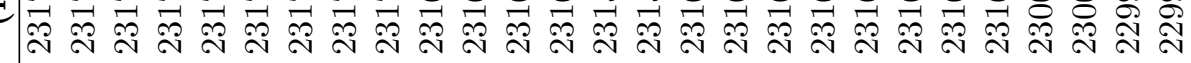

60

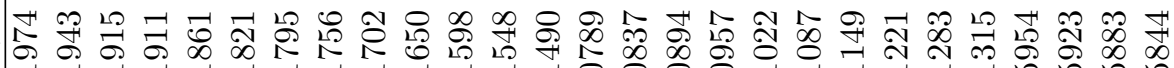

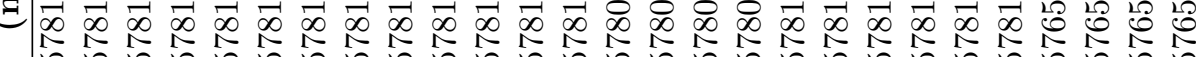

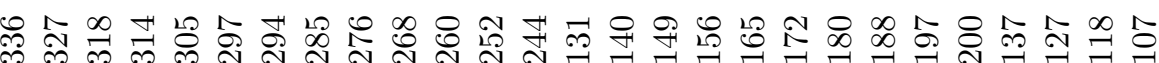

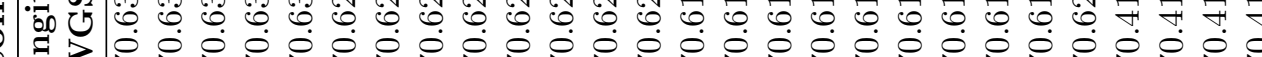

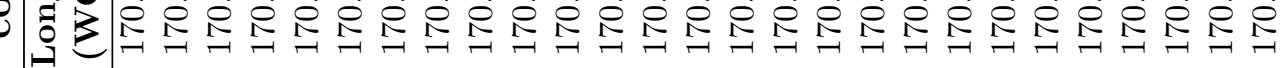

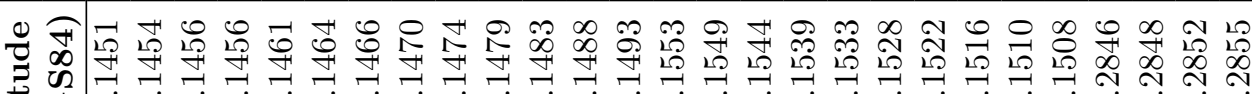

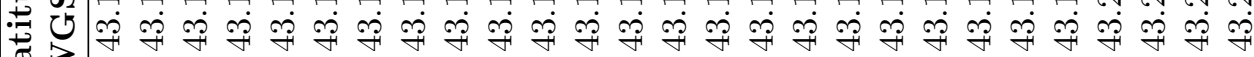

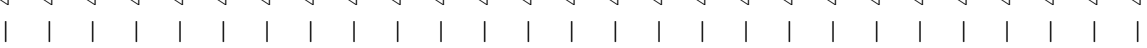

$\approx$

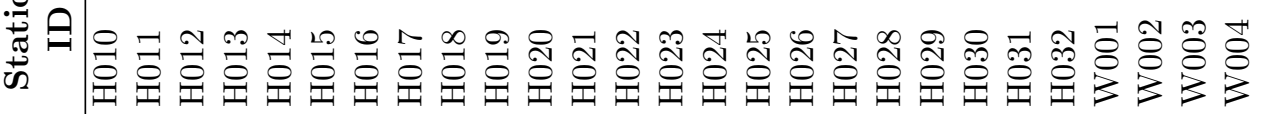




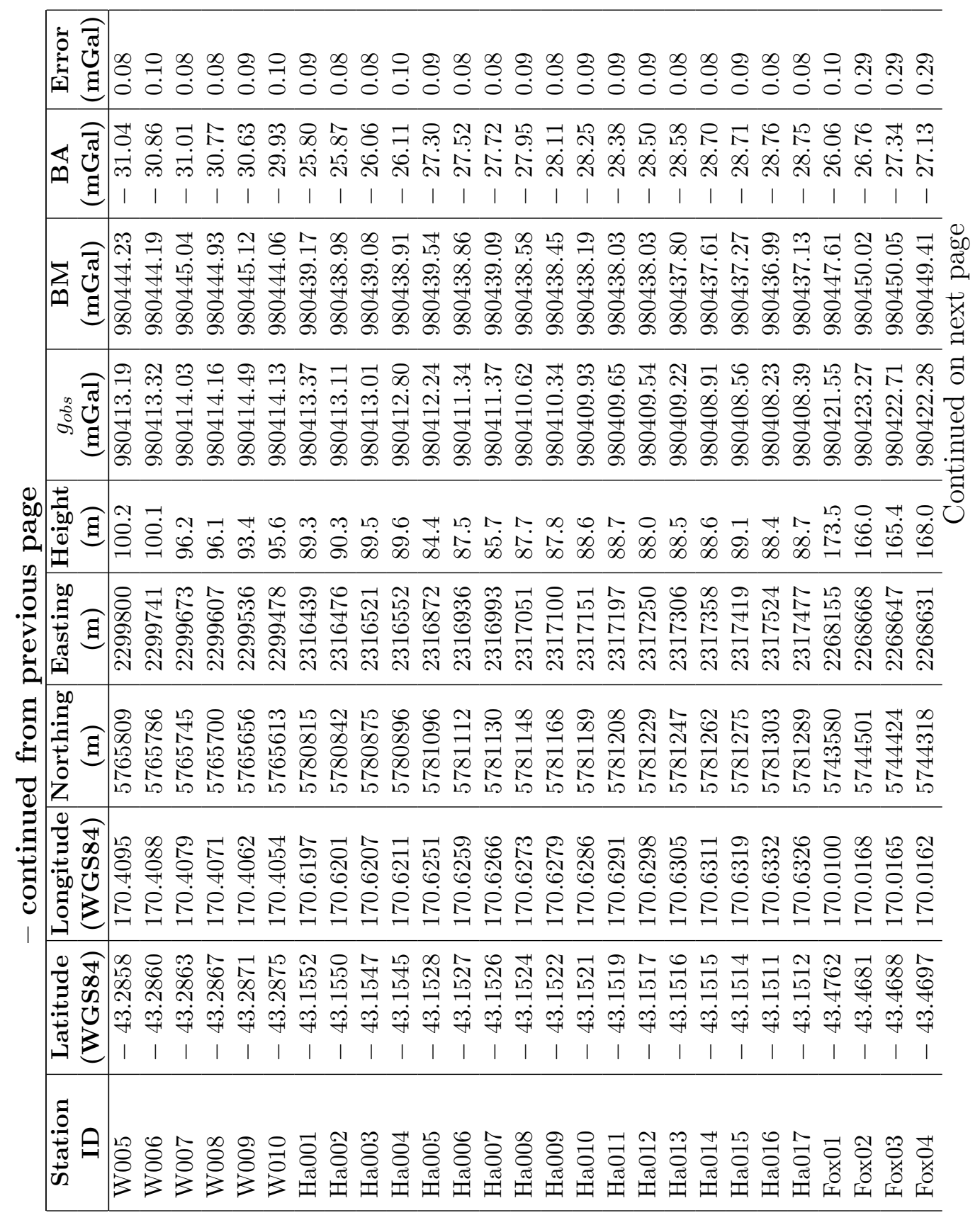




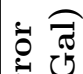

氙

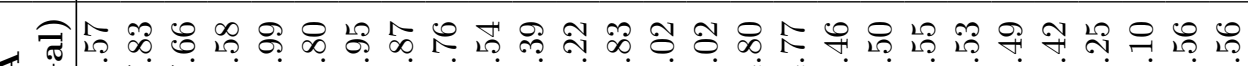

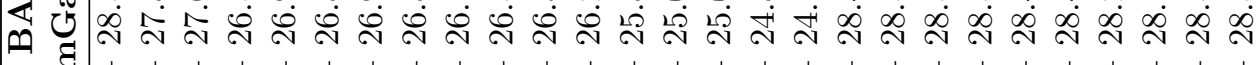

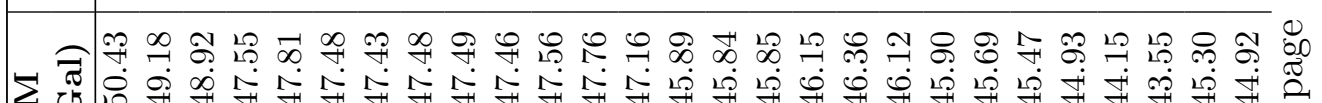

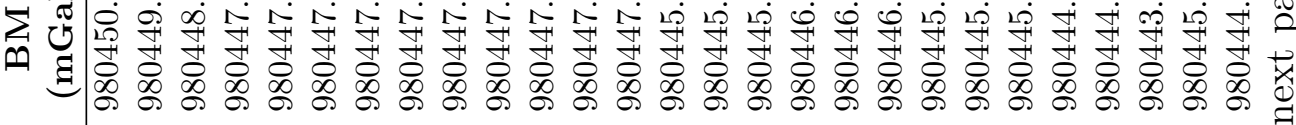

శ⿻

需

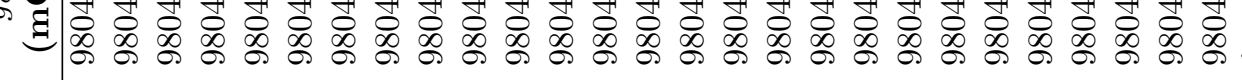

8

H

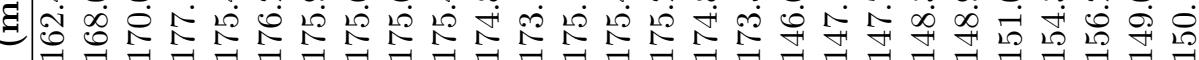

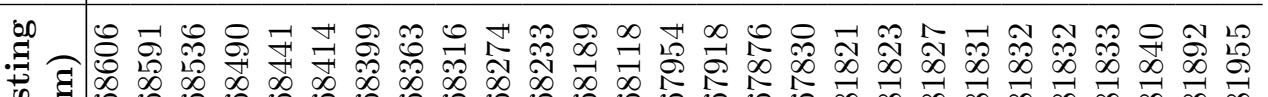

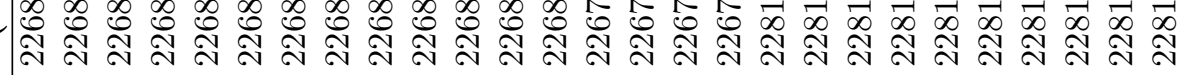

సี

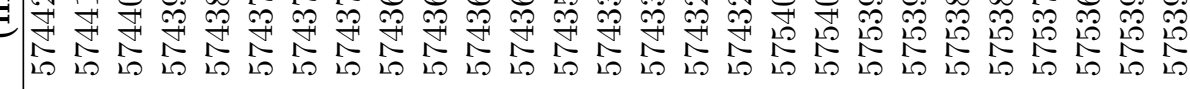

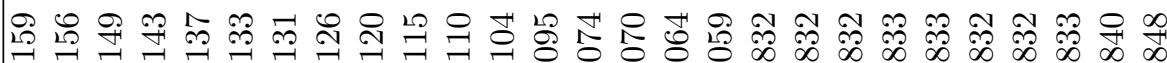

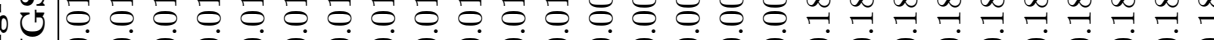

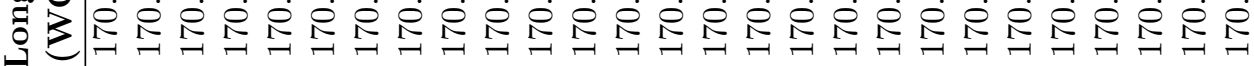

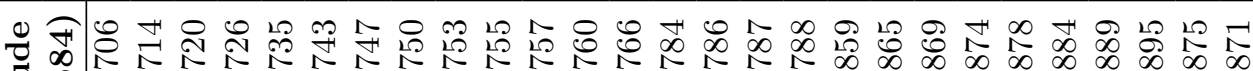

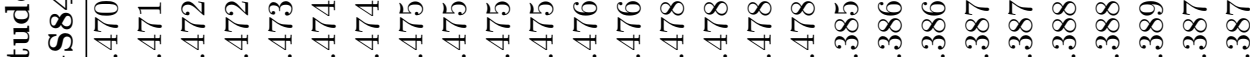

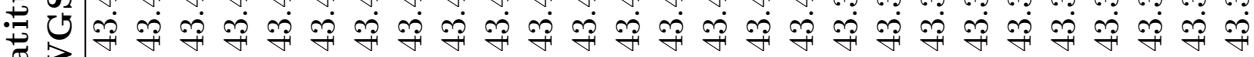

๘

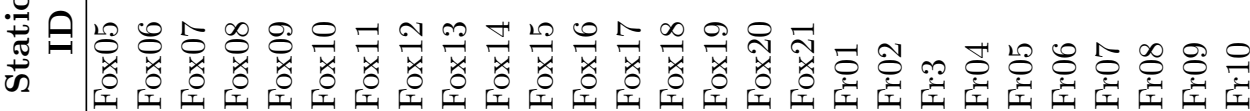




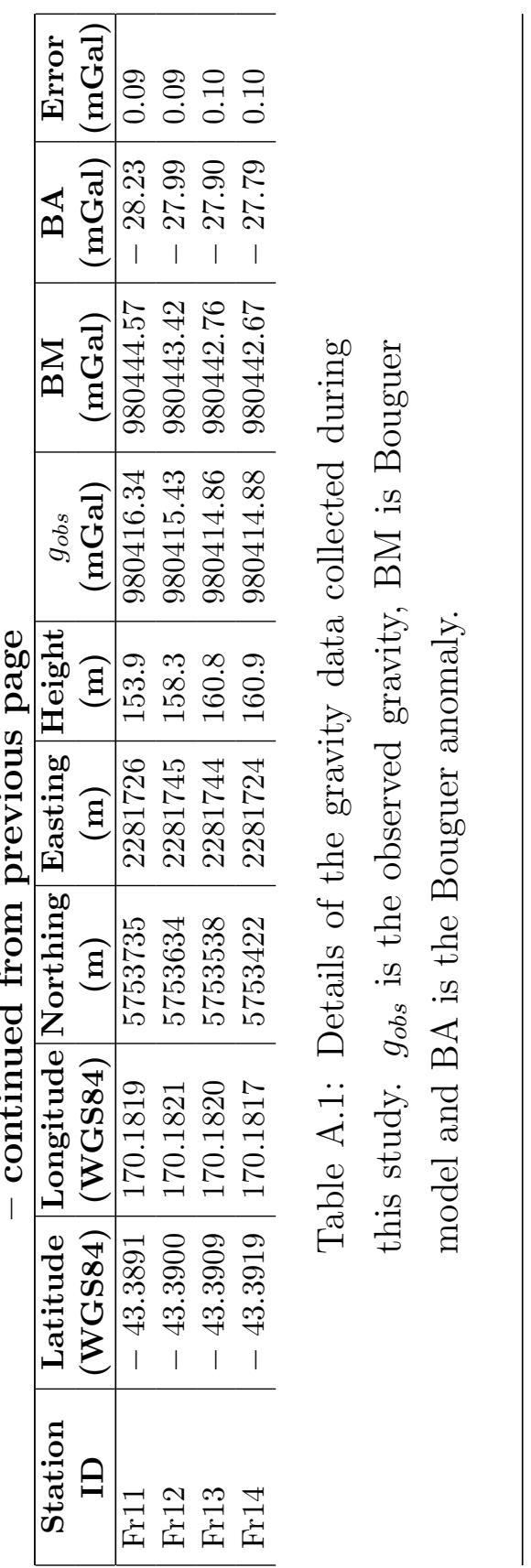


Appendix B

Appendix B 

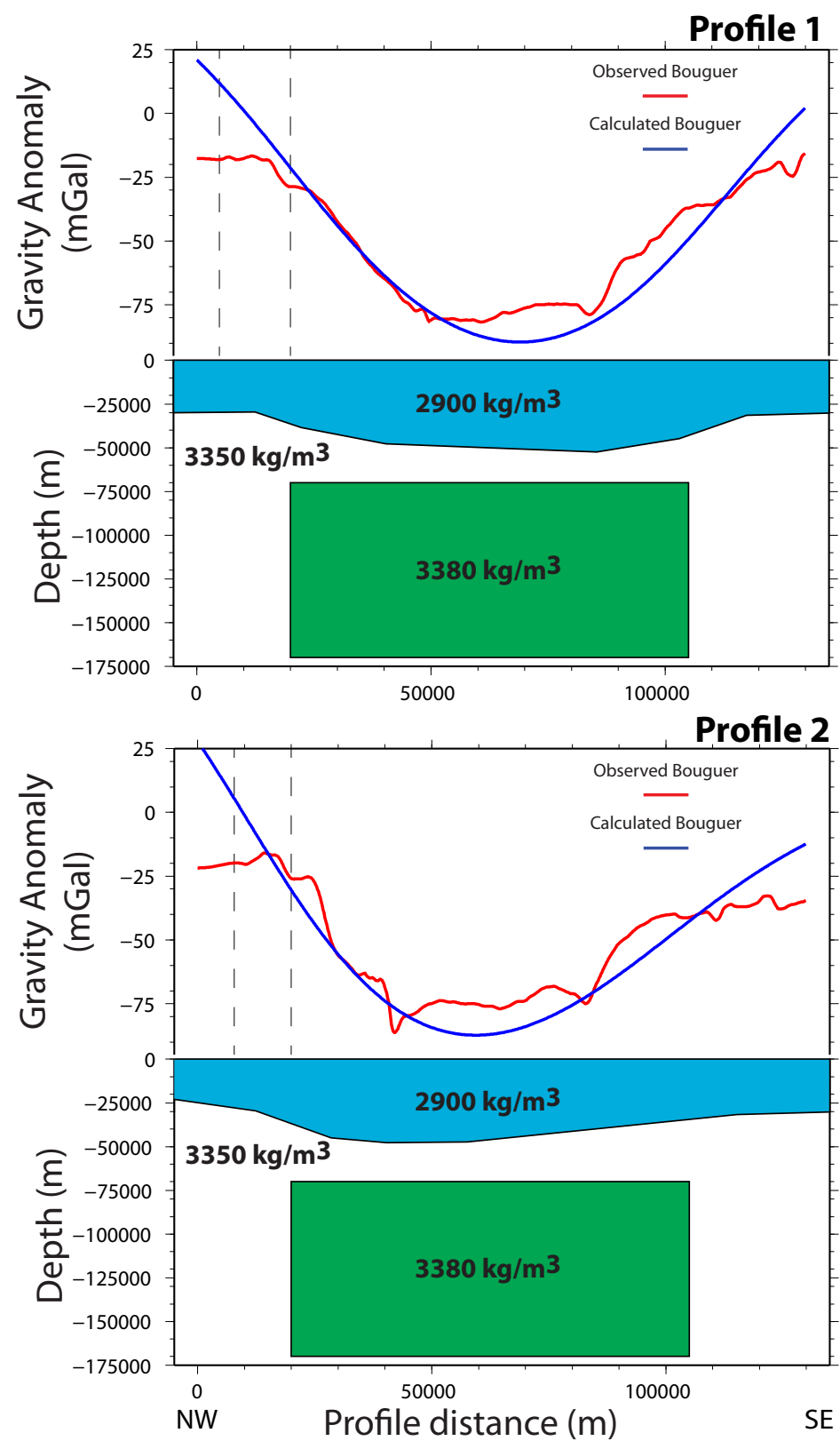

Figure B.1: Gravity models of the mantle and crustal structure below profiles 1 and 2 for the dynamic regional gravity model. 

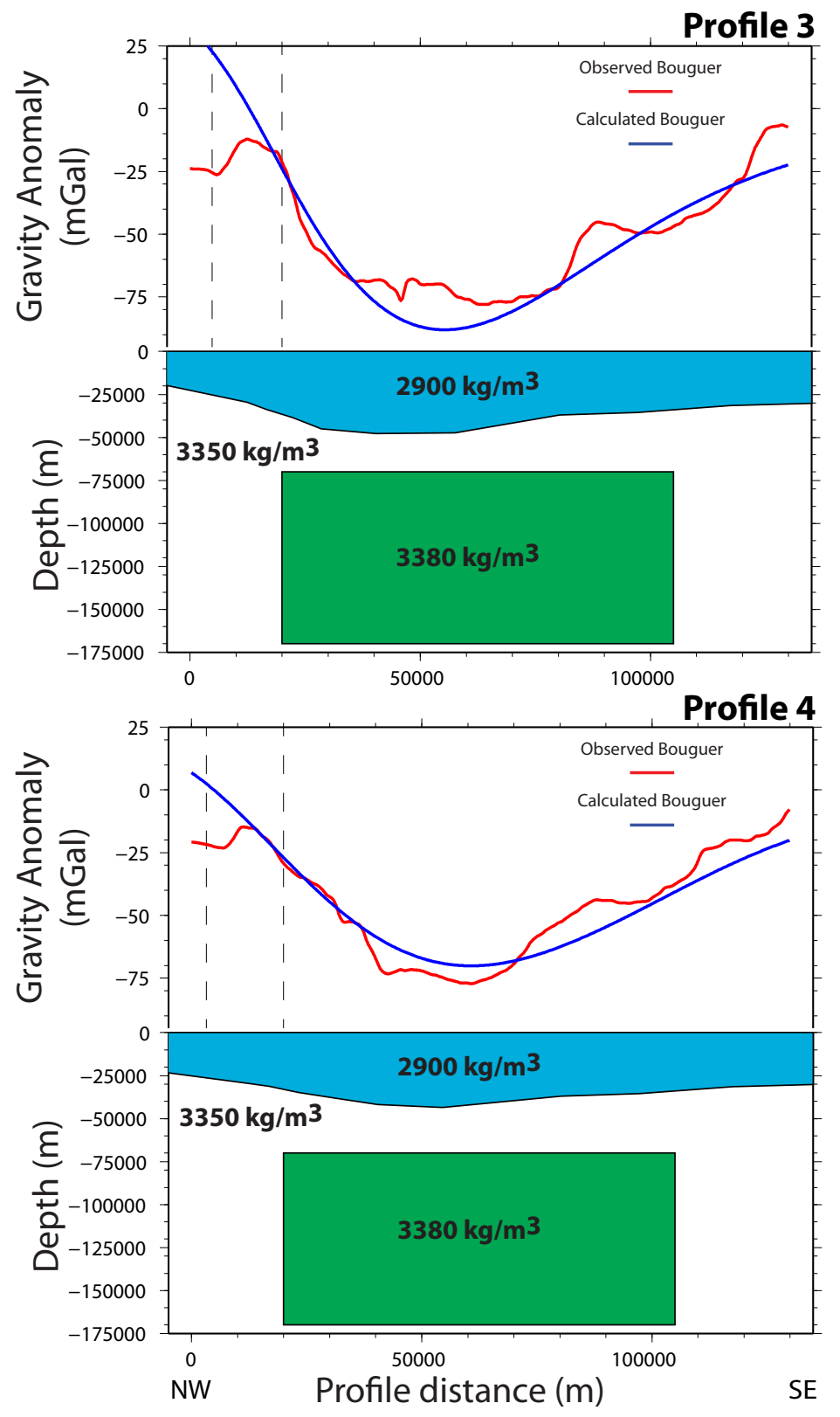

Figure B.2: Gravity models of the mantle and crustal structure below profiles 3 and 4 for the dynamic regional gravity model. 

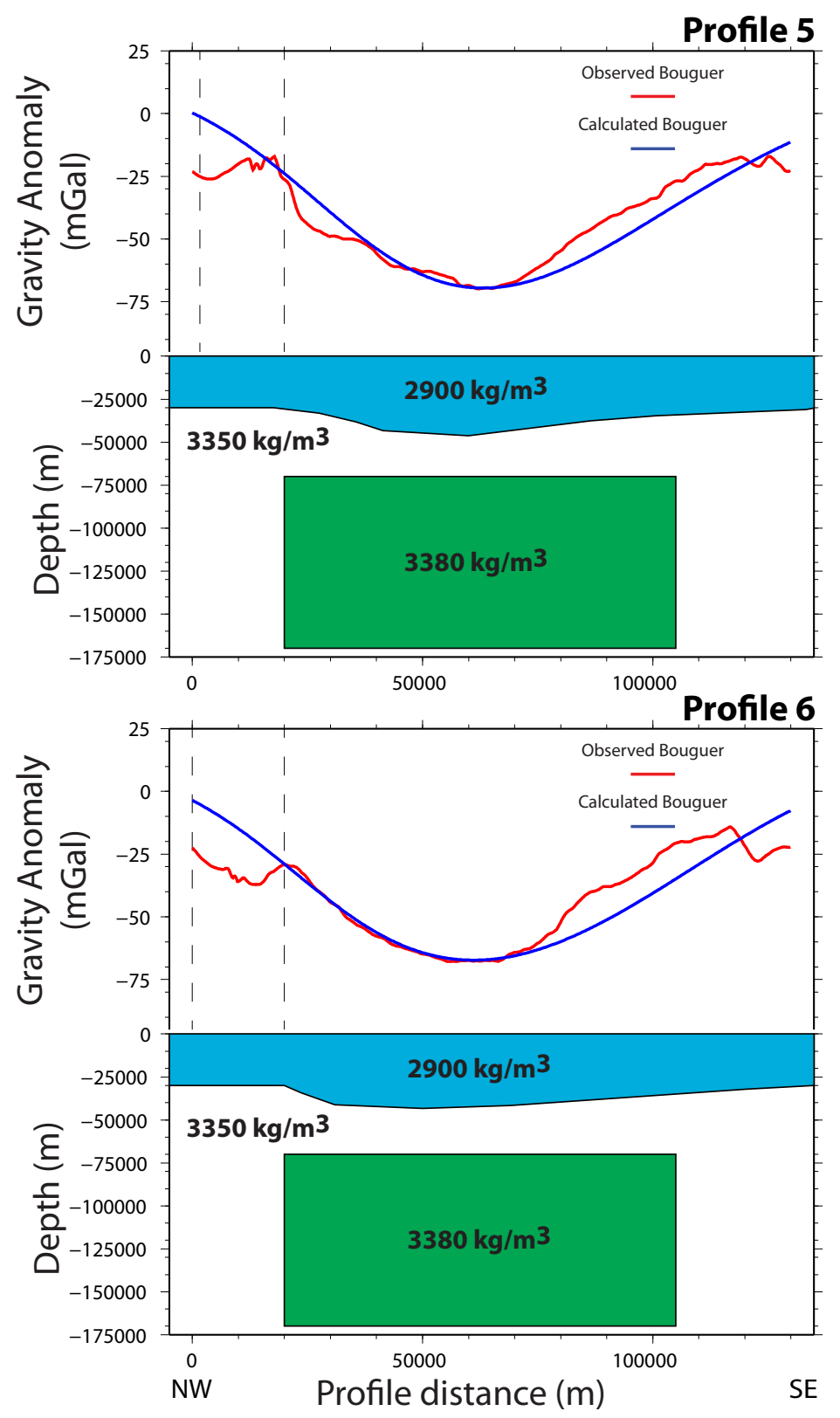

Figure B.3: Gravity models of the mantle and crustal structure below profiles 5 and 6 for the dynamic regional gravity model. 

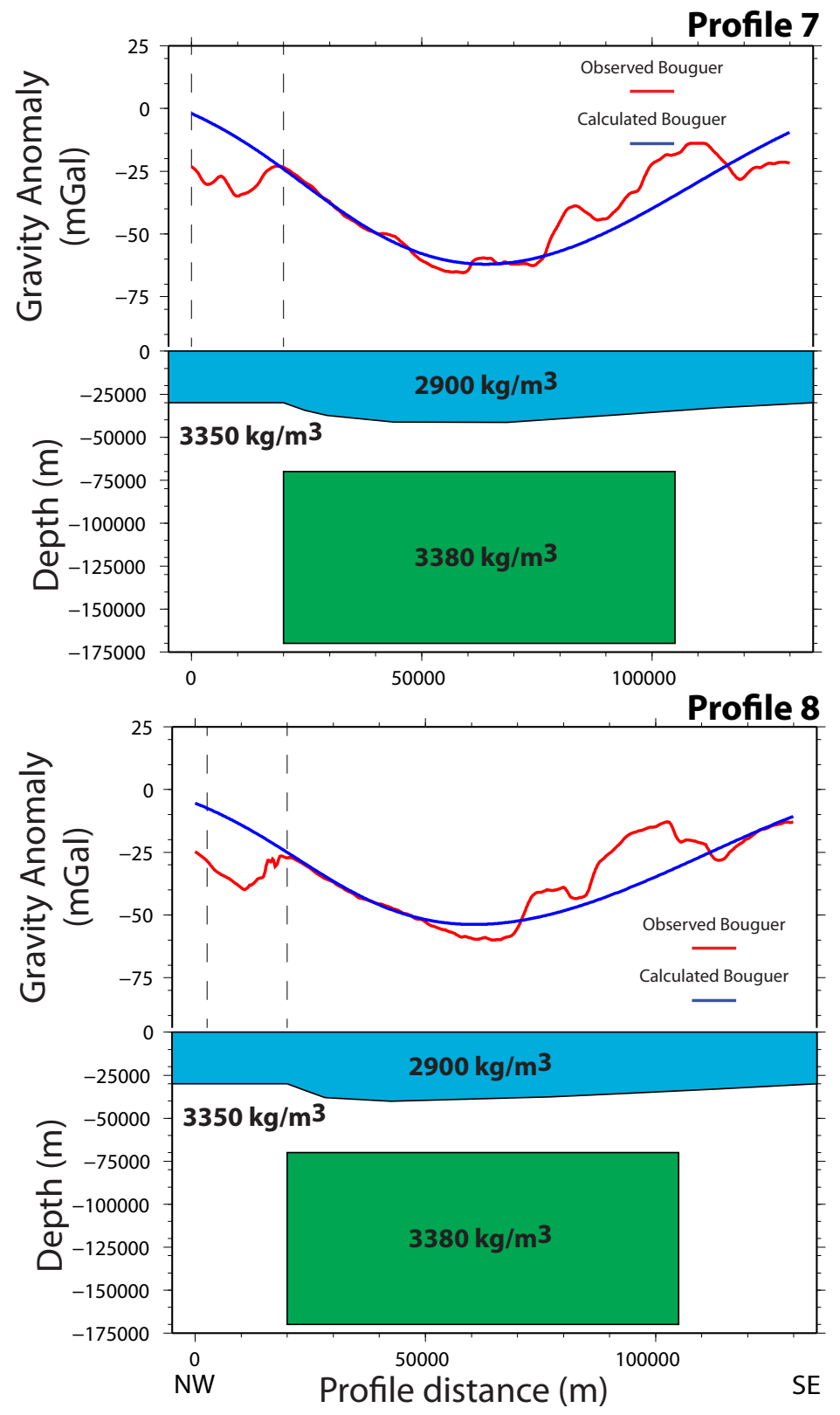

Figure B.4: Gravity models of the mantle and crustal structure below profiles 7 and 8 for the dynamic regional gravity model. 

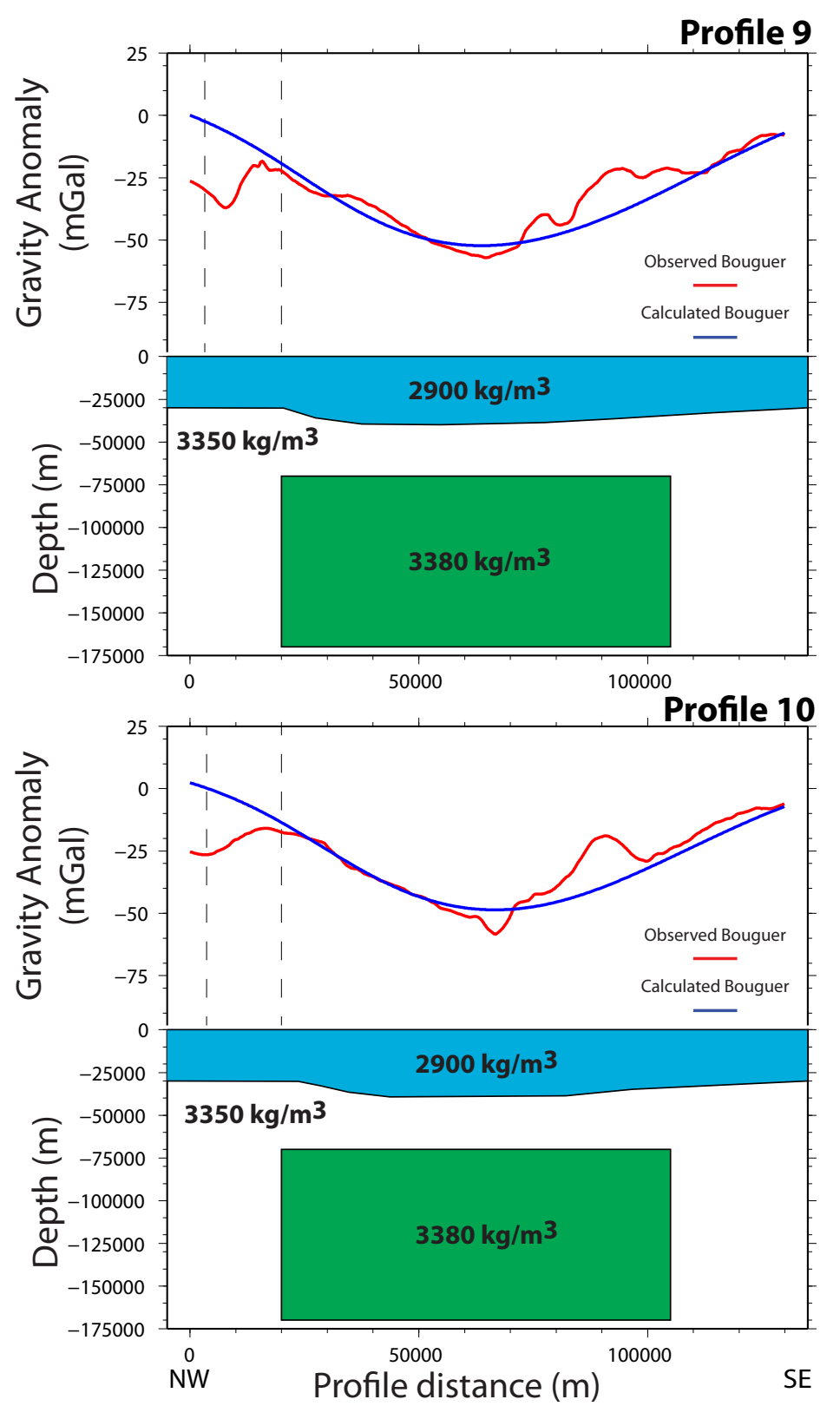

Figure B.5: Gravity models of the mantle and crustal structure below profiles 9 and 10 for the dynamic regional gravity model. 
Appendix C

Appendix C 


\begin{tabular}{|c|c|c|c|c|c|c|}
\hline & \multicolumn{2}{|c|}{ Wanganui } & \multicolumn{2}{|c|}{ Whataroa } & \multicolumn{2}{|c|}{ Fox } \\
\hline Profile & $\begin{array}{c}\text { Easting } \\
(\mathrm{m})\end{array}$ & $\begin{array}{c}\text { Northing } \\
\text { (m) }\end{array}$ & $\begin{array}{c}\text { Easting } \\
(\mathrm{m})\end{array}$ & $\begin{array}{c}\text { Northing } \\
\text { (m) }\end{array}$ & $\begin{array}{c}\text { Easting } \\
(\mathrm{m})\end{array}$ & $\begin{array}{c}\text { Northing } \\
\text { (m) }\end{array}$ \\
\hline $0 \mathrm{~m}$ & NA & NA & 2299530 & 5765953 & 2268217 & 5743402 \\
\hline $250 \mathrm{~m}$ & 2316991 & 5780474 & 2299622 & 5765669 & 2268476 & 5743353 \\
\hline $500 \mathrm{~m}$ & 2317036 & 5780172 & 2299683 & 5765375 & 2268779 & 5743311 \\
\hline $750 \mathrm{~m}$ & 2317003 & 5779846 & 2299801 & 5765125 & 2268953 & 5743248 \\
\hline $1000 \mathrm{~m}$ & 2316894 & 5779440 & 2299910 & 5764854 & 2269112 & 5743090 \\
\hline $1250 \mathrm{~m}$ & 2317001 & 5779224 & 2300040 & 5764625 & 2269219 & 5742907 \\
\hline $1500 \mathrm{~m}$ & 2317131 & 5778997 & 2300118 & 5764350 & 2269378 & 5742745 \\
\hline $1750 \mathrm{~m}$ & 2317121 & 5778676 & 2300227 & 5764079 & 2269508 & 5742583 \\
\hline $2000 \mathrm{~m}$ & 2317206 & 5778432 & 2300238 & 5763751 & 2269588 & 5742374 \\
\hline $2250 \mathrm{~m}$ & 2317083 & 5778022 & 2300321 & 5763507 & 2269708 & 5742168 \\
\hline
\end{tabular}

Table C.1: Glacial centres picked along fault-parallel topography profiles.

\begin{tabular}{ccccccc}
\hline & \multicolumn{3}{c}{ Wanganui } & \multicolumn{2}{c}{ Whataroa } & \multicolumn{2}{c}{ Fox } \\
\hline Profile & Easting & Northing & Easting & Northing & Easting & Northing \\
& $(\mathrm{m})$ & $(\mathrm{m})$ & $(\mathrm{m})$ & $(\mathrm{m})$ & $(\mathrm{m})$ & $(\mathrm{m})$ \\
\hline $0 \mathrm{~m}$ & NA & NA & - & - & 2268217 & 5743402 \\
$250 \mathrm{~m}$ & 2316991 & 5780474 & - & - & 2268476 & 5743353 \\
$500 \mathrm{~m}$ & 2317036 & 5780172 & 2299683 & 5765375 & 2268779 & 5743311 \\
$750 \mathrm{~m}$ & 2317003 & 5779846 & 2299801 & 5765125 & 2268953 & 5743248 \\
$1000 \mathrm{~m}$ & 2316894 & 5779440 & 2299910 & 5764854 & - & - \\
$1250 \mathrm{~m}$ & - & - & 2300040 & 5764625 & - & - \\
$1500 \mathrm{~m}$ & - & - & - & - & - & - \\
$1750 \mathrm{~m}$ & - & - & - & - & - & - \\
$2000 \mathrm{~m}$ & - & - & - & - & - & - \\
$2250 \mathrm{~m}$ & - & - & - & - & - & -
\end{tabular}

Table C.2: Proximal glacial centres picked on fault-parallel profiles. 


\section{Wanganui}

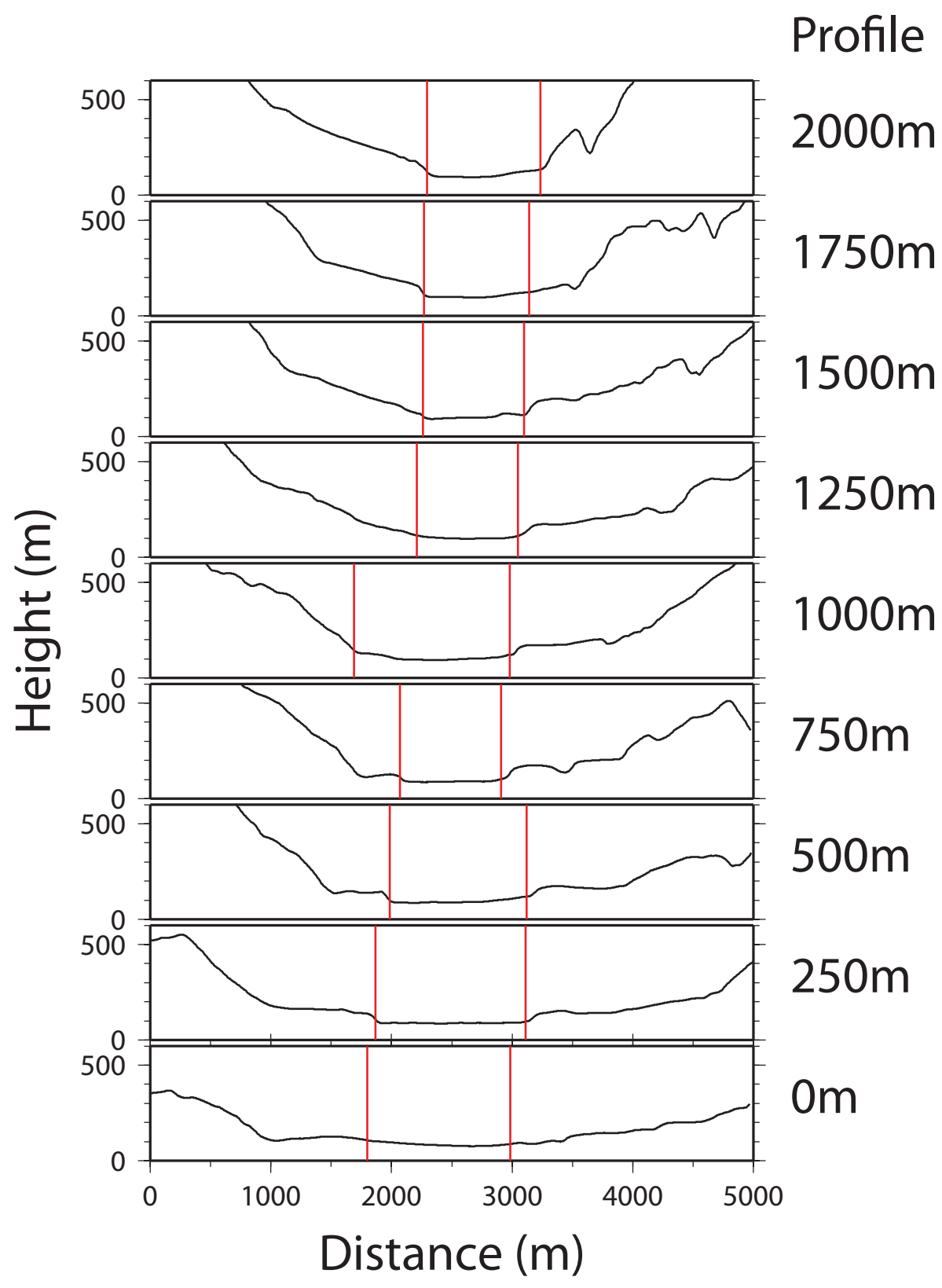

Figure C.1: Wanganui fault-parallel topography picks. 


\section{Whataroa}

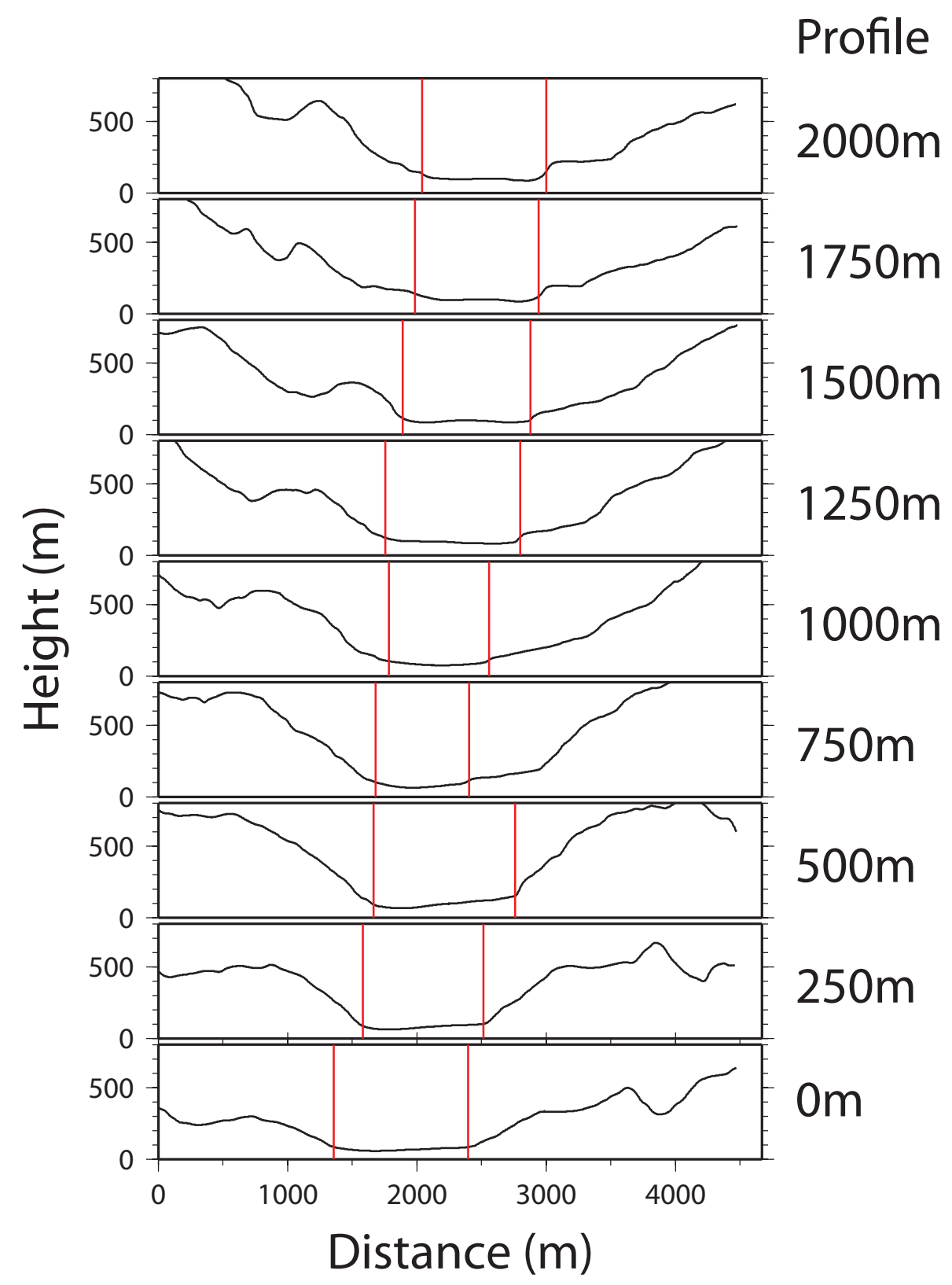

Figure C.2: Whataroa fault-parallel topography picks. 
Fox

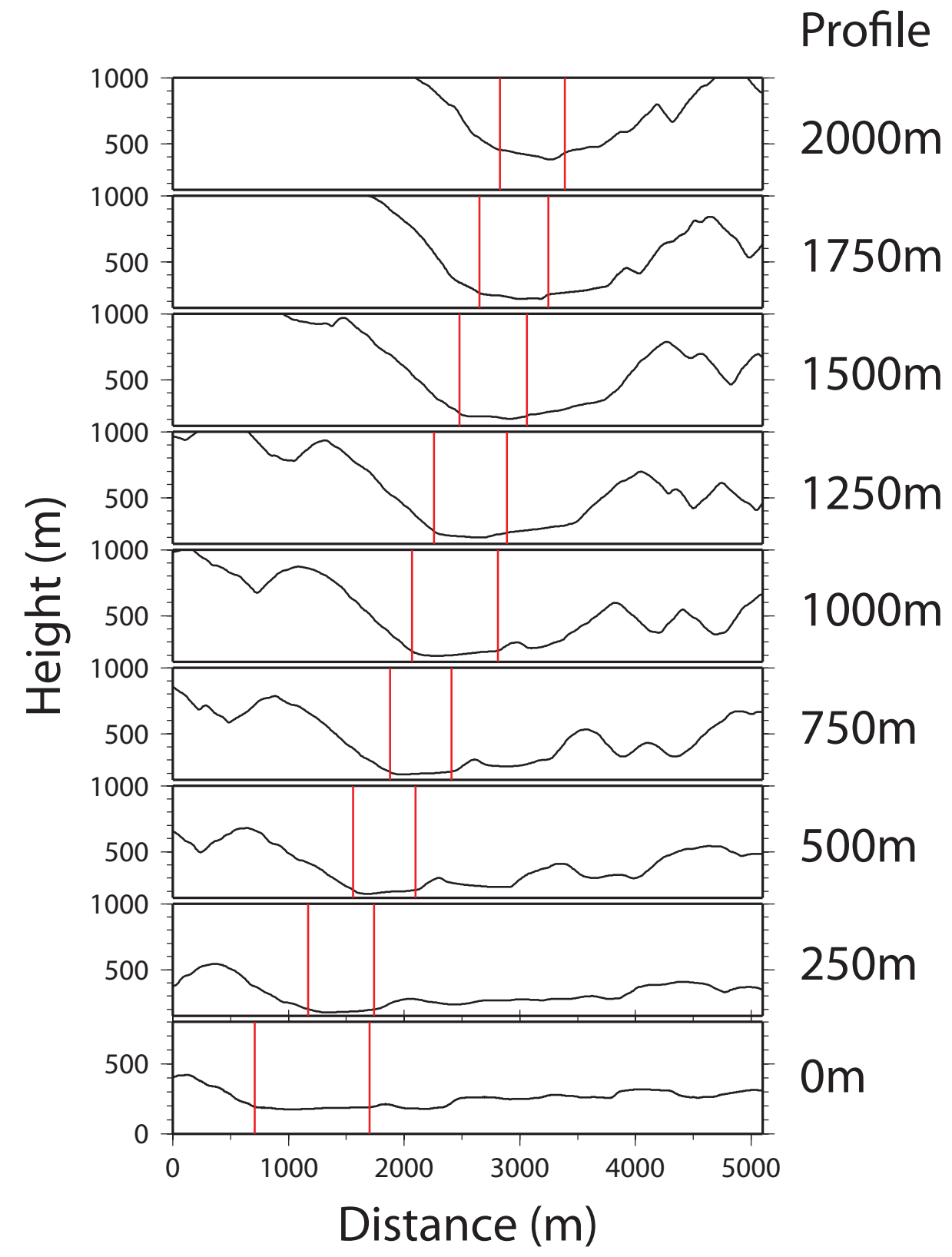

Figure C.3: Fox fault-parallel topography picks. 

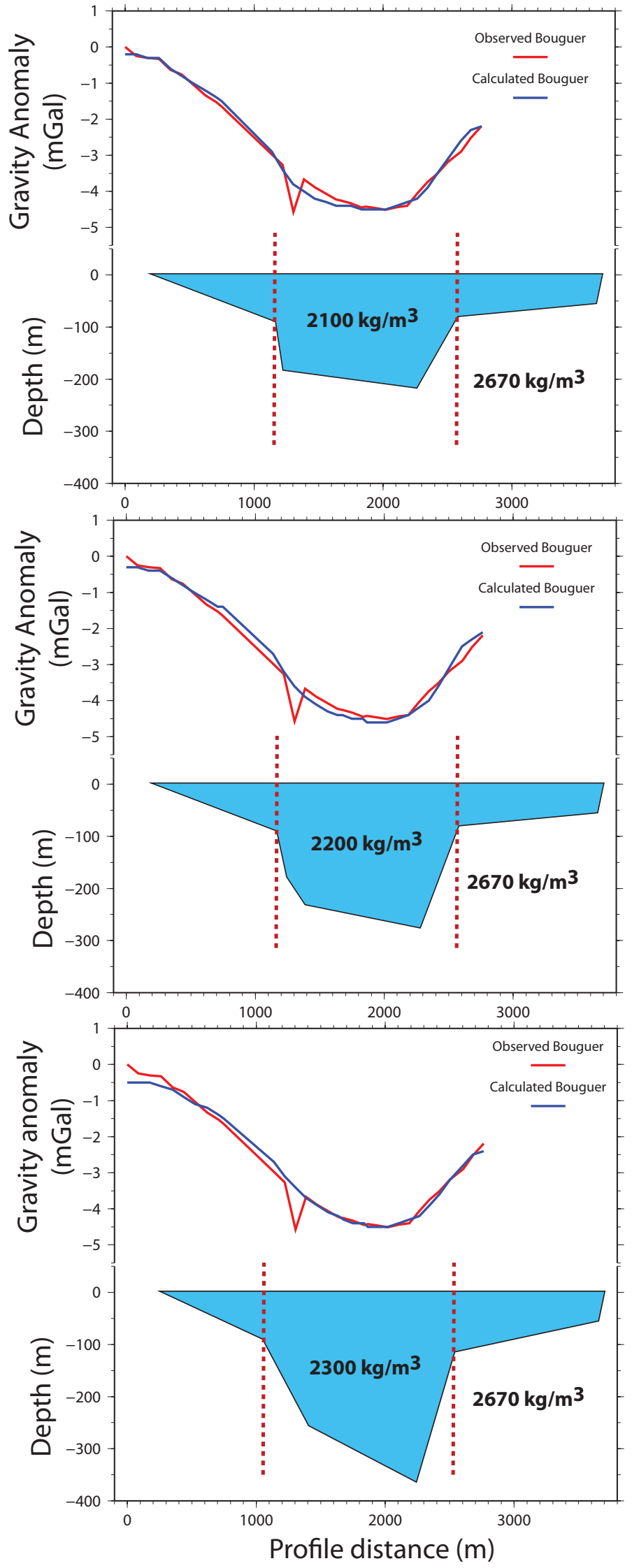

Figure C.4: Models for the Wanganui foot wall channel using the densities 2100 $\mathrm{kg} / \mathrm{m}^{3}, 2200 \mathrm{~kg} / \mathrm{m}^{3}$ and $2300 \mathrm{~kg} / \mathrm{m}^{3}$. 

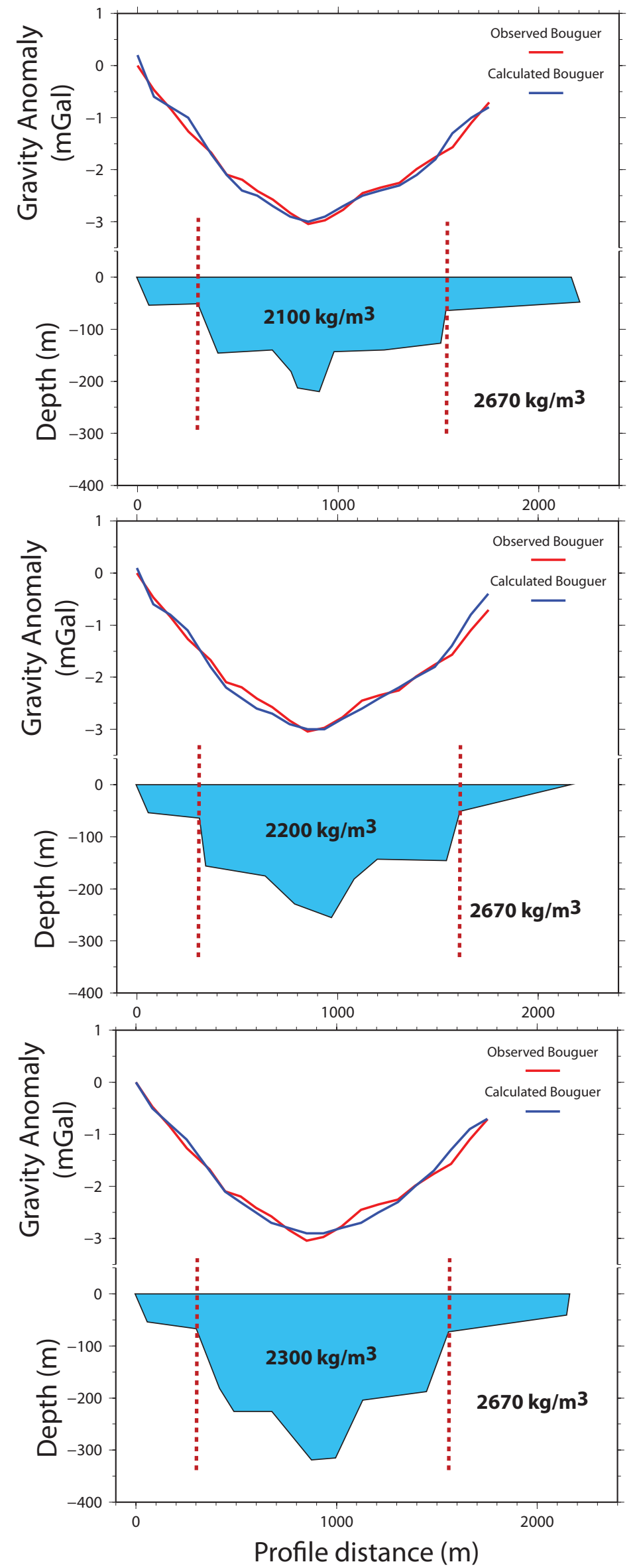

Figure C.5: Models for the Whataroa foot wall channel using the densities 2100 $\mathrm{kg} / \mathrm{m}^{3}, 2200 \mathrm{~kg} / \mathrm{m}^{3}$ and $2300 \mathrm{~kg} / \mathrm{m}^{3}$. 

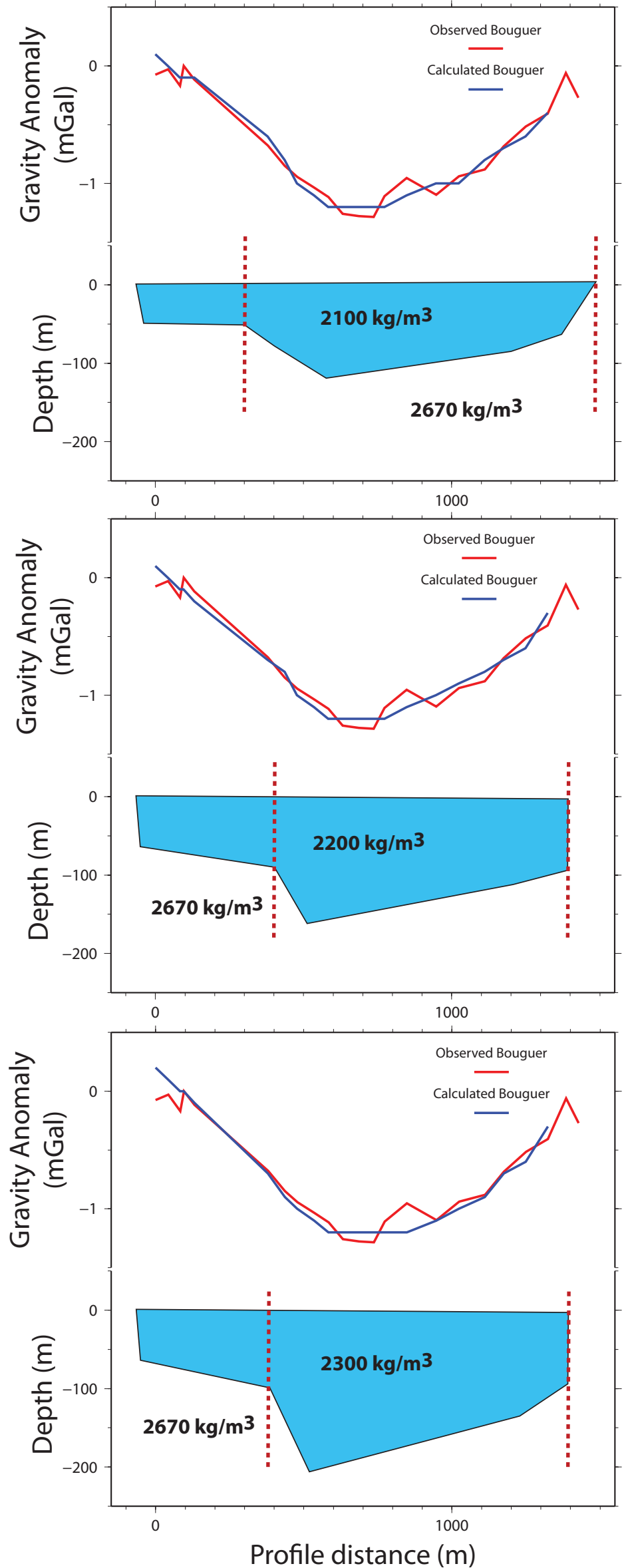

Figure C.6: Models for the Fox foot wall channel using the densities $2100 \mathrm{~kg} / \mathrm{m}^{3}$, $2200 \mathrm{~kg} / \mathrm{m}^{3}$ and $2300 \mathrm{~kg} / \mathrm{m}^{3}$. 


\section{Bibliography}

Ackers, P. and White, W. (1973). Sediment transport: new approach and analysis. Journal of the Hydraulics Division, 99(11):2041-2060.

Adams, C. (1981). Uplift rates and thermal structure in the Alpine Fault Zone and Alpine schists, Southern Alps, New Zealand. Geological Society, London, Special Publications, 9:211-222.

Adams, J. (1980). Contemporary uplift and erosion of the Southern Alps, New Zealand: summary. Geological Society of America Bulletin, 91(1):2-4.

Almond, P., Barrell, D., Hyatt, O., Rother, H., Shulmeister, J., and Vandergoes, M. (2007). Quaternary geomorphology, stratigraphy, and paleoclimate of the central Southern Alps, South Island, New Zealand. Otago University, Duniden. Otago University field course booklet.

Almond, P., Moar, N., and Lian, O. (2001). Reinterpretation of the glacial chronology of South Westland, New Zealand. New Zealand Journal of Geology and Geophysics, 44:1-15.

Beavan, J., Denys, P., Denham, M., Hager, B., Herring, T., and Molnar, P. (2010). Distribution of present day vertical deformation across the Southern Alps, New Zealand, from 10 years of GPS data. Geophysical Research Letters, 37:L16305 1-5.

Beavan, J., Ellis, S., Wallace, L., and Denys, P. (2007). Kinematic constraints from GPS on oblique convergence of the Pacific and Australian 
plates, central South Island, New Zealand. In Okaya, D., Stern, T., and Davey, F., editors, A Continental Plate Boundary: Tectonics at South Island, New Zealand, Geophysical Monograph Series, pages 75-94. American Geophysical Union.

Beavan, J., Moore, M., Pearson, C., Henderson, M., Parsons, B., Bourne, S., England, P., Walcott, R. I., Blick, G., Darby, D., and Hodgkinson, K. (1999). Crustal deformation during 1994-98 due to oblique continental collision in the central Southern Alps, New Zealand, and implications for seismic potential of the Alpine Fault. Journal of Geophysical Research, 104(B11):25,233-25,255.

Beck, A. E. (1981). Physical principles of exploration methods. The Macmillian Press Ltd., London and Basingstoke.

Ben-Avraham, Z., Brink, U., Bell, R., and Reznikov, M. (1996). Gravity field over the Sea of Galilee: Evidence for a composite basin along a transform fault. Journal of Geophysical Research, 101(B1):533-544.

Bierlein, F. (2006). Distribution of orogenic gold deposits in relation to fault zones and gravity gradients: targeting tools applied to the Eastern Goldfields, Yilgarn Craton, Western Australia. Mineralium deposita, 41(2):107-127.

Boese, C., Stern, T., Smith, E., Townend, J., and Henderson, M. (2010). Background and triggered microseismicity in the Alpine Fault Zone, central Southern Alps, New Zealand. In American Geophysical Union, fall meeting.

Boese, C., Townend, J., Smith, E., and Stern, T. (2011). Microseismicity and stress in the vicinity of the Alpine Fault, central Southern Alps, New Zealand. Sumbitted to Journal of Geophysical Research, under review as at 18th November 2011. 
Brikke, N. (2007). Seismic velocity structure of the shallow part of the Alpine Fault and gravity study of the basement features in the Whataroa River flood plain, central Westland, South Island. Unpublished Grad Dip thesis, Victoria University of Wellington.

Brikke, N. (2010). 3D Seismic traveltime tomography of the central South Island, New Zealand. Unpublished MSc thesis, Victoria University of Wellington.

Brocher, T. (2005). Empirical relations between elastic wavespeeds and density in the Earths crust. Bulletin of the Seismological Society of America, 95(6):2081-2092.

Burger, H. R., Sheenan, A. F., and Jones, C. H. (2006). Introduction to applied geophysics. W.W. Norton and Company, Inc., New York.

Cande, S. and Stock, J. (2004). PacificAntarcticAustralia motion and the formation of the Macquarie Plate. Geophysical Journal International, 157(1):399-414.

Cooper, R. and Tulloch, A. (1992). Early Palaeozoic terranes in New Zealand and their relationship to the Lachlan fold belt. Tectonophysics, 214:129 144 .

Cox, S. and Barrell, D. (2007a). Geology of the Aoraki area. Institute of Geological and Nuclear Sciences 1:250,000 geological map.

Cox, S. and Barrell, D. (2007b). Geology of the Greymouth area. Institute of Geological and Nuclear Sciences 1:250,000 geological map.

Cox, S. and Sutherland, R. (2007). Regional geological framework of South Island, New Zealand, and its significance for understanding the active plate boundary. In Okaya, D., Stern, T., and Davey, F., editors, A Continental Plate Boundary: Tectonics at South Island, New Zealand, Geophysical Monograph Series, pages 19-46. American Geophysical Union. 
Davey, F., Henyey, T., Kleffmann, S., Melhuish, A., Okaya, D., Stern, T., and Woodward, D. (1995). Crustal reflections from the Alpine Fault Zone, South Island, New Zealand. New Zealand Journal of Geology and Geophysics, 38(3):601-604.

Davey, F. J. (2010). Crustal seismic reflection profile across the Alpine Fault and coastal plain at Whataroa, South Island. New Zealand Journal of Geology and Geophysics, 53:359-368.

Davey, F. J., Eberhart-Phillips, D., Kohler, M. D., Bannister, S., Caldwell, G., Henrys, S., Scherwath, M., Stern, T., and Van Avendonk, H. J. A. (2007). Geophysical structure of the Southern Alps orogen, South Island, New Zealand. In Okaya, D., Stern, T., and Davey, F., editors, Geophysical Monograph, Geophysical Monograph Series, pages 47-73. American Geophysical Union.

Davey, F. J., Henyey, T., Holbrook, W., Kaya, D., Stern, T., Melhuish, A., Henrys, S., Anderson, H., Eberhart-Phillips, D., McEvilly, T., Uhrhammer, R., Wu, R., Jiracek, G., Wannamaker, P., Caldwell, G., and Christensen, N. (1998). Preliminary results from a geophysical study across a modern, continent-continent collisional plate boundary — the Southern Alps, New Zealand. Tectonophysics, 288:221-235.

Davies, R. (2005). Using Rob Davies's terrain correctionsoftware. Victoria University, Wellington. Terrain correction instructions.

De Mets, C., Gordon, R., Argus, D., and Stein, S. (1990). Current plate motions. Geophysics Journal International, 101:425-478.

De Mets, C., Gordon, R., Argus, D., and Stein, S. (1994). Effect of recent revisions to the geomagnetic reversal time scale on estimates of current plate motions. Geophysical Research Letters, 21:2191-2194. 
Dobrin, M. B. and Savit, C. H. (1988). Introduction to geophysical prospecting. Geology Series. McGraw-Hill Book Company, Singapore, Fourth edition.

Eberhart-Phillips, D. (1995). Examination of seismicity in the central Alpine Fault region, South Island, New Zealand. New Zealand Journal of Geology and Geophysics, 38:571-578.

Gardner, G., Gardner, L., and Gregory, A. (1974). Formation velocity and density - the diagnostic basics for stratigraphy traps. Geophysics, $39(6): 770-780$.

Gerkens, J. C. A. (1989). Foundation of exploration geophysics. Elsevier Science Publishers B.V., Amsterdam.

Ghisetti, F. and Sibson, R. (2006). Accommodation of compressional inversion in north-western South Island (New Zealand): Old faults versus new? Journal of Structural Geology, 28(11):1994-2010.

Greenwood, M. and Humphrey, N. (2002). Glaciated valley profiles: An application of nonlinear regression. In Proceedings of the 34th Symposium on the Interface, Montreal, Quebec, Canada.

Hallet, B., Hunter, L., and Bogen, J. (1996). Rates of erosion and sediment evacuation by glaciers: a review of field data and their implications. Blobal and Planetary Change, 12:213-235.

Hammer, S. (1939). Terrain corrections for gravimeter stations. Geophysics, $4: 184-194$.

Henderson, R. and Thompson, S. (1999). Extreme rainfalls in the Southern Alps of New Zealand. Journal of Hydrology (NZ), 38(2):309-330.

Henrys, S., Woodward, D., Okaya, D., and Yu, J. (2004). Mapping the Moho beneath the Southern Alps continent-continent collision, New Zealand, 
using wide-angle reflections. Geophysical research Letters, 31:L17602 14.

Herman, F., Braun, J., and Dunlap, W. (2007). Tectonomorphic scenarios in the Southern Alps of New Zealand. Journal of Geophysical Research, 112:1-25.

Herman, F., Rhodes, E., Braun, J., and Heiniger, L. (2010). Uniform erosion rates and relief amplitude during glacial cycles in the Southern Alps of New Zealand, as revealed from osl-thermochronology. Earth and planetary science letters, 297:183-189.

Hicks, D., McSaveney, M., and Chinn, T. (1990). Sedimentation in proglacial Ivory Lake, Southern Alps, New Zealand. Arctic and Alpine Research, $22(1): 26-42$.

Imbrie, J., Beger, A., Boyle, E., Clemens, S., Duffy, A., Howard, W., Kukla, G., Kutzbach, J., Martinson, D., McIntyre, A., Mix, A., Molfino, B., Morley, J., Peterson, L., Pisias, N., Prell, W., Raymo, M., Shackleton, N., and Toggweiler, J. (1993). On the structure and origin of major glaciation cycles: the 100,000-year cycle. Paleoceanography, 8(6):699-735.

Kamp, P., Green, P., and Tippett, M. (1992). Tectonic architechture of the mountain front-foreland basin transition, South Island, New Zealand, assessed by fission track analysis. Tectonics, 11(1):98-113.

Kohler, M. and Eberhart-Phillips, D. (2002). Three-dimensional lithospheric structure below the New Zealand Southern Alps. Journal of Geophysical Research, 107:1-16.

Koons, P. (187). Some thermal and mechanical consequences of rapid uplift: an example from the Southern Alps, New Zealand. Earth and Planetary Science Letters, 86:307-319.

Koons, P. (1990). Two-sided orogen: Collision and erosion from the sandbox to the Southern Alps, New Zealand. Geology, 18:679-682. 
Koppes, M. and Montgomery, D. (2009). The relative efficacy of fluvial and glacial erosion over modern to orgogenic timescales. Nature Geoscience, 2:644-647.

Korup, O., Schmidt, J., and McSaveney, M. (2005). Regional relief characteristics and denudation patterns of the western Southern Alps, New Zealand. Geomorphology, 72:402-423.

Leitner, B., Eberhart-Phillips, D., Anderson, H., and Nabelek, J. (2001). A focused look at the Alpine Fault, New Zealand: seismicity, focal mechanisms, and stress observations. Journal of Geophysical Research, 106(B2):2193-2220.

Little, T., Holcombe, R., and Ilg, B. (2002). Kinematics of oblique collision and ramping inferred from microstructures and strain in middle crustal rocks, central Southern Alps, New Zealand. Journal of Structural Geology, 24:219-239.

Ludwig, W., Nafe, J., and Drake, C. (1970). Seismic refraction. In Maxwell, A., editor, The Sea, volume 4, pages 53-84. Wiley-Interscience.

Milsom, J. (2003). Field Geophysics. The Geological Field Guide Series. John Wiley and Sons Ltd., Chichester, Third edition.

Molnar, P., Anderson, H., Audoine, E., Eberhart-Phillips, D., Gledhill, K., Klosko, E., McEvilly, T., Okaya, D., Savage, M., Stern, T., and Wu, F. (1999). Continuous deformation versus faulting through the continental lithosphere of New Zealand. Science, 286:516-519.

Mortimer, N. (2004). New Zealand's geological foundations. Gondwana Research, $7(1): 261-272$.

Muller, R. and MacDonald, G. (1997). Glacial cycles and astronomical forcing. Science, 277:215-218. 
Nathan, S. (2005). Harold Wellman: A man who moved New Zealand. Victoria University Press, Victoria University of Welllington, PO Box 600 Wellington, First edition.

Nathan, S. (2011). Personal communication.

Nathan, S., Anderson, H., Cook, R., Herzer, R., Hoskins, R., Raine, J., and Smale, D. (1986). Cretaceous and Cenozoic sedimentary basins of the West Coast Region, South Island, New Zealand. New Zealand Geological Survey Basin Studies. Department of Scientific and Industrial Research, Wellington, New Zealand.

Norris, R. and Cooper, A. (2003). Very high strains recorded in mylonites along the Alpine Fault, New Zealand: implications for the deep structure of plate boundary faults. Journal of Structural Geology, 25:2141-2157.

Norris, R. J. and Cooper, A. F. (2001). Late Quaternary slip rates and slip partitioning on the Alpine Fault, New Zealand. Journal of Structural Geology, 23:507-520.

Norris, R. J. and Cooper, A. F. (2007). The Alpine Fault, New Zealand: surface geology and field relationships. In Okaya, D., Stern, T., and Davey, F., editors, A Continental Plate Boundary: tectonics at South Island, New Zealand, Geophysical Monograph Series, page 157175. American Geophysical Union.

Northwest Geophysical Associates, I. (2004). GM-SYS Gravity/Magnetic Modeling Software: User's Guide.

Okaya, D., Stern, T., Davey, F., Henrys, S., and Cox, S. (2007). Continentcontinent collision at the Pacific/Indo-Australian plate boundary: background, motivation, and principal results. In Okaya, D., Stern, T., and Davey, F., editors, A Continental Plate Boundary: Tectonics at South Island, New Zealand, Geophysical Monograph Series, pages 1-18. American Geophysical Union. 
O'Keefe, B. (2008). Microseismicity of the Central Alpine Fault Region, New Zealand. Unpublished MSc thesis, Victoria University of Wellington.

Reilly, W. (1972). New Zealand gravity map series. New Zealand Journal of Geology and Geophysics, 15:3-15.

Reilly, W. and Whiteford, C. (1979). South Island: Bouguer anomalies, gravity map of New Zealand 1:1,000,000. DSIR, Wellington, New Zealand.

Robertson, E. and Reilly, W. (1960). The New Zealand primary gravity network. New Zealand Journal of Geology and Geophysics, 3:41-68.

Scherwath, M., Okaya, D., Stern, T., Henrys, S., Kleffmann, S., and Davey, F. (2001). Sight'96 seismic land data acquisition report. Unpublished report, accessed from Victoria University of Wellington's Geophysics department.

Scherwath, M., Stern, T., Davey, F., and Davies, R. (2006). Threedimensional lithospheric deformation and gravity anomalies associated with oblique continental collision in South Island, New Zealand. Geophysical Journal International, 167:906-916.

Scherwath, M., Stern, T., Davy, F., Okaya, D., Holbrook, W., Davies, R., and Kleffmann, S. (2003). Lithospheric structure across oblique continental collision in new zealand from wide-angle $\mathrm{p}$ wave modeling. Journal of Geophysical Research, 108:2566-84.

Shulmeister, J., Goodwin, I., Renwick, J., Harle, K., Armard, L., McGlone, M. amd Cook, E., Dodson, J., Hesse, P., Mayewski, P., and Curran, M. (2004). The Southern Hemisphere westerlies in the Australasian sector over the last glacial cycle: a synthesis. Quaternary International, 118/119:2353.

Sircombe, K. and Kamp, P. (1998). The South Westland basin: seismic stratigraphy, basin geometry and evolution of a foreland basin within the Southern Alps collision zone, New Zealand. Tectonophysics, 300:359-387. 
Sivell, W. and McCulloch, M. (2000). Reassessment of the origin of the Dun Mountain Ophiolite, New Zealand: Nd-isotopic and geochemical evolution of magma suites. New Zealand Journal of Geography and Geophysics, 43:133-146.

Smart, G. (1971). Petroleum report series PR528: Harihari-1. New Zealand Petroleum Company Ltd., 1(1):1-52.

Smart, G. (1972). Petroleum report series PR529: Waihoi-1. New Zealand Petroleum Company Ltd., 1(2):1-114.

Stern, T. (2011). Karangarua seismic shot gather. Unpublished shot gather from the SIGHT geophysical experiment, provided by Tim Stern.

Stern, T., Molnar, P., Okaya, D., and Eberhart-Phillips, D. (2000). Teleseismic $\mathrm{P}$ wave delays and modes of shortening the mantle lithosphere beneath South Island, New Zealand. Journal of Geophysical Research, 105:2161521631.

Stern, T. A. (1979). Regional and residual gravity fields, central North Island, New Zealand. New Zealand Journal of Geology and Geophysics, 22(4):479485.

Suggate, P. (1990). Late Pliocene and Quaternary glaciations of New Zealand. Quaternary Science Reviews, 9:175-197.

Suggate, P. and Almond, P. (2005). The last glacial maximum (LGM) in western South Island, New Zealand: implications for the global LGM and MIS 2. Quaternary Science Reviews, 24:1923-1940.

Sutherland, R. (1995a). The Australia-Pacific boundary and Cenozoic plate motions in the SW Pacific: some constraints from Geosat data. Tectonics, 14(4):819-831.

Sutherland, R. (1995b). Late Quaternary displacement rate, paleoseismicity, and geomorphic evolution of the Alpine Fault: evidence from Hokuri 
Creek, South Westland, New Zealand. New Zealand Journal of Geology and Geophysics, 38:419-430.

Sutherland, R. (1996). Transpressional development of the Australia-Pacific boundary through southern South Island, New Zealand: constraints from Miocene-Pliocene sediments, Waiho-1 borehole, South Westland. New Zealand Journal of Geology and Geophysics, 39:251-264.

Sutherland, R., Berryman, K., and Norris, R. (2006). Quaternary slip rate and geomorphology of the Alpine Fault: implications for kinematics and seismic hazard in southwest New Zealand. Geological Society of America Bulletin, 118(3-4):464-474.

Sutherland, R., Davey, F., and Beavan, J. (2000). Plate boundary deformation in South Island, New Zealand, is related to inherited lithospheric structure. Earth and planetary science letters, 177:141-151.

Telford, W. M., Geldart, L. P., and Sheriff, R. E. (1990). Applied geophysics. Cambridge University Press, Cambridge, Second edition.

Van Avendonk, H. J. A., Holbrook, W. S., Okaya, D., Austin, J. K., Davey, F., and Stern, T. (2004). Continental crust under compression; a seismic refraction study of South Island geophysical transect; I, South Island, New Zealand. Journal of Geophysical Research, 109(B6):1-16.

Waight, T. (1995). The geology and geochemistry of the Hohonu Batholith and adjacent rocks, North Westland, New Zealand. Unpublished Phd thesis, University of Canterbury.

Walcott, R. (1978). Present tectonics and late Cenozoic evolution of New Zealand. Geophysical Journal. Royal Astronomical Society, 52:137-164.

Walcott, R. (1998). Modes of oblique compression: Late Cenozoic tectonics of the South Island of New Zealand. Reviews of Geophysics, 36(1):1-26. 
Wallace, L., Beavan, J., McCaffrey, R., Berryman, K., and Denys, P. (2007). Balancing the plate motion budget in the South Island, New Zealand using GPS, geological and seismological data. Geophysics Journal International, 168:332-352.

Wells, A., Yetton, M., Duncan, R., and Stewart, G. (1999). Prehistoric dates of the most recent Alpine Fault Earthquakes, New Zealand. Geology, 27(11):995-998.

Wessel, P. and Smith, W. (2011). The Generic Mapping Tools.

Whiteford, C. and Lumb, J. (1975). A Catalogue of physical properties of rocks. Department of Scientific and Industrial Research New Zealand, Geophysics Division, Department of Scientific and Industrial Research, Wellington, New Zealand, first edition. 